\title{
BEITRAG ZUR ERMITTLUNG DER BIOCHEMISCHEN URSACHEN DER SCHWARZFLECKIGKEIT BEI KARTOFFELN
}

\author{
Dissertation \\ zur Erlangung des Doktorgrades \\ der Fakultät für Agrarwissenschaften \\ der Georg- August- Universität Göttingen
}

vorgelegt von

Annemarie Heinecke,

geb. Schulze

geboren in Lich

Göttingen, den 30.3.2007 
D7

Referentin: Prof. Dr. E. Pawelzik

Korreferent: Prof. Dr. B. Märländer

Tag der mündlichen Prüfung: 10.Mai 2007 


\section{Danksagung}

Ein herzlicher Dank gilt der Konrad- Adenauer- Stiftung, die mich während meiner Promotion nicht nur finanziell, sondern auch in großem Maße ideell begleitet hat.

Die herzliche Betreuung durch die Abteilung „Graduiertenförderung“ wird mir stets in Erinnerung bleiben.

An dieser Stelle danke ich meiner Betreuerin Frau Prof. Pawelzik für ihre gewährte Unterstützung. Herrn Prof. Märländer und Herrn Prof. Lücke danke ich für die Übernhame der Begutachtung dieser Arbeit.

Des Weiteren möchte ich der Fördergemeinschaft der deutschen Kartoffelwirtschaft für Ihre finanzielle Unterstützung danken, da sie die Aminosäureuntersuchungen getragen haben.

Darüber hinaus danke ich der Gesellschaft der Freunde der landwirtschaftlichen Fakultät Göttingen für ihre finanzielle Unterstützung.

Danken möchte ich auch den Mitarbeiterinnen des Departments für Nutzpflanzenwissenschaften, Abteilung Qualität, die meine Arbeit auf vielfache Weise unterstützt haben.

Der Versuch wurde gemeinsam mit der Versuchsstation für Kartoffelbau in Dethlingen und der Bundesanstalt für Ernährung und Lebensmittel (BEL) in Detmold durchgeführt. Stellvertretend für alle möchte ich Herrn Dr. Peters und Herrn Wulf aus Dethlingen sowie Herrn Dr. Haase aus Detmold für ihre Unterstützung danken. 
Für Hajo und Hans jun. 
INHALTSVERZEICHNIS

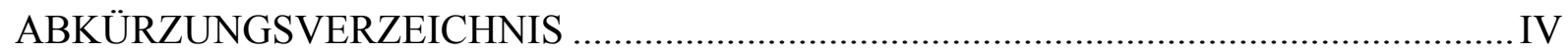

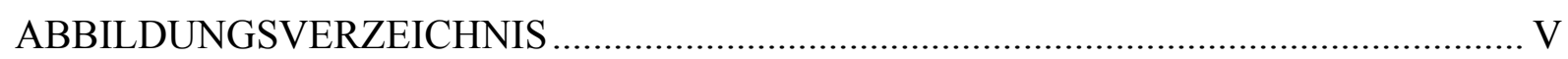

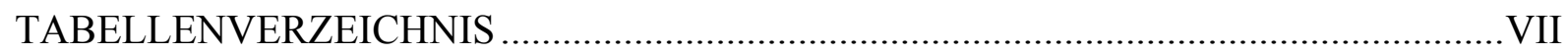

1. STAND DES WISSENS.

1.1. Bedeutung der Schwarzfleckigkeit für die Landwirtschaft und die nachgelagerten Bereiche.

1.2. Die physiologischen Vorgänge in einer Kartoffelknolle nach einer mechanischen

Belastung - Prozess der Bildung der Schwarzfleckigkeit............................................. 2

1.3. Einflussfaktoren bei der Ausbildung der Schwarzfleckigkeit..................................... 4

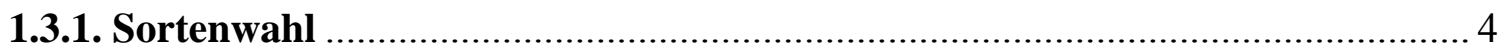

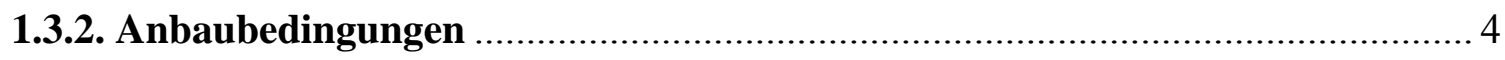

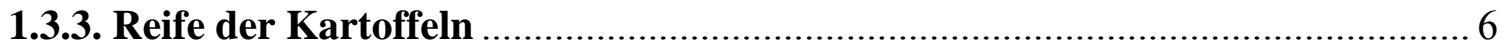

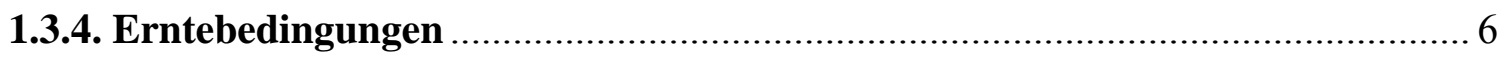

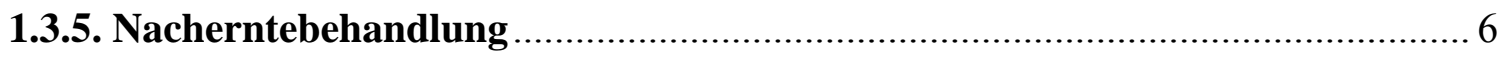

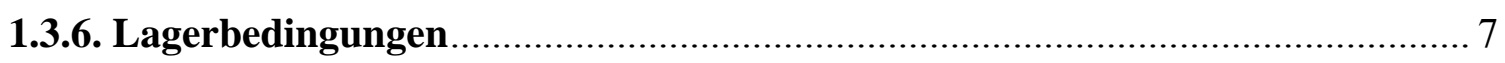

1.3.7. Inhaltsstoffe der Kartoffel und ihre Einflussnahme auf die Schwarzfleckigkeit

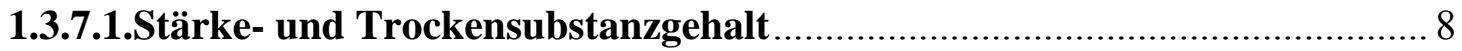

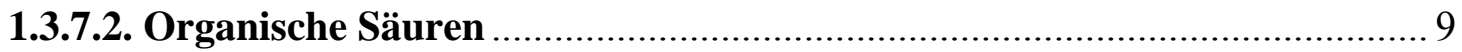

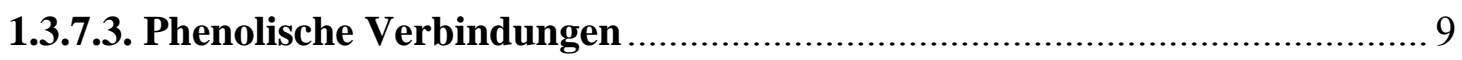

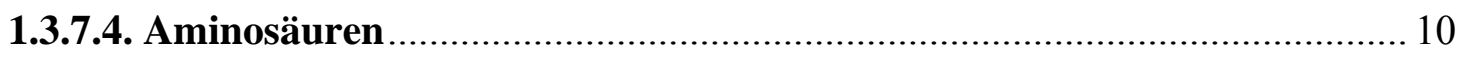

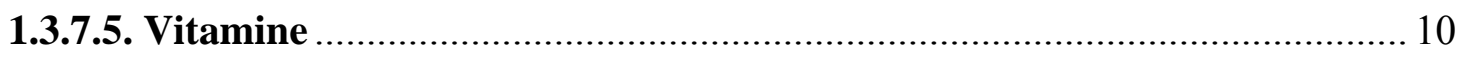

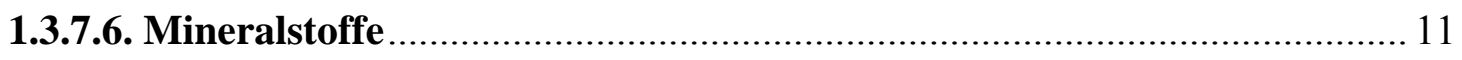

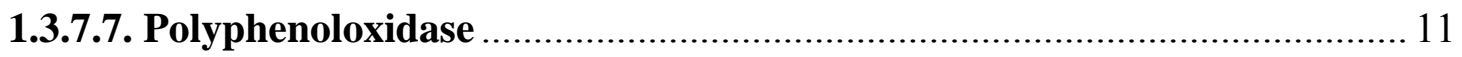

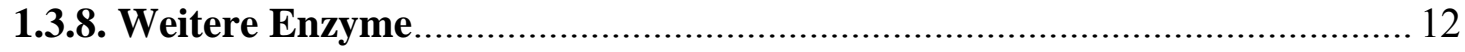

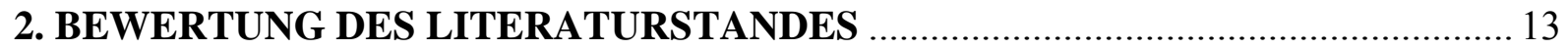

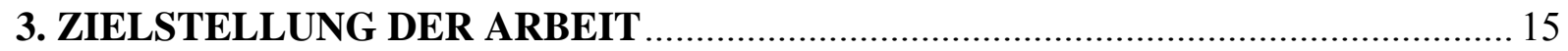

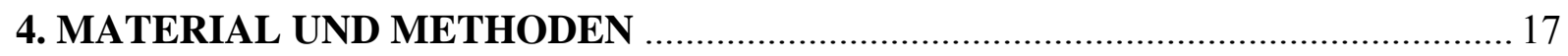

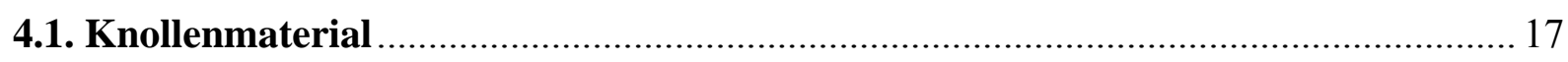

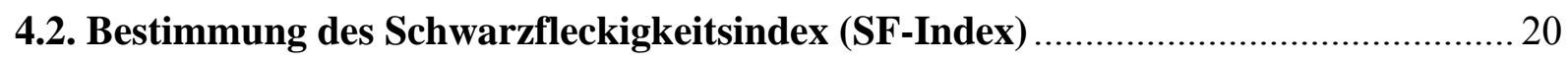

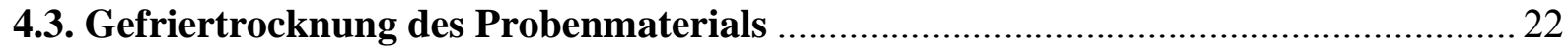




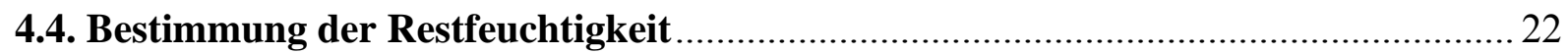

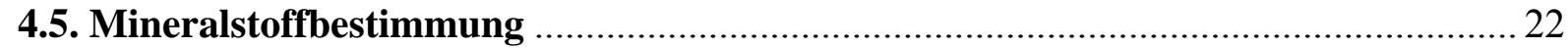

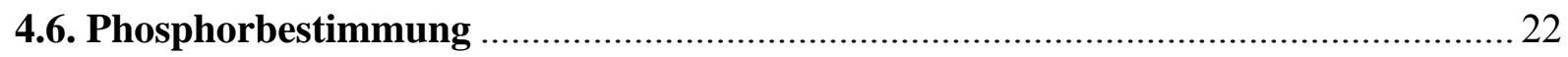

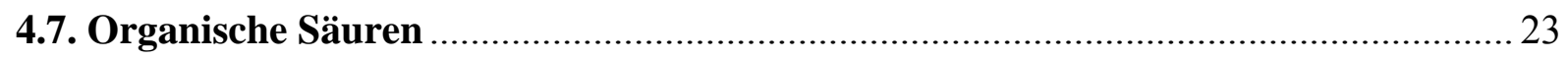

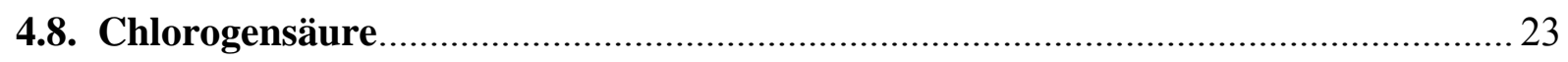

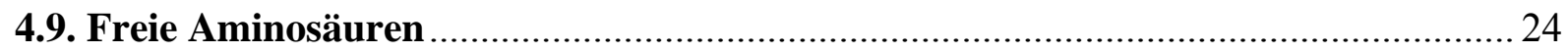

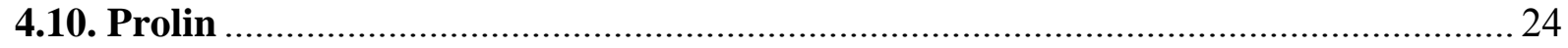

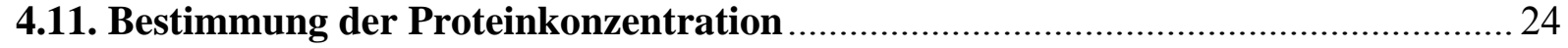

4.12. Probenvorbereitung für die Enzymanalysen ......................................................... 24

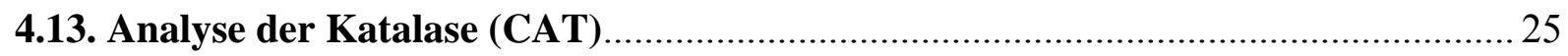

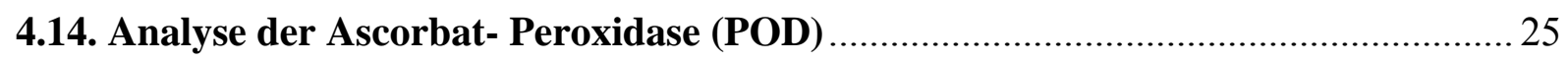

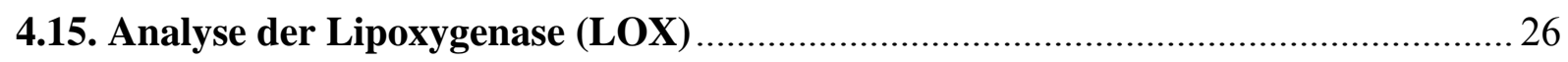

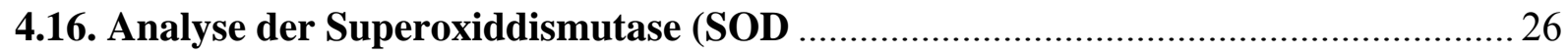

4.17. Polyphenoloxidase, Stärkegehalt und Ascorbinsäure ............................................26

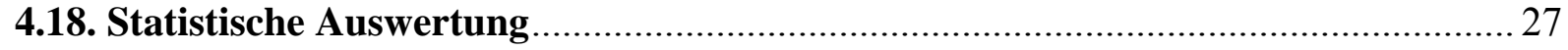

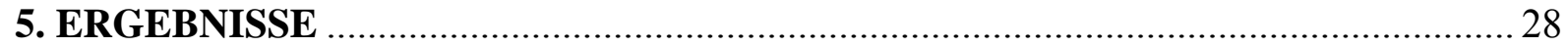

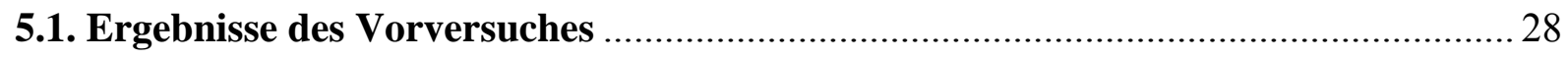

5.1.1. Beziehung der spezifischen Dichte zur Schwarzfleckigkeit............................2 28

5.1.2. Aktivität ausgewählter Enzyme in Abhängigkeit von der Sorte, der

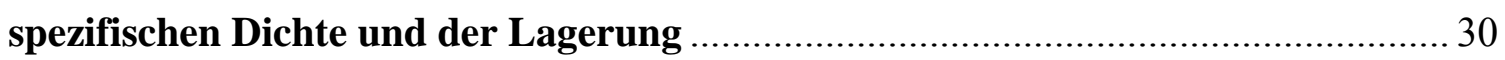

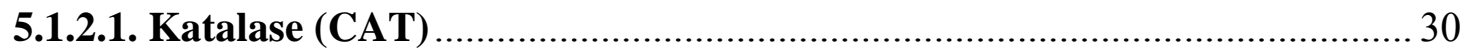

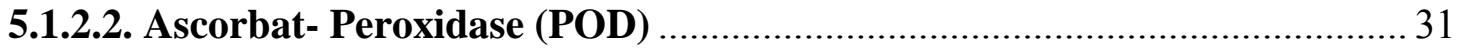

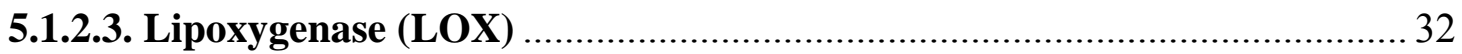

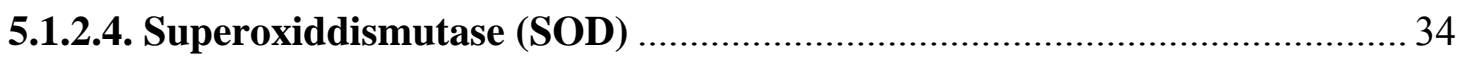

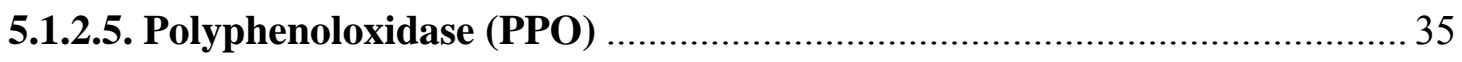

5.1.3. Gehalt freier Aminosäuren in Abhängigkeit von der Sorte, der spezifischen

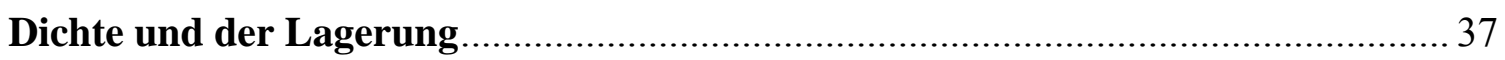

5.1.4. Gehalt an organischen Säuren in Abhängigkeit von der Sorte, der

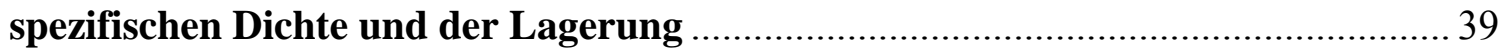

5.1.5. Mineralstoffgehalte in Abhängigkeit von der Sorte, der spezifischen Dichte

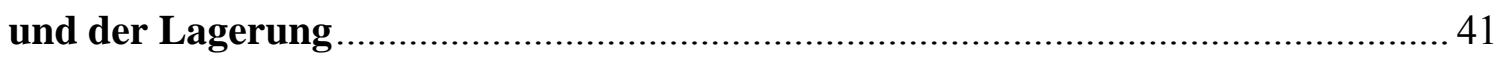

5.1.6. Zusammenfassung der Ergebnisse aus dem Vorversuch ............................... 44

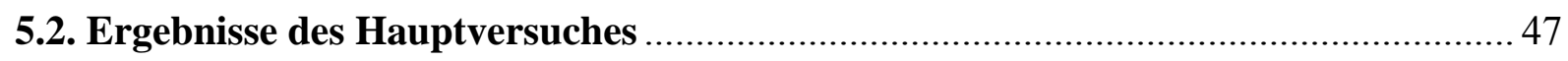

5.2.1. Beziehung der spezifischen Dichte zur Schwarzfleckigkeit........................... 47 
5.2.2. Aktivität ausgewählter Enzyme in Abhängigkeit von der Sorte, der spezifischen Dichte und der Lagerung

5.2.2.1. Katalase

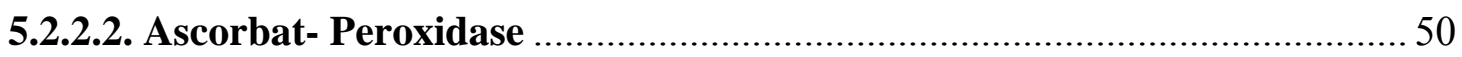

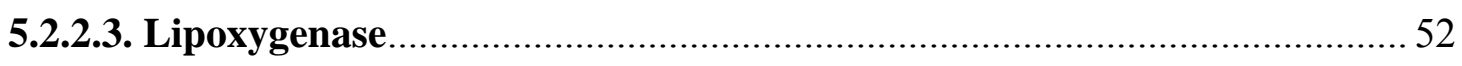

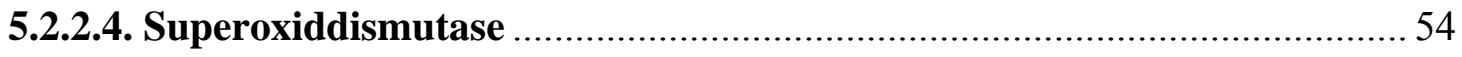

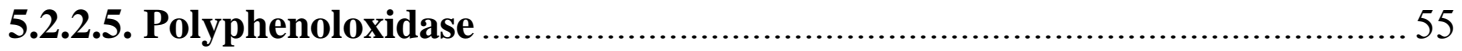

5.2.3. Gehalt freier Aminosäuren in Abhängigkeit von der Sorte, der spezifischen Dichte und der Lagerung. 56

5.2.4. Gehalt an organischen Säuren in Abhängigkeit von der Sorte, der spezifischen Dichte und der Lagerung

5.2.5. Mineralstoffgehalte in Abhängigkeit von der Sorte, der spezifischen Dichte und der Lagerung.

5.2.6. Zusammenfassung der Ergebnisse aus dem Hauptversuch

6.1. Rolle der spezifischen Dichte bei der Ausprägung der Schwarzfleckigkeit 67

6.2. Enzymaktivitäten und ihre Rolle bei der Ausprägung der Schwarzfleckigkeit. 68

6.2.1. Aktivitäten der CAT, POD, SOD und LOX und ihre Rolle bei der Ausprägung der Schwarzfleckigkeit.

6.2.2. Aktivität der PPO und ihre Rolle bei der Ausprägung der Schwarzfleckigkeit

6.3. Aminosäuregehalte und deren Verbindung zur Schwarzfleckigkeit ....................... 72

6.4. Organische Säuren und ihre Rolle bei der Ausprägung der Schwarzfleckigkeit ..... 74

6.5. Mineralstoffgehalte und deren Verbindung zur Schwarzfleckigkeit ....................... 77

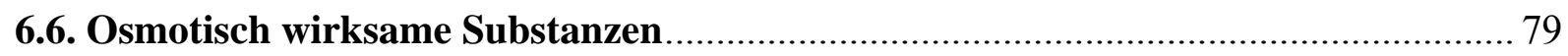

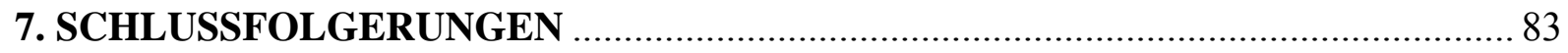

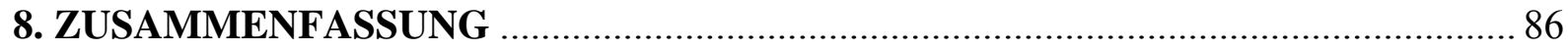

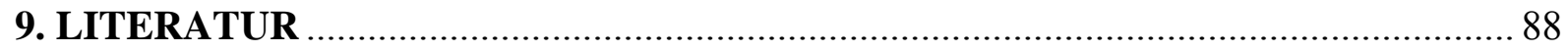

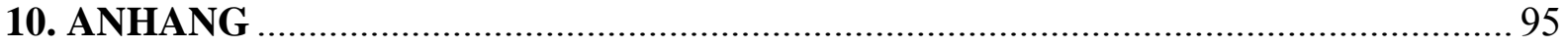

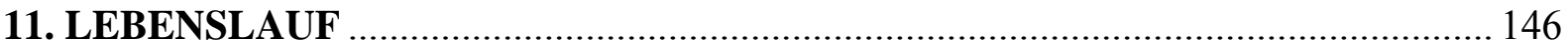




\section{ABKÜRZUNGSVERZEICHNIS}

Abb. Abbildung

AHL Ammoniumnitrat- Harnstoff- Lösung (Düngemittel)

BEL Bundesforschungsanstalt für Ernährung und Lebensmittel

CAT Katalase

DAP Diammonphosphat (Düngemittel)

DOPA Dihydroxyphenylalanin

EC Enzyme Commission

HPLC Hochleistungsflüssigkeitschromatographie

LOX Lipoxygenase

LWK Landwirtschaftskammer Niedersachsen

MA membranassoziiert

MES 2-Morpholinoethansulfonsäure-Monohydrat (Puffersubstanz)

N Stickstoff

n.s. nicht signifikant

$\mathrm{p} \quad$ Signifikanzniveau

POD Ascorbat-Peroxidase

PPO Polyphenoloxidase

ROS reaktive $\mathrm{O}_{2}-$ Spezien

SD spezifische Dichte

SF- Index Schwarzfleckigkeitsindex

SOD Superoxiddismutase

Tab. Tabelle

TM Trockenmasse

UV ultraviolett 


\section{ABBILDUNGSVERZEICHNIS}

Abb. 1 Verfärbungsreaktion im Schwarzfleckigkeitsprozess. 2

Abb. 2 Knollenverletzungen infolge mechanischer Einwirkung 3

Abb. 3 Einfluss des Wasserverlustes auf die Ausprägung der Schwarzfleckigkeit .................... 7

Abb. 4 Beziehung zwischen Schwarzfleckigkeit und spezifischer Dichte. .28

Abb. 5 Beziehung zwischen Schwarzfleckigkeit und der spezifischen Dichte unter

Berücksichtigung verschiedener Sorten 29

Abb. 6 Veränderung der Schwarzfleckigkeit während der Lagerung unter Berücksichtigung verschiedener Sorten 29

Abb. 7 Beziehung zwischen der CAT-Aktivität und der spezifischen Dichte ......................... 30

Abb. 8 Beziehung zwischen der POD-Aktivität und der spezifischen Dichte........................... 32

Abb. 9 Beziehung zwischen der LOX-Aktivität und der spezifischen Dichte ......................... 33

Abb. 10 Beziehung zwischen der SOD- Aktivität und der spezifischen Dichte ........................ 35

Abb. 11 Beziehung zwischen der PPO- Aktivität und der spezifischen Dichte ........................ 36

Abb. 12a Beziehung zwischen den Aminosäuren und der spezifischen Dichte ....................... 38

Abb. $12 b$ Beziehung zwischen den Aminosäuren und der spezifischen Dichte ........................ 38

Abb. 13 Beziehung zwischen den organischen Säuren und der spezifischen Dichte .............. 40

Abb. 14a Beziehung zwischen den Mineralstoffen und der spezifischen Dichte.................... 42

Abb. 14b Beziehung zwischen den Mineralstoffen und der spezifischen Dichte.................... 43

Abb. 15 Beziehung zwischen dem Chlorogensäure-Zitronensäure-Verhältnis und dem SF-

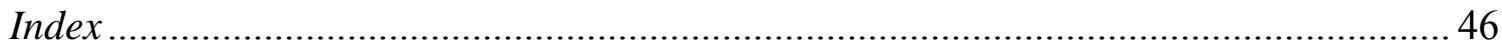

Abb. 16 Beziehung zwischen Schwarzfleckigkeit und spezifischer Dichte ............................ 47

Abb. 17 Beziehung zwischen Schwarzfleckigkeit und der spezifischer Dichte unter

Berücksichtigung verschiedener Sorten

Abb. 18 Veränderung der Schwarzfleckigkeit während der Lagerung unter Berücksichtigung

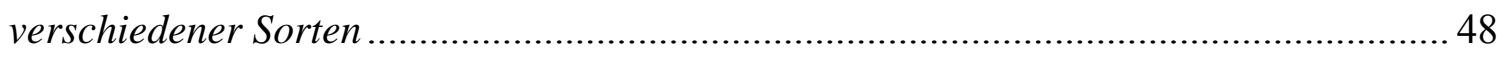

Abb. 19 Beziehung zwischen der CAT-Aktivität und der spezifischen Dichte ......................50

Abb. 20 Beziehung zwischen der POD- Aktivität und der spezifischen Dichte...................... 51

Abb. 21 Beziehung zwischen der LOX-Aktivität und der spezifischen Dichte ....................... 53

Abb. 22 Beziehung zwischen der SOD- Aktivität und der spezifischen Dichte........................54

Abb. 23 Beziehung zwischen der PPO-Aktivität und der spezifischen Dichte (Sorte: Aula,

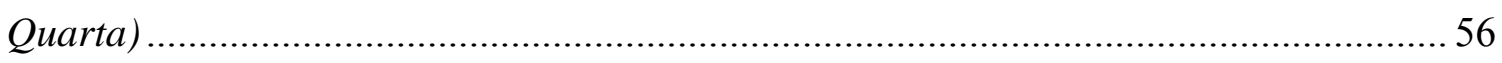

Abb. 24a Beziehung zwischen den freien Aminosäuren und der spezifischen Dichte............. 58

Abb. 24b Beziehung zwischen den freien Aminosäuren und der spezifischen Dichte............. 58 
Abb. 25 Beziehung zwischen den organischen Säuren und der spezifischen Dichte

Abb. 26a Beziehung zwischen Mineralstoffen und der spezifischen Dichte 63

Abb. $26 b$ Beziehung zwischen Mineralstoffen und der spezifischen Dichte 63

Abb. 27 Beziehung zwischen dem Chlorogensäure- Zitronensäure-Verhältnis und dem SFIndex 66

Abb. 28 Summe osmotisch wirksamer Substanzen in Abhängigkeit von den Sorten des Vorversuches und deren Schwarzfleckigkeitsneigung (Vorversuch) 79

Abb. 29 Summe osmotisch wirksamer Substanzen in Abhängigkeit von den Sorten des Hauptversuches und deren Schwarzfleckigkeitsneigung (Hauptversuch) 80

Abb. 30 Summe osmotisch wirksamer Substanzen in Abhängigkeit von der spezifischen Dichte (Vorversuch)

Abb. 31 Summe osmotisch wirksamer Substanzen in Abhängigkeit von der spezifischen Dichte (Hauptversuch) 


\section{TABELLENVERZEICHNIS}

Tab. 1 Inhaltsstoffzusammensetzung frischer Kartoffeln

Tab. 2 Eigenschaften der verwendeten Sorten

Tab. 3 Klassen der spezifischen Dichte im Vorversuch ........................................................ 19

Tab. 4 Klassen der spezifischen Dichte im Hauptversuch .................................................... 20

Tab. 5 Einfluss der Sorte auf die CAT- Aktivität ................................................................ 30

Tab. 6 Veränderung der CAT- Aktivität während der Lagerung ........................................... 31

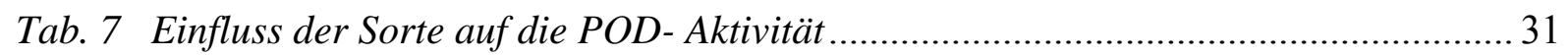

Tab. 8 Veränderung der POD- Aktivität während der Lagerung …...................................... 32

Tab. 9 Einfluss der Sorte auf die LOX-Aktivität.................................................................... 33

Tab. 10 Veränderung der LOX- Aktivität während der Lagerung ......................................... 34

Tab. 11 Einfluss der Sorte auf die SOD- Aktivität ................................................................. 34

Tab. 12 Veränderung der SOD- Aktivität während der Lagerung ......................................... 35

Tab. 13 Einfluss der Sorte auf die PPO- Aktivität ............................................................. 36

Tab. 14 Veränderung der PPO- Aktivität während der Lagerung .......................................... 36

Tab. 15a Einfluss der Sorte auf den Gehalt an freien Aminosäuren ....................................... 37

Tab. 15b Einfluss der Sorte auf den Gehalt an freien Aminosäuren....................................... 37

Tab. 16a Veränderung der Aminosäuregehalte während der Lagerung ................................ 39

Tab. 16b Veränderung der Aminosäuregehalte während der Lagerung ................................. 39

Tab. 17 Einfluss der Sorte auf den Gehalt an organischen Säuren ....................................... 40

Tab. 18 Veränderung der Gehalte der organischen Säuren während der Lagerung ............. 41

Tab. 19 Einfluss der Sorte auf den Gehalt an Mineralstoffen ................................................. 42

Tab. 20 Veränderung der Gehalte der organischen Säuren während der Lagerung ............. 44

Tab. 21 Summe einzelner Inhaltsstoffe in den Sorten des Vorversuches ................................ 44

Tab. 22 Prozentualer Anteil des Tyrosins an der Summe der freien Aminosäuren in

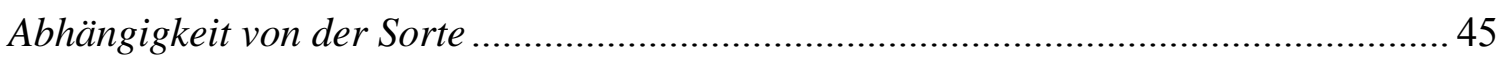

Tab. 23 Summe einzelner Inhaltsstoffe in Abhängigkeit von der spezifischen Dichte ............ 45

Tab. 24 Prozentualer Anteil des Tyrosins an der Summe der freien Aminosäuren in

Abhängigkeit von der spezifischen Dichte ................................................................. 45

Tab. 25 Korrelationen zwischen de SF-Index und Inhaltsstoffen ......................................... 46

Tab. 26 Einfluss der Sorte auf die CAT- Aktivität ............................................................... 49

Tab. 27 Veränderung der CAT- Aktivität während der Lagerung .......................................... 50

Tab. 28 Einfluss der Sorte auf die POD- Aktivität ............................................................... 51

Tab. 29 Veränderung der POD- Aktivität während der Lagerung ....................................... 52

Tab. 30 Einfluss der Sorte auf die LOX- Aktivität.............................................................. 52 
Tab. 31 Veränderung der LOX- Aktivität während der Lagerung .......................................... 53

Tab. 32 Einfluss der Sorte auf die SOD- Aktivität ................................................................. 54

Tab. 33 Veränderung der SOD- Aktivität während der Lagerung ......................................... 55

Tab. 34 Einfluss der Sorte auf die PPO- Aktivität ............................................................... 55

Tab. 35 Veränderung der PPO- Aktivität während der Lagerung (Sorten: Aula, Quarta) .... 56

Tab. 36a Einfluss der Sorte auf den Gehalt an freien Aminosäuren........................................ 57

Tab. 36b Einfluss der Sorte auf den Gehalt an freien Aminosäuren....................................... 57

Tab. 37a Veränderung der Aminosäuregehalte während der Lagerung ................................. 59

Tab. 37b Veränderung der Aminosäuregehalte während der Lagerung ................................ 59

Tab. 38 Einfluss der Sorte auf den Gehalt an organischen Säuren ....................................... 60

Tab. 39 Veränderung der Gehalte der organischen Säuren während der Lagerung ............. 61

Tab. 40 Einfluss der Sorte auf den Mineralstoffgehalt ........................................................... 62

Tab. 41 Veränderung der Mineralstoffgehalte während der Lagerung ................................... 64

Tab. 42 Summe einzelner Inhaltsstoffe in den Sorten des Hauptversuches ............................ 64

Tab. 43 Prozentualer Anteil des Tyrosins an der Summe der freien Aminosäuren in

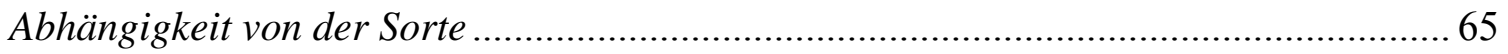

Tab. 44 Summe einzelner Inhaltsstoffe in Abhängigkeit von der spezifischen Dichte. 65

Tab. 45 Prozentualer Anteil des Tyrosins an der Summe der freien Aminosäuren in Abhängigkeit von der Sorte. 


\section{STAND DES WISSENS}

\subsection{Bedeutung der Schwarzfleckigkeit für die Landwirtschaft und die nachgelagerten Bereiche}

Sowohl bei der Ernte, dem Transport und der Lagerung als auch bei der Aufbereitung sind Kartoffelknollen vielfältiger mechanischer Belastung ausgesetzt, so dass es an und in der Kartoffel zu Beschädigungen kommen kann. Diese sichtbaren und unsichtbaren Beschädigungen können in der Kartoffelknolle gemeinsam oder getrennt auftreten und führen zu wirtschaftlichen Verlusten für die landwirtschaftlichen Betriebe und die nachgelagerten Bereiche wie Handel und Verarbeitung.

Ein Verbraucher, der mehrmals qualitativ minderwertige Ware erworben hat, wird zukünftig daraufhin mit einer ablehnenden Kaufentscheidung für Speisekartoffeln reagieren.

Problematisch erweisen sich vor allem die äußerlich nicht sichtbaren Beschädigungen, zu denen die Schwarzfleckigkeit und Nekrosen gehören.

Diese Mängel, die erst beim Schälen bzw. Zerkleinern der Kartoffelknolle sichtbar werden, beeinträchtigen das Erscheinungsbild der geschälten oder zubereiteten Kartoffel erheblich. Für den Verbraucher vermindert sich dadurch der Genusswert der Kartoffel.

Auch aus Sicht der Veredlungsindustrie sind Kartoffeln mit inneren Beschädigungen für die Verarbeitung ungeeignet, da diese Ware einerseits nur durch höhere Schälverluste verarbeitbar sein kann oder für den Produktionsprozess verworfen werden muss.

Die Schwarzfleckigkeit ist unter den inneren Beschädigungen der Kartoffelknolle der schwerwiegendste Qualitätsmangel.

Problematisch dabei ist, dass die Verfärbungsreaktion erst ein bis zwei Tage nach der mechanischen Einwirkung einsetzt und für den Landwirt, die abnehmende Hand und den Verbraucher von außen nicht sichtbar ist. Bei der Auswertung der Boniturbefunde der freiwilligen Qualitätskontrolle der LWK Niedersachsen 2003 ergeben sich aus Sicht der Anbauer in der Bundesrepublik Deutschland jährliche finanzielle Verluste von etwa 39,75 Mio. Euro. Für den Verbraucher betragen die Verluste sogar 241,4 Mio. Euro, wenn man einen durchschnittlichen Anteil an schwarzfleckigen Knollen von 15\% zugrunde legt. In den USA werden bis zu 7\% aller in der Veredlungsindustrie verarbeiteten Kartoffeln aufgrund Schwarzfleckigkeit verworfen. Monetär beurteilt, spricht man von etwa 200 Mio. US\$ Verlusten durch Beschädigungen (Thornton, 1994). 
1.2. Die physiologischen Vorgänge in einer Kartoffelknolle nach einer mechanischen Belastung - Prozess der Bildung der Schwarzfleckigkeit

Die Schwarzfleckigkeit wird nicht durch ein Pathogen, sondern durch eine physiologische Veränderung innerhalb der Knolle hervorgerufen.

Die Reaktionspartner für die schwarzfleckigkeitsauslösende, enzymatische Reaktion sind in von einander getrennten Zellorganellen lokalisiert (Cobb, 1999).

Erst eine äußere mechanische Belastung kann im Inneren der Kartoffelknolle eine Beschädigung der Zellwände sowie der Zellmembranen hervorrufen, wodurch diese für Sauerstoff durchlässig werden und die subzelluläre Integrität abnimmt. Bricht die Tonoplastenmembran auf, können die phenolischen Verbindungen aus der Vakuole austreten und mit dem Enzym Polyphenoloxidase (PPO), das in den Vesikeln im Inneren der Amyloplasten lokalisiert ist, reagieren, wodurch die Verfärbungsreaktion beginnt (Ojala, 1995).

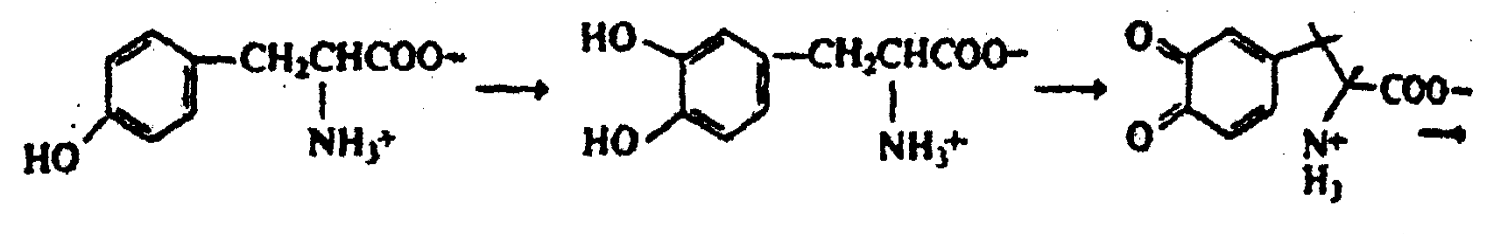

Tyrosine

3,4-Dihydroxyphenylalanine (DOPA)

Phenylalanine-3,4quinone<smiles>CC(=O)C1(C)CC2C[C@H](O)C(O)C[C@@H]2N1</smiles><smiles>CC1Cc2cc(O)c(O)cc2N1</smiles>

2-Carboxy-2,3-dihydro-5,6 dihydroxyindole

\section{2-Carboxy-2,3-dihydroindole- 5,6-Dihydroxyindole 3,6-quinone}

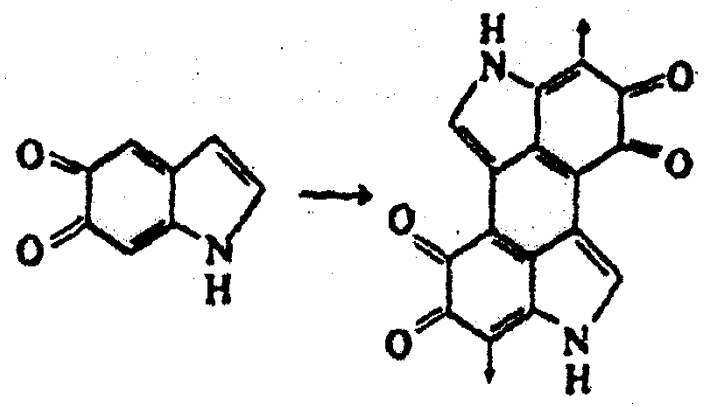

Indole-5,6-quinone Melanin

Abb. 1 Verfärbungsreaktion im Schwarzfleckigkeitsprozess

[nach Burton (1966), aus Laerke (2001) 
In Anwesenheit von molekularem Sauerstoff kommt es $\mathrm{zu}$ einer Oxidation von Monophenolen oder o-Diphenolen zu konjugierten Quinonen (Abb.2). Dieser enzymatischen Reaktion folgt eine nicht-enzymatische, in der die Quinone zu Melanin umgewandelt werden (Stevens \& Davelaar, 1997), das sich als dunkel gefärbte Pigmente unterhalb der Kartoffelschale, vor allem in den Knollenrandzonen im Bereich des Gefäßbündelringes, zeigt (Kolbe \& Haase, 1997).

Entscheidend für das Verständnis des Schwarzfleckigkeitsprozesses ist, dass die Schwarzfleckigkeit zwar auf einer äußeren mechanischen Belastung bzw. Einwirkung beruht, jedoch keine äußerlich sichtbare mechanische Beschädigung vorliegt. Nachfolgend in Abb.2 sind die verschiedenartigen Auswirkungen einer mechanischen Einwirkung dargestellt (Hughes, 1980).

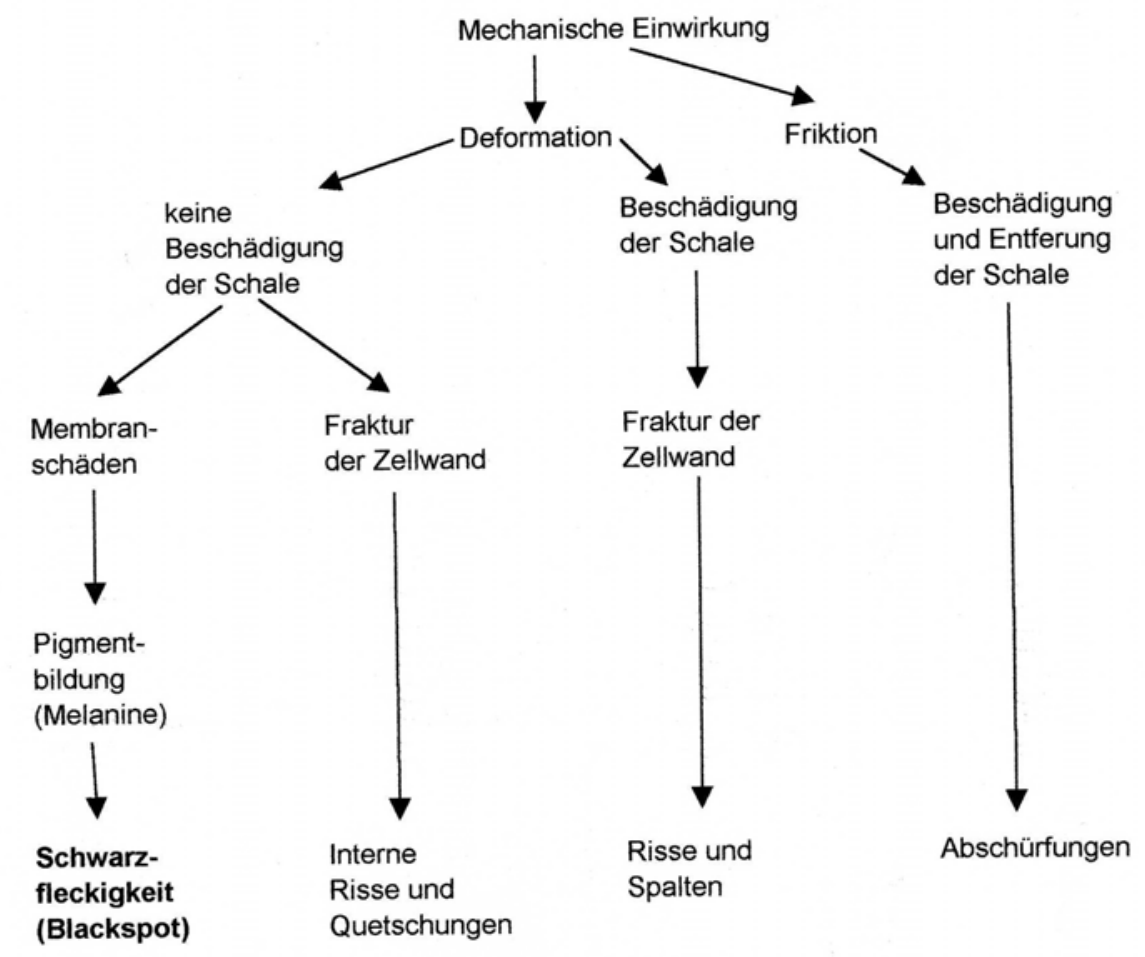

Abb. 2 Knollenverletzungen infolge mechanischer Einwirkung (Hughes, 1980) 


\subsection{Einflussfaktoren bei der Ausbildung der Schwarzfleckigkeit 1.3.1. Sortenwahl}

In der Schwarzfleckigkeitsneigung von Kartoffeln zeigen sich deutliche Sortenunterschiede (Brown et al., 1999; Amberger \& Schaller, 1975). Man geht davon aus, dass etwa 32 bis $40 \%$ der Schwarzfleckigkeitsanfälligkeit genetisch fixiert sind (Aeppli, 1979). Dean (1997) weist darauf hin, dass zu dem Sorteneinfluss auch Umwelteinflüsse kommen. Dabei sei jedoch zu beachten, dass die Einflussnahme der Sorte ausschlaggebender als der Einfluss durch Wetter und Anbaumaßnahmen ist (Baumgartner, 1982).

Des Weiteren basiert die Schwarzfleckigkeitsneigung der Sorten auf einer unterschiedlichen Inhaltsstoffzusammensetzung. Spätreife Sorten neigen aufgrund der höheren Trockenmassegehalte oftmals zu höherer Schwarzfleckigkeit (Aeppli, 1979). Kolbe (1995) ergänzt, dass spätreife Sorten zusätzlich einen höheren Tyrosingehalt aufweisen, wodurch ein verstärktes Verfärbungspotential gegeben ist.

Gefäßversuche mit Solanum hjertingii unterstreichen eine stark sortenabhängige Schwarzfleckigkeitsneigung. Es wurde festgestellt, dass Solanum hjertingii und deren Hybride im Vergleich zu tetraploiden Sorten geringere Schwarzfleckigkeitsneigung aufwiesen. Grund dafür ist nicht der Mangel an phenolischen Verbindungen, sondern geringe PPOAktivität (Brown et al., 1999).

Von Seiten der Züchtung wird als Strategie der Bekämpfung der Schwarzfleckigkeit die Selektion gering anfälliger bzw. resistenter Sorten forciert (Brown et al., 1999; Ojala, 1995).

Dabei ist jedoch zu beachten, dass die Schwarzfleckigkeitsempfindlichkeit polygen vererbt wird (Miller, 1996).

In Deutschland sind alle zugelassenen Sorten in der beschreibenden Sortenliste des Bundessortenamtes (2001) mit ihren spezifischen Sorteneigenschaften, wozu auch die Beschädigungsempfindlichkeit und die Schwarzfleckigkeitsneigung zählen, gelistet. Damit kann sich ein Landwirt bei der Sortenauswahl über mögliche Stärken und Schwächen einer Sorte informieren.

\subsubsection{Anbaubedingungen}

Die Witterung hat einen Einfluss auf die Ausprägung der Schwarzfleckigkeit. Stricker (1981) beobachtete bei hohen Durchschnittstemperaturen in der Hauptwachstumsphase geringe Schwarzfleckigkeit. Hohe Temperaturen $\left(>25^{\circ} \mathrm{C}\right)$ bewirken eine gesteigerte Respiration der Kartoffelpflanzen und ein verstärktes Krautwachstum, welches mit den Knollen um die Einlagerung von Assimilaten konkurriert, wodurch die verringerte 
Schwarzfleckigkeitsneigung zu erklären wäre (Burton, 1966). Außerdem steigt mit zunehmender Temperatur und Trockenheit der Gehalt an Ascorbinsäure, Zitronensäure und Äpfelsäure in der Kartoffelknolle an (Kolbe, 1996).

Dieser positiven Auswirkung hoher Temperaturen steht das Ergebnis gegenüber, dass mit zunehmender Temperatur eine verstärkte Akkumulation von phenolischen Verbindungen, die Reaktionspartner für die PPO sind, eintritt (Dean, 1997).

Mangelnde Wasserversorgung während des Knollenwachstums bedeutet Stress für die Kartoffelpflanze, der eine erhöhte PPO- Aktivität induziert (Pawelzik \& Delgado, 1999).

Zusätzlich steigen durch die mangelnde Wasserversorgung bzw. eine hohe Sonnenscheindauer die Trockensubstanzgehalte der Kartoffelknolle an, so dass die Schwarzfleckigkeitsneigung erhöht wird (Aeppli, 1979).

Bei der Düngung ist zu beachten, dass einseitig gesteigerte N-Gaben einen Anstieg der Schwarzfleckigkeitsneigung aufgrund Anstiegs der Gehalte an Chlorogensäure und Tyrosin sowie Abnahme des Gehalts an organischen Säuren bewirken (Kolbe, 1995). Laerke (2001) bewertet die Rolle des Stickstoffs und den Einfluss auf die Schwarzfleckigkeit mit der Aussage, dass zwar eine Reihe von Untersuchungen gezeigt haben, dass hohe Stickstoffgehalte die Schwarzfleckigkeitsneigung fördern, jedoch läge das nicht ausschließlich am Stickstoff, sondern lasse sich auf ein verlängertes Pflanzenwachstum mit längerer Nährstoffzufuhr zurückführen.

Phosphordüngung beeinflusst die Schalenfestigkeit positiv, wodurch das Pflanzengewebe gestärkt wird und die Kartoffeln einen höheren Belastungswiderstand aufweisen (Schuhmann, 1999). Phosphor übernimmt eine entscheidende Rolle in der Membran- und Zellwandausbildung (Kolbe, 1995).

Gefäßversuche in den 60-iger Jahren hatten gezeigt, dass eine ausreichende Mineralstoffernährung der wachsenden Pflanze, vor allem mit Kalium, das Ausmaß der Schwarzfleckigkeit deutlich reduziert (Welte \& Müller, 1966).

In neueren Feldversuchen bestätigte sich der Zusammenhang und konnte tiefer gehender erklärt werden: Bei Kaliumgehalten von weniger als 2\% in der Kartoffeltrockenmasse nimmt die Schwarzfleckigkeit deutlich zu (Orlovius, 1996). Der Anstieg des Kaliumgehaltes in den Kartoffeln bewirkt im Sinne eines elektrostatischen Ausgleichs einen Anstieg des Säuregehaltes, wodurch die PPO- Aktivität gehemmt wird (Müller, 1977). Dabei wird mit steigenden Kaliumgaben (bis 3\% Kalium in der Kartoffeltrockensubstanz) vor allem der Gehalt an Zitronensäure und Äpfelsäure angehoben (Kolbe, 1996). Darüber hinaus nimmt 
gleichzeitig der Gehalt an freiem Tyrosin ab (Dean, 1997). Kaliumionen wirken als Coenzyme in der Proteinsynthese, wodurch ein Abbau bzw. Umbau von Tyrosin bewirkt wird (McNabnay et al., 1999).

Kaliummangel sorgt für einen Anstieg an freien Aminosäuren, Amiden, reduzierenden Zuckern und Saccharose (Kolbe, 1995). Ein steigender Gesamtzuckergehalt erhöht die Verfärbungsneigung zusätzlich (Bodin, 1984).

\subsubsection{Reife der Kartoffeln}

Laerke (2001), Corsini et al. (1999), Dean (1997) und Mondy \& Munshi (1987) weisen daraufhin, dass die Reife der Kartoffel eine Schlüsselfunktion bei der Entstehung der Schwarzfleckigkeit einnimmt. Je reifer (je physiologisch älter) die Knollen sind, desto anfälliger sind sie für Schwarzfleckigkeit. Corsini et al. (1999) erklären diesen Zusammenhang mit einer mit zunehmender Reife ansteigenden spezifischen Dichte.

\subsubsection{Erntebedingungen}

Die Entstehung der Schwarzfleckigkeit wird von dem Knollenwassergehalt und der Knollentemperatur zur Zeit der Ernte beeinflusst.

Dünnschalige Kartoffeln, die durch einen hohen Bodenwassergehalt zum Zeitpunkt der Abreife hervorgerufen wird, neigen $\mathrm{zu}$ einer verstärkten Wasserabgabe an den trockenen Erdboden. Dadurch werden die Knollen welk und neigen verstärkt zur Schwarzfleckigkeit (Bohl, 1999).

Auch die Knollentemperatur nimmt Einfluss auf die Schwarzfleckigkeit. Bei einer Knollentemperatur unter $4^{\circ} \mathrm{C}$ und einer Umgebungstemperatur von $10^{\circ} \mathrm{C}$ steigt die Schwarzfleckigkeitsanfälligkeit unabhängig von der Sorteneigenschaft beträchtlich (Corsini et al., 1999).

\subsubsection{Nacherntebehandlung}

Während der Nacherntebehandlung nimmt die Schwarzfleckigkeit an Volumen und Tiefe bei zunehmender Häufigkeit der Kollisionen zu (Molema \& Bosma, 1998). Beschädigungen sorgen für erhöhte Wasser- und Atmungsverluste der Knollen, wodurch die Knollen physiologisch schneller altern. Neben höheren Lagerverlusten kommt es durch mechanische Belastung vor der Einlagerung zur Erhöhung der Schwarzfleckigkeitsneigung zum Zeitpunkt der Auslagerung (Wirsing, 1997). 
Um eine mechanische Beschädigung der Kartoffeln $\mathrm{zu}$ vermeiden, sollten in der Nacherntebehandlung Fallstufen bei der Verladung, die Umlaufgeschwindigkeit von Fördereinrichtungen, die Anzahl der Gutstromumlenkungen und die Anzahl der Umschlagprozesse minimiert werden (Wormanns, 1999).

\subsubsection{Lagerbedingungen}

Mit zunehmender Lagerdauer kommt es zu steigenden Wasserverlusten der Kartoffelknollen, wodurch, wie in Abb. 3 ersichtlich wird, die Schwarzfleckigkeitsneigung der Kartoffeln stark ansteigt. Dabei handelt sich um eine fast lineare Beziehung zwischen Wasserverlust und Anstieg der Schwarzfleckigkeitsneigung (Effmert \& Schüler, 1978).

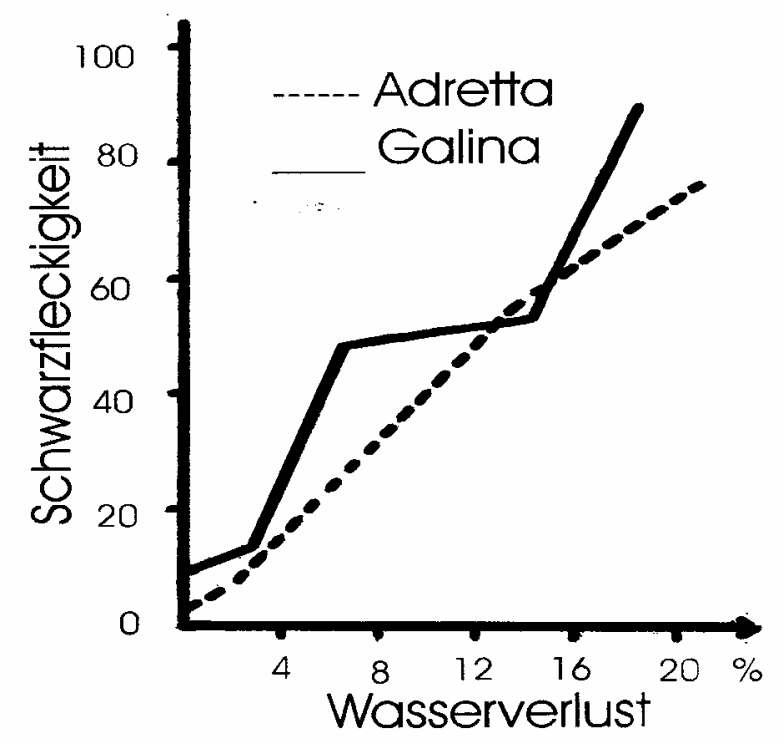

Abb. 3 Einfluss des Wasserverlustes auf die Ausprägung der Schwarzfleckigkeit (nach Effmert et al., 1980, aus Bodin, 1984)

Zwangsbelüftung sowie höhere Lagertemperaturen fördern die Wasserverluste zusätzlich und führen zu einer schnelleren Alterung der Kartoffeln. Dabei kommt es zur verstärkten Ausprägung von Lagerdruckstellen, die besonders von der Stapelhöhe der Kartoffeln abhängig ist (Bodin, 1984). Je höher gelagert wird und je stärker die Gewichtsverluste im Lager sind, desto ausgeprägter sind die Druckstellen und damit auch die Schwarzfleckigkeitsneigung (Wirsing, 1997). Als derzeit übliche Stapelhöhe werden 3,4 bis 4 $m$ angesehen (Bodin, 1984). Kartoffelnknollen in der untersten Lagerschicht sowie in direkter Nähe zum Belüftungskanal neigen aufgrund des verstärkten Turgorverlustes besonders zur Schwarzfleckigkeit (Schuhmann, 1999). 


\subsubsection{Inhaltsstoffe der Kartoffel und ihre Einflussnahme auf die Schwarzfleckigkeit}

Nachfolgende Tabelle zeigt die Inhaltstoffzusammensetzung der Kartoffeln in \% bezogen auf die Frischmasse.

Tab. 1 Inhaltsstoffzusammensetzung frischer Kartoffeln

(geordnet nach Durchschnittsgehalten; Putz, 1998)

\begin{tabular}{|c|c|}
\hline Inhaltsstoffe & $\begin{array}{c}\text { Durchschnittsgehalt in \% bezogen auf die } \\
\text { Frischmasse }\end{array}$ \\
\hline Stärke & 15,0 \\
\hline Protein & 2,0 \\
\hline Organische Säuren & 1,5 \\
\hline Mineralstoffe & 1,0 \\
\hline Aminosäuren & 0,8 \\
\hline andere Polysaccharide & 0,7 \\
\hline Zucker & 0,5 \\
\hline Lipide & 0,2 \\
\hline Polyphenole & 0,2 \\
\hline Vitamine & 0,02 \\
\hline Pigmente & 0,015 \\
\hline Alkaloide & 0,01 \\
\hline RNA, Nukleotide & 0,01 \\
\hline
\end{tabular}

\subsubsection{Stärke- und Trockensubstanzgehalt}

Der Stärke- bzw. Trockensubstanzgehalt steht in direkter Verbindung zur Schwarzfleckigkeit. Die Schwarzfleckigkeitsneigung nimmt mit steigenden Trockensubstanzgehalten zu (Baumgartner, 1982). Die Ergebnisse von McNabnay et al. (1999) und Corsini et al. (1999) unterstreichen jedoch, dass der Stärkegehalt allein betrachtet keine Rückschlüsse auf die Schwarzfleckigkeit zulässt, sondern eine Gesamtbetrachtung der Trockensubstanz, die durch die spezifische Dichte repräsentiert ist, erforderlich ist. McNabnay et al.(1999) und Corsini et al. (1999) ermittelten folgenden Zusammenhang: Je höher die spezifische Dichte ist, desto höher ist die Schwarzfleckigkeitsneigung.

Hudson (1975) hatte in seinen Untersuchungen jedoch festgestellt, dass eine Kartoffel mit hoher Beschädigungsempfindlichkeit eine geringe Dichte, große Zellvolumina und große 
interzelluläre Zwischenräume aufweist. Dieser dargestellte Gegensatz erweist sich jedoch nicht als Widerspruch zu McNabnay et al. (1999) und Corsini et al. (1999),sondern unterstreicht die vielfach auftretende Problematik im Umgang mit Begrifflichkeiten. Hudson (1975) hat sich mit Erntebeschädigungen, die keinesfalls mit der Schwarzfleckigkeit verwechselt oder gleichgesetzt werden dürfen (s. Kap.1.2.), auseinander gesetzt.

Die spezifische Dichte einer Kartoffel ist von Faktoren wie Temperatur, Niederschlag, Bodentyp und Dünger sowie Reife zum Zeitpunkt der Ernte abhängig (Hudson, 1975).

\subsubsection{Organische Säuren}

Die organischen Säuren sind weitgehend in der Rindenschicht der Knolle lokalisiert, dabei findet man eine höhere Konzentration organischer Säuren am Kronenende als am Nabelende der Knolle (Schick \& Klinkowski, 1961).

Die Bedeutung der organischen Säuren liegt in ihrer zentralen Stellung im Stoffwechsel. Der Zitronensäurezyklus übernimmt die Rolle der Schaltstelle der biochemischen Reaktionen, zum einen bei der Energiegewinnung, zum anderen beim Kohlenhydrat-, Fett- und Proteinabbau (Schlegel, 1992).

Durch Absenken des pH- Wertes im Zellsaft wirken die organischen Säuren, wie Zitronensäure und Äpfelsäure, farbstabilisierend (Kolbe, 1995). Zusätzlich bewirken sie eine Aktivitätsabnahme der PPO von bis zu 50\% (Müller, 1977). Bei Zitronensäure tritt dieser Effekt besonders deutlich ab Gehalten von 3\% in der Trockenmasse auf (Baumgartner, 1982). In warmen und trockenen Jahren haben die Kartoffelknollen höhere Gehalte an Zitronen- und Äpfelsäure. Während Phosphordüngung keinen Einfluss auf den Gehalt an organischen Säuren in den Kartoffelknollen nimmt, senken steigende Stickstoffgaben den Gehalt. Steigende Kaliumdüngung fördert hingegen die Bildung (Kolbe, 1996; Kolbe, 1995).

Amberger \& Schaller (1975) ermittelten einen starken Standorteinfluss auf die sortentypische Ausprägung des Zitronensäuregehaltes in den unterschiedlichen Kartoffelsorten.

\subsubsection{Phenolische Verbindungen}

$\mathrm{Zu}$ den phenolischen Verbindungen zählen u.a. Kaffee- und Chlorogensäure. Diese Phenole können ebenso wie die Aminosäure Tyrosin als Substrat der PPO dienen.

Swain et al. (1964) ermittelten in ihren Feldversuchen, dass die Intensität der Schwarzfleckigkeit weder von der Konzentration der Enzyme noch von den Chlorogensäuregehalten in der Knolle beeinflusst wird. Diesem Ergebnis widerspricht jedoch Dean (1997). Die Aktivität der PPO steigt mit Präsenz der Kaffee- und Chlorogensäure an 
(Dean, 1997). Die Plausibilität der Aussage Deans (1997) ist jedoch nicht zu überprüfen, da er keine Darstellung des Versuchsaufbaus und der Versuchsergebnisse gibt, sondern nur eine allgemeine Zusammenfassung.

Die Bildung der Chlorogensäure ist in großem Maße vom Standort abhängig. Kaffeesäure reagiert hingegen weder auf den Standort noch auf die Sorte (Amberger \& Schaller, 1975). Griffith \& Bain (1997) ergänzen, dass die Chlorogensäuregehalte in Kartoffeln nicht nur durch Umweltfaktoren, sondern auch entscheidend von genetischen Faktoren beeinflusst werden. Außerdem steigt der Gehalt an Chlorogensäure in der Knolle bei Lagerung unter $5{ }^{\circ} \mathrm{C}$ an. Das Ausmaß ist vom physiologischen Zustand der Knollen zum Zeitpunkt der Ernte abhängig (Griffith \& Bain, 1997). Bei der Düngung beeinflussen vor allem einseitig gesteigerte Stickstoffgaben den Gehalt an Chlorogensäure in den Knollen positiv (Kolbe \& Haase, 1997).

\subsubsection{Aminosäuren}

Freies Tyrosin ist entsprechend Dean et al. (1993) das Hauptsubstrat der PPO. Stevens et al. (1998) identifizierten freies Tyrosin und Cystein als Hauptsubstrate der PPO.

Ein hoher Gehalt an Tyrosin im Pool der freien Aminosäuren erhöht die Gefahr der Schwarzfleckigkeit (Brown et al., 1999).

Der Gehalt an freiem Tyrosin in der Knolle ist jahresabhängig und wird von der Bodenart beeinflusst (Hughes \& Mapson, 1967) Eine ansteigende Kaliumdüngung bewirkt einen Rückgang des Tyrosingehaltes (Dean, 1997), wobei in Gefäßversuchen der Effekt durch Kaliumchlorid- Düngung größer als von sulfathaltigem Kaliumdünger gewesen ist (Hughes \& Mapson, 1967).

\subsubsection{Vitamine}

Vitamin C (Ascorbinsäure und Dehydroascorbinsäure) ist das in der Kartoffel mengenmäßig am stärksten vertretende Vitamin (Putz, 1998). Das Redoxsystem Ascorbinsäure Dehydroascorbinsäure ist in der Lage, die in beschädigten Zellen bereits gebildeten Quinone wieder in farblose Verbindungen (Phenole) umzuwandeln.

In der Literatur ist man sich jedoch uneins, ob die Dehydroascorbinsäure im weiteren Verlauf wieder reduziert werden kann. Müller (1975) nimmt eine Reduktion durch weitere pflanzliche Redoxsysteme an, während Baumgartner (1982) diese in einer beschädigten Zelle ausschließt. Aus Feldversuchen von Mondy \& Munshi (1993) ist der Einfluss der Reife der Kartoffel auf den Gehalt an Ascorbinsäure bekannt. 
Bei der Rolle des Ascorbinsäuregehalts für die Ausprägung der Schwarzfleckigkeit ergab sich bei Mondy \& Munshi (1993) nur eine Tendenz, wonach eine schwarzfleckigkeitsanfällige Sorte mehr Ascorbinsäure enthält als eine unanfällige Sorte. Da die Ergebnisse jedoch nicht signifikant sind, widerlegen sie daher nicht die These von Thornton \& Workmann (1987), wonach die Schwarzfleckigkeitsneigung mit anderen Inhaltsstoffen, jedoch nicht mit Ascorbinsäure, im Zusammenhang steht.

\subsubsection{Mineralstoffe}

Die Bedeutung der Mineralstoffe Kalium und Phosphor für die Ausprägung der Schwarzfleckigkeit ist bereits im Abschnitt 1.3.2. erläutert worden.

Calcium übernimmt spezifische Zellfunktionen, dazu gehören die Stabilisation des Plasmalemmas, der Endomembranen und der Zellwand. Man nimmt an, dass ein eingeschränktes Angebot an Calcium in der Knolle zu einem modifizierten subzellulären Abbau führt und eine Freilegung der Membranlipide hervorruft, wodurch diese für endogene Lipasen oder Lipoxygenasen zugänglich werden (Davies, 1998). Bei einer möglichen Einflussnahme der Lipoxygenase (Abschnitt 1.3.7.8.) auf den Schwarzfleckigkeitsprozess könnte daher über eine ausreichende Calciumversorgung die Schwarzfleckigkeit verhindert werden.

Kupfer ist ein Strukturelement der PPO. Wenn Pflanzen unter Kupfermangel wachsen, ist die PPO- Aktivität geringer (Dean, 1997).

\subsubsection{Polyphenoloxidase}

Polyphenoloxidase (PPO) ist ein kupferhaltiges Enzym und gilt als das Schlüsselenzym der Schwarzfleckigkeitsreaktion (Cobb, 1999).

In der Pflanze kann PPO sowohl in jungen als auch älteren Blättern nachgewiesen werden, wobei in jungen Blättern eine höhere Konzentration nachweisbar ist. Darüber hinaus findet man PPO in den Blüten, Wurzeln und den Knollen. Die höchste Aktivität liegt in den Stolonen und den Augen der Knollen vor (Miller, 1996).

Die PPO ist einerseits im Cytoplasma lokalisiert, zum anderen an Membranen von Zellorganellen wie Mitochondrien oder Plastiden gebunden. Ob die PPO in freier Form oder membranassoziierter Form vorliegt, ist vom physiologischen Zustand der Knollen abhängig (Haeseler, 1980). Insgesamt gesehen ist die PPO- Aktivität vom Entwicklungsstadium der Pflanze abhängig. Die Gesamtaktivität steigt in einem nahezu linearen Verhältnis zum Wachstumsverlauf der Knolle (Miller, 1996). 
Mit zunehmender Versorgung der Pflanze mit Kalium kommt es aufgrund der Bildung organischer Säuren und der damit verbundenen $\mathrm{pH}$ - Wert- Absenkung zu einer immer stärker werdenden Hemmung der PPO (Welte \& Müller, 1966).

Adler (1971) verweist auf die temperaturabhängige Aktivität der PPO. Kartoffeln nach einer Lagerung bei $4,5{ }^{\circ} \mathrm{C}$ wiesen eine geringere PPO-Aktivität als bei $10{ }^{\circ} \mathrm{C}$ gelagerte Kartoffeln auf. Darüber hinaus entfaltet die PPO die höchste Aktivität im $\mathrm{pH}-$ Bereich von pH 5-7. (Haeseler, 1980).

\subsubsection{Weitere Enzyme}

Die Enzyme Katalase (CAT), Ascorbat- Peroxidase (POD), Superoxiddismutase (SOD) und Lipoxygenase (LOX) gehören $\mathrm{zu}$ der Gruppe der Oxidoreduktasen. Während CAT hauptsächlich innerhalb der Pflanzenzelle in den Peroxysomen, Glyoxysomen und Mitochondrien lokalisiert ist (Willekens et al., 1997), ist POD in Zellorganellen wie den Chloroplasten, Amyloplast, den Mitochondrien (Zimmermann \& Zentgraf, 2004) und im Cytosol (Barka, 2001) auffindbar. LOX befindet sich ebenfalls in den Chloroplasten, aber auch im Cytosol, den Mitochondrien und der Vakuole (Siedow, 1991). Bei der SOD gibt es in der Lokalisation Unterschiede in Abhängigkeit vom Metall-Co-Faktor. Die Eisen-SOD befindet sich in den Chloroplasten, die Mangan-SOD in den Mitochondrien und Peroxysomen und die Kupfer-Zink-SOD in den Chloroplasten sowie im Cytosol (Alscher et al, 2002).

Jedes Enzym übernimmt in der Pflanze spezifische Aufgaben. CAT und POD katalysieren die Umwandlung des für die Zelle toxischen Wasserstoffperoxids $\left(\mathrm{H}_{2} \mathrm{O}_{2}\right)$. Beide Enzyme schützen die Zellorganellen vor oxidativem oder photooxidativem Schaden durch $\mathrm{H}_{2} \mathrm{O}_{2}$ und Hydroxylradikale (Zimmermann \& Zentgraf, 2004; Asada, 1992). Die SOD wirkt ähnlich. Sie schützt die Pflanzenzellen vor reaktiven $\mathrm{O}_{2}$-Spezies (ROS), wie $\mathrm{H}_{2} \mathrm{O}_{2}$, Hydroxylradikalen, Singulettsauerstoff, Superoxidradikale und Hydroperoxylradikale (Bowler et al, 1992). LOX fördert die Umsetzung ungesättigter Fettsäuren (Rosahl, 1996).

CAT, POD, LOX und SOD haben damit eine ausgeprägte Schutzwirkung gegen oxidative Schädigung. Darüber hinaus wirkt CAT an der Lignifikation entscheidend mit. Expressionsanalysen haben gezeigt, dass es durch oxidative oder osmotische Stressfaktoren zu einer Induktion der CAT-, POD-, LOX- und SOD- Aktivität kommen kann (Kiefer, 2002). Damit ist anzunehmen, dass die mechanische Belastung im Vorfeld der Schwarzfleckigkeitsreaktion mit der einhergehenden Beschädigung der Zellwände sowie der Zellmembranen eine verstärkte Enzymaktivität induziert. 


\section{BEWERTUNG DES LITERATURSTANDES}

Während fast 100- jähriger Forschung zum Thema Schwarzfleckigkeit -erste Hinweise auf Schwarzfleckigkeit durch Horne (1913)- wurden zahlreiche Versuche zur Klärung der Ursachen durchgeführt.

Die Schwarzfleckigkeit stellt ein multifaktorielles Problem dar. Unter allen Faktoren ist dem Einflussfaktor ,Sorte' die größte Bedeutung zuzuschreiben. Dies muss in zukünftigen Versuchen besonders beachtet werden.

Die Literaturrecherche hat gezeigt, dass die Versuchsgrundlage, die mechanische Belastung der Kartoffelknolle, auf vielfältige Weise erzeugt worden ist.

In Deutschland wird für die Untersuchungen der Schwarzfleckigkeitsneigung die gängige Methode des Bundessortenamtes (s. Kap.4.2.), die so genannte Waschmaschinenmethode verwandt.

Aeppli und Keller (1979) haben einen Schütteltest verwendet, bei dem die Knollen 30 Sekunden bei einer Hubhöhe von $45 \mathrm{~cm}$ mit einer Schüttelmaschine geschüttelt worden sind. Ein weiterer Belastungstest ist der Fallbolzentest, bei dem ein eiserner Fallbolzen durch ein Fallrohr auf die Knolle (Nabelende) fällt (Baumgartner, 1982). Eine ähnliche Methode ist der so genannte Fallstempeltest. Bei diesem Test werden jedoch in allen Knollenteilen Beschädigungen vorgenommen. Die verwendeten Knollen werden mit einem Stempel an zwei Stellen im Nabelbereich, einer im Kronenteil und zwei im Knollenmittelteil angeschlagen und 48 Stunden gelagert (Amberger \& Schaller, 1975). Darüber hinaus existiert ein Schältest, bei dem die Kartoffeln 30 Sekunden in einer rotierenden Schälmaschine durch Beseitigung der Schale oberflächlich beschädigt werden sollen (Stark et al., 1985). Das Institut für Agrartechnik Bornin hat die Belastungssimulation mit gezielten Stößen durchgeführt, deren Intensität mit einer in Bornin entwickelten Druckmesskugel gemessen worden ist (Wormanns, 1999). Auch Molema \& Bosma (1998) nutzen computergesteuerte Technik. Bei ihrer Belastungsmethode handelt es sich um ein Schlagpendel mit kugelförmigem Kollisionskörper, bei dem jedoch lediglich ein Punkt auf einer Linie zwischen Krone und Nabel mehrfach belastet wird. Allen Tests gemeinsam ist eine visuelle Bonitur der Beschädigung, mit Ausnahme der Methode von Stark et al. (1985). In deren Fall wird neben der visuellen Bonitur eine Messung mit einem Reflektiometer durchgeführt.

Die verschiedenen Versuchsanstellungen machen deutlich, dass die verfügbaren Daten untereinander nicht vergleichbar sind. Daher sollten sich die Wissenschaftler auf eine einheitliche Belastungsmethode verständigen. Zusätzlich sollte eine einheitliche Begrifflichkeit angestrebt werden, da dadurch Widersprüche, die sich nur durch die 
Vermischung der Phänomene „Schwarzfleckigkeit“ und „Erntebeschädigung“ ergeben, vermieden werden.

Ein weiteres Problem liegt in dem verwendeten Knollenmaterial. Zum Teil wurden nur Ausschnitte der Kartoffelknollen, so zum Beispiel das Nabel- bzw. das Kronenende, verwendet. Die ermittelten Ergebnisse wurden anschließend jedoch auf die gesamte Knolle bezogen, wodurch sich aufgrund der unterschiedlichen Lokalisation der Inhaltsstoffe Verfälschungen der Ergebnisse ergeben haben können.

Weiterhin wurden Sorten- und Umwelteinflüsse einschließlich der Jahreseffekte auf die Inhaltsstoffzusammensetzung gar nicht oder nur ungenügend berücksichtigt.

Als Fazit bleibt, dass der Bedeutung der Sorte für die Ausprägung der Schwarzfleckigkeit zukünftig Rechnung getragen werden muss. Darüber hinaus sollte neben der Einführung einer Standardbelastungsmethode stets die gesamte Kartoffelknolle zur Gewinnung des Probenmaterials dienen. 


\section{ZIELSTELLUNG DER ARBEIT}

Aufgrund der beschriebenen widersprüchlichen Ergebnisse befinden sich Wissenschaftler, Züchter, Landwirte und Verarbeiter in einer unbefriedigenden Situation, wodurch das Bedürfnis entstand, durch Grundlagenforschung aussagekräftige Ergebnisse über pflanzenphysiologische Ursachen der Beschädigungsempfindlichkeit einer Kartoffelknolle zu erlangen, um unter besonderer Berücksichtigung der Sorte konkrete Empfehlungen für die Praxis geben zu können. Damit dienen die nachfolgenden Untersuchungen der Förderung und der Verbesserung der Wirtschaftlichkeit in der Züchtung, der landwirtschaftlichen Produktion und der Verarbeitung.

Grundsätzlich soll mit dieser Arbeit ein Beitrag zur Abklärung folgender Fragen bzw. Hypothesen geleistet werden:

1. Ist es mittels spezifischer Dichte der Knollen möglich, verschiedene Kartoffelsorten bei gleicher Knollengröße in ihrer stofflichen Zusammensetzung zu unterscheiden sowie die unterschiedliche Anfälligkeit gegenüber Schwarzfleckigkeit abzubilden?

Es ist anzunehmen, dass ein Vergleich zwischen verschiedenen Sorten nur möglich ist, wenn eine einheitliche Knollengröße gewählt ist und die Kartoffeln nach ihrer spezifischen Dichte unterteilt wurden. Die spezifische Dichte eignet sich als Bezugsbasis, da dieser Versuchsparameter eine klar bestimmbare, objektive Versuchsgröße ist.

2. Gibt es sortenspezifische Unterschiede in der Inhaltsstoffzusammensetzung der Kartoffeln? Lassen sich anhand möglicher Unterschiede Rückschlüsse auf die Ausprägung der Schwarzfleckigkeit ziehen?

a. Wie verändern sich die Gehalte an Aminosäuren, Mineralstoffe und organische Säuren in Abhängigkeit von der Sorte und der spezifischen Dichte?

b. Gibt es Unterschiede in den Enzymaktivitäten in Abhängigkeit von der Sorte und der spezifischen Dichte?

Grundsätzlich ist zu erwarten, dass die Gehalte an Aminosäuren, Mineralstoffen und organischen Säuren sortenspezifisch variieren und die spezifische Dichte die Einflussnahme der Aminosäuren, Mineralstoffe und organische Säuren auf die Ausprägung der Schwarzfleckigkeit besser erklären lassen. 
Da der Schwarzfleckigkeitsprozess neben dem Schlüsselenzym PPO von weiteren Enzymen, wie zum Beispiel Ascorbat- Peroxidase (POD), Superoxiddismutase (SOD), Katalase (CAT) und Lipoxygenase (LOX) beeinflusst sein könnte, sind unterschiedliche Enzymaktivitäten in Abhängigkeit von der Sorte und der spezifischen Dichte denkbar. Es wird außerdem angenommen, dass sich die Aktivitäten freier und membrangebundener Enzyme in Abhängigkeit der jeweiligen Sorte unterscheiden, da die Schwarzfleckigkeit auf einer mechanischen Beschädigung beruht, woraus eine erhöhte Aktivität membrangebundener Enzyme resultieren könnte. 


\section{MATERIAL UND METHODEN}

\subsection{Knollenmaterial}

In einem gemeinsamen Versuch des Departments für Nutzpflanzenwissenschaften, Abteilung Qualität, der Universität Göttingen, der Versuchsstation für Kartoffelbau, Dethlingen, und der Bundesanstalt für Ernährung und Lebensmittel (BEL), Detmold, sind in zwei Versuchsabschnitten von je zwei Jahren Kartoffeln unter praxisüblichen Bedingungen angebaut worden. Die Feldversuche sind auf humosem Sandboden ( $\mathrm{pH} 5,5)$ am Standort Dethlingen/ Landkreis Soltau- Fallingbostel durchgeführt worden.

Für den ersten Versuchsabschnitt in den Jahren 2000/2001, nachfolgend mit dem Begriff ,Vorversuch' bezeichnet, wurden die Sorten Ponto, Solara und Cilena ausgewählt. Im zweiten Versuchsabschnitt in den Jahren 2002/ 2003, nachfolgend als ,Hauptversuch' bezeichnet, wurden die Sorten Aula, Granola, Nicola und Quarta angebaut (Tab.2)

Tab. 2 Eigenschaften der verwendeten Sorten (in Anlehnung an Bundessortenamt, 2001)

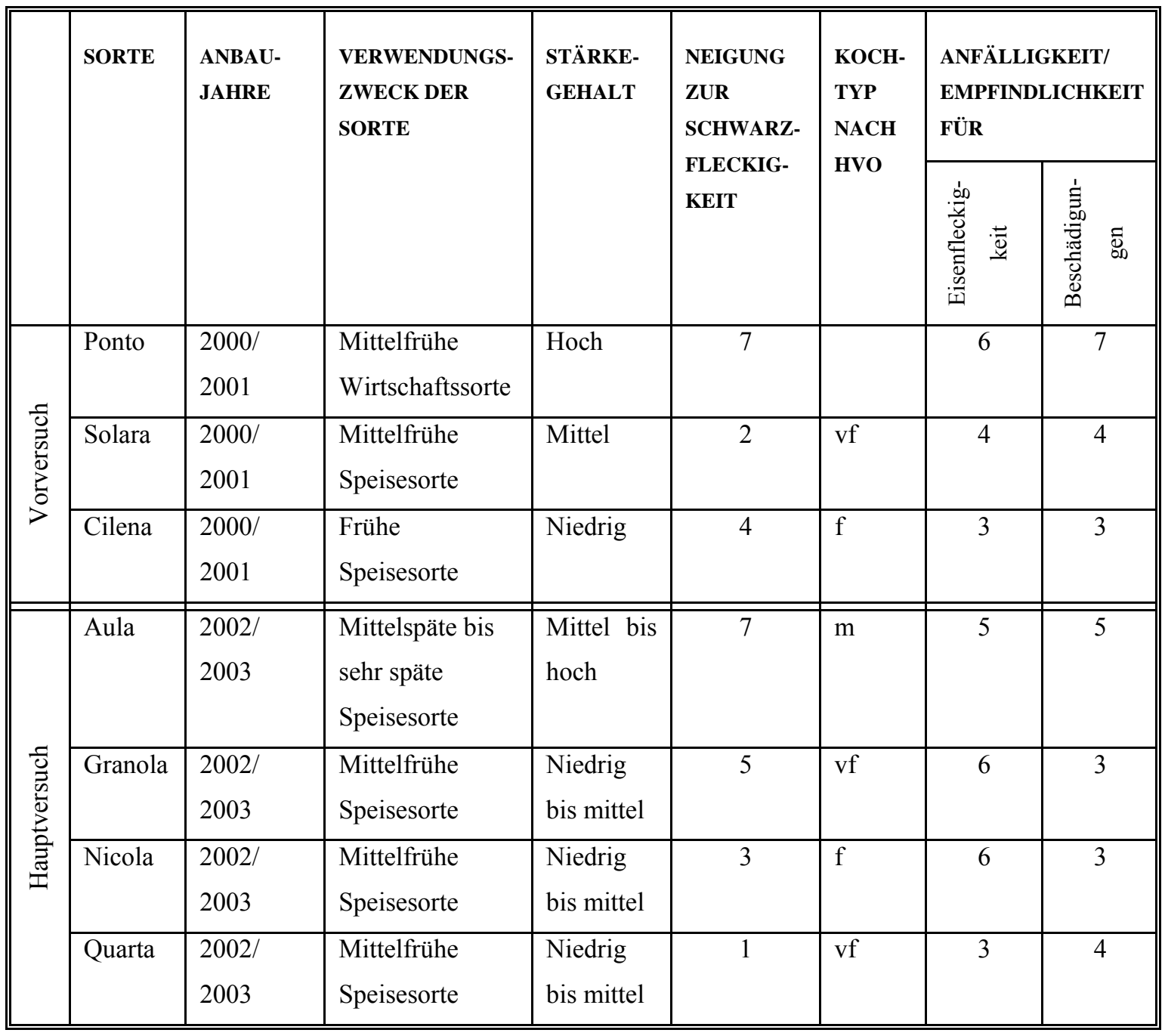


Kochtyp:

$\mathrm{f}=$ festkochend, $\mathrm{vf}=$ vorwiegend festkochend, $\mathrm{m}=$ mehlig

Anfälligkeit/ Empfindlichkeit/ Neigung:

$1=$ sehr gering, $3=$ gering, $5=$ mittel, $7=$ stark, $9=$ sehr stark

Der Sortenwechsel zwischen dem Vorversuch und dem Hauptversuch erfolgte, um Sorten mit gleicher Verwertungsrichtung und einem vergleichbaren Stärkegehalt prüfen zu können. Die Sorte Ponto zeichnet sich zwar durch eine starke Empfindlichkeit gegenüber Erntebeschädigungen und einer hohen Neigung zur Schwarzfleckigkeit aus, liegt aber im Stärkegehalt deutlich höher als die übrigen Sorten des Versuchsabschnittes. Außerdem wurde bei der Auswahl der Sorten für den Hauptversuch verstärkt auf eine einheitliche Knollenform, die einen Einfluss auf die Beschädigungsempfindlichkeit nimmt, geachtet. Im Vorversuch war die Sorte Cilena aufgrund ihrer lang- ovalen Form verstärkt beschädigungsgefährdet. Dieser möglichen Benachteiligung einer Sorte sollte durch eine einheitlichere Knollenform vorgebeugt werden.

Die Düngung erfolgte in Anlehnung an die Düngeempfehlung der Landwirtschaftskammer Niedersachen. Bei Stickstoff in Kartoffeln gilt ein Richtwert von $160 \mathrm{~kg} \mathrm{ha}^{-1}$ abzüglich der Nmin- Werte. Unter Berücksichtigung der standortbedingten Nmin- Werte wurden daher im Jahr $2000126 \mathrm{~kg} \mathrm{ha}^{-1} \mathrm{~N}$ über Ammoniumnitratharnstofflösung (AHL) gegeben. Im Jahr 2001 waren es $90 \mathrm{~kg} \mathrm{ha}^{-1} \mathrm{~N}$ über AHL und $32 \mathrm{~kg} \mathrm{ha}^{-1} \mathrm{~N}$ über Diammonphosphat (DAP).

Im Hauptversuch wurden jeweils $72 \mathrm{~kg} \mathrm{ha}^{-1} \mathrm{~N}$ über AHL und $54 \mathrm{~kg} \mathrm{ha}^{-1} \mathrm{~N}$ über DAP gegeben. Die Phosphordüngung wurde in allen Jahren anhand der Bodenuntersuchungsergebnisse durchgeführt. Aufgrund der Versorgungsstufe C erfolgte die P- Düngung über DAP mit 70$100 \mathrm{~kg} \mathrm{ha}^{-1} \mathrm{P}_{2} \mathrm{O}_{5}$. Die Kaliumdüngung, die von der Verwertungsrichtung der Kartoffel und der Bodenversorgungsstufe abhängig ist, lag im Jahr 2000 bei $288 \mathrm{~kg} \mathrm{ha}^{-1} \mathrm{~K}_{2} \mathrm{O}$ Phosphatkali und im Jahr 2001 bei $195 \mathrm{~kg} \mathrm{ha}^{-1} \mathrm{~K}_{2} \mathrm{O}$ über Kalimagnesia. Im Hauptversuch wurde eine Kombination aus Kalimagnesia $\left(90 \mathrm{~kg} \mathrm{ha}^{-1} \mathrm{~K}_{2} \mathrm{O}\right)$ und 40er Kornkali $\left(172 \mathrm{~kg} \mathrm{ha}^{-1} \mathrm{~K}_{2} \mathrm{O}\right)$ gedüngt. Da im ersten Versuchsabschnitt mit der Sorte Ponto eine Wirtschaftssorte vertreten war, wurde die Düngung mit Phosphatkali bzw. Kalimagnesia durchgeführt, damit es nicht zur Absenkung des Stärkegehaltes kommt. Die Pflanzenschutzmaßnahmen erfolgten nach Empfehlung des örtlichen Pflanzenschutzamtes.

Die Witterungsbedingungen im Vorversuch lassen sich als Durchschnittjahre mit durchschnittlichen Temperaturen und mäßigem Niederschlag zusammenfassen. Dennoch gab es in beiden Jahren jeweils kurze Phasen extremer Witterungsbedingungen. 
Die Temperaturen boten mit $18-26^{\circ} \mathrm{C}$ grundsätzlich gute Wachstumsbedingungen, dennoch gab es im Jahr 2000 im Juni und im Jahr 2001 im August Phasen mit jeweils ca. 3 Wochen hohen Temperaturen, die anschließend in einen kurzen Zeitraum mit hohen Niederschlägen (Jahr $2000>70 \mathrm{~mm}$, Jahr $2001>80 \mathrm{~mm}$ ) übergingen.

Der Hauptversuch (2002/2003) war durch zwei extreme Witterungsperioden gekennzeichnet. Das Jahr 2002 hatte einen niederschlagsreichen Sommer (Ende Juni bis Anfang August $>250$ $\mathrm{mm}$ ) bei durchschnittlichen Temperaturen. Dem gegenüber steht das Jahr 2003, das einen sehr niederschlagsarmen Sommer bei extrem hohen Temperaturen ab Juni aufwies (Anhang, Kapitel 9.8.).

Die Rodung der Kartoffeln erfolgte je nach Witterungsbedingungen jeweils Ende August bzw. Anfang September. Um eine gleichmäßige Abreife zu gewährleisten, ist in allen Jahren nach beginnender Abreife eine chemische Krautminderung durchgeführt worden.

Die Kartoffeln in der Größensortierung 40-50mm wurden über die Dauer von bis zu acht Monaten gelagert. Die Lagerung erfolgte bei $4{ }^{\circ} \mathrm{C}$. Das Material wurde nach der Ernte, nach vier und acht Monaten Lagerung in drei Dichtefraktionen unterteilt (Tab. 3\&4). Die Gradierung erfolgte in einem Salzwasserbad aus reiner Kochsalzlösung (Corsini et al., 1999; Davenport, 2000).

Nachfolgend werden die Begriffe ,Klassen der spezifischen Dichte' und ,Dichtefraktionen' analog verwandt.

Tab. 3 Klassen der spezifischen Dichte im Vorversuch

\begin{tabular}{|c|c|c|c|c|c|c|}
\hline \multirow{3}{*}{$\begin{array}{c}\text { KLASSEN DER } \\
\text { SPEZIFISCHEN } \\
\text { DICHTE (SD) }\end{array}$} & \multicolumn{6}{|c|}{$\begin{array}{l}\text { GRADIERUNG DER SORTEN }\left(\mathrm{G} \mathrm{L}^{-1}\right) \\
2000 / 2001\end{array}$} \\
\hline & \multicolumn{2}{|c|}{ PONTO } & \multicolumn{2}{|c|}{ SOLARA } & \multicolumn{2}{|c|}{ CILENA } \\
\hline & 2000 & 2001 & 2000 & 2001 & 2000 & 2001 \\
\hline 1 & $<1.085$ & $<1.095$ & $<1.065$ & $<1.075$ & $<1.055$ & $<1.075$ \\
\hline 2 & $<1.095$ & $<1.105$ & $<1.075$ & $<1.085$ & $<1.065$ & $<1.085$ \\
\hline 3 & $>1.095$ & $>1.105$ & $>1.075$ & $>1.085$ & $>1.065$ & $>1.085$ \\
\hline 0 & \multicolumn{2}{|c|}{ Nicht gradiert } & \multicolumn{2}{|c|}{ Nicht gradiert } & \multicolumn{2}{|c|}{ Nicht gradiert } \\
\hline
\end{tabular}


Tab. 4 Klassen der spezifischen Dichte im Hauptversuch

\begin{tabular}{|c|c|c|c|c|c|c|c|c|}
\hline \multirow{3}{*}{$\begin{array}{l}\text { KLASSEN DER } \\
\text { SPEZIFISCHEN } \\
\text { DICHTE (SD) }\end{array}$} & \multicolumn{8}{|c|}{$\begin{array}{c}\text { GRADIERUNG DER SORTEN }\left(\mathrm{G} \mathrm{L}^{-1}\right) \\
2002 / 2003\end{array}$} \\
\hline & \multicolumn{2}{|c|}{ AULA } & \multicolumn{2}{|c|}{ GRANOLA } & \multicolumn{2}{|c|}{ NICOLA } & \multicolumn{2}{|c|}{ QUARTA } \\
\hline & 2002 & 2003 & 2000 & 2003 & 2002 & 2003 & 2002 & 2003 \\
\hline 1 & \multicolumn{2}{|c|}{$<1.075$} & \multicolumn{2}{|c|}{$<1.065$} & \multicolumn{2}{|c|}{$<1.065$} & $<1.065$ & $<1.075$ \\
\hline 2 & \multicolumn{2}{|c|}{$<1.085$} & \multicolumn{2}{|c|}{$<1.075$} & \multicolumn{2}{|c|}{$<1.075$} & $<1.075$ & $<1.085$ \\
\hline 3 & \multicolumn{2}{|c|}{$>1.085$} & \multicolumn{2}{|c|}{$>1.075$} & \multicolumn{2}{|c|}{$>1.075$} & $>1.075$ & $>1.085$ \\
\hline 0 & \multicolumn{2}{|c|}{ Nicht gradiert } & \multicolumn{2}{|c|}{ Nicht gradiert } & \multicolumn{2}{|c|}{ Nicht gradiert } & \multicolumn{2}{|c|}{ Nicht gradiert } \\
\hline
\end{tabular}

\subsection{Bestimmung des Schwarzfleckigkeitsindex (SF-Index)}

Zur Bestimmung der Schwarzfleckigkeitsneigung gemäß Bundessortenamt (2006) sind je Sorte $25 \mathrm{~kg}$ gesunde, unbeschädigte und ausgereifte Knollen der mittleren Fraktion erforderlich. Die Proben sind bis zum Prüfungstermin unter normaler, ortsüblicher Kartoffellagerung zwischen $4^{\circ}-6^{\circ} \mathrm{C}$ zu lagern.

Vor der Prüfung ist die Keimbildung je Sorte nach folgender Boniturskala zu bonitieren, da die Keimbildung den Grad des physiologischen Alters einer Knolle charakterisiert:

$$
\begin{aligned}
& 1=\text { nicht gekeimt } \\
& 2=\text { gespitzt } \\
& 3=\text { Keime bis } 0,5 \mathrm{~cm} \\
& 4=\text { Keime } 0,6 \text { bis } 1,0 \mathrm{~cm} \\
& 5=\text { Keime } 1,1 \text { bis } 2,0 \mathrm{~cm} \\
& 6=\text { Keime } 2,1 \text { bis } 3,0 \mathrm{~cm} \\
& 7=\text { Keime } 3,1 \text { bis } 4,0 \mathrm{~cm} \\
& 8=\text { Keime } 4,1 \text { bis } 5,0 \mathrm{~cm} \\
& 9=\text { Keime ab } 5,0 \mathrm{~cm}
\end{aligned}
$$

\section{Durchführung:}

Die Kartoffeln werden unmittelbar vor Beginn der Prüfung aus dem Lager entnommen, so dass sie bei der mechanischen Belastung die Lagertemperatur von $4^{\circ}-6^{\circ} \mathrm{C}$ aufweisen. Aus der gelagerten Menge ist mit mindestens zwei Proben gleichen Volumens die Prüfung durchzuführen. Der Probenumfang richtet sich nach dem angegebenen Füllinhalt der 
Waschmaschine.

Bei $12 \mathrm{~kg}$ Fassungsvermögen (Typ KS 12) sind 8-Liter Proben und bei $8 \mathrm{~kg}$

Fassungsvermögen (Typ KS 8) 6-Liter Proben zu verwenden. Die Abmessung der Probe ist mit einem entsprechenden Eimer oder einem anderen Gefäß vorzunehmen. Die Probe einer mechanischen Belastung unterzogen. Die Laufzeit wird jährlich an Standardsorten festgelegt. Nach bisherigen Erfahrungswerten liegt die Laufzeit zwischen 45 bis $90 \mathrm{sec}$. Die mechanisch belasteten Knollenproben werden bis zur Bonitur bei Zimmertemperatur im Dunkeln oder abgedeckt $4-5$ Tage gelagert.

Bonitur der Schwarzfleckigkeit:

Alle Knollen werden in der jeweils größten Schnittfläche geschnitten. An den Knollenhälften ist der Anteil der verfärbten Fläche (grau, blau oder schwarz) nach folgendem Boniturschema zu ermitteln.

- keine Verfärbung

- leichte Verfärbung (L)

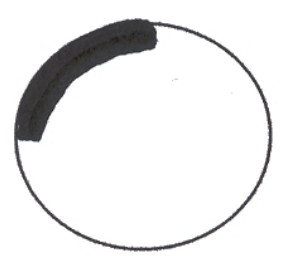

bis $1 / 4$ des Umfanges bis $5 \mathrm{~mm}$ Tiefe

- mittlere Verfärbung (M)
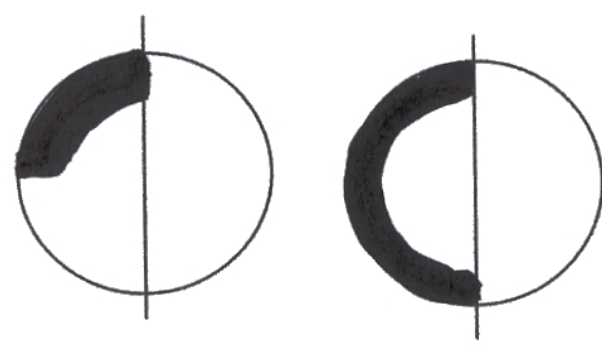

bis $1 / 4$ des Umfanges und tiefer als $5 \mathrm{~mm}$ und / oder bis $1 / 2$ des Umfanges bis $5 \mathrm{~mm}$ Tiefe

- starke Verfärbung (S)
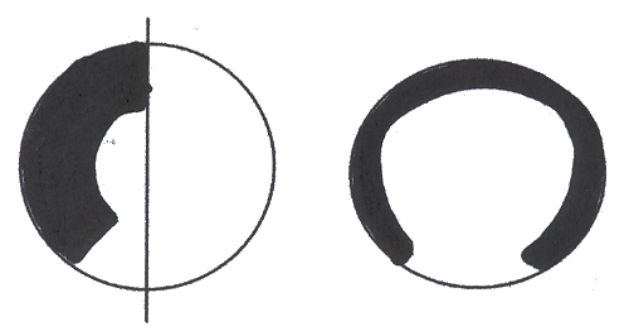

bis $1 / 2$ des Umfanges und tiefer als $5 \mathrm{~mm}$ und / oder mehr als $1 / 2$ des Umfanges bis $5 \mathrm{~mm}$ Tiefe

Die Auswertung erfolgt über die Berechnung des Schwarzfleckigkeitsindex nach folgender Formel:

Schwarzfleckigkeitsindex $(\mathrm{SI})=(0,3 \mathrm{~L}+0,5 \mathrm{M}+\mathrm{S}) * 100 /$ Knollenzahl gesamt 
L- Anzahl Knollen mit leichten Symptomen

M-Anzahl Knollen mit mittleren Symptomen

S- Anzahl Knollen mit starken Symptomen

und Zuordnung einer Boniturskala 1-9 (1= sehr geringe Neigung, 9= sehr starke Neigung)

\subsection{Gefriertrocknung des Probenmaterials}

Das unbelastete Kartoffelfrischmaterial wurde in der Bundesanstalt für Ernährung und Lebensmittel (BEL) nach der Bestimmung der spezifischen Dichte zur Konservierung gefriergetrocknet (Epsilon 2-40, Firma Christ). Das getrocknete Probenmaterial wurde anschließend mittels Kaffeemühle (Firma Krupps) zu Mehl vermahlen und in Plastiktüten, in der Tiefkühltruhe bei $-18{ }^{\circ} \mathrm{C}$ bis zur Analyse aufbewahrt.

\subsection{Bestimmung der Restfeuchtigkeit}

Zur Auswertung der Versuchsergebnisse ist es erforderlich, die Restfeuchtigkeit des gefriergetrockneten Probenmaterials zu kennen, um den Ergebnisbezug zur Trockensubstanz herstellen zu können. Gefriergetrocknetes Kartoffelmaterial wurde bei $105^{\circ} \mathrm{C}$ über die Dauer von 3 Stunden getrocknet. Anhand der Gewichtsdifferenz vor und nach der Trocknung ließ sich der Restfeuchtigkeitsgehalt bestimmen.

\subsection{Mineralstoffbestimmung}

Die Mineralstoffe wurden mittels Atomabsorptionsspektroskopie bestimmt (Welz, 1983).

Die Probenaufbereitung erfolgte an gefriergetrocknetem Material. Unter Zugabe von $4 \mathrm{ml}$ 65\%-iger Salpetersäure wurden zweimal 0,2 g je Probe binnen 11 Stunden bei $180{ }^{\circ} \mathrm{C}$ unter Druck aufgeschlossen. Die Aufschlusslösungen wurden mit Seralpur jeweils auf $10 \mathrm{~mL}$ aufgefüllt. Bis zur Messung wurden die Proben kühl gelagert.

\subsection{Phosphorbestimmung}

Die Phosphorbestimmung erfolgte an den im Druckaufschlussverfahren aufgeschlossenen Proben (Methode siehe Abschnitt 4.5.) unter Anwendung der Standardmethode des VDLUFA (1976). Die Messung wurde am Photometer (Hewlett Packard [HP] 8453) bei $436 \mathrm{~nm}$ durchgeführt. 


\subsection{Organische Säuren}

Die organischen Säuren wurden mittels Hochleistungsflüssigkeitschromatographie (HPLC) getrennt und mit UV- Detektion quantitativ erfasst.

Grundsätzlich können nachfolgende organische Säuren in folgenden Konzentrationsbereichen ( $\left.\mathrm{mg} \mathrm{L}^{-1}\right)$ bestimmt werden:

- Weinsäure $\quad 5-50$

- Äpfelsäure $\quad 5-50$

- Milchsäure 15-150

- Maleinsäure $\quad 0,05-0,5$

- Zitronensäure 10-100

- Bernsteinsäure 25-250

- Fumarsäure $\quad 0,05-0,5$

Zur Aufbereitung der Proben wurden 4 g Kartoffelmehl nach Zugabe von 70 mL destilliertem Wasser sowohl $2 \mathrm{~mL}$ Carrez I- Lösung als auch $2 \mathrm{~mL}$ Carrez II Lösung zugesetzt. Anschließend wurde der $\mathrm{pH}-$ Wert auf $\mathrm{pH}$ 7,5- 8,5 eingestellt.

Da die Kartoffelstärke nicht genügend ausfällt und bei der Messung am HPLC (Waters/ Knauer) ungenaue Ergebnisse bedingte, musste die Methode durch eine Aufbereitung mit Dichlormethan ergänzt werden. $7,5 \mathrm{~mL}$ der aufbereiteten Probe wurde mit 2,5 mL Dichlormethan versetzt, 45 Minuten geschüttelt und anschließend filtriert.

Vor der Messung am HPLC wurden die Standards der einzelnen organischen Säuren angesetzt. Die Messung erfolgte unter folgenden Bedingungen:

Injektionsvolumen $20 \mu \mathrm{L}$, Eluent: 18mM Kaliumdihydrogenphosphat, $\mathrm{pH}=2,0$, Flussrate: 0,4 mg L ${ }^{-1}$, Säule: Purospher STAR RP-8e, $5 \mu \mathrm{m}, 3 \times 250 \mathrm{~mm}$, Säulentemperatur: $22^{\circ} \mathrm{C}$, Detektion: UV $210 \mathrm{~nm}$.

\subsection{Chlorogensäure}

Die Untersuchung erfolgte photometrisch anhand der Methodik aus Griffith et al. (1992).

Gefriergetrocknetes Probenmaterial wird unter Zugabe von Harnstoff- Essigsäurelösung, bidestilliertem Wasser, Natriumnitrit- und Natriumhydroxidlösung gelöst. Nach der 
Zerkleinerung werden Kartoffeln in Phosphatpuffer zentrifugiert, um eine Trennung der flüssigen von der festen Phase zu erzielen. Die Messung wurde am Photometer (Hewlett Packard [HP] 8453) bei $510 \mathrm{~nm}$ durchgeführt und die Chlorogensäuregehalte wurden aus den Extinktionswerten mittels einer zuvor erstellten Eichkurve berechnet.

\subsection{Freie Aminosäuren}

Die freien Aminosäuren wurden mit der Methode von Cohen \& Michaud (1993) am HPLC bestimmt.

Im Vorfeld der Messung wurden 2mg gefriergetrocknetes Material mit $500 \mu \mathrm{L} 6 \mathrm{M} \mathrm{HCl}$ - und $3 \%$-igerPhenollösung versetzt und über die Dauer von $24 \mathrm{~h}$ bei $110{ }^{\circ} \mathrm{C}$ im Trockenschrank hydrolisiert. Nach Zugabe von $100 \mu \mathrm{L} 20 \mathrm{mM} \mathrm{HCl}$ und anschließender Filtration $(0,45 \mu \mathrm{m}$ Filter) wurden die Proben bis zur Messung am HPLC tiefgefroren.

\subsection{Prolin}

Da Prolin nicht mit der unter 4.9. genannten Methode bestimmbar war, wurde diese Aminosäure mit dem Photometer (Hewlett Packard [HP] 8453) bei $546 \mathrm{~nm}$ anhand der Methode von Streubing \& Fangmeier (1992) bestimmt. Zur Probenaufbreitung wurden 0,4 g gefriergetrocknete Probe mit $10 \mathrm{~mL}$ 3\%-iger Sulfosalicylsäure versetzt, vermischt, 20 Minuten geschüttelt und anschließend zentrifugiert und filtriert. Bis zur Messung wurden die Proben tiefgefroren.

\subsection{Bestimmung der Proteinkonzentration}

Die Bestimmung erfolgte mit der Methode nach Bradford (1975).

Dafür notwendig sind die Reagenzien aus der Probenaufbereitung (Abschnitt 4.12.), eine Standardlösung (Rinder-Serum-Albumin) sowie der Farbstoff Coomassie- Blau. Der Farbstoff reagiert mit basischen Aminosäuren. Bei einer Absorption von $595 \mathrm{~nm}$ kann die Proteinkonzentration am Photometer (HP 8453) unter der Voraussetzung bestimmt werden, dass die Eichkurve mit einem annährend gleichen Gehalt an basischen Aminosäuren versetzt ist wie das unbekannte Protein.

\subsection{Probenvorbereitung für die Enzymanalysen}

Die Aufbereitung erfolgte in Anlehnung an die Methodik von Birecka \& Miller (1974) und Civello et al. (1995). Mittels Kalium-Phoshatpuffers (0,1 M Kaliumdihydrogenphosphat und 
0,029225 g NaEDTA*2 H2O Triplex III, Einstellung des pH-Wertes auf pH 6 mittels 1M $\mathrm{NaOH}$ ) wurden die freien Enzyme aufgeschlossen. $1 \mathrm{M}$ Natriumchloridlösung diente zum Aufschluss der membranassoziierten (MA) Enzyme. Nachfolgend wird der Begriff Enzymfraktionen verwandt, gemeint sind dann entweder die MA Enzyme oder die freien Enzymen.

Bei der Aufbereitung wurden zu 2 g gefriergetrocknetem Probenmaterial $6 \mathrm{~mL}$ KaliumPhosphatpuffer zugegeben. Nach Vermischen wurde die Probe 30 Minuten bei 1500 Upm zentrifugiert. Der Überstand konnte anschließend mit der Pasteurpipette abgenommen und in einen $10 \mathrm{~mL}$ Kolben überführt werden. Der $10 \mathrm{~mL}$ Kolben wurde mit Kaliumphosphatpuffer aufgefüllt. Auf das Zentrifugenglas mit dem verbliebenen Kartoffelmehl wurden daraufhin 5 mL Natriumchlorid gegeben. Nach Vermischen wurde erneut bei 1500 Upm über 30 Minuten zentrifugiert. Nach Abnahme des Überstandes und Zugabe von $4 \mathrm{~mL}$ Natriumchlorid konnte die Probe erneut zentrifugiert werden. Der Überstand wurde mit dem vorhergehenden Überstand vereinigt, und auf $10 \mathrm{~mL}$ aufgefüllt. Sowohl der Kaliumphosphatpufferaufschluss als auch der Aufschluss mit Natriumchlorid wurden bis zur Messung tiefgefroren.

\subsection{Analyse der Katalase (CAT)}

Die Analyse erfolgte in Anlehnung an die Methodik von Aebi (1967).

$2 \mathrm{~mL} \mathrm{1:10} \mathrm{verdünnte} \mathrm{Probe} \mathrm{wurden} \mathrm{mit} \mathrm{0,5} \mathrm{mL} \mathrm{Phosphatpuffer}(50 \mathrm{mM}, \mathrm{pH} 7,0)$ und $10 \mu 1$ 1\%-ige Katalaselösung versetzt. Der Reaktionsstart wurde durch die Zugabe von 0,5 mL 30 mM Wasserstoffperoxidlösung erzeugt. Die Messung erfolgte am Photometer (HP 8453) bei $240 \mathrm{~nm}$ über die Dauer von 20 Minuten im Zeitabstand von $15 \mathrm{sec}$. Da jedoch nach 10 Minuten Messdauer keine Veränderung der Enzymaktivität mehr messbar war, wurden zur Auswertung die Ergebnisse nach 10 Minuten Messdauer verwendet.

\subsection{Analyse der Ascorbat- Peroxidase (POD)}

Die Analyse erfolgte in Anlehnung an die Methodik von Laerke (2001).

Die Proben wurden nach dem Auftauen im Verhältnis 1:10 mit bidest. wasserverdünnt. 100 $\mu \mathrm{L}$ verdünnte Probe, $1700 \mu \mathrm{L}$ MES- NaOH (100 mM, pH 6), $100 \mu \mathrm{L}$ Ascorbinsäure (3 mM) wurden durch Zugabe von $100 \mu \mathrm{L} \mathrm{H}_{2} \mathrm{O}_{2}$ - Lösung $(10 \mathrm{mM})$ in Reaktion gebracht. Die Messung erfolgte am Photometer (HP 8453) bei $265 \mathrm{~nm}$ über die Dauer von 20 Minuten im Zeitintervall von je 15 Sekunden. Analog zur CAT- Messung wurden auch bei der POD die Messwerte nach 10 Minuten Messdauer verwendet. 


\subsection{Analyse der Lipoxygenase (LOX)}

Die Analyse erfolgte in Anlehnung an die Methodik von Fauconnier et al. (2002).

$50 \mu \mathrm{L}$ der 1:10 verdünnte Proben wurden mit $1900 \mu \mathrm{L}$ Boratpuffer (100 mM, pH 9) versetzt und gut verrührt. Die Messung am Photometer (HP 8453) bei $234 \mathrm{~nm}$ wurde gestartet, worauf nachfolgend zur Reagenz $50 \mu \mathrm{L}$ einer 8mM Linolsäurelösung, bestehend aus Tween 20, Boratpuffer (100 mM, pH 9), Linolsäure, $\mathrm{NaOH}$ und konzentrierter $\mathrm{HCl}$, zugegeben wurde. Die Messung wurde über einen Zeitraum von 200 Sekunden im Zeitabstand von je 15 Sekunden fortgeführt.

\subsection{Analyse der Superoxiddismutase (SOD}

Die Analyse erfolgte anhand der Methodik von Meixner (1999).

$\mathrm{Zu}$ Beginn der Analyse wurde eine Lösung aus 0,5 M Kalium- Phosphatpuffer (pH 9), 1,8 mM Xanthin- Lösung, 2,24 mM Nitroblau- Tetrazoliumchlorid- Lösung (NBT), 1,33 mM Triplex V- Lösung und 40 U/ mL Katalase- Lösung erstellt. Zu $800 \mu \mathrm{L}$ dieser Lösung wurden $100 \mu \mathrm{L}$ 1:10 verdünnter Probe zugefügt. In Abhängigkeit von der Enzymform (frei oder membranassoziiert) wurden zusätzlich 1,33 mM Triplex V- Lösung und Xanthin- Oxidase (EC 1.1.3.22; Nr. 110434) beigemischt. Bei Natriumchlorid aufbereiteten Proben handelte es sich um $20 \mu \mathrm{L}$ Xanthin- Oxidase und $80 \mu \mathrm{L}$ 1,33 mM Triplex V- Lösung, bei KaliumPhosphatpuffer aufbereiteten Proben um $10 \mu \mathrm{L}$ Xanthin- Oxidase und $90 \mu \mathrm{L}$

1,33 mM Triplex V- Lösung. Nach Inkubation der Proben bei ca. $25{ }^{\circ} \mathrm{C}$ im Wasserbad wurden die Proben am Photometer (HP 8453) bei $560 \mathrm{~nm}$ gemessen.

\subsection{Polyphenoloxidase, Stärkegehalt und Ascorbinsäure}

Diese Untersuchungen erfolgten in der Bundesanstalt für Ernährung und Lebensmittel (BEL). Die Ergebnisse wurden freundlicherweise dem Department für Nutzpflanzenwissenschaften, Abteilung Qualität, der Universität Göttingen für diese Arbeit zur Verfügung gestellt.

Der PPO- Bestimmung lagen die Methoden von Bachem et al. (1994) und Haase (1999) zu Grunde. Stärke wurde mittels Polarimetrie (VO 228/67/EWG Amtsblatt der europäischen Gemeinschaft (ABI) Nr. 136 vom 30.6.1997) und Ascorbinsäure anhand der Methode von Beutler und Beinstingl (1980) mit einer Test- Kombination der Firma Roche Diagnostics für Dehydroascorbinsäure/ L-Ascorbinsäure (Bestellnummer 409677) bestimmt. 


\subsection{Statistische Auswertung}

Die statistische Auswertung erfolgte mit Hilfe des Computerprogramms SigmaStat für Windows, Version 2.03..

Die Auswertung der Ergebnisse erfolgte über den t-Test, den Mittelwertvergleich, bei dem getestet wird, ob sich die Mittelwerte von zwei Stichproben nur zufällig unterscheiden oder ob ein signifikanter Unterschied vorliegt. Die Berechnung des t-Wertes setzt sich aus der Ermittlung der Differenz der Stichprobenmittelwerte und der Ermittlung des Fehlers der Differenz zusammen (Haiger, 1978).

$$
\sigma \delta=\sqrt{\mathrm{s}_{1}}{ }^{2} / \mathrm{n}+\mathrm{s}_{2}{ }^{2} / \mathrm{n} \quad \tau=\delta / \sigma \delta
$$

Darüber hinaus wurden die Beziehungen zwischen einzelnen Parametern mittels PearsonKorrelationen ermittelt.

Die Erstellung der Graphiken erfolgte mittels Computerprogramm SigmaPlot 2001. 


\section{ERGEBNISSE}

\subsection{Ergebnisse des Vorversuches}

Nachfolgend werden die Ergebnisse des Vorversuches, d.h. der Versuchsjahre 2000/2001, dargestellt. Ergänzend zu den Ergebnissen sind die Messergebnisse dem Anhang (Kapitel 9) zu entnehmen. Bei den Enzymen, Aminosäuren und organischen Säuren handelt es sich um verrechnete Daten von Einzelmessungen, bei den Mineralstoffen sind die Mittelwerte aus zwei Einzelmessungen angegeben.

\subsubsection{Beziehung der spezifischen Dichte zur Schwarzfleckigkeit}

Zwischen der Schwarzfleckigkeit und der spezifischen Dichte zeigt sich eine enge Beziehung (Abb.4).

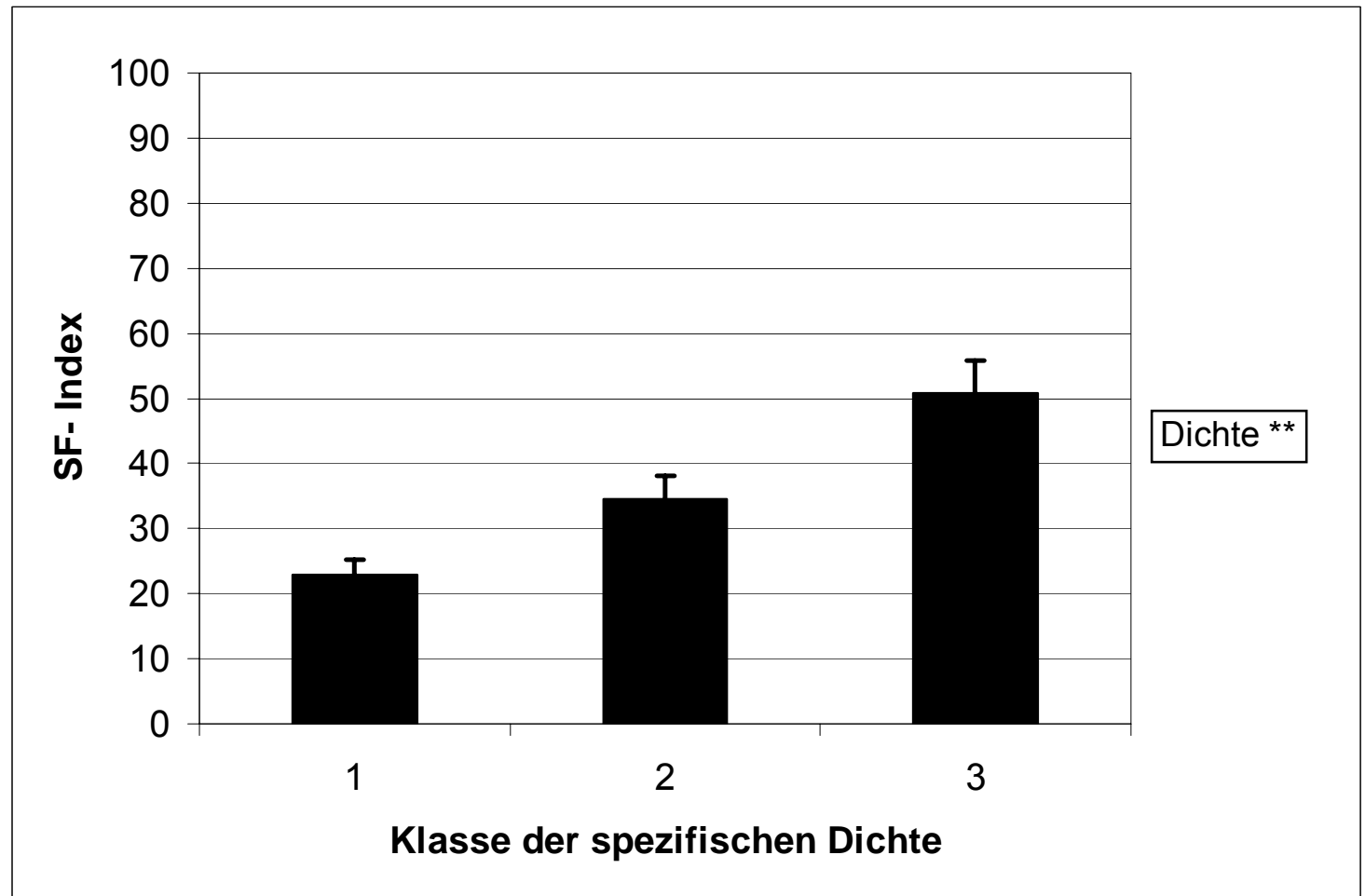

Abb. 4 Beziehung zwischen Schwarzfleckigkeit und spezifischer Dichte (im Mittel aller Sorten und Termine)

${ }^{* *} \mathrm{p}<0,01$

Mit zunehmender spezifischer Dichte nimmt die Schwarzfleckigkeit signifikant $(p=0,004) z u$.

Dieser Zusammenhang hat auch bei der unterschiedlichen Schwarzfleckigkeitsneigung der Sorten, wie in den Abb. 5 ersichtlich wird, Bestand. 


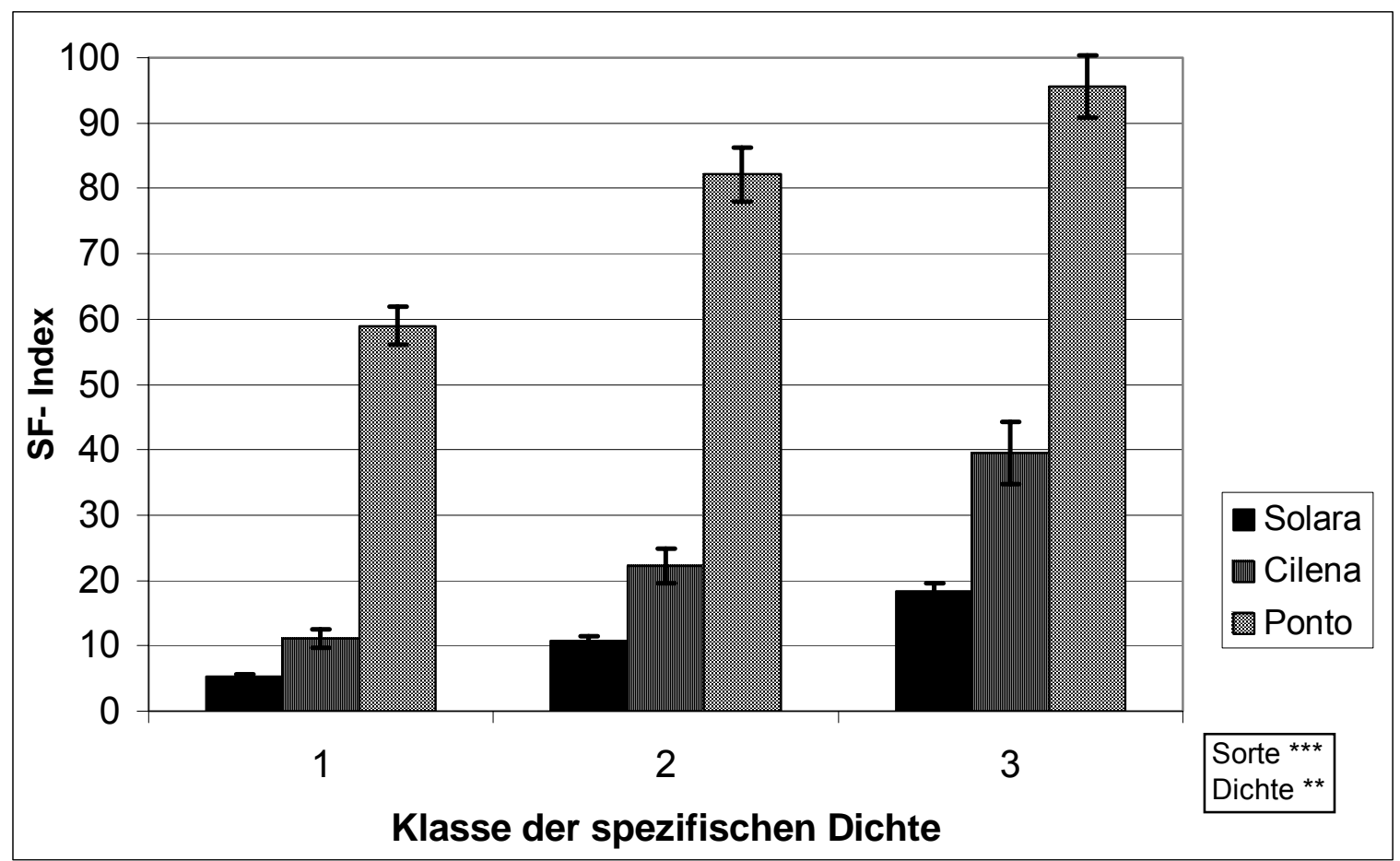

Abb. 5 Beziehung zwischen Schwarzfleckigkeit und der spezifischen Dichte unter Berücksichtigung verschiedener Sorten $* * \mathrm{p}<0,01 ; * * * \mathrm{p}<0,001$

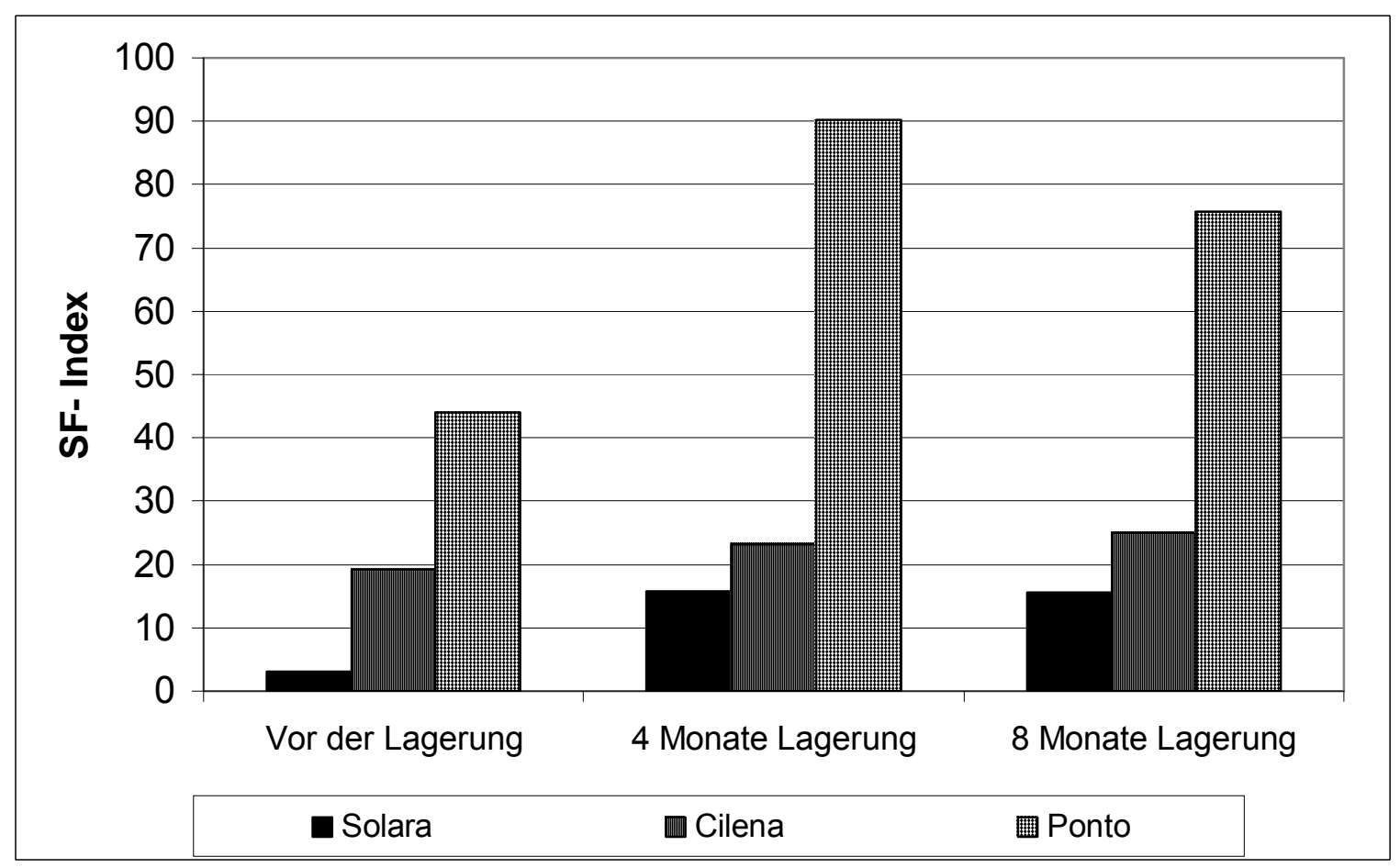

Abb. 6 Veränderung der Schwarzfleckigkeit während der Lagerung unter Berücksichtigung verschiedener Sorten

Während der Lagerung kommt es bei den Sorten Solara und Cilena in den ersten vier Lagermonaten zum Anstieg der Schwarzfleckigkeit, die sich anschließend bis zum Ende der Lagerung nach 8 Monaten nicht mehr signifikant verändert. Bei der Sorte Ponto steigt der SF- 
Index bis zum 4. Lagermonat signifikant an und geht bis zum Ende der Lagerung nach 8 Monaten zurück $(\mathrm{p}<0,01)$.

\subsubsection{Aktivität ausgewählter Enzyme in Abhängigkeit von der Sorte, der spezifischen Dichte und der Lagerung}

\subsubsection{Katalase (CAT)}

Zwischen den Sorten des Vorversuches besteht ein signifikanter Unterschied sowohl in der Aktivität der freien CAT als auch in der Aktivität der MA CAT (Tab.5). Solara weist in beiden Enzymfraktionen die geringste CAT- Aktivität auf, während bei Ponto die höchste Enzymaktivität nachweisbar war.

Tab. 5 Einfluss der Sorte auf die CAT-Aktivität

\begin{tabular}{|c|c|c|c|c|}
\hline \multirow[t]{2}{*}{ Sorte } & \multicolumn{2}{|c|}{ Freie CAT } & \multicolumn{2}{|c|}{ MA CAT } \\
\hline & \multicolumn{4}{|c|}{$\Delta$ Aktivität $10 \mathrm{~min}^{-1} \mathrm{mg}$ Protein } \\
\hline Solara & $0,383 \pm 0,0176$ & $\mathrm{a}$ & $0,666 \pm 0,0466$ & $\mathrm{a}$ \\
\hline Cilena & $0,409 \pm 0,0180$ & $\mathrm{~b}$ & $0,758 \pm 0,0620$ & $\mathrm{~b}$ \\
\hline \multirow[t]{2}{*}{ Ponto } & $0,466 \pm 0,0176$ & c & $0,925 \pm 0,0652$ & $\mathrm{c}$ \\
\hline & \multicolumn{2}{|l|}{ 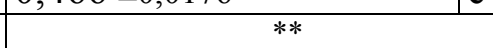 } & & \\
\hline
\end{tabular}

Unterschiedliche Buchstaben kennzeichnen signifikante Unterschiede zwischen den Sorten;

$* \mathrm{p}<0,05 ; * * \mathrm{p}<0,01$;

Zur Betrachtung der Enzymaktivitäten in Abhängigkeit von der spezifischen Dichte wurden aufgrund mangelnder Sortenunterschiede die Ergebnisse der Sorten Solara, Cilena und Ponto zusammengefasst (Abb.7).

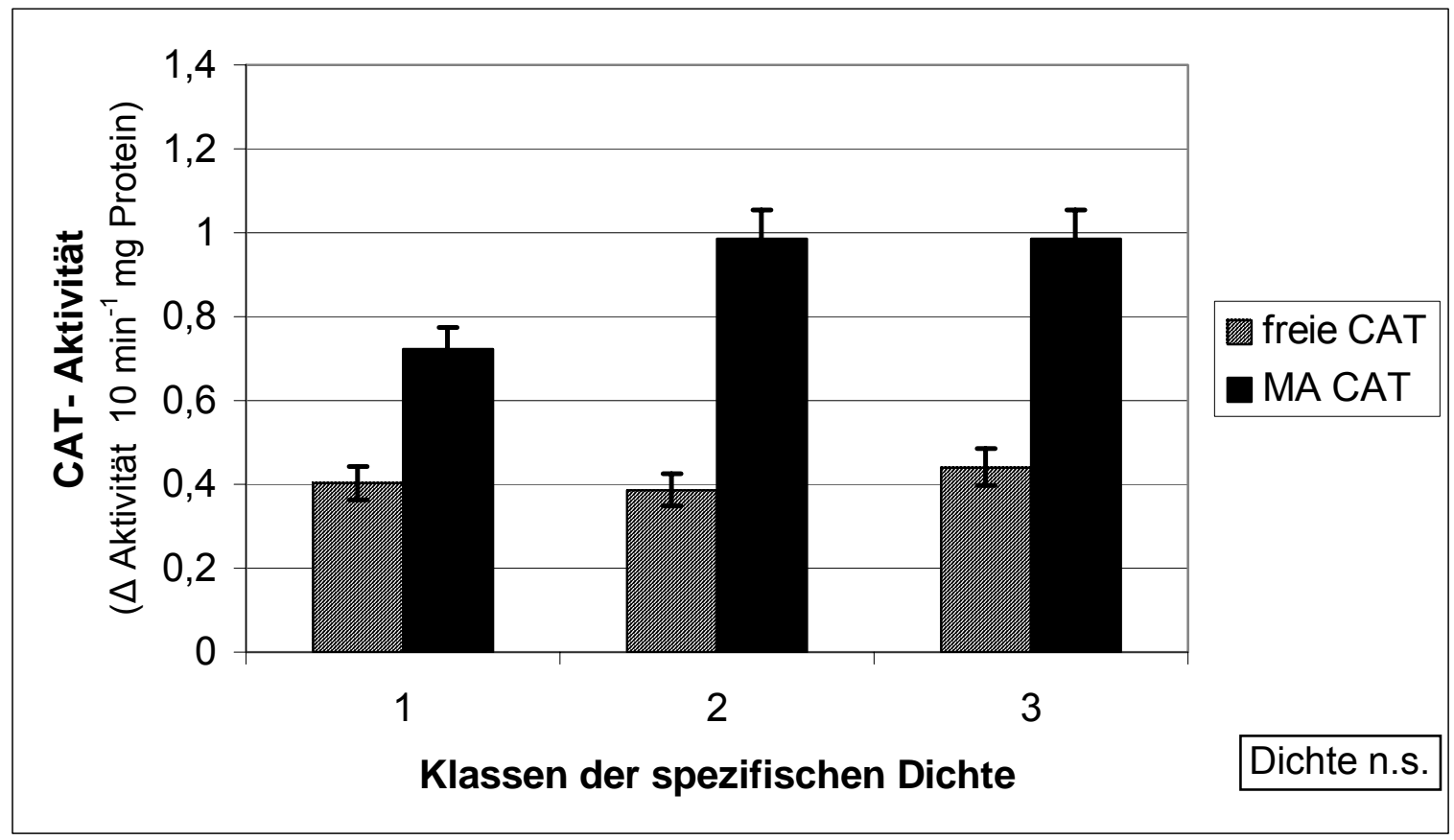

Abb. 7 Beziehung zwischen der CAT-Aktivität und der spezifischen Dichte (im Mittel aller Sorten und Termine) 
Zwischen den einzelnen Dichteklassen gibt es keine signifikanten Unterschiede in den Aktivitäten der freien bzw. MA CAT. Dennoch ist erkennbar, dass die MA CAT ein höheres Aktivitätsniveau als die freie CAT aufweist $(\mathrm{p}<0,05)$.

Über die Dauer der 8-monatigen Lagerung ist die Aktivität der freien CAT weitgehend unverändert, während die MA CAT bis Ende des 4. Lagermonats tendenziell, aber nicht signifikant, zurückgeht und bis zum Ende der Lagerung wieder ansteigt (Tab.6).

Tab. 6 Veränderung der CAT- Aktivität während der Lagerung (alle Sorten)

\begin{tabular}{|l|l|l|l|l|}
\hline \multirow{2}{*}{ Termin } & \multicolumn{3}{|c|}{ Freie CAT } & \multicolumn{2}{c|}{ MA CAT } \\
\cline { 2 - 5 } & \multicolumn{4}{|c|}{$\Delta$ Aktivität $10 \mathrm{~min}^{-1} \mathrm{mg}$ Protein } \\
\hline Vor der Lagerung & $0,452 \pm 0,0168$ & $\mathrm{a}$ & $1,042 \pm 0,0736$ & $\mathrm{a}$ \\
\hline 4 Monate Lagerung & $0,408 \pm 0,0164$ & $\mathrm{a}$ & $0,643 \pm 0,0483$ & $\mathrm{a}$ \\
\hline 8 Monate Lagerung & $0,400 \pm 0,0164$ & $\mathrm{a}$ & $0,712 \pm 0,0490$ & $\mathrm{a}$ \\
\hline & \multicolumn{3}{|c|}{ n.s. } & \multicolumn{2}{c|}{ n.s. } \\
\hline
\end{tabular}

Unterschiedliche Buchstaben kennzeichnen signifikante Unterschiede zwischen den Sorten; n.s.= nicht signifikant;

\subsubsection{Ascorbat- Peroxidase (POD)}

Die signifikant höchste Aktivität der freien POD ist bei Cilena nachgewiesen worden, gefolgt von Ponto und Solara. Bei der MA POD ergeben sich keine Sortenunterschiede (Tab.7). Ein Unterschied zwischen den Enzymfraktionen konnte aufgrund der hohen Standardabweichungen bei der Sorte Cilena nicht ermittelt werden.

Tab. 7 Einfluss der Sorte auf die POD- Aktivität

\begin{tabular}{|l|l|l|l|l|}
\hline \multirow{2}{*}{ Sorte } & \multicolumn{3}{c|}{ Freie POD } & \multicolumn{2}{c|}{ MA POD } \\
\cline { 2 - 5 } & \multicolumn{4}{|c|}{$\Delta$ Aktivität $10 \mathrm{~min}^{-1} \mathrm{mg}$ Protein } \\
\hline Solara & $0,00170 \pm 0,000525$ & $\mathrm{a}$ & $0,00422 \pm 0,000652$ & $\mathrm{a}$ \\
\hline Cilena & $0,00218 \pm 0,000964$ & $\mathrm{c}$ & $0,00626 \pm 0,0011$ & $\mathrm{a}$ \\
\hline Ponto & $0,00178 \pm 0,000472$ & $\mathrm{~b}$ & $0,00530 \pm 0,000620$ & $\mathrm{a}$ \\
\hline & & & & n.s. \\
\hline
\end{tabular}

Unterschiedliche Buchstaben kennzeichnen signifikante Unterschiede zwischen den Sorten; $* \mathrm{p}<0,05 ;$ n.s. $=$ nicht signifikant;

Die Untersuchung der POD- Aktivität in Abhängigkeit von der spezifischen Dichte hat ergeben, dass die MA POD bei allen Sorten mit zunehmender spezifischer Dichte signifikant ansteigt, während die Aktivität der freien POD unverändert bleibt (Abb.8). 


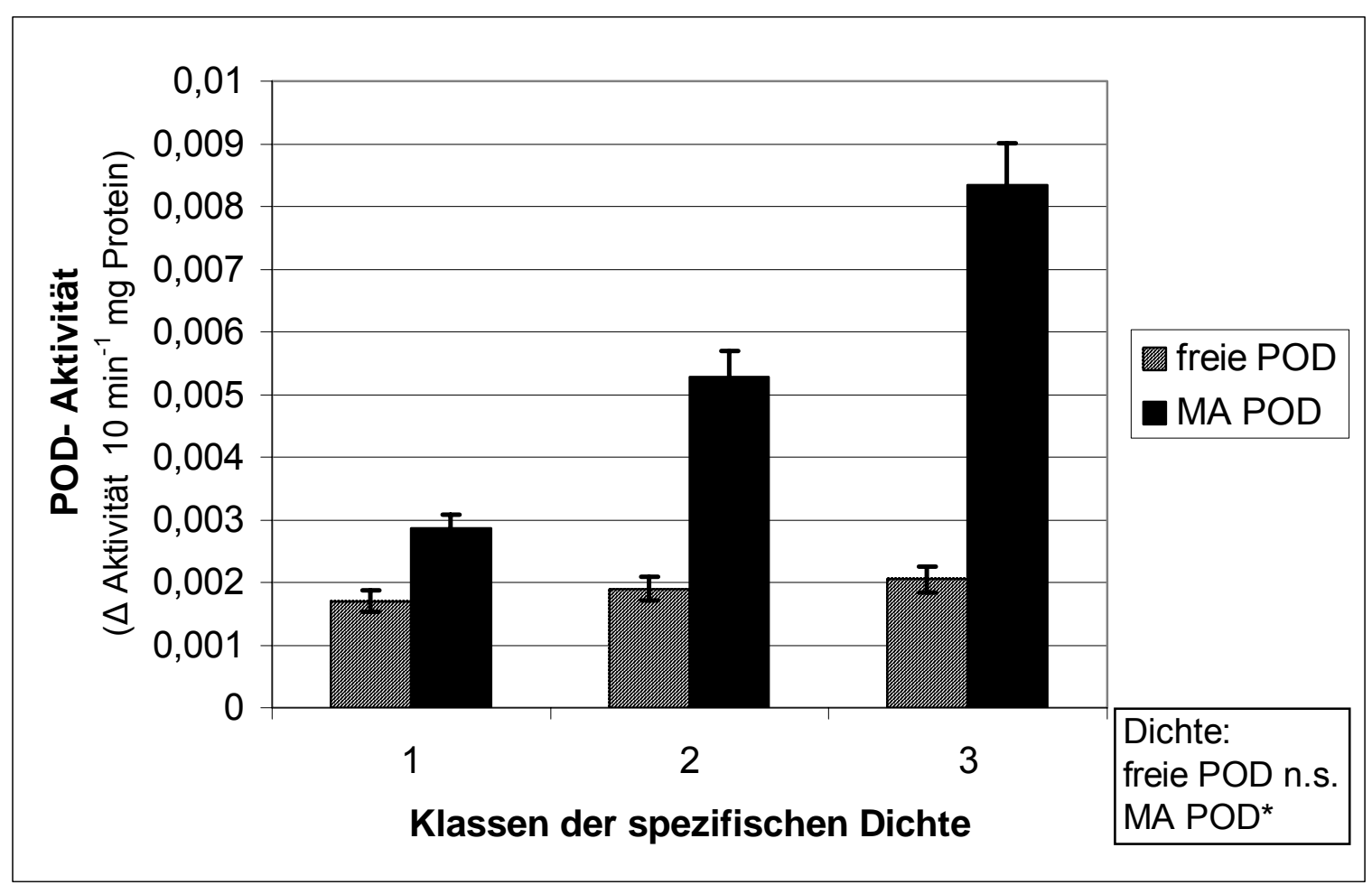

Abb. 8 Beziehung zwischen der POD-Aktivität und der spezifischen Dichte (im Mittel aller Sorten und Termine)

$* \mathrm{p}<0,05 ; \quad$ n.s. $=$ nicht signifikant

Während der Lagerung gibt es keine Veränderung in der Aktivität der freien POD.

Die MA POD nimmt bis zum Ende des 4. Lagermonats tendenziell ab, erreicht jedoch am Ende der 8-monatigen Lagerung weitgehend das Anfangsniveau (Tab.8).

Tab. 8 Veränderung der POD- Aktivität während der Lagerung (alle Sorten)

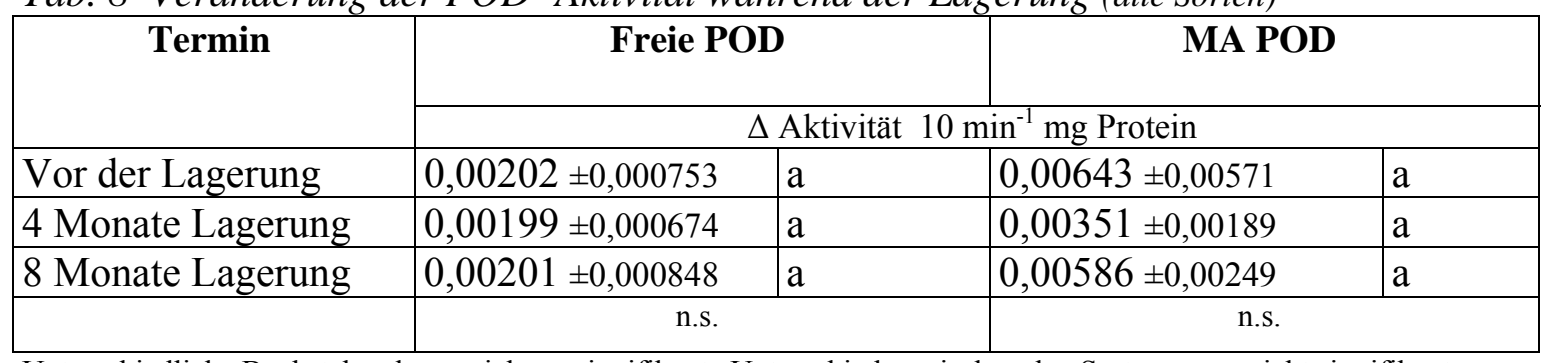

Unterschiedliche Buchstaben kennzeichnen signifikante Unterschiede zwischen den Sorten; n.s.= nicht signifikant;

\subsubsection{Lipoxygenase (LOX)}

Die Betrachtung der LOX- Aktivität in Abhängigkeit von verschiedenen Sorten hat den signifikant höchsten Gehalt der freien LOX bei der Sorte Ponto ergeben. Solara und Cilena unterscheiden sich nicht, haben jedoch eine geringere Aktivität als Ponto.

Bei der MA LOX zeigen alle drei Sorten eine annähernd gleiche Enzymaktivität (Tab.9) 
Tab. 9 Einfluss der Sorte auf die LOX-Aktivität

\begin{tabular}{|l|l|l|l|l|}
\hline \multirow{2}{*}{ Sorte } & \multicolumn{3}{c|}{ Freie LOX } & \multicolumn{2}{c|}{ MA LOX } \\
\cline { 2 - 5 } & \multicolumn{3}{|c|}{$\left(\Delta\right.$ Aktivität $\mathrm{mmol} \mathrm{sec}^{-1} \mathrm{mg}$ Protein $)$} & $\mathrm{a}$ \\
\hline Solara & $0,0274 \pm 0,00397$ & $\mathrm{a}$ & $0,0596 \pm 0,0184$ & $\mathrm{a}$ \\
\hline Cilena & $0,0276 \pm 0,00457$ & $\mathrm{a}$ & $0,0918 \pm 0,0350$ & $\mathrm{a}$ \\
\hline Ponto & $0,0320 \pm 0,00711$ & $\mathrm{~b}$ & $0,0718 \pm 0,00426$ & \multicolumn{2}{c|}{ n.s. } \\
\hline & \multicolumn{2}{|c|}{} & \multicolumn{2}{c}{} \\
\hline
\end{tabular}

Unterschiedliche Buchstaben kennzeichnen signifikante Unterschiede zwischen den Sorten;

$* * \mathrm{p}<0,01 ;$ n.s. $=$ nicht signifikant;

Zwischen den einzelnen Klassen der spezifischen Dichte gibt es bei allen Sorten weder bei der freien noch bei der MA LOX signifikante Unterscheide (Abb.9). Hohe Standardabweichungen in der Dichtefraktion 3 bei der MA LOX machen eine Unterscheidung der Klassen der spezifischen Dichte unmöglich.

Zwischen den Enzymfraktionen, der freien und der MA LOX, besteht jedoch ein signifikanter Unterschied $(\mathrm{p}<0,05)$, der sich in Form einer höheren Aktivität der MA LOX zeigt.

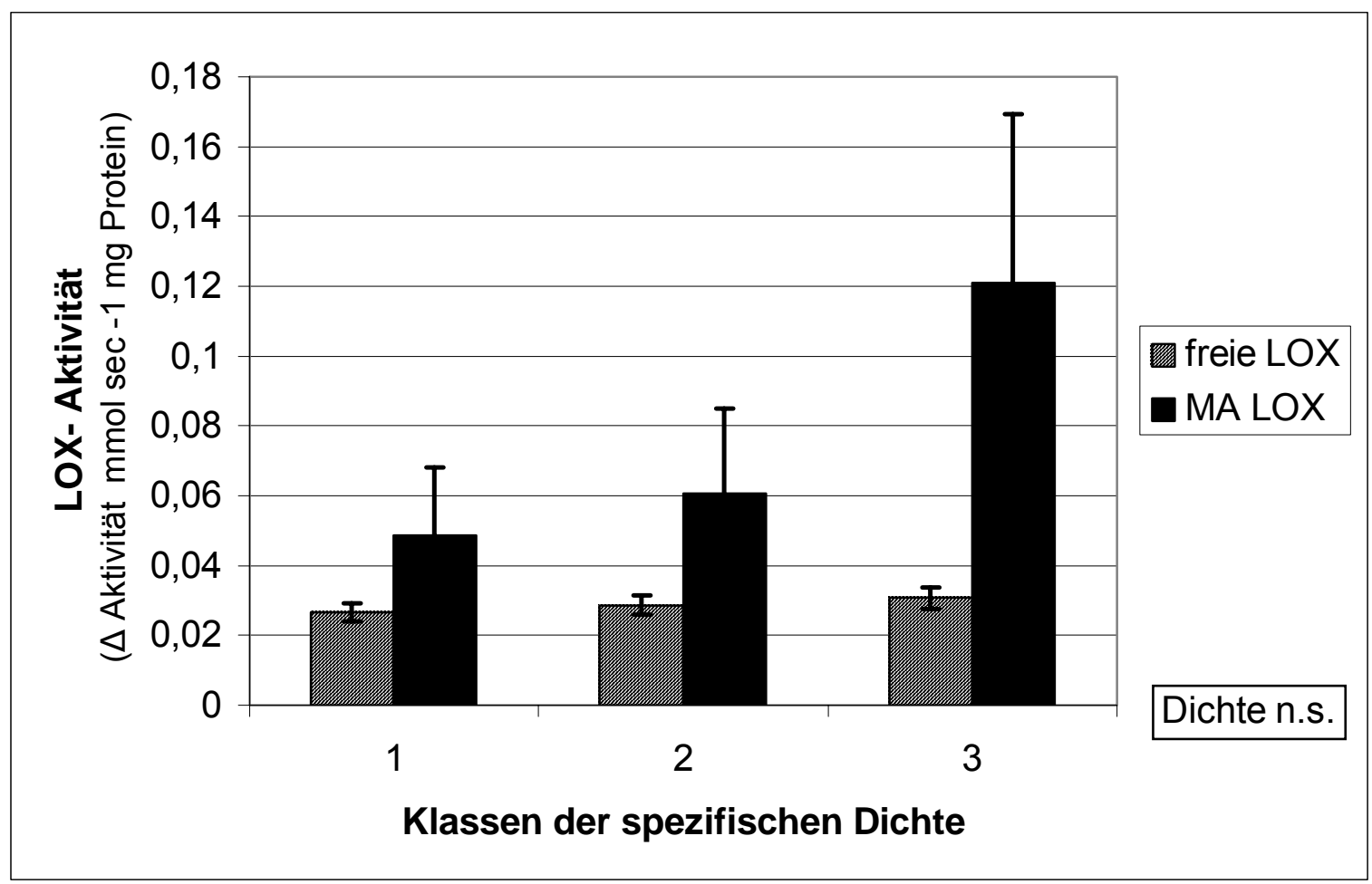

Abb. 9 Beziehung zwischen der LOX-Aktivität und der spezifischen Dichte (im Mittel aller Sorten und Termine)

n.s.= nicht signifikant

Im Laufe der Lagerung nehmen die Gehalte der freien LOX tendenziell, jedoch nicht signifikant ab. Bei der MA LOX gibt es ebenfalls keine signifikanten Unterschiede. Es zeigt 
sich tendenziell, dass die Aktivität der MA LOX zunächst zurückgeht, ehe sie nach 8monatiger Lagerung fast wieder das Ausgangsniveau erreicht (Tab.10).

Tab. 10 Veränderung der LOX-Aktivität während der Lagerung (alle Sorten)

\begin{tabular}{|l|l|l|l|l|}
\hline \multirow{2}{*}{ Termin } & \multicolumn{3}{c|}{ Freie LOX } & \multicolumn{2}{c|}{ MA LOX } \\
\cline { 2 - 5 } & \multicolumn{3}{|c|}{$\left(\Delta\right.$ Aktivität $\mathrm{mmol} \mathrm{sec}^{-1} \mathrm{mg}$ Protein $)$} \\
\hline Vor der Lagerung & $0,0305 \pm 0,00679$ & $\mathrm{a}$ & $0,0882 \pm 0,0730$ & $\mathrm{a}$ \\
\hline 4 Monate Lagerung & $0,0285 \pm 0,00416$ & $\mathrm{a}$ & $0,0562 \pm 0,0307$ & $\mathrm{a}$ \\
\hline 8 Monate Lagerung & $0,0281 \pm 0,00598$ & $\mathrm{a}$ & $0,0787 \pm 0,0948$ & $\mathrm{a}$ \\
\hline & \multicolumn{2}{|c|}{ n.s. } & \multicolumn{2}{c|}{ n.s. } \\
\hline
\end{tabular}

Unterschiedliche Buchstaben kennzeichnen signifikante Unterschiede zwischen den Sorten; n.s.= nicht signifikant;

\subsubsection{Superoxiddismutase (SOD)}

In der Aktivität der SOD bestehen signifikante Sortenunterschiede. Sowohl bei der freien als auch bei der MA SOD weist die Sorte Ponto die höchste Aktivität auf, gefolgt von Cilena. Solara zeigt in beiden Enzymfraktionen die niedrigste SOD- Aktivität (Tab.11).

Darüber hinaus besteht zwischen der freien und der MA SOD ein signifikanter Unterschied in ihrer Aktivität $(\mathrm{p}<0,01)$.

Tab. 11 Einfluss der Sorte auf die SOD- Aktivität

\begin{tabular}{|l|l|l|l|l|l|}
\hline \multirow{2}{*}{ Sorte } & \multicolumn{3}{|c|}{ Freie SOD } & \multicolumn{2}{c|}{ MA SOD } \\
\cline { 2 - 6 } & \multicolumn{3}{|c|}{$\Delta$ Aktivität $\mathrm{mg}^{-1}$ Protein } & $\mathrm{a}$ \\
\hline Solara & $4,953 \pm 2,012$ & $\mathrm{a}$ & $6,206 \pm 3,263$ & $\mathrm{~b}$ \\
\hline Cilena & $5,323 \pm 1,923$ & $\mathrm{~b}$ & $13,826 \pm 6,417$ & $\mathrm{c}$ \\
\hline Ponto & $6,599 \pm 2,325$ & $\mathrm{c}$ & $16,663 \pm 9,654$ & \\
\hline & \multicolumn{3}{|c|}{$*$} & & \\
\hline
\end{tabular}

Unterschiedliche Buchstaben kennzeichnen signifikante Unterschiede zwischen den Sorten; ${ }^{*} \mathrm{p}<0,05$;

Bei der MA SOD besteht bei allen Sorten eine Beziehung zwischen der SOD- Aktivität und der spezifischen Dichte. Die Enzymaktivität steigt bis zur Dichtefraktion 3 an. Die Aktivität der freien SOD unterscheidet sich dagegen in keiner Sorte zwischen den Klassen der spezifischen Dichte (Abb.10). 


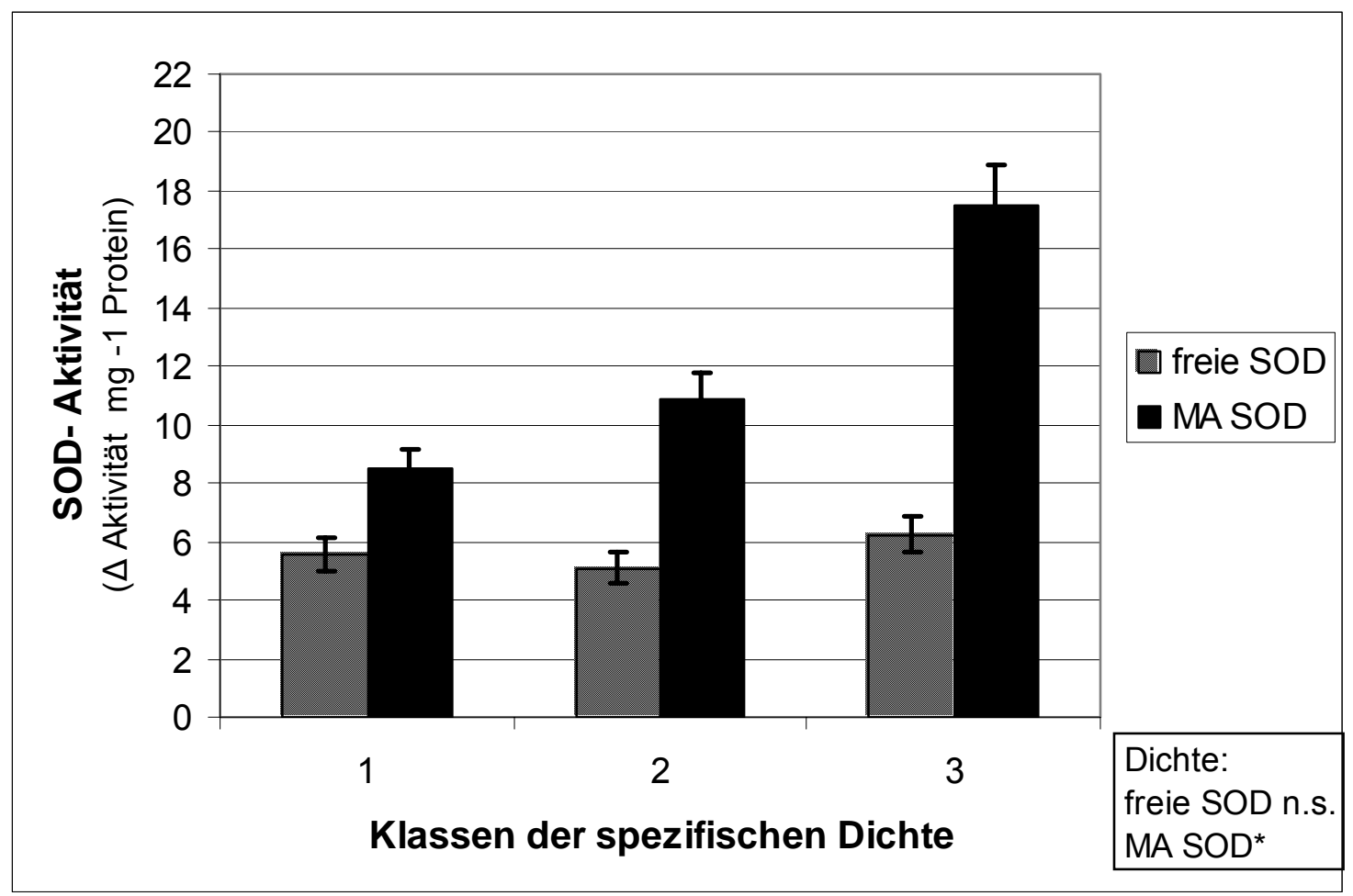

Abb. 10 Beziehung zwischen der SOD-Aktivität und der spezifischen Dichte (im Mittel aller Sorten und Termine)

${ }^{*} \mathrm{p}<0,05 ; \quad$ n.s. $=$ nicht signifikant

Während der Lagerung haben sich keine signifikanten SOD- Aktivitätsunterschiede ergeben. Dennoch wird tendenziell deutlich, dass die freie SOD während der ersten vier Monate Lagerung eine Aktivitätszunahme aufweist, die zum Ende der Lagerung wieder zurückgeht. Bei der MA SOD ergibt sich tendenziell eine genau gegensätzliche Entwicklung. In den ersten vier Monaten geht die Aktivität zurück, während sie nach 8 Monaten geringfügig über dem Ausgangsniveau liegt (Tab.12).

Tab. 12 Veränderung der SOD- Aktivität während der Lagerung (alle Sorten)

\begin{tabular}{|l|l|l|l|l|l|}
\hline \multirow{2}{*}{ Termin } & \multicolumn{3}{c|}{ Freie SOD } & \multicolumn{2}{c|}{ MA SOD } \\
\cline { 2 - 6 } & \multicolumn{3}{|c|}{$\Delta$ Aktivität mg $^{-1}$ Protein } \\
\hline Vor der Lagerung & $5,163 \pm 1,910$ & $\mathrm{a}$ & $13,117 \pm 2,591$ & $\mathrm{a}$ \\
\hline 4 Monate Lagerung & $6,077 \pm 2,061$ & $\mathrm{a}$ & $10,009 \pm 7,138$ & $\mathrm{a}$ \\
\hline 8 Monate Lagerung & $5,805 \pm 2,371$ & $\mathrm{a}$ & $13,540 \pm 6,246$ & $\mathrm{a}$ \\
\hline & \multicolumn{3}{|c|}{ n.s. } & \multicolumn{2}{c|}{ n.s. } \\
\hline
\end{tabular}

Unterschiedliche Buchstaben kennzeichnen signifikante Unterschiede zwischen den Sorten; n.s.= nicht signifikant;

\subsubsection{Polyphenoloxidase (PPO)}

Bei der PPO existieren hoch signifikante Sortenunterschiede. Ponto weist die höchste PPOAktivität auf, gefolgt von Cilena und Solara (Tab.13). 
Tab. 13 Einfluss der Sorte auf die PPO- Aktivität

\begin{tabular}{|l|l|l|}
\hline \multirow{2}{*}{ Sorte } & \multicolumn{2}{|c|}{ PPO } \\
\cline { 2 - 3 } & \multicolumn{2}{|c|}{$\Delta \mathrm{E}$ min $^{-1} \mathrm{~g}^{-1} \mathrm{FM}$} \\
\hline Solara & $0,456 \pm 0,0711$ & $\mathrm{a}$ \\
\hline Cilena & $1,214 \pm 0,0551$ & $\mathrm{~b}$ \\
\hline Ponto & $1,593 \pm 0,0854$ & $\mathrm{c}$ \\
\hline & \multicolumn{2}{|c|}{$* * *$} \\
\hline
\end{tabular}

Unterschiedliche Buchstaben kennzeichnen signifikante Unterschiede

zwischen den Sorten; $* * * p<0,001$

Zwischen den Klassen der spezifischen Dichte (Abb.11) und den Lagerungsterminen (Tab.14) gibt es jedoch bei allen Sorten keine signifikanten Unterschiede.

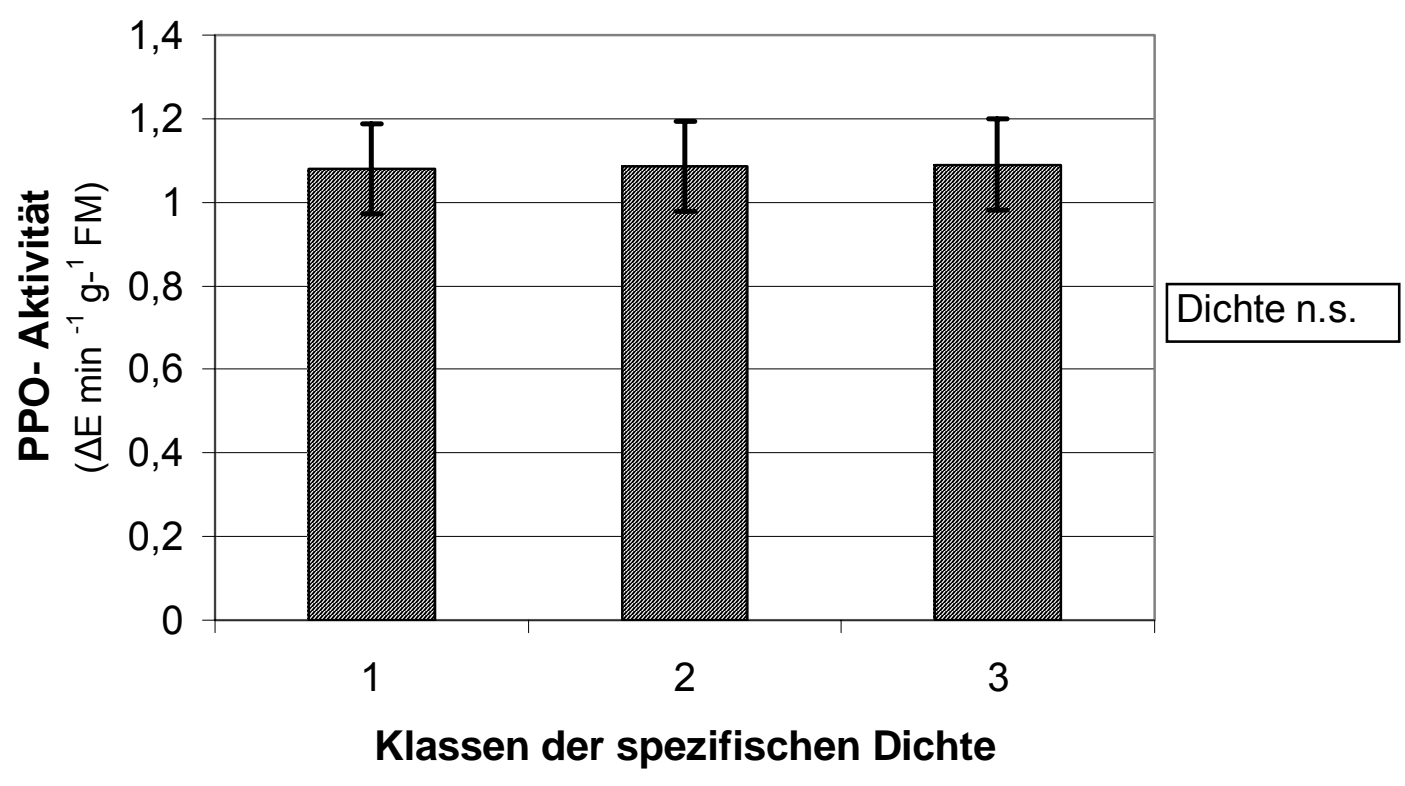

Abb. 11 Beziehung zwischen der PPO-Aktivität und der spezifischen Dichte (im Mittel aller Sorten und Termine)

n.s. $=$ nicht signifikant

Es ist jedoch zu beobachten, dass die PPO- Aktivität während der Lagerung tendenziell ansteigt.

Tab. 14 Veränderung der PPO- Aktivität während der Lagerung (alle Sorten)

\begin{tabular}{|l|c|c|}
\hline \multirow{2}{*}{\multicolumn{1}{|c|}{ Termin }} & \multicolumn{2}{|c|}{ PPO } \\
\cline { 2 - 3 } & \multicolumn{2}{|c|}{$\Delta \mathrm{E} \mathrm{min}^{-1} \mathrm{~g}^{-1} \mathrm{FM}$} \\
\hline Vor der Lagerung & $1,006 \pm 0,495$ & $\mathrm{a}$ \\
\hline 4 Monate Lagerung & $1,113 \pm 0,494$ & $\mathrm{a}$ \\
\hline 8 Monate Lagerung & $1,130 \pm 0,506$ & $\mathrm{a}$ \\
\hline & \multicolumn{2}{|c|}{ n.s. } \\
\hline
\end{tabular}

Unterschiedliche Buchstaben kennzeichnen signifikante Unterschiede; n.s.= nicht signifikant; 


\subsubsection{Gehalt freier Aminosäuren in Abhängigkeit von der Sorte, der spezifischen Dichte und der Lagerung}

Die Gehalte an freien Aminosäuren variieren deutlich zwischen den Sorten. Bei allen Aminosäuren, mit Ausnahme von Serin und Histidin, weist die Sorte Cilena die höchsten Gehalte auf. Ponto hat nachweislich stets die geringsten Gehalte (Tab.15a\& b).

Tab. $15 a$ Einfluss der Sorte auf den Gehalt an freien Aminosäuren

\begin{tabular}{|c|c|c|c|c|c|c|c|c|}
\hline Sorten & 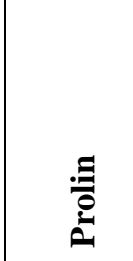 & 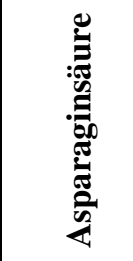 & 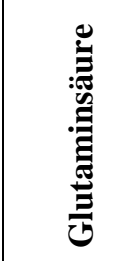 & ڤั & 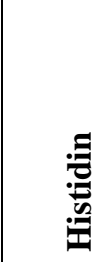 & $\begin{array}{l}\text { 㤩 } \\
\text { 惫 }\end{array}$ & 竞 & 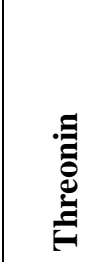 \\
\hline & \multicolumn{8}{|c|}{$\mu \mathrm{g} \mathrm{g}^{-1} \mathrm{TM}$} \\
\hline Solara & \begin{tabular}{|l}
779,3 \\
$\pm 285,4$
\end{tabular} & \begin{tabular}{|l|}
657,9 \\
$\pm 281,6$
\end{tabular} & $\begin{array}{l}280,2 \\
\pm 155,5\end{array}$ & $\begin{array}{l}84,6 \\
\pm 26,2\end{array}$ & \begin{tabular}{|l|}
38,0 \\
$\pm 33,4$
\end{tabular} & $\begin{array}{l}280,6 \\
\pm 131,6\end{array}$ & $\begin{array}{l}56,5 \\
\pm 27,1\end{array}$ & $\begin{array}{l}61,0 \\
\pm 3,6\end{array}$ \\
\hline Cilena & $\begin{array}{l}960,3 \\
\pm 264,7\end{array}$ & $\begin{array}{l}795,3 \\
\pm 295\end{array}$ & $\begin{array}{l}375,8 \\
\pm 180,5\end{array}$ & $\begin{array}{l}79,4 \\
\pm 33,7\end{array}$ & $\begin{array}{l}39,5 \\
\pm 19,7\end{array}$ & $\begin{array}{l}319,0 \\
\pm 130,0\end{array}$ & $\begin{array}{l}85,8 \\
\pm 39,7\end{array}$ & \begin{tabular}{|l}
65,7 \\
$\pm 25,4$
\end{tabular} \\
\hline Ponto & \begin{tabular}{|l}
574,8 \\
$\pm 328,5$
\end{tabular} & $\begin{array}{l}333,4 \\
\pm 156,2\end{array}$ & $\begin{array}{l}142,8 \\
\pm 79,9\end{array}$ & $\begin{array}{l}79,6 \\
\pm 34,7\end{array}$ & $\begin{array}{l}22,0 \\
\pm 15,2\end{array}$ & $\begin{array}{l}157,7 \\
\pm 97,9\end{array}$ & $\begin{array}{l}35,9 \\
\pm 12,9\end{array}$ & \begin{tabular}{|l|}
39,3 \\
$\pm 14,6$
\end{tabular} \\
\hline & $* *$ & $* * *$ & $* * *$ & n.s. & n.s. & $* *$ & $* * *$ & $*$ \\
\hline
\end{tabular}

Tab. 15b Einfluss der Sorte auf den Gehalt an freien Aminosäuren

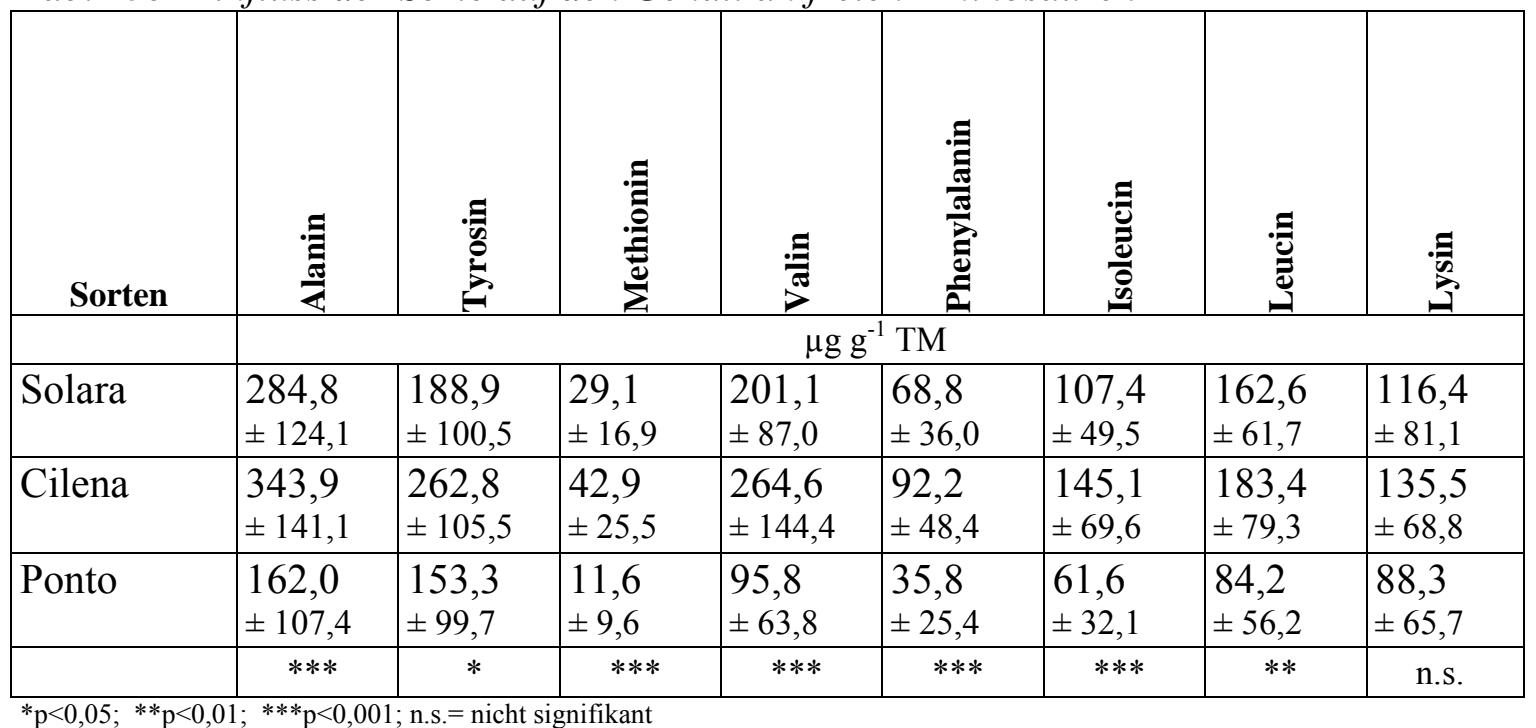

Unter Berücksichtigung aller Sorten ist die Beziehung zwischen den Aminosäuregehalten und der spezifischen Dichte ermittelt worden. Lediglich Isoleucin (Abb.12a) und Valin (Abb.12b) haben signifikant abgenommen. Bei den übrigen Aminosäuren, mit Ausnahme von Tyrosin, Asparaginsäure und Glutaminsäure, ist diese Abnahme tendenziell erkennbar. 


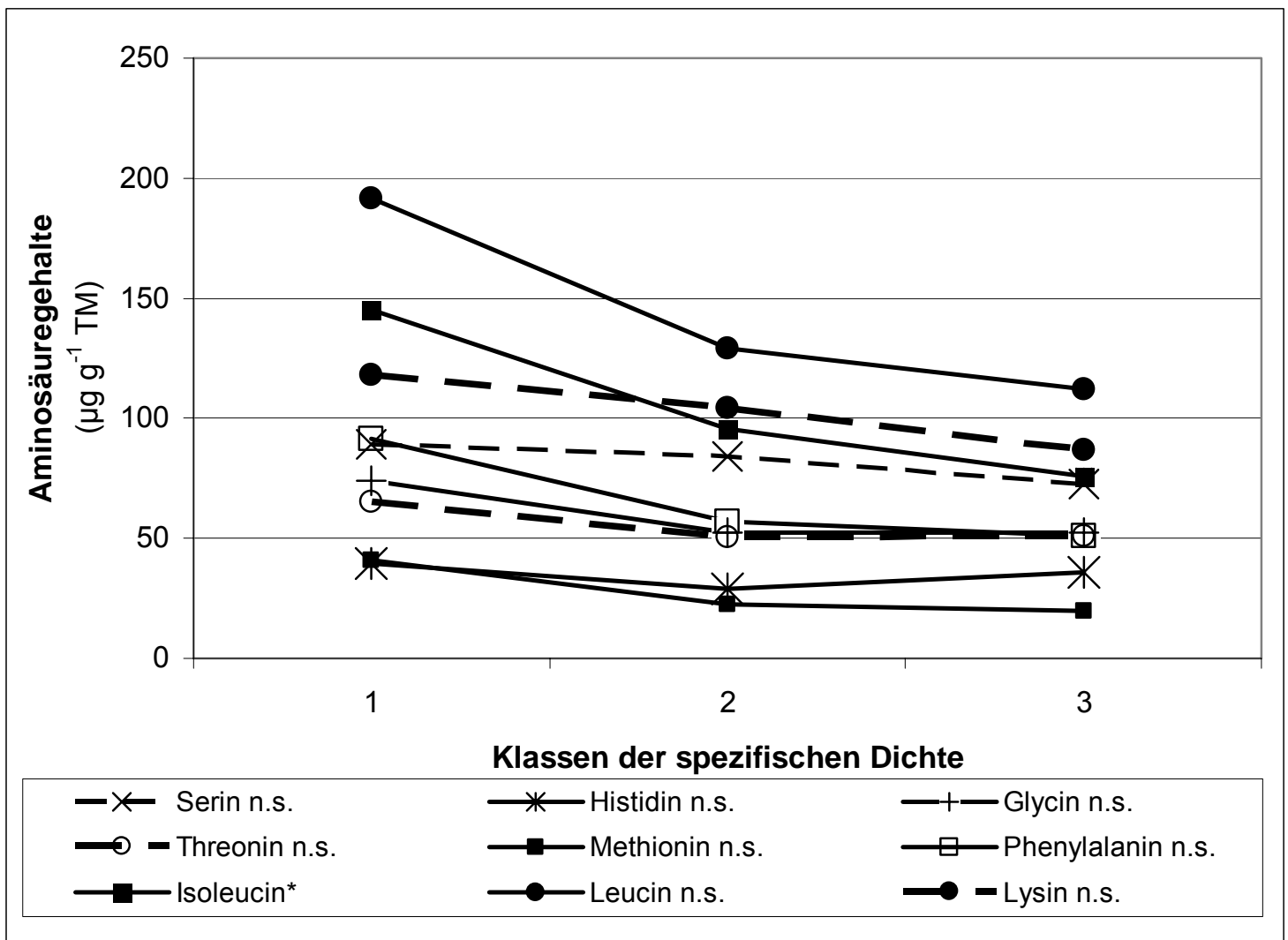

Abb. 12a Beziehung zwischen den Aminosäuren und der spezifischen Dichte (im Mittel aller Sorten und Termine) $* \mathrm{p}<0,05$; n.s. $=$ nicht signifikant

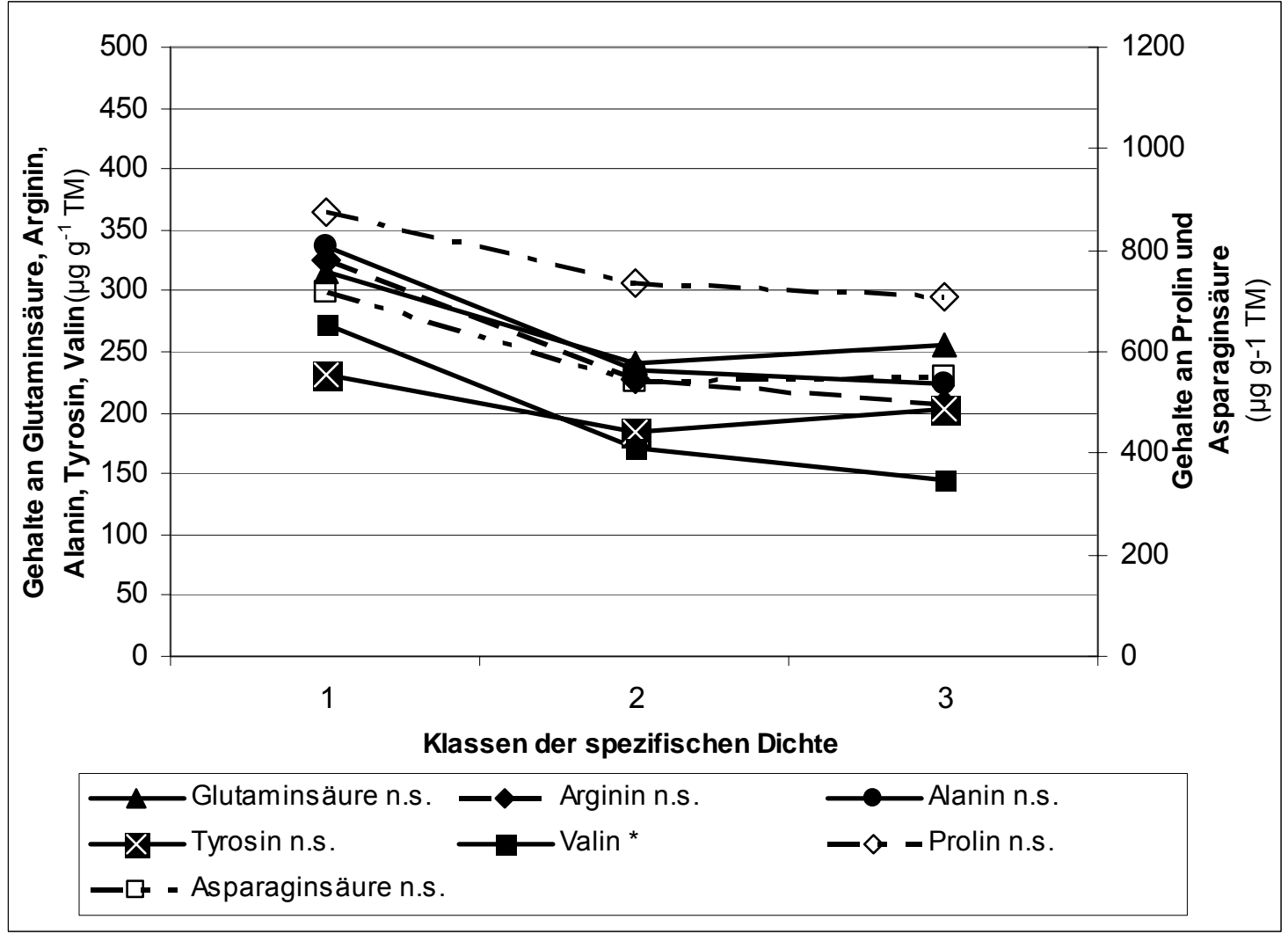

Abb. $12 b$ Beziehung zwischen den Aminosäuren und der spezifischen Dichte (im Mittel aller Sorten und Termine) $*$ $p<0,05 ;$ n.s. $=$ nicht signifikant 
Die Aminosäuregehalte wurden aufgrund des Probenvolumens im Gegensatz zu den übrigen Inhaltsstoffen nur vor Beginn und nach 8 Monaten Lagerung bestimmt (Tab.16a\& b). Die Gehalte an Prolin, Serin, Histidin, Arginin, Threonin, Alanin, Tyrosin, Leucin und Lysin nehmen bis zum Ende der Lagerung signifikant zu.

Tab. 16a Veränderung der Aminosäuregehalte während der Lagerung (alle Sorten)

\begin{tabular}{|c|c|c|c|c|c|c|c|c|}
\hline Termin & $\begin{array}{l}\text { E } \\
0 \\
0\end{array}$ & 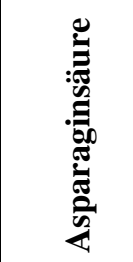 & 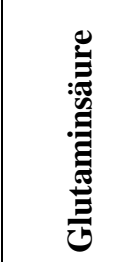 & 春 & 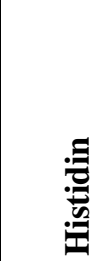 & $\begin{array}{l}\text { 㤩 } \\
\text { 惫 } \\
\end{array}$ & $\frac{\Xi}{0}$ & 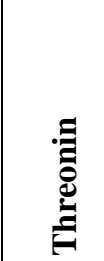 \\
\hline & \multicolumn{8}{|c|}{$\mu \mathrm{g} \mathrm{g}^{-1} \mathrm{TM}$} \\
\hline $\begin{array}{l}\text { Vor der } \\
\text { Lagerung }\end{array}$ & $\begin{array}{l}585,2 \\
\pm 307,9\end{array}$ & \begin{tabular}{|l|}
548,5 \\
$\pm 306,1$
\end{tabular} & $\begin{array}{l}240,9 \\
\pm 63,4\end{array}$ & $\begin{array}{l}70,7 \\
\pm 23,6\end{array}$ & \begin{tabular}{|l|}
20,8 \\
$\pm 13,1$
\end{tabular} & $\begin{array}{l}200,1 \\
\pm 120,3\end{array}$ & \begin{tabular}{|l|}
54,4 \\
$\pm 30,8$
\end{tabular} & $\begin{array}{l}44,8 \\
\pm 13,9\end{array}$ \\
\hline $\begin{array}{l}8 \text { Monate } \\
\text { Lagerung }\end{array}$ & $\begin{array}{l}933,9 \\
\pm 255,9\end{array}$ & $\begin{array}{l}632,27 \\
\pm 322,4\end{array}$ & $\begin{array}{l}286,0 \\
\pm 78,2\end{array}$ & $\begin{array}{l}91,3 \\
\pm 34,5\end{array}$ & $\begin{array}{l}44,8 \\
\pm 28,1\end{array}$ & $\begin{array}{l}299,8 \\
\pm 136,4\end{array}$ & $\begin{array}{l}63,1 \\
\pm 38,0\end{array}$ & $\begin{array}{l}65,0 \\
\pm 22,3\end{array}$ \\
\hline & $* * *$ & n.s. & n.s. & * & $* * *$ & $* *$ & n.s. & $* *$ \\
\hline
\end{tabular}

Tab. 16b Veränderung der Aminosäuregehalte während der Lagerung (alle Sorten)

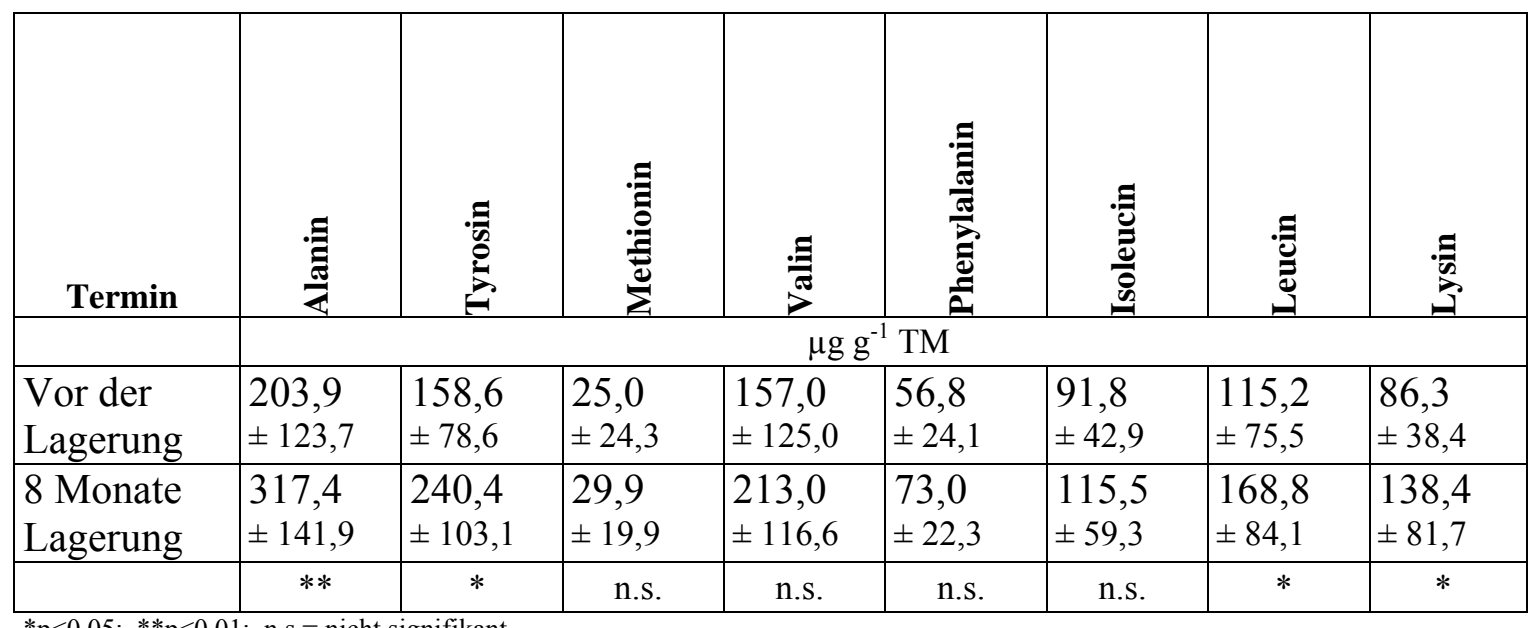

\subsubsection{Gehalt an organischen Säuren in Abhängigkeit von der Sorte, der spezifischen Dichte und der Lagerung}

Zwischen den Sorten existiert ein deutlicher Unterschied in den Gehalten der organischen Säuren. In der Sorte Ponto ist bei allen organischen Säuen, mit Ausnahme der Chlorogensäure und der Ascorbinsäure, die geringste Konzentration messbar (Tab.17). 
Tab. 17 Einfluss der Sorte auf den Gehalt an organischen Säuren

\begin{tabular}{|c|c|c|c|c|c|c|c|}
\hline Sorten & 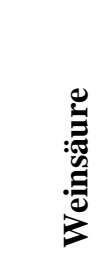 & 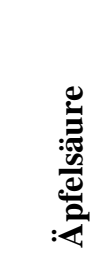 & 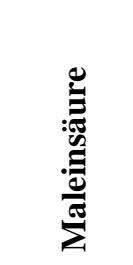 & 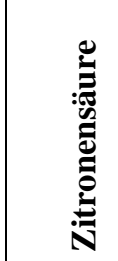 & 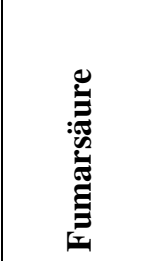 & 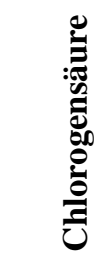 & 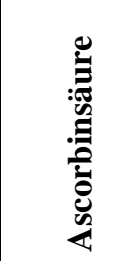 \\
\hline & \multicolumn{7}{|c|}{$\mathrm{g} \mathrm{kg}^{-1} \mathrm{TM}$} \\
\hline Solara & $\begin{array}{l}1,35 \\
\pm 0,43\end{array}$ & $\begin{array}{l}7,76 \\
\pm 1,74\end{array}$ & $\begin{array}{l}0,0097 \\
\pm 0,0047\end{array}$ & $\begin{array}{l}23,01 \\
\pm 2,09\end{array}$ & $\begin{array}{l}0,0175 \\
\pm 0,0059\end{array}$ & $\begin{array}{l}0,80 \\
\pm 0,11\end{array}$ & $\begin{array}{l}0,51 \\
\pm 0,111\end{array}$ \\
\hline Cilena & $\begin{array}{l}1,18 \\
\pm 0,35\end{array}$ & $\begin{array}{l}8,63 \\
\pm 1,68\end{array}$ & $\begin{array}{l}0,0100 \\
\pm 0,0066\end{array}$ & $\begin{array}{l}20,89 \\
\pm 2,32\end{array}$ & $\begin{array}{l}0,0264 \\
\pm 0,0088\end{array}$ & $\begin{array}{l}1,01 \\
\pm 0,25\end{array}$ & \begin{tabular}{|l|}
0,54 \\
$\pm 0,130$
\end{tabular} \\
\hline Ponto & $\begin{array}{l}0,89 \\
\pm 0,46\end{array}$ & $\begin{array}{l}5,87 \\
\pm 1,93\end{array}$ & $\begin{array}{l}0,0056 \\
\pm 0,0047\end{array}$ & $\begin{array}{l}15,77 \\
\pm 2,82\end{array}$ & $\begin{array}{l}0,0031 \\
\pm 0,0090\end{array}$ & $\begin{array}{l}1,51 \\
\pm 0,30\end{array}$ & $\begin{array}{l}0,44 \\
\pm 0,078\end{array}$ \\
\hline & $* * *$ & $* * *$ & $* *$ & $* * *$ & $* * *$ & $* * *$ & n.s. \\
\hline
\end{tabular}

Die Ascorbinsäuregehalte sind bei allen Sorten weitgehend gleich, während Chlorogensäure mit der höchsten Konzentration in Ponto nachweisbar ist (Tab.17).

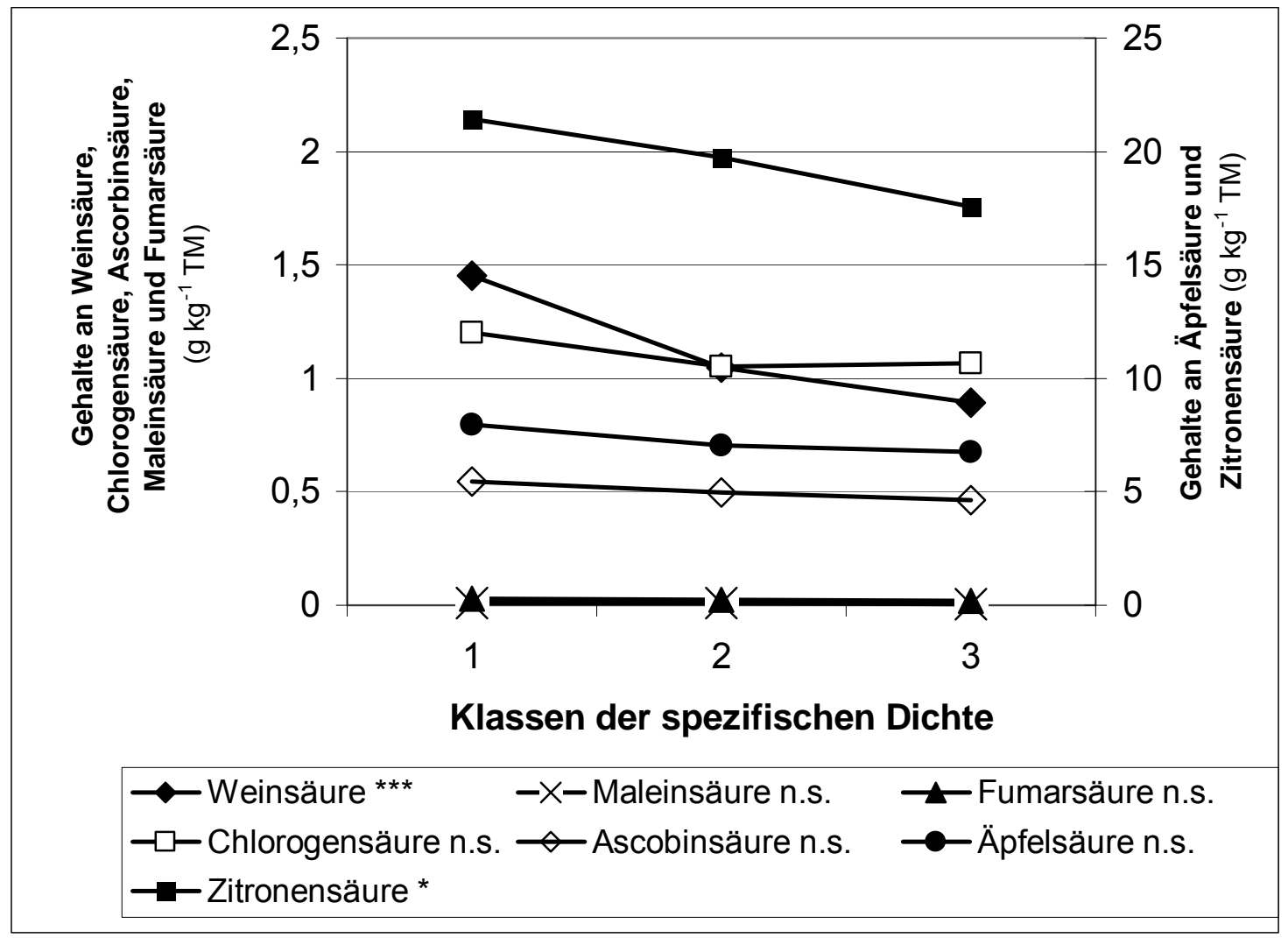

Abb. 13 Beziehung zwischen den organischen Säuren und der spezifischen Dichte (im Mittel aller Sorten und Termine) ${ }^{*} \mathrm{p}<0,05 ;{ }^{* *} \mathrm{p}<0,001 ;$ n.s. $=$ nicht signifikant

Bei der Betrachtung der spezifischen Dichte hat sich nur bei Zitronensäure und Weinsäure eine signifikante Abnahme mit zunehmender spezifischer Dichte ergeben (Abb.13). Die Beziehung zwischen den organischen Säuren und der spezifischen Dichte unter 
Berücksichtigung aller Sorten und Termine verhält sich analog zu den Einzelergebnissen der Sorten.

Während der Lagerung ist es zu einem erkennbaren Rückgang der Ascorbinsäuregehalte gekommen. Bei der Maleinsäure ist in den ersten vier Monaten Lagerung ein Anstieg der Gehalte und bis zum Ende der Lagerung ein Rückgang messbar gewesen. Die übrigen organischen Säuren zeigen während der 8-monatigen Lagerung keine signifikanten Veränderungen (Tab.18).

Tab. 18 Veränderung der Gehalte der organischen Säuren während der Lagerung (alle Sorten)

\begin{tabular}{|c|c|c|c|c|c|c|c|}
\hline Termin & 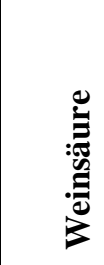 & 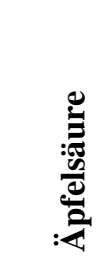 & 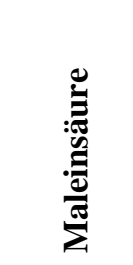 & 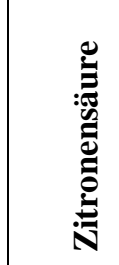 & 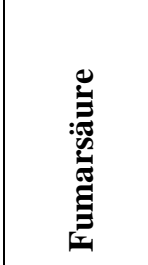 & 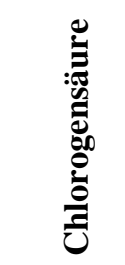 & 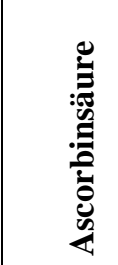 \\
\hline & \multicolumn{7}{|c|}{$\mathrm{g} \mathrm{kg}^{-1} \mathrm{TM}$} \\
\hline $\begin{array}{l}\text { Vor der } \\
\text { Lagerung }\end{array}$ & $\begin{array}{l}1,26 \\
\pm 0,49\end{array}$ & $\begin{array}{l}7,52 \\
\pm 2,33\end{array}$ & $\begin{array}{l}0,0051 \\
\pm 0,0021\end{array}$ & $\begin{array}{l}20,16 \\
\pm 3,56\end{array}$ & $\begin{array}{l}0,023 \\
\pm 0,0097\end{array}$ & $\begin{array}{l}1,15 \\
\pm 0,446\end{array}$ & $\begin{array}{l}0,63 \\
\pm 0,094\end{array}$ \\
\hline $\begin{array}{l}4 \text { Monate } \\
\text { Lagerung }\end{array}$ & $\begin{array}{l}1,06 \\
\pm 0,42\end{array}$ & $\begin{array}{l}7,72 \\
\pm 1,80\end{array}$ & $\begin{array}{l}0,0082 \\
\pm 0,0048\end{array}$ & $\begin{array}{l}19,45 \\
\pm 3,68\end{array}$ & $\begin{array}{l}0,027 \\
\pm 0,0103\end{array}$ & $\begin{array}{l}1,13 \\
\pm 0,352\end{array}$ & $\begin{array}{l}0,44 \\
\pm 0,037\end{array}$ \\
\hline $\begin{array}{l}8 \text { Monate } \\
\text { Lagerung }\end{array}$ & $\begin{array}{l}1,11 \\
\pm 0,44\end{array}$ & $\begin{array}{l}6,98 \\
\pm 2,20\end{array}$ & $\begin{array}{l}0,0067 \\
\pm 0,0034\end{array}$ & $\begin{array}{l}19,08 \\
\pm 3,82\end{array}$ & $\begin{array}{l}0,026 \\
\pm 0,0094\end{array}$ & $\begin{array}{l}1,046 \\
\pm 0,34\end{array}$ & $\begin{array}{l}0,40 \\
\pm 0,054\end{array}$ \\
\hline & n.s. & n.s. & $* * *$ & n.s. & n.s. & n.s. & $* * *$ \\
\hline
\end{tabular}

\subsubsection{Mineralstoffgehalte in Abhängigkeit von der Sorte, der spezifischen Dichte und der Lagerung}

Bei den Mineralstoffgehalten bestehen hoch signifikante Sortenunterschiede. In der Sorte Ponto sind mit Abstand die geringsten Gehalte an Kalium, Calcium, Magnesium, Phosphor, Zink und Mangan nachweisbar. Die Sorte Cilena zeichnet sich durch die höchsten Mineralstoffgehalte aus. Die Mineralstoffgehalte von Solara liegen zwischen den beiden anderen Sorten (Tab.19). 
Tab. 19 Einfluss der Sorte auf den Gehalt an Mineralstoffen

\begin{tabular}{|c|c|c|c|c|c|c|c|c|c|}
\hline Sorten & 声 & 声 & 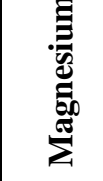 & 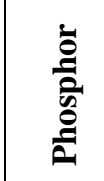 & $\begin{array}{l}\text { 咅 } \\
\text { 穵 }\end{array}$ & 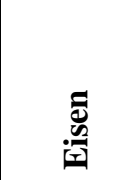 & 离 & 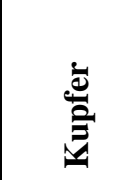 & 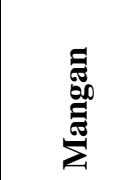 \\
\hline & \multicolumn{9}{|c|}{$\mathrm{g} \mathrm{kg}^{-1} \mathrm{TM}$} \\
\hline Solara & $\begin{array}{l}24,55 \\
\pm 2,63\end{array}$ & $\begin{array}{l}0,18 \\
\pm 0,05\end{array}$ & \begin{tabular}{|l|}
1,07 \\
$\pm 0,15$
\end{tabular} & \begin{tabular}{|l|}
2,21 \\
$\pm 0,30$
\end{tabular} & \begin{tabular}{|l|}
0,14 \\
$\pm 0,08$
\end{tabular} & \begin{tabular}{|l|}
0,040 \\
$\pm 0,043$
\end{tabular} & $\begin{array}{l}0,015 \\
\pm 0,0026\end{array}$ & $\begin{array}{l}0,0106 \\
\pm 0,011\end{array}$ & \begin{tabular}{|l|}
0,0076 \\
$\pm 0,0022$
\end{tabular} \\
\hline Cilena & $\begin{array}{l}26,36 \\
\pm 3,35\end{array}$ & $\begin{array}{l}0,19 \\
\pm 0,06\end{array}$ & $\begin{array}{l}1,08 \\
\pm 0,12\end{array}$ & $\begin{array}{l}2,73 \\
\pm 0,49\end{array}$ & $\begin{array}{l}0,15 \\
\pm 0,09\end{array}$ & $\begin{array}{l}0,048 \\
\pm 0,026\end{array}$ & $\begin{array}{l}0,018 \\
\pm 0,0038\end{array}$ & $\begin{array}{l}0,0108 \\
\pm 0,013\end{array}$ & $\begin{array}{l}0,0110 \\
\pm 0,0036\end{array}$ \\
\hline Ponto & $\begin{array}{l}20,39 \\
\pm 2,51\end{array}$ & $\begin{array}{l}0,17 \\
\pm 0,05\end{array}$ & $\begin{array}{l}0,80 \\
\pm 0,12\end{array}$ & $\begin{array}{l}2,14 \\
\pm 0,01\end{array}$ & $\begin{array}{l}0,27 \\
\pm 0,13\end{array}$ & $\begin{array}{l}0,037 \\
\pm 0,043\end{array}$ & $\begin{array}{l}0,013 \\
\pm 0,0035\end{array}$ & $\begin{array}{l}0,0091 \\
\pm 0,010\end{array}$ & $\begin{array}{l}0,0066 \\
\pm 0,0022\end{array}$ \\
\hline & $* * *$ & n.s. & $* * *$ & $* * *$ & n.s. & n.s. & $* *$ & n.s. & $* * *$ \\
\hline
\end{tabular}

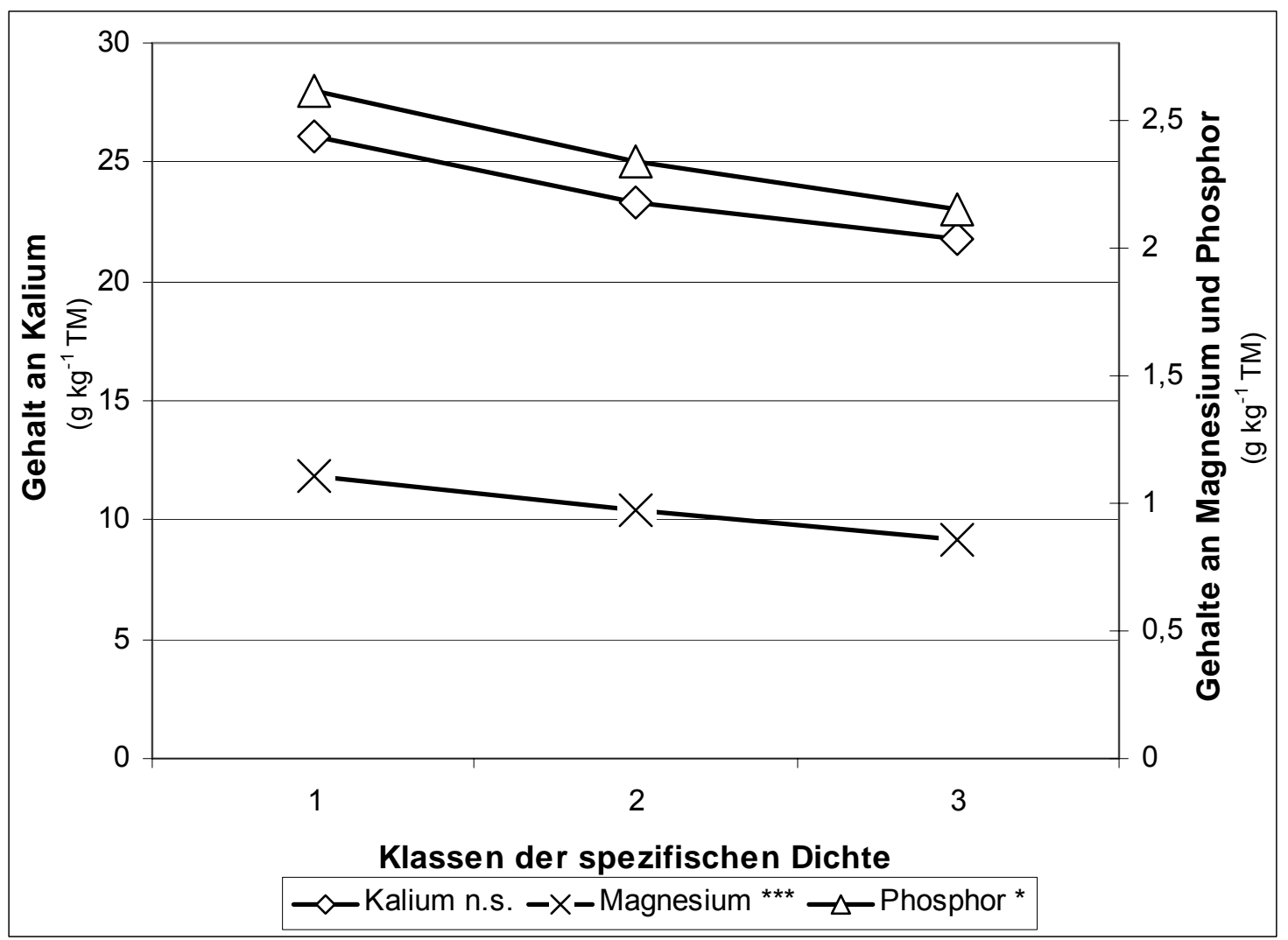

Abb. 14a Beziehung zwischen den Mineralstoffen und der spezifischen Dichte (im Mittel aller Sorten und Termine)

$* \mathrm{p}<0,05 ; * * * \mathrm{p}<0,001 ;$ n.s. $=$ nicht signifikant

Zwischen der spezifischen Dichte und den Mineralstoffen Magnesium und Phosphor besteht eine deutliche Beziehung. Die Gehalte beider Mineralstoffe gehen mit zunehmender 
spezifischer Dichte zurück. Diese Veränderung ist tendenziell auch bei Kalium erkennbar (Tab. 14a).

Bei den übrigen Mineralstoffen ist aufgrund zum Teil sehr hoher Standardabweichungen keine Beziehung zur spezifischen Dichte erkennbar (Abb. 14b). Die im Mittel aller Sorten dargestellten Ergebnisse entsprechen den Ergebnissen der Einzelsorten.

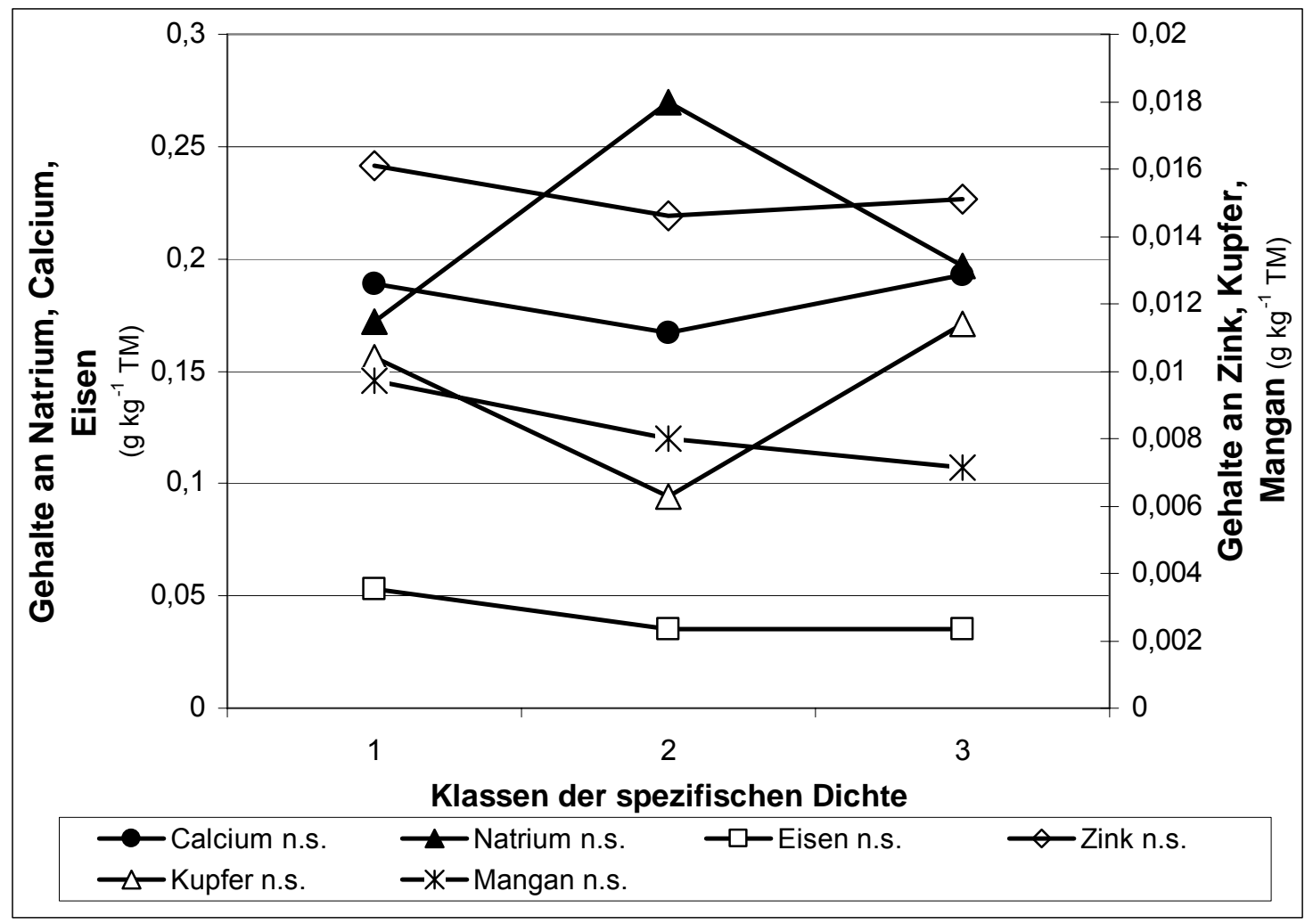

Abb. 14b Beziehung zwischen den Mineralstoffen und der spezifischen Dichte (im Mittel aller Sorten und Termine) n.s.= nicht signifikant

Während der Lagerung ist es lediglich zum Anstieg der Kupfergehalte gekommen. Die übrigen Mineralstoffe verändern sich nicht in ihren Konzentrationen (Tab.20). 
Tab. 20 Veränderung der Gehalte der organischen Säuren während der Lagerung

\begin{tabular}{|c|c|c|c|c|c|c|c|c|c|}
\hline Termin & 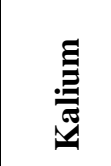 & 声 & 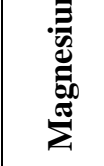 & 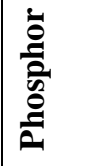 & 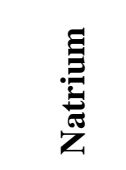 & 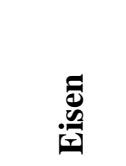 & 莣 & 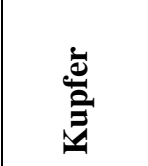 & 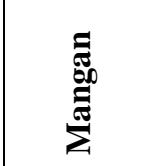 \\
\hline & \multicolumn{9}{|c|}{$\mathrm{g} \mathrm{kg}^{-1} \mathrm{TM}$} \\
\hline $\begin{array}{l}\text { Vor der } \\
\text { Lagerung }\end{array}$ & $\begin{array}{l}23,24 \\
\pm 3,73\end{array}$ & $\begin{array}{l}0,17 \\
\pm 0,04\end{array}$ & $\begin{array}{l}0,92 \\
\pm 0,18\end{array}$ & $\begin{array}{l}2,34 \\
\pm 0,44\end{array}$ & \begin{tabular}{|l|}
0,27 \\
$\pm 0,20$
\end{tabular} & $\begin{array}{l}0,034 \\
\pm 0,019\end{array}$ & $\begin{array}{l}0,014 \\
\pm 0,0029\end{array}$ & $\begin{array}{l}0,0063 \\
\pm 0,0029\end{array}$ & $\begin{array}{l}0,0077 \\
\pm 0,0028\end{array}$ \\
\hline $\begin{array}{l}4 \text { Monate } \\
\text { Lagerung }\end{array}$ & $\begin{array}{l}23,67 \\
\pm 3,74\end{array}$ & $\begin{array}{l}0,18 \\
\pm 0,05\end{array}$ & $\begin{array}{l}1,01 \\
\pm 0,17\end{array}$ & $\begin{array}{l}2,40 \\
\pm 0,42\end{array}$ & $\begin{array}{l}0,13 \\
\pm 0,063\end{array}$ & $\begin{array}{l}0,055 \\
\pm 0,047\end{array}$ & $\begin{array}{l}0,016 \\
\pm 0,0046\end{array}$ & $\begin{array}{l}0,0097 \\
\pm 0,0089\end{array}$ & $\begin{array}{l}0,0087 \\
\pm 0,0035\end{array}$ \\
\hline $\begin{array}{l}8 \text { Monate } \\
\text { Lagerung }\end{array}$ & $\begin{array}{l}24,24 \\
\pm 3,96\end{array}$ & $\begin{array}{l}0,19 \\
\pm 0,07\end{array}$ & $\begin{array}{l}1,01 \\
\pm 0,20\end{array}$ & $\begin{array}{l}2,33 \\
\pm 0,43\end{array}$ & $\begin{array}{l}0,16 \\
\pm 0,079\end{array}$ & $\begin{array}{l}0,036 \\
\pm 0,017\end{array}$ & $\begin{array}{l}0,016 \\
\pm 0,0064 \\
\end{array}$ & $\begin{array}{l}0,0145 \\
\pm 0,0165 \\
\end{array}$ & $\begin{array}{l}0,0087 \\
\pm 0,0037\end{array}$ \\
\hline & n.s. & n.s. & n.s. & n.s. & n.s. & n.s. & n.s. & * & n.s. \\
\hline
\end{tabular}

\subsubsection{Zusammenfassung der Ergebnisse aus dem Vorversuch}

Aus den bereits dargestellten Einzelergebnissen lassen sich nachfolgende Zusammenfassungen bzw. Verknüpfungen erstellen.

Es wird deutlich, dass die Summen der freien Aminosäuren, der untersuchten organischen Säuren und der ermittelten Mineralstoffe in der am stärksten zur Schwarzfleckigkeit neigenden Kartoffelsorte Ponto am geringsten sind. Cilena als Sorte mittlerer Schwarzfleckigkeitsneigung weist die höchste Summe an freien Aminosäuren bzw. Mineralstoffen auf. Bei der Summe der organischen Säuren sind die Sorten Cilena und Solara annähernd gleich (Tab.21).

Tab. 21 Summe einzelner Inhaltsstoffe in den Sorten des Vorversuches

\begin{tabular}{|c|c|c|c|}
\hline \multirow[t]{2}{*}{ Sorte } & \multicolumn{3}{|c|}{ Summe } \\
\hline & Freie Aminosäuren & Organischen Säuren & Mineralstoffe \\
\hline & $\mu \mathrm{g} \mathrm{g}^{-1} \mathrm{TM}$ & \multicolumn{2}{|c|}{$\mathrm{g} \mathrm{kg}^{-1} \mathrm{TM}$} \\
\hline Solara & $3397,2 \pm 273$ & $33,46 \pm 4,3$ & $28,22 \pm 4,8$ \\
\hline Cilena & $4191,2 \pm 733$ & $32,29 \pm 3,8$ & $30,60 \pm 2,7$ \\
\hline Ponto & $2078,1 \pm 289$ & $24,49 \pm 3,2$ & $23,84 \pm 1,9$ \\
\hline & $* * *$ & $*$ & $* *$ \\
\hline
\end{tabular}

Betrachtet man die Summe der freien Aminosäuren genauer, fällt auf, dass die Aminosäure Tyrosin in allen Sorten zu unterschiedlichen prozentualen Anteilen vertreten ist (Tab. 22). Solara enthält am wenigsten Tyrosin, gefolgt von Cilena. Der höchste prozentuale Anteil des Tyrosins an der Summe der freien Aminosäuren ist in der Sorte Ponto nachweisbar. 
Tab. 22 Prozentualer Anteil des Tyrosins an der Summe der freien Aminosäuren in Abhängigkeit von der Sorte

\begin{tabular}{|l|c|}
\hline \multicolumn{1}{|c|}{ Sorte } & Tyrosin \\
\hline & $\%$ \\
\hline Solara & 5,56 \\
\hline Cilena & 6,27 \\
\hline Ponto & 7,38 \\
\hline & $* * *$ \\
\hline$* * * \mathrm{p}<0,001$ &
\end{tabular}

Es gibt jedoch nicht nur sortenspezifische Unterschiede in den Summen einzelner Inhaltsstoffe, sondern auch in Abhängigkeit der Klassen der spezifischen Dichte. Mit zunehmender spezifischer Dichte nehmen sowohl die Summen der freien Aminosäuren und der organischen Säuren als auch die Summe der Mineralstoffe ab (Tab.23).

Tab. 23 Summe einzelner Inhaltsstoffe in Abhängigkeit von der spezifischen Dichte

\begin{tabular}{|l|c|c|c|}
\hline \multirow{2}{*}{$\begin{array}{c}\text { Klassen der } \\
\text { spezifischen Dichte }\end{array}$} & \multicolumn{3}{|c|}{ Summe der } \\
\cline { 2 - 4 } & Freie Aminosäuren & Organischen Säuren & Mineralstoffe \\
\hline & $\mu \mathrm{g} \mathrm{g}^{-1} \mathrm{TM}$ & \multicolumn{2}{|c|}{$\mathrm{g} \mathrm{kg}^{-1} \mathrm{TM}$} \\
\hline 1 & $3931,69 \pm 670$ & $32,63 \pm 3,9$ & $30,30 \pm 2,9$ \\
\hline 2 & $2961,76 \pm 310$ & $29,40 \pm 1,9$ & $27,09 \pm 2,1$ \\
\hline 3 & $2849,88 \pm 438$ & $26,80 \pm 2,7$ & $25,25 \pm 1,8$ \\
\hline & \multicolumn{3}{|c|}{$* *$} \\
\hline$* \mathrm{p}<0,05 ; * * \mathrm{p}<0,01$ & \multicolumn{3}{|c|}{} \\
\hline
\end{tabular}

Darüber hinaus variiert der prozentuale Anteil des Tyrosins an der Summe der freien Aminosäuren in Abhängigkeit von der spezifischen Dichte. Mit zunehmender spezifischer Dichte nimmt auch der prozentuale Anteil des Tyrosins zu (Tab. 24).

Tab. 24 Prozentualer Anteil des Tyrosins an der Summe der freien Aminosäuren in Abhängigkeit von der spezifischen Dichte

\begin{tabular}{|l|c|}
\hline $\begin{array}{c}\text { Klassen der } \\
\text { spezifischen Dichte }\end{array}$ & $\begin{array}{c}\text { Prozentualer Anteil } \\
\text { Tyrosin } \\
\text { an den freien Aminosäuren }\end{array}$ \\
\hline & $\%$ \\
\hline 1 & 5,90 \\
\hline 2 & 6,23 \\
\hline 3 & 7,14 \\
\hline & $* * *$ \\
\hline$* * \mathrm{p}^{2} 0,001$ &
\end{tabular}

Ergänzend zur Einzeldarstellung der organischen Säuren ist in Abb. 15 das ChlorogensäureZitronensäure- Verhältnis in Beziehung zum SF-Index gesetzt. Es wird deutlich, dass Solara 
mit dem geringsten SF- Index (vgl. Abb.6) das kleinste und damit engste ChlorogensäureZitronensäure- Verhältnis aufweist.

Mit zunehmendem SF-Index wird auch das Chlorogensäure- Zitronensäure- Verhältnis größer $(p<0,01)$. Ponto als Sorte mit dem größten SF- Index $(p<0,01)$ hat das größte ChlorogensäureZitronensäure- Verhältnis.

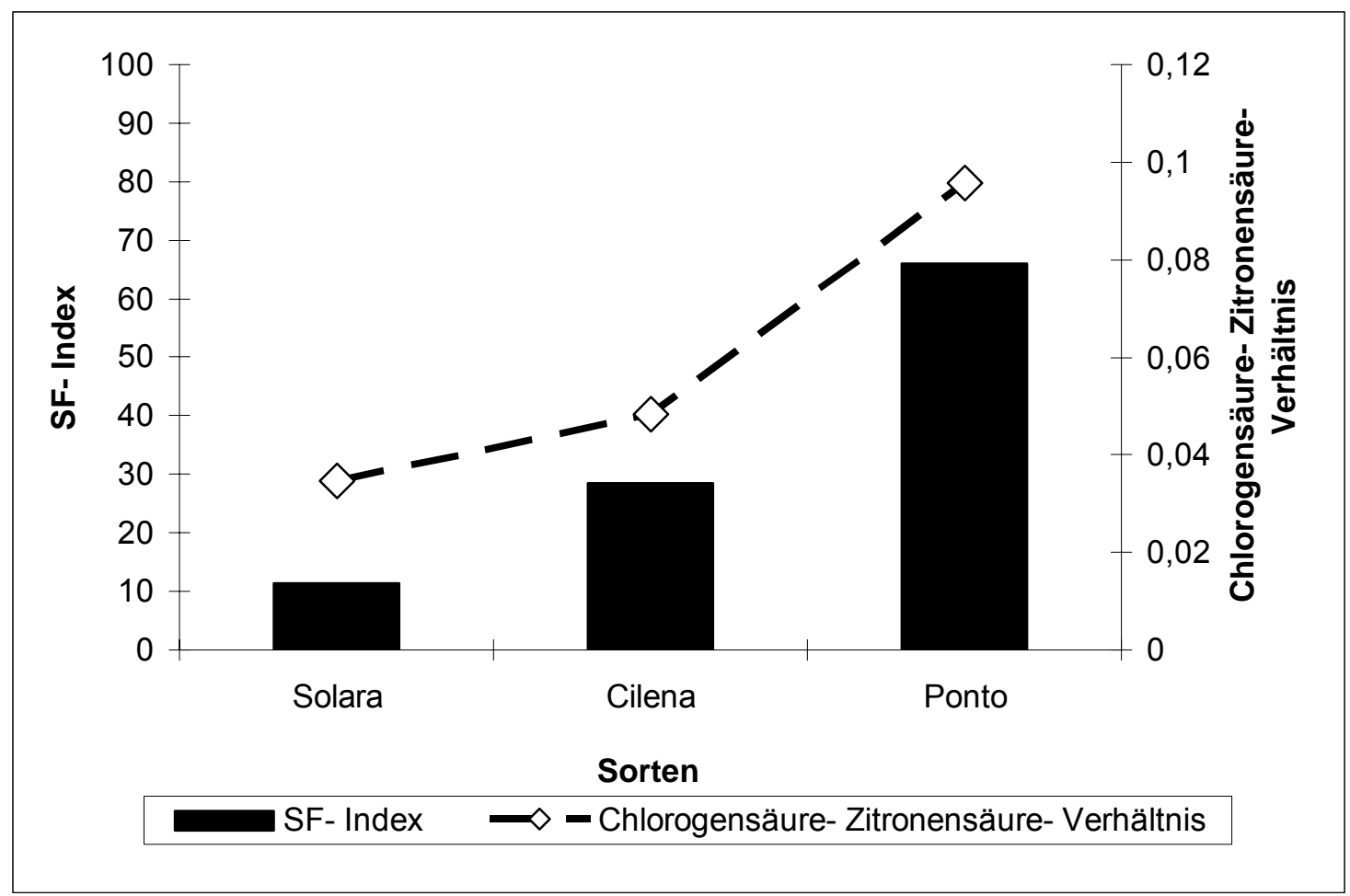

Abb. 15 Beziehung zwischen dem Chlorogensäure- Zitronensäure-Verhältnis und dem SFIndex

Als Abschluss der Zusammenfassung der Ergebnisse des Vorversuches sind in Tab.25 bestehende Korrelationen zwischen dem SF- Index und Inhaltsstoffen dargestellt.

Es ist erkennbar, dass die Mineralstoffe Kalium und Magnesium sowie die organischen Säuren Zitronensäure, Weinsäure und Ascorbinsäure in negativer Korrelation zum SF-Index stehen. Darüber hinaus existiert eine negative Korrelation zwischen PPO und Zitronensäure sowie eine hoch signifikante positive Korrelation zwischen dem SF-Index und der PPO.

Tab. 25 Korrelationen zwischen de SF-Index und Inhaltsstoffen

\begin{tabular}{|l|c|c|c|c|c|c|}
\hline & PPO & Kalium & Magnesium & Zitronensäure & Weinsäure & Ascorbinsäure \\
\hline SF- Index & $0,730^{* * *}$ & $-0,615^{* * *}$ & $-0,589^{* *}$ & $-0,839^{* * *}$ & $-0,595^{* * *}$ & $-0,520^{* * *}$ \\
\hline PPO & & n.s. & n.s. & $-0,721^{* * *}$ & n.s. & n.s. \\
\hline
\end{tabular}




\subsection{Ergebnisse des Hauptversuches}

Nachfolgend werden die Ergebnisse des Hauptversuches, d.h. der Versuchsjahre 2002/2003, dargestellt. Ergänzend zu den Ergebnissen sind die Messergebnisse dem Anhang (Kapitel 10) zu entnehmen. Bei den Enzymen, Aminosäuren und organischen Säuren handelt es sich um verrechneten Daten von Einzelmessungen, bei den Mineralstoffen sind die Mittelwerte aus zwei Einzelmessungen angegeben.

\subsubsection{Beziehung der spezifischen Dichte zur Schwarzfleckigkeit}

Analog zum Vorversuch (vgl. Abb.5) besteht auch im Hauptversuch eine enge Beziehung zwischen Schwarzfleckigkeit und spezifischer Dichte. Je größer die spezifische Dichte ist, desto stärker ist die Ausprägung der Schwarzfleckigkeit (Abb.16).

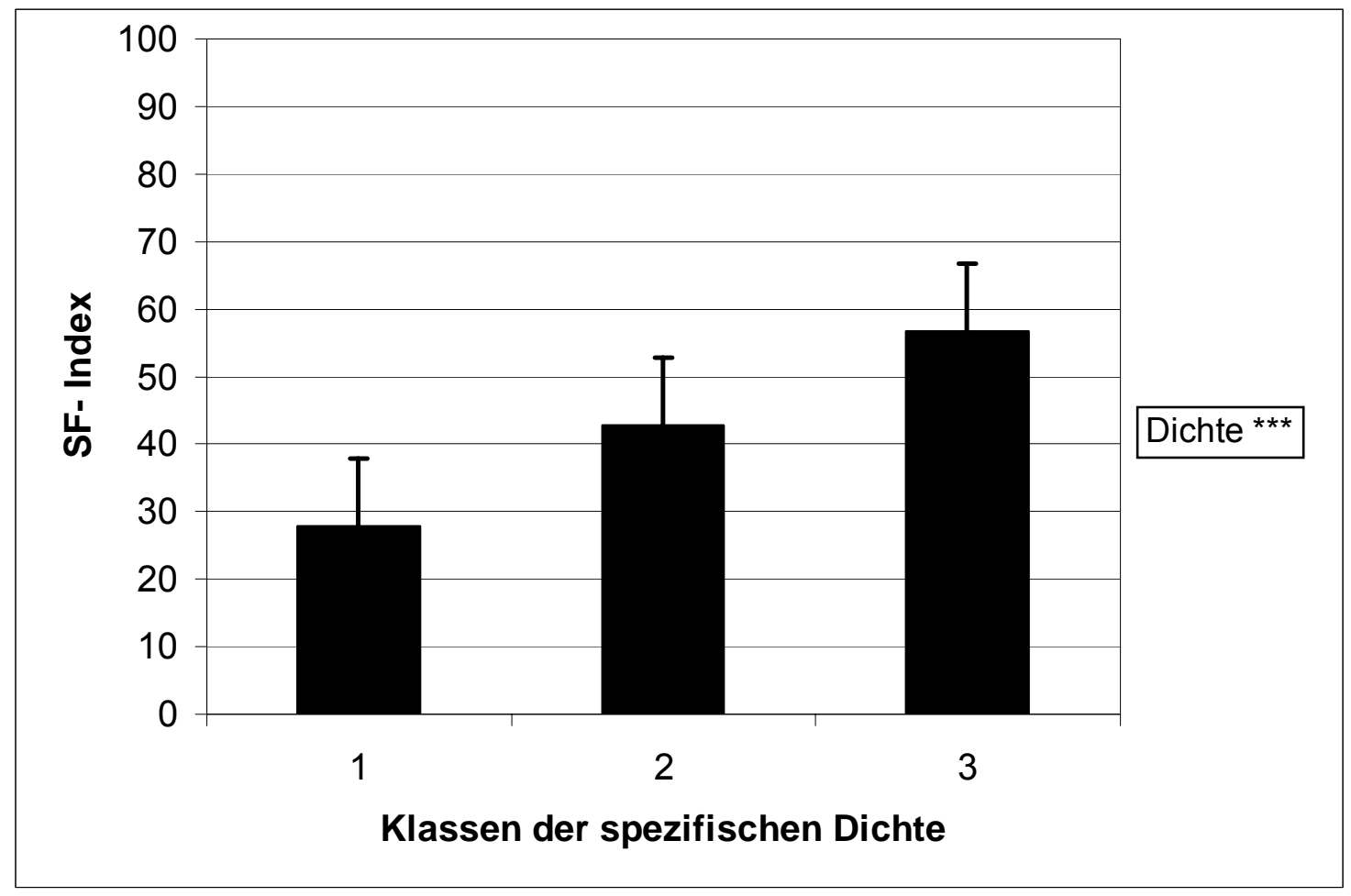

Abb. 16 Beziehung zwischen Schwarzfleckigkeit und spezifischer Dichte (im Mittel aller Sorten und Termine); ${ }^{* * *}<<0,001$

Dieser Zusammenhang prägt sich unabhängig von der Schwarzfleckigkeitsneigung einer Sorte aus. Sowohl bei Aula, der Sorte mit hoher Schwarzfleckigkeitsneigung, als auch bei Quarta, der Sorte mit der geringsten Anfälligkeit für Schwarzfleckigkeit, weist die Dichtefraktion 3 den höchsten SF- Index aus (Abb.17). 


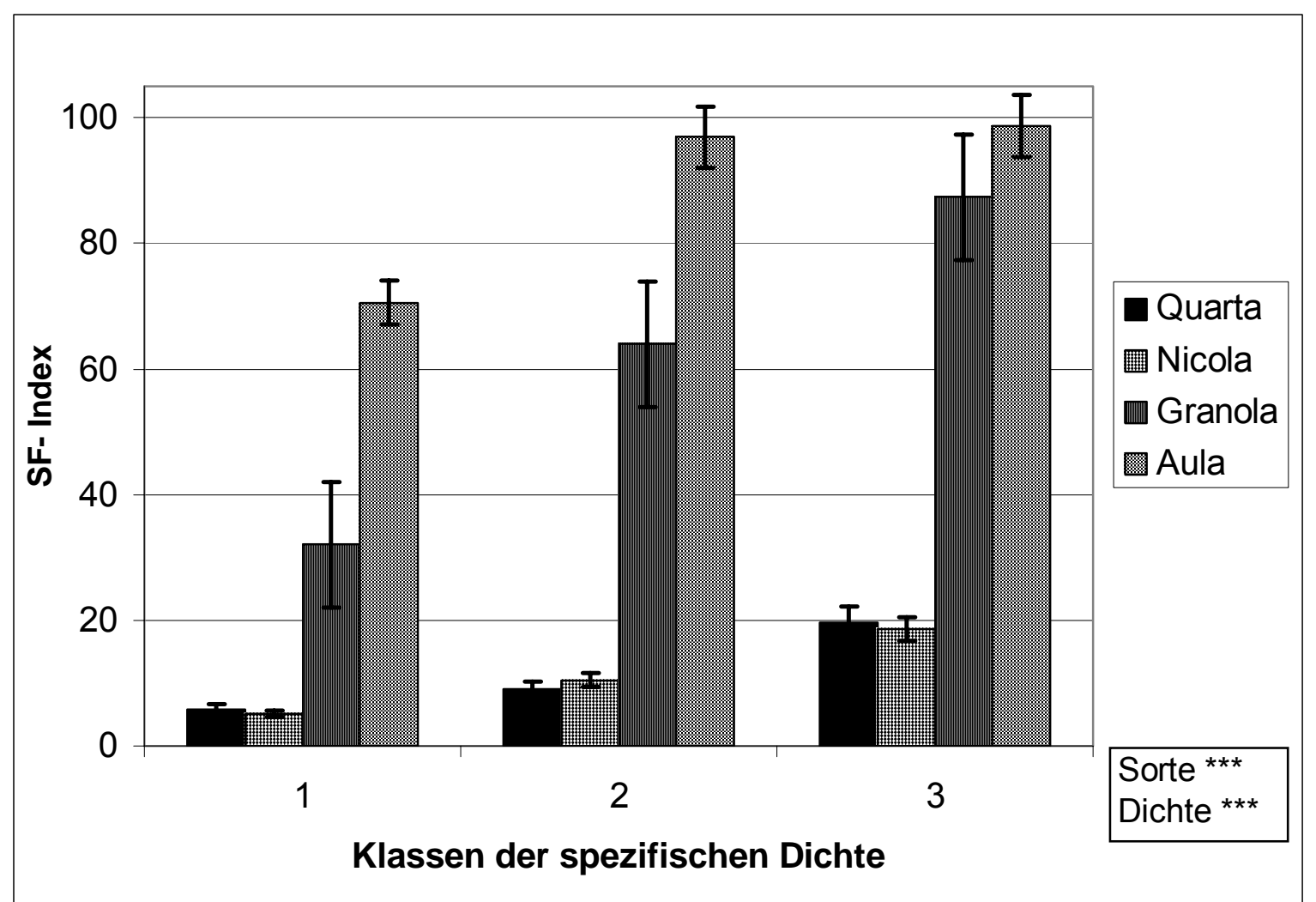

Abb. 17 Beziehung zwischen Schwarzfleckigkeit und der spezifischer Dichte unter Berücksichtigung verschiedener Sorten $* * * \mathrm{p}<0,001$

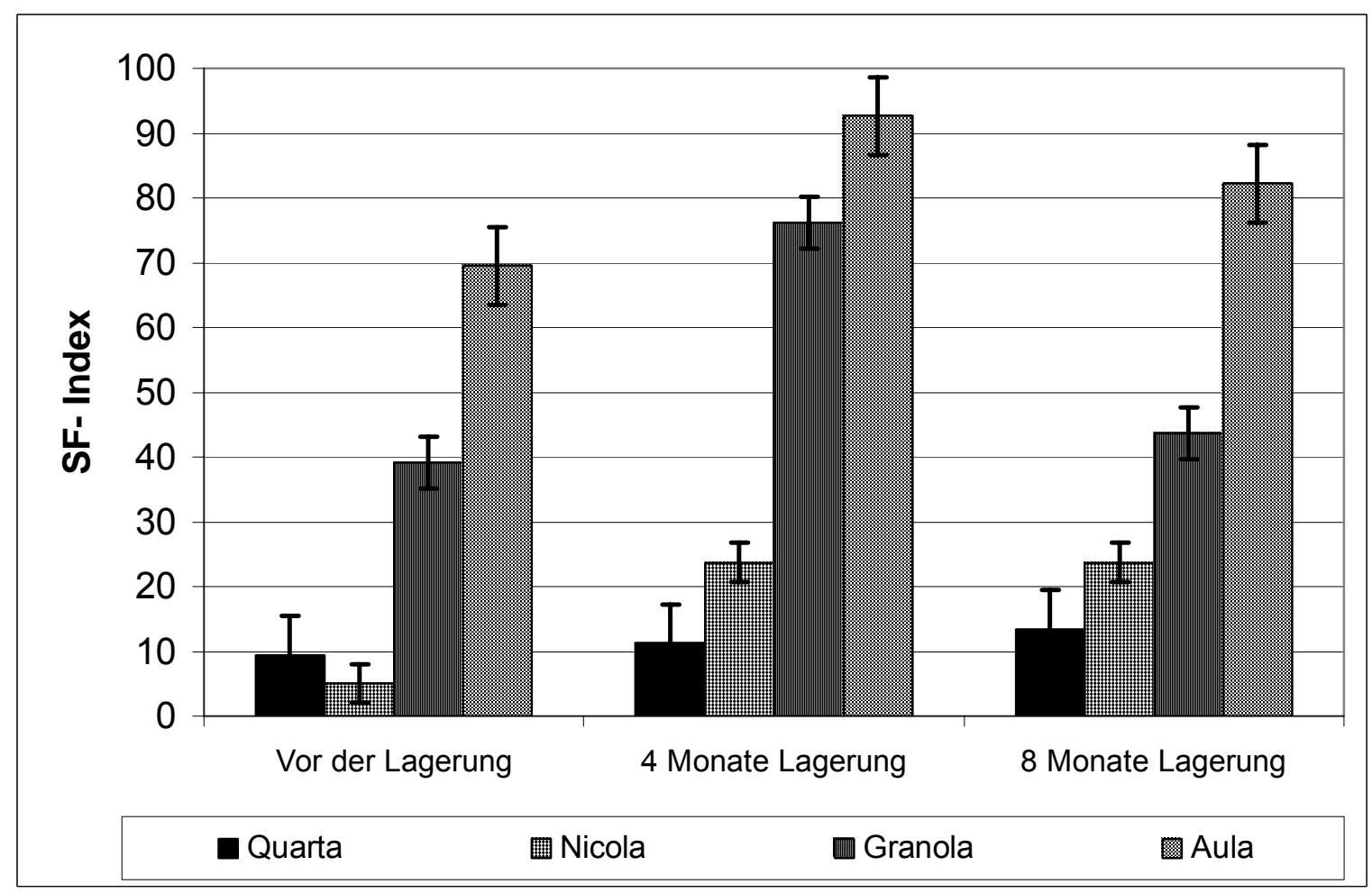

Abb. 18 Veränderung der Schwarzfleckigkeit während der Lagerung unter Berücksichtigung verschiedener Sorten 
Bei den Sorten Aula, Granola und Nicola steigt der SF- Index bis zum 4. Lagermonat signifikant an und geht bis zum Ende der Lagerung nach 8 Monaten zurück $(p<0,01)$. Bei Quarta steigt die Schwarzfleckigkeit über die gesamte Lagerdauer leicht an $(\mathrm{p}<0,05)$.

\subsubsection{Aktivität ausgewählter Enzyme in Abhängigkeit von der Sorte, der spezifischen Dichte und der Lagerung}

\subsubsection{Katalase}

Die Sorten Aula, Granola, Nicola und Quarta unterscheiden sich nicht in der Aktivität der freien CAT. Bei der MA CAT konnte die höchste Aktivität bei Granola, gefolgt von Quarta, Nicola und Aula nachgewiesen werden (Tab.26). Der Unterschied zwischen den zwei Enzymfraktionen, der MA CAT und der freien CAT, besteht in der signifikant höheren Aktivität der MA CAT $(\mathrm{p}<0,05)$.

Tab. 26 Einfluss der Sorte auf die CAT-Aktivität

\begin{tabular}{|l|l|l|l|l|l|}
\hline \multirow{2}{*}{ Sorte } & \multicolumn{3}{c|}{ Freie CAT } & \multicolumn{2}{c|}{ MA CAT } \\
\cline { 2 - 6 } & \multicolumn{3}{c|}{$\Delta$ Aktivität $10 \mathrm{~min}^{-1} \mathrm{mg}$ Protein } & $\mathrm{a}$ \\
\hline Aula & $0,436 \pm 0,0914$ & $\mathrm{a}$ & $0,639 \pm 0,222$ & $\mathrm{~d}$ \\
\hline Granola & $0,452 \pm 0,0858$ & $\mathrm{a}$ & $1,488 \pm 0,953$ & $\mathrm{~b}$ \\
\hline Nicola & $0,397 \pm 0,0895$ & $\mathrm{a}$ & $0,745 \pm 0,061$ & $\mathrm{c}$ \\
\hline Quarta & $0,433 \pm 0,0820$ & $\mathrm{a}$ & $1,030 \pm 0,267$ & \\
\hline \multicolumn{2}{|c|}{ n.s. } & & & $*$ \\
\hline
\end{tabular}

Unterschiedliche Buchstaben kennzeichnen signifikante Unterschiede zwischen den Sorten; n.s. $=$ nicht signifikant; ${ }^{*} \mathrm{p}<0,05$

Unter Berücksichtigung aller vier Sorten des Hauptversuches wurde die Enzymaktivität in Abhängigkeit von der spezifischen Dichte ermittelt (Abb.19). Zwischen den Dichteklassen existieren analog zu den Einzelergebnissen der Sorten keine signifikanten Unterschiede. Bei der MA CAT ist das Ergebnis auf hohe Standardabweichungen, ausgelöst durch besonders stark schwankende Werte der Sorte Granola, zurückzuführen. 


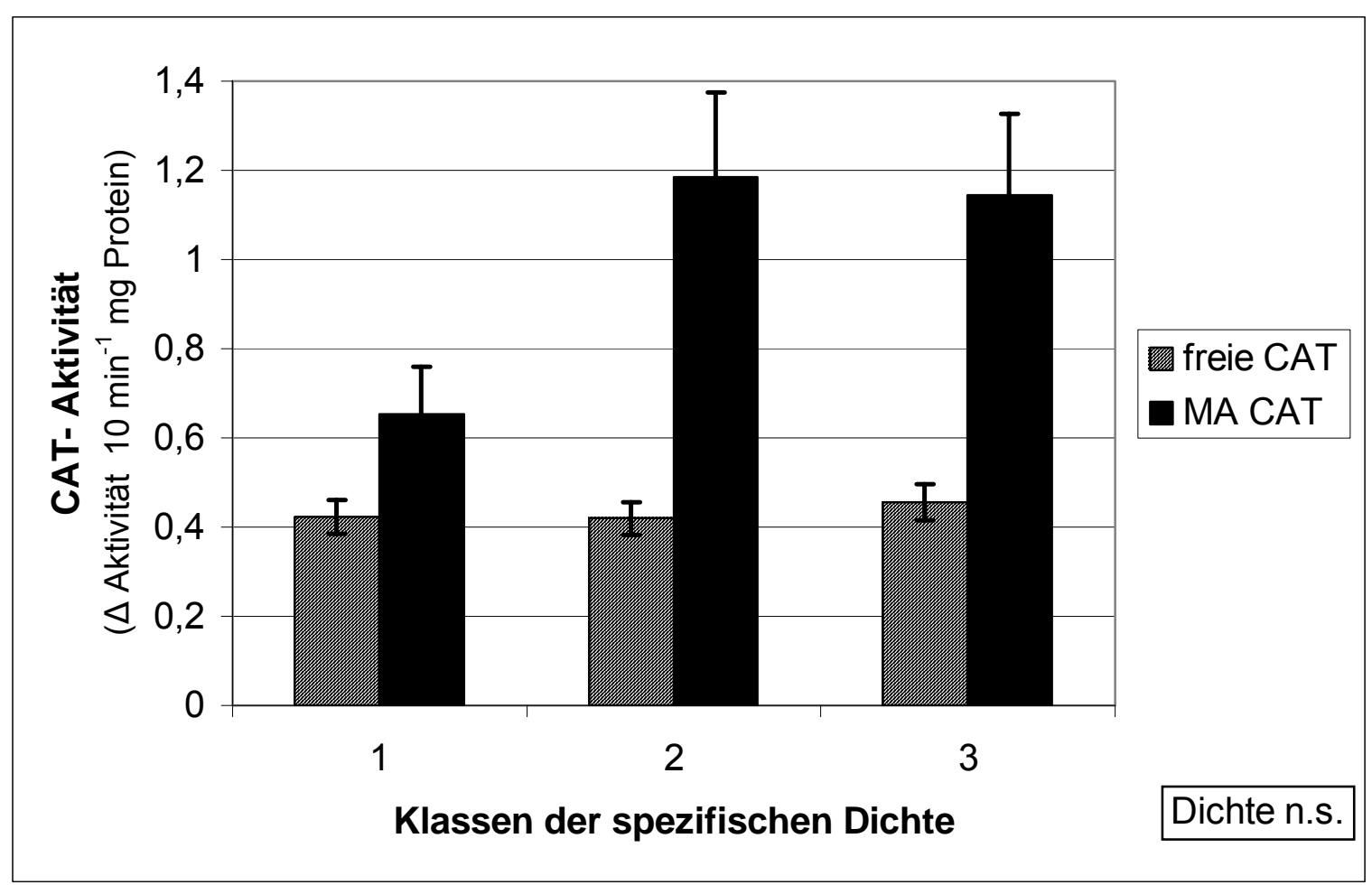

Abb. 19 Beziehung zwischen der CAT-Aktivität und der spezifischen Dichte (im Mittel aller Sorten und Termine)

n.s.= nicht signifikant;

Die Untersuchung der CAT- Aktivität in Abhängigkeit von der Lagerung (Tab.27) hat ergeben, dass die Aktivität der freien CAT während der ersten vier Monate zunächst zurückgeht, ehe sie bis zum Ende der 8-monatigen Lagerung erneut ansteigt, wobei das Ausgangsniveau nicht mehr erreicht wird. Die Aktivität der MA CAT hat sich nicht verändert.

Tab. 27 Veränderung der CAT- Aktivität während der Lagerung (alle Sorten)

\begin{tabular}{|l|l|l|l|l|}
\hline \multirow{2}{*}{ Termin } & \multicolumn{3}{|c|}{ Freie CAT } & MA CAT \\
\cline { 2 - 5 } & $\Delta$ Aktivität $10 \mathrm{~min}^{-1} \mathrm{mg}$ Protein & \\
\hline Vor der Lagerung & $0,473 \pm 0,0962$ & $\mathrm{c}$ & $0,971 \pm 0,0962$ & a \\
\hline 4 Monate Lagerung & $0,391 \pm 0,0720$ & $\mathrm{a}$ & $0,808 \pm 0,0720$ & a \\
\hline 8 Monate Lagerung & $0,422 \pm 0,0770$ & $\mathrm{~b}$ & $1,097 \pm 0,0770$ & a \\
\hline & $* * *$ & n.s. & \\
\hline
\end{tabular}

Unterschiedliche Buchstaben kennzeichnen signifikante Unterschiede zwischen den Sorten;

$* * * \mathrm{p}<0,001 ; \mathrm{n} . \mathrm{s} .=$ nicht signifikant;

\subsubsection{Ascorbat- Peroxidase}

Die freie POD und die MA POD variieren nicht sortenspezifisch (Tab.28). Außerdem gibt es zwischen den beiden Enzymfraktionen keine Aktivitätsunterschiede. 
Tab. 28 Einfluss der Sorte auf die POD- Aktivität

\begin{tabular}{|l|l|l|l|l|}
\hline \multirow{2}{*}{ Sorte } & \multicolumn{3}{c|}{ Freie POD } & \multicolumn{2}{c|}{ MA POD } \\
\cline { 2 - 5 } & $0,00262 \pm 0,000935$ & $\mathrm{a}$ & $0,00358 \pm 0,000988$ & $\mathrm{a}$ \\
\hline Aula & $0,00322 \pm 0,00146$ & $\mathrm{a}$ & $0,01040 \pm 0,00740$ & $\mathrm{a}$ \\
\hline Granola & $0,00306 \pm 0,00153$ & $\mathrm{a}$ & $0,00443 \pm 0,000381$ & $\mathrm{a}$ \\
\hline Nicola & $0,00303 \pm 0,00112$ & $\mathrm{a}$ & $0,00474 \pm 0,000367$ & $\mathrm{a}$ \\
\hline Quarta & n.s. & & \multicolumn{2}{c|}{ n.s. } \\
\hline
\end{tabular}

Unterschiedliche Buchstaben kennzeichnen signifikante Unterschiede zwischen den Sorten; n.s.= nicht signifikant;

Bei der Betrachtung der POD- Aktivität in Abhängigkeit von der spezifischen Dichte sind sowohl bei der freien als auch der MA POD keine signifikanten Unterschiede zwischen den Klassen der spezifischen Dichte messbar. Die MA POD scheint in der Dichtefraktion 2 die höchste Aktivität zu zeigen. Doch unterliegen die Ergebnisse, ausgelöst durch die großen Standardabweichungen bei der Sorte Granola, großen Schwankungen, so dass die Ergebnisse keine Signifikanzen ergeben (Abb.20).

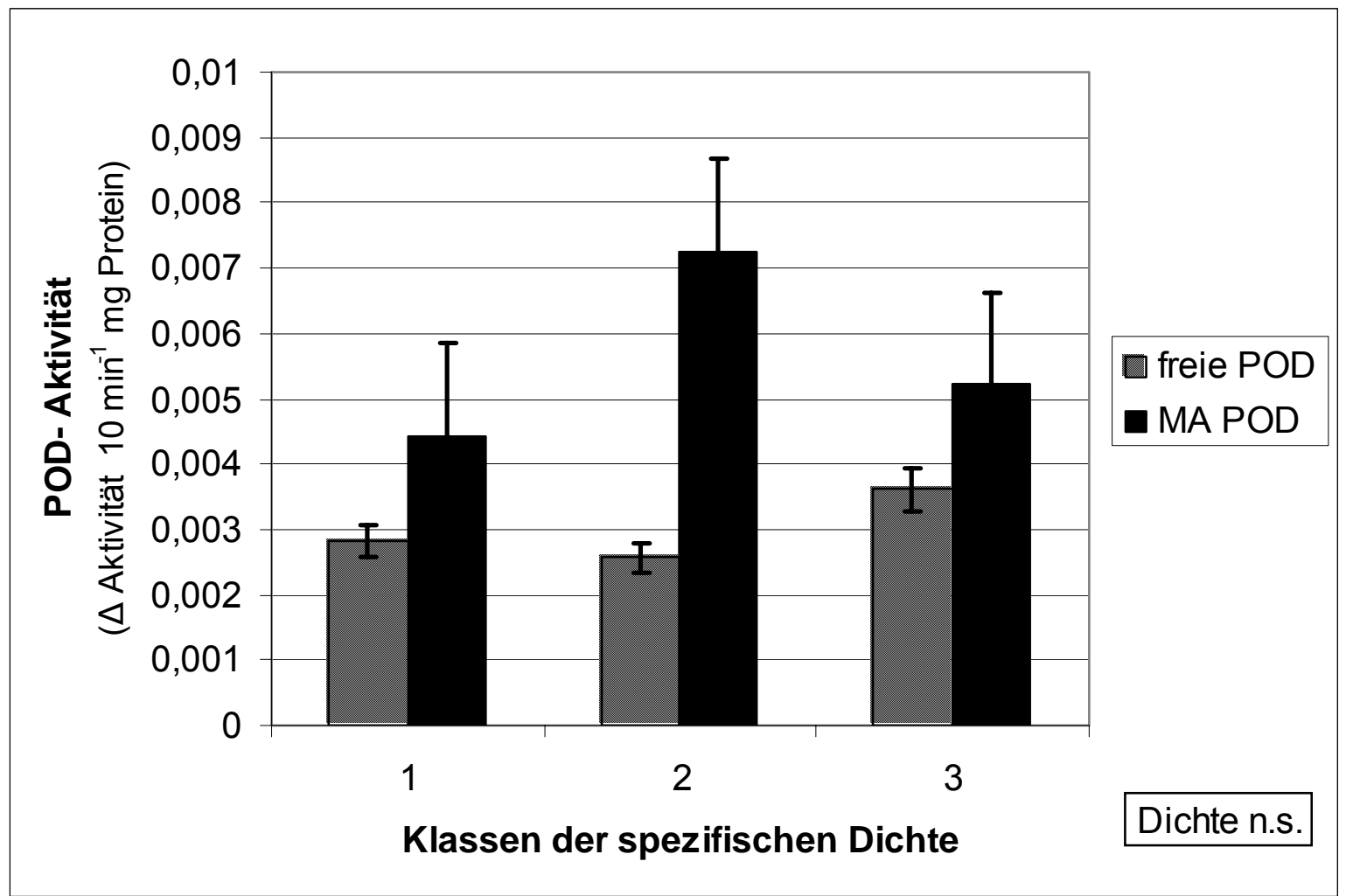

Abb. 20 Beziehung zwischen der POD- Aktivität und der spezifischen Dichte (im Mittel aller Sorten und Termine)

n.s.= nicht signifikant;

Die Aktivität der freien bzw. MA POD variiert während der Lagerdauer von 8 Monaten nicht signifikant (Tab.29). 
Tab. 29 Veränderung der POD- Aktivität während der Lagerung (alle Sorten)

\begin{tabular}{|l|l|l|l|l|}
\hline \multirow{2}{*}{ Termin } & \multicolumn{3}{c|}{ Freie POD } & \multicolumn{2}{c|}{ MA POD } \\
\cline { 2 - 6 } & \multicolumn{3}{|c|}{$\Delta$ Aktivität $10 \mathrm{~min}^{-1}$ mg Protein } \\
\hline Vor der Lagerung & $0,00285 \pm 0,00120$ & $\mathrm{a}$ & $0,00551 \pm 0,00158$ & $\mathrm{a}$ \\
\hline 4 Monate Lagerung & $0,00346 \pm 0,00170$ & $\mathrm{a}$ & $0,00521 \pm 0,00145$ & $\mathrm{a}$ \\
\hline 8 Monate Lagerung & $0,00269 \pm 0,000977$ & $\mathrm{a}$ & $0,00618 \pm 0,00149$ & $\mathrm{a}$ \\
\hline \multicolumn{2}{|c|}{ n.s. } & n.s. & \\
\hline
\end{tabular}

Unterschiedliche Buchstaben kennzeichnen signifikante Unterschiede zwischen den Sorten; n.s.= nicht signifikant;

\subsubsection{Lipoxygenase}

Bei der freien LOX und der MA LOX haben sich signifikante Sortenunterschiede ergeben. Die Sorte Nicola hat in beiden Enzymfraktionen die geringste LOX- Aktivität. Die höchste Aktivität konnte bei der Sorte Granola nachgewiesen werden, gefolgt von Aula und Quarta (Tab.30).

Tab. 30 Einfluss der Sorte auf die LOX-Aktivität

\begin{tabular}{|l|l|l|l|l|}
\hline \multirow{2}{*}{ Sorte } & \multicolumn{3}{c|}{ Freie LOX } & \multicolumn{2}{c|}{ MA LOX } \\
\cline { 2 - 5 } & \multicolumn{3}{|c|}{$\left(\Delta\right.$ Aktiviät mmol sec $^{-1}$ mg Protein $)$} & a \\
\hline Aula & $0,0264 \pm 0,00526$ & b & $0,0409 \pm 0,0159$ & d \\
\hline Granola & $0,0337 \pm 0,0134$ & d & $0,100 \pm 0,0480$ & b \\
\hline Nicola & $0,0255 \pm 0,00780$ & a & $0,0539 \pm 0,0367$ & c \\
\hline Quarta & $0,0272 \pm 0,00548$ & c & $0,0818 \pm 0,0491$ & ${ }^{*}$ \\
\hline \multicolumn{7}{|c|}{$*$} & \\
\hline
\end{tabular}

Darüber hinaus besteht zwischen der freien und der MA LOX ein signifikanter Unterschied in der Enzymaktivität $(\mathrm{p}<0,05)$.

Die Untersuchung der Enzymaktivitäten in Abhängigkeit von der spezifischen Dichte hat dagegen bei allen Sorten keine signifikanten Unterschiede zwischen den Dichtefraktionen ergeben (Abb.21).

Die Ergebnisse der freien LOX sind dabei graphisch eindeutig, bei der MA LOX hat es den Anschein, dass die Dichtefraktionen 2 und 3 ein signifikant höheres Aktivitätsniveau als die Dichtefraktion 1 erreichen. Dieser Eindruck entsteht durch die Einbeziehung der zum Teil stark schwankenden Ergebnisse der Sorten Granola und Quarta. Dennoch besteht bei der MA LOX kein signifikanter Unterschied zwischen den Dichtefraktionen. 


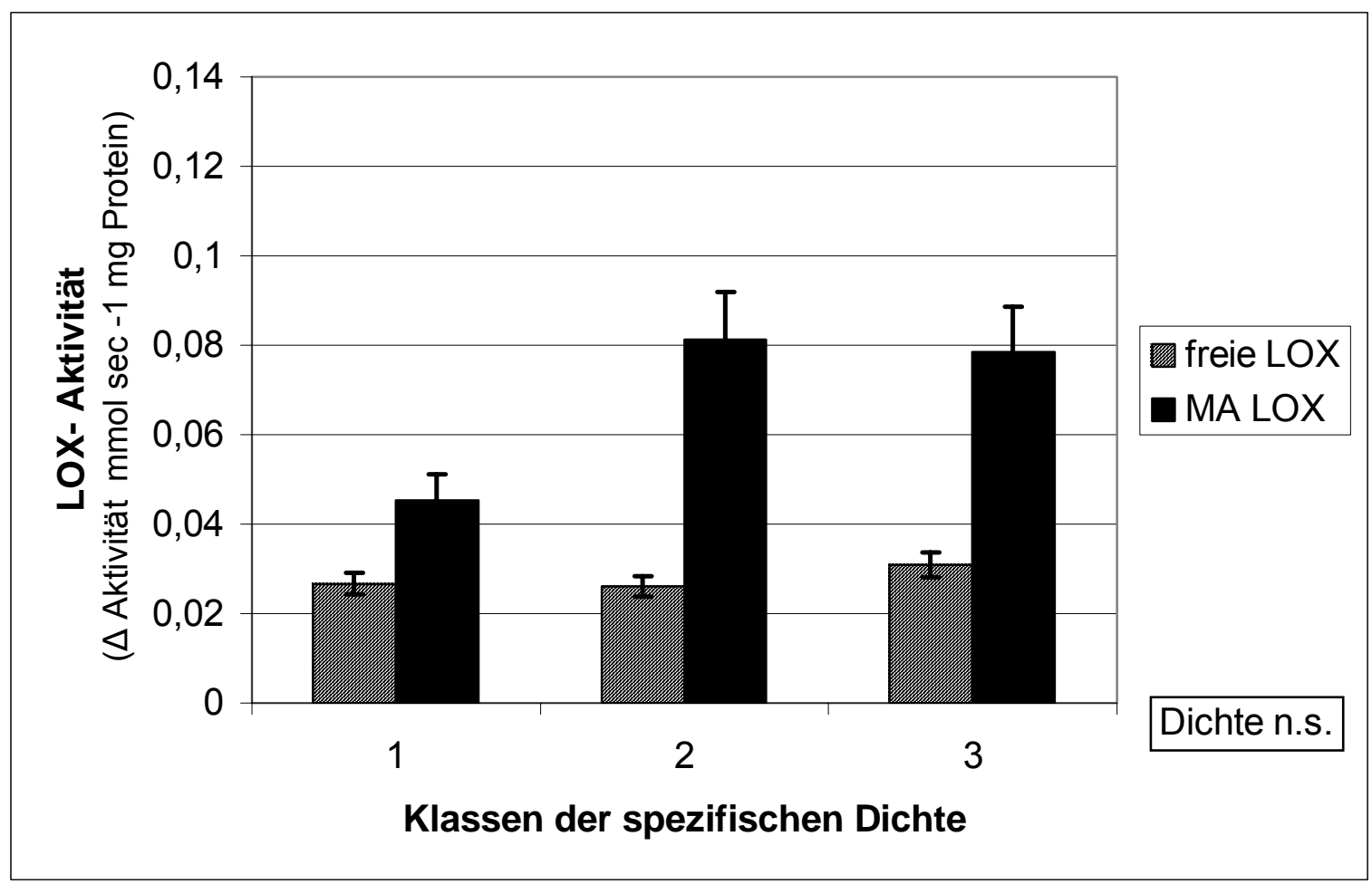

Abb. 21 Beziehung zwischen der LOX-Aktivität und der spezifischen Dichte (im Mittel aller Sorten und Termine)

n.s.= nicht signifikant;

Während im Vorversuch ein Rückgang der Aktivität der freien LOX während der Lagerung nur tendenziell erkennbar gewesen ist, ist im Hauptversuch ein signifikanter Rückgang ermittelbar (Tab.31).

Die Aktivität der MA LOX verhält sich analog zum Vorversuch. Während der ersten vier Lagermonate geht die Aktivität tendenziell zurück, ehe sie nach 8 Monaten das Ausgangsniveau wieder erreicht.

Tab. 31 Veränderung der LOX-Aktivität während der Lagerung (alle Sorten)

\begin{tabular}{|l|l|l|l|l|}
\hline \multirow{2}{*}{ Termin } & \multicolumn{3}{c|}{ Freie LOX } & \multicolumn{2}{c|}{ MA LOX } \\
\cline { 2 - 6 } & \multicolumn{4}{c|}{$\left(\Delta\right.$ Aktivität mmol sec $^{-1}$ mg Protein $)$} \\
\hline Vor der Lagerung & $0,0314 \pm 0,0114$ & $\mathrm{c}$ & $0,0711 \pm 0,01612$ & $\mathrm{a}$ \\
\hline 4 Monate Lagerung & $0,0263 \pm 0,00756$ & $\mathrm{~b}$ & $0,0549 \pm 0,01423$ & $\mathrm{a}$ \\
\hline 8 Monate Lagerung & $0,0251 \pm 0,00498$ & $\mathrm{a}$ & $0,0754 \pm 0,02685$ & $\mathrm{a}$ \\
\hline & \multicolumn{2}{|c|}{$* *$} & \multicolumn{2}{c|}{ n.s. } \\
\hline
\end{tabular}

Unterschiedliche Buchstaben kennzeichnen signifikante Unterschiede zwischen den Sorten;

$*^{*} \mathrm{p}<0,01 ; \mathrm{n} . \mathrm{s} .=$ nicht signifikant; 


\subsubsection{Superoxiddismutase}

Zwischen den Sorten Aula, Granola, Nicola und Quarta bestehen keine signifikanten Unterschiede in der Aktivität der freien und MA SOD. Bei der MA SOD führen schwankende Ergebnisse der Sorte Granola zu großen Standardabweichungen (Tab.32).

Tab. 32 Einfluss der Sorte auf die SOD-Aktivität

\begin{tabular}{|l|l|l|r|l|l|}
\hline \multirow{2}{*}{ Sorte } & \multicolumn{3}{c|}{ Freie SOD } & \multicolumn{2}{c|}{ MA SOD } \\
\cline { 2 - 6 } & \multicolumn{3}{|c|}{$\Delta$ Aktivität $\mathrm{mg}^{-1}$ Protein } & $\mathrm{a}$ \\
\hline Aula & $5,538 \pm 1,930$ & $\mathrm{a}$ & $8,758 \pm 3,751$ & $\mathrm{a}$ \\
\hline Granola & $5,873 \pm 2,893$ & $\mathrm{a}$ & $25,705 \pm 15,076$ & $\mathrm{a}$ \\
\hline Nicola & $5,471 \pm 2,491$ & $\mathrm{a}$ & $13,184 \pm 8,704$ & $\mathrm{a}$ \\
\hline Quarta & $5,746 \pm 2,208$ & $\mathrm{a}$ & $15,248 \pm 9,786$ & n.s. \\
\hline \multicolumn{2}{|c|}{ n.s. } & & \multicolumn{2}{c}{} \\
\hline
\end{tabular}

Unterschiedliche Buchstaben kennzeichnen signifikante Unterschiede zwischen den Sorten; n.s.= nicht signifikant;

Zwischen den Enzymfraktionen lässt sich ein signifikanter Unterschied ermitteln. Die MA SOD hat eine höhere Aktivität als die freie SOD $(p<0,05)$.

Unter Berücksichtigung der Klassen der spezifischen Dichte ist bei der MA SOD eine zunehmende Aktivität bei zunehmender spezifischer Dichte messbar. Die Aktivität der freien SOD variiert entsprechend den Einzelergebnissen der Sorten nicht (Abb.22).

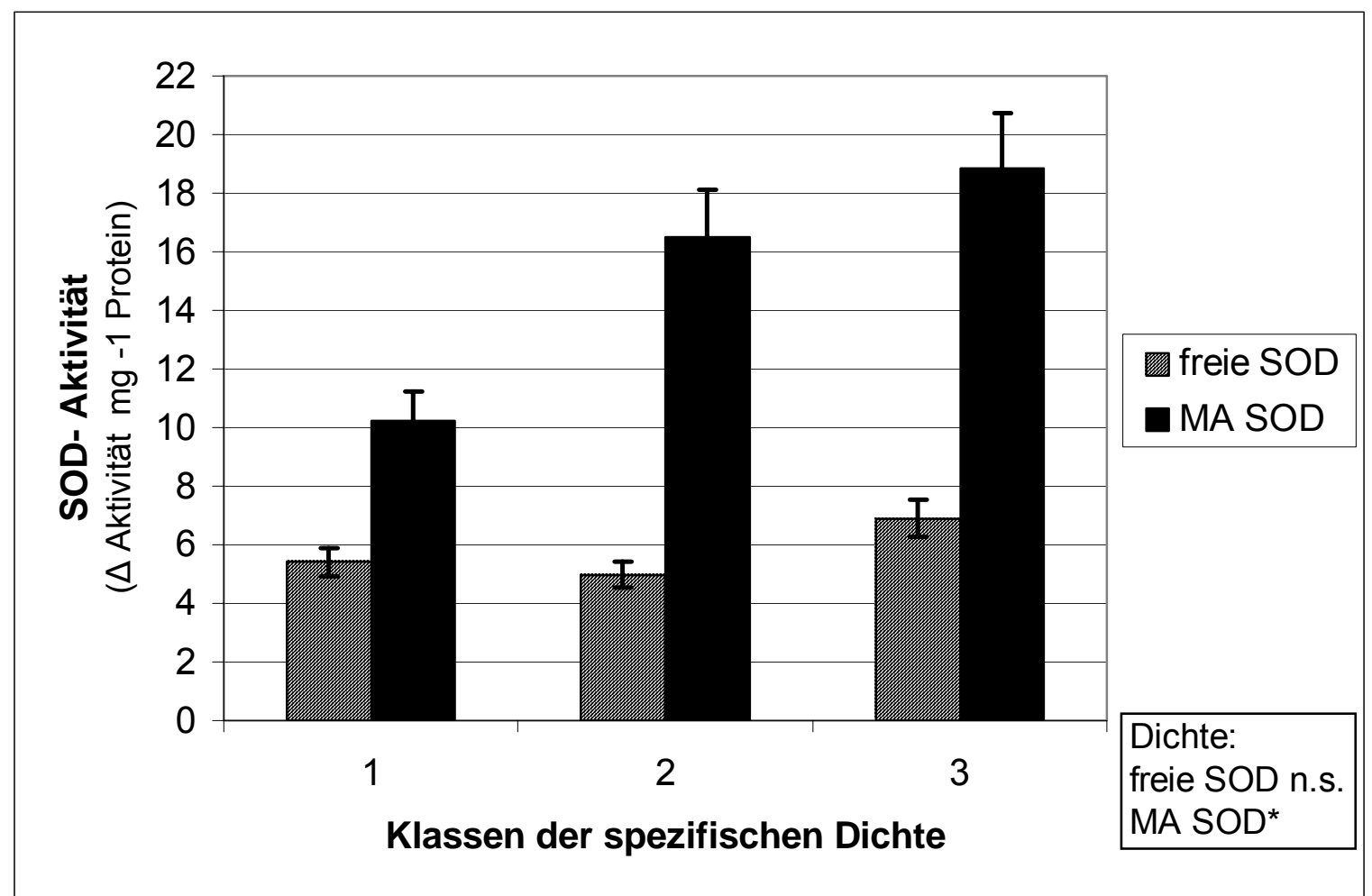

Abb. 22 Beziehung zwischen der SOD- Aktivität und der spezifischen Dichte (im Mittel aller Sorten und Termine)

$* \mathrm{p}<0,05 ; \quad$ n.s. $=$ nicht signifikant 
Während der Lagerung kommt es zu signifikanten Veränderungen in der SOD- Aktivität. Kennzeichnend für beide Enzymfraktionen ist, dass die SOD- Aktivität im ersten Lagerabschnitt zunächst zurückgeht. Am Ende der 8-monatigen Lagerung ist die Aktivität jedoch deutlich über dem Ausgangsniveau (Tab.33).

Tab. 33 Veränderung der SOD- Aktivität während der Lagerung (alle Sorten)

\begin{tabular}{|c|c|c|c|c|}
\hline \multirow[t]{2}{*}{ Termin } & \multicolumn{2}{|c|}{ Freie SOD } & \multicolumn{2}{|c|}{ MA SOD } \\
\hline & \multicolumn{4}{|c|}{$\Delta$ Aktivität $\mathrm{mg}^{-1}$ Protein } \\
\hline Vor der Lagerung & $5,191 \pm 1,774$ & $\mathrm{~b}$ & $15,311 \pm 6,014$ & $b$ \\
\hline 4 Monate Lagerung & $5,035 \pm 2,786$ & $\mathrm{a}$ & $11,799 \pm 8,757$ & $\mathrm{a}$ \\
\hline 8 Monate Lagerung & $6,723 \pm 2,074$ & $\mathrm{c}$ & $19,094 \pm 10,66$ & $\mathrm{c}$ \\
\hline & \multicolumn{2}{|l|}{ 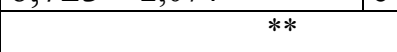 } & \multicolumn{2}{|l|}{$*$} \\
\hline
\end{tabular}

\subsubsection{Polyphenoloxidase}

Die Untersuchung der PPO wurde im Hauptversuch nur noch an den zwei Sorten Aula und Quarta, den Sorten mit der höchsten und geringsten Schwarzfleckigkeitsneigung, durchgeführt. Damit findet die nachfolgende Darstellung der PPO- Aktivität in Abhängigkeit von der Sorte, der spezifischen Dichte und der Lagerung nur anhand der Sorten Aula und Quarta statt.

Zwischen beiden Sorten existiert ein signifikanter Unterschied in der Aktivität der PPO. Aula weist eine mehr als doppelt so hohe Aktivität der PPO auf (Tab.34).

Tab. 34 Einfluss der Sorte auf die PPO- Aktivität

\begin{tabular}{|l|l|l|}
\hline \multirow{2}{*}{ Sorte } & \multicolumn{2}{c|}{ PPO } \\
\cline { 2 - 3 } & \multicolumn{2}{|c|}{$\Delta \mathrm{E} \mathrm{min}^{-1} \mathrm{~g}^{-1} \mathrm{FM}$} \\
\hline Aula & $1,294 \pm 0,134$ & $\mathrm{~b}$ \\
\hline Granola & liegt nicht vor & - \\
\hline Nicola & liegt nicht vor & - \\
\hline Quarta & $0,459 \pm 0,0735$ & $\mathrm{a}$ \\
\hline \multicolumn{2}{|c|}{$* * *$} \\
\hline $\begin{array}{l}\text { Unterschiedliche Buchstaben kennzeichnen signifikante Unterschiede zwischen } \\
\text { den Sorten; *** }<0,001\end{array}$ \\
\hline
\end{tabular}

Zwischen den Klassen der spezifischen Dichte variiert die PPO- Aktivität jedoch nicht (Abb.23). 


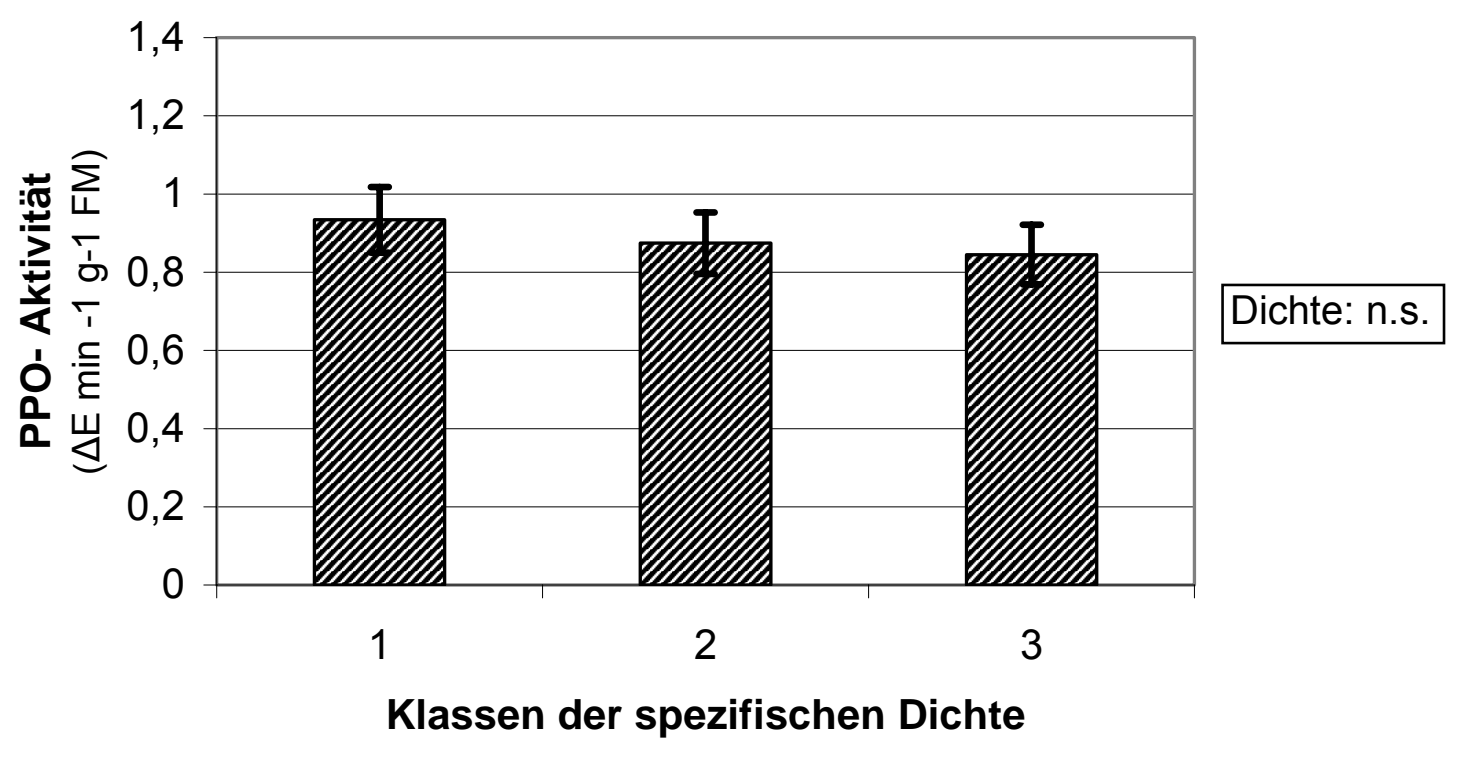

Abb. 23 Beziehung zwischen der PPO- Aktivität und der spezifischen Dichte (Sorte: Aula, Quarta) n.s. = nicht signifikant

Darüber hinaus bleibt die Aktivität der PPO während der Lagerung annähernd unverändert (Tab.35).

Tab. 35 Veränderung der PPO- Aktivität während der Lagerung (Sorten: Aula, Quarta)

\begin{tabular}{|l|l|l|}
\hline \multirow{2}{*}{ Termin } & \multicolumn{2}{|c|}{ PPO } \\
\cline { 2 - 3 } & \multicolumn{2}{|c|}{$\Delta \mathrm{E} \mathrm{min}^{-1} \mathrm{~g}^{-1} \mathrm{FM}$} \\
\hline Vor der Lagerung & $0,946 \pm 0,482$ & $\mathrm{a}$ \\
\hline 4 Monate Lagerung & $0,886 \pm 0,433$ & $\mathrm{a}$ \\
\hline 8 Monate Lagerung & $0,798 \pm 0,403 \quad$ n.s. \\
\hline \multicolumn{2}{|c|}{$\mathrm{a}$} \\
\hline $\begin{array}{l}\text { Unterschiedliche Buchstaben kennzeichnen signifikante Unterschiede } \\
\text { zwischen den Sorten; n.s.= nicht signifikant }\end{array}$ \\
\hline
\end{tabular}

\subsubsection{Gehalt freier Aminosäuren in Abhängigkeit von der Sorte, der spezifischen Dichte und der Lagerung}

Die Gehalte der freien Aminosäuren Prolin, Serin, Arginin, Threonin, Alanin und Leucin variieren sortenspezifisch. Dabei ist auffällig, dass Quarta- mit Ausnahme von Prolin- stets die höchsten Gehalte aufweist. In Granola sind stets die geringsten Gehalte messbar. Bei Prolin befinden sich die höchsten Gehalte in der Sorte Nicola, die geringsten in Quarta.

Auffällig ist, dass die Sorte Aula kontinuierlich in allen Aminosäuren nach Granola die zweitgeringsten Gehalte aufweist. Bei den übrigen Aminosäuren sind die geschilderten sortenspezifischen Gehalte tendenziell erkennbar (Tab.36a\& b). 
Tab. 36a Einfluss der Sorte auf den Gehalt an freien Aminosäuren

\begin{tabular}{|c|c|c|c|c|c|c|c|c|}
\hline Sorten & : & 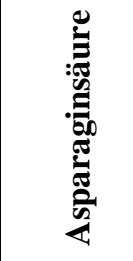 & 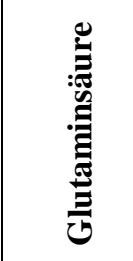 & מू & 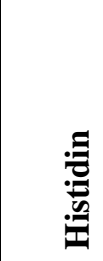 & 畐 & 咅 & 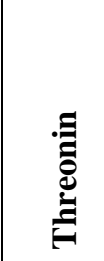 \\
\hline & \multicolumn{8}{|c|}{$\mu \mathrm{g} \mathrm{g}^{-1} \mathrm{TM}$} \\
\hline Aula & $\begin{array}{l}754,7 \\
\pm 236,5\end{array}$ & \begin{tabular}{|l|}
610,9 \\
$\pm 372,4$
\end{tabular} & $\begin{array}{l}240,5 \\
\pm 88,0\end{array}$ & \begin{tabular}{|l|}
58,1 \\
$\pm 32,5$
\end{tabular} & \begin{tabular}{|l|}
33,7 \\
$\pm 7,6$
\end{tabular} & $\begin{array}{l}232,0 \\
\pm 44,3\end{array}$ & $\begin{array}{l}32,6 \\
\pm 18,3\end{array}$ & \begin{tabular}{|l}
44,9 \\
$\pm 29,5$
\end{tabular} \\
\hline Granola & $\begin{array}{l}879,1 \\
\pm 145,7\end{array}$ & \begin{tabular}{|l|}
573,3 \\
$\pm 469,1$
\end{tabular} & $\begin{array}{l}226,9 \\
\pm 88,1\end{array}$ & \begin{tabular}{|l}
38,7 \\
$\pm 20,4$
\end{tabular} & $\begin{array}{l}33,9 \\
\pm 9,9\end{array}$ & $\begin{array}{l}195,1 \\
\pm 48,4\end{array}$ & $\begin{array}{l}26,4 \\
\pm 20,2\end{array}$ & \begin{tabular}{|l}
34,6 \\
$\pm 29,1$
\end{tabular} \\
\hline Nicola & $\begin{array}{l}951,5 \\
\pm 260,2\end{array}$ & $\begin{array}{l}737,6 \\
\pm 455,3\end{array}$ & $\begin{array}{l}285,4 \\
\pm 124,6\end{array}$ & \begin{tabular}{|l|}
67,5 \\
$\pm 29,6$
\end{tabular} & \begin{tabular}{|l}
45,6 \\
$\pm 12,4$
\end{tabular} & $\begin{array}{l}337,2 \\
\pm 68,0\end{array}$ & $\begin{array}{l}38,3 \\
\pm 23,6\end{array}$ & \begin{tabular}{|l|}
64,9 \\
$\pm 53,3$
\end{tabular} \\
\hline Quarta & $\begin{array}{l}724,1 \\
\pm 249,6\end{array}$ & $\begin{array}{l}1048,7 \\
\pm 898,8\end{array}$ & \begin{tabular}{|l}
539,4 \\
$\pm 233,7$
\end{tabular} & \begin{tabular}{|l}
71,7 \\
$\pm 35,1$
\end{tabular} & \begin{tabular}{|l}
71,7 \\
$\pm 19,1$
\end{tabular} & $\begin{array}{l}475,5 \\
\pm 95,8\end{array}$ & $\begin{array}{l}49,0 \\
\pm 40,4\end{array}$ & $\begin{array}{l}106,5 \\
\pm 77,9\end{array}$ \\
\hline & * & n.s. & n.s. & * & n.s. & * & n.s. & * \\
\hline
\end{tabular}

${ }^{*} \mathrm{p}<0,05 ;$ n.s. $=$ nicht signifikant;

Tab. 36b Einfluss der Sorte auf den Gehalt an freien Aminosäuren

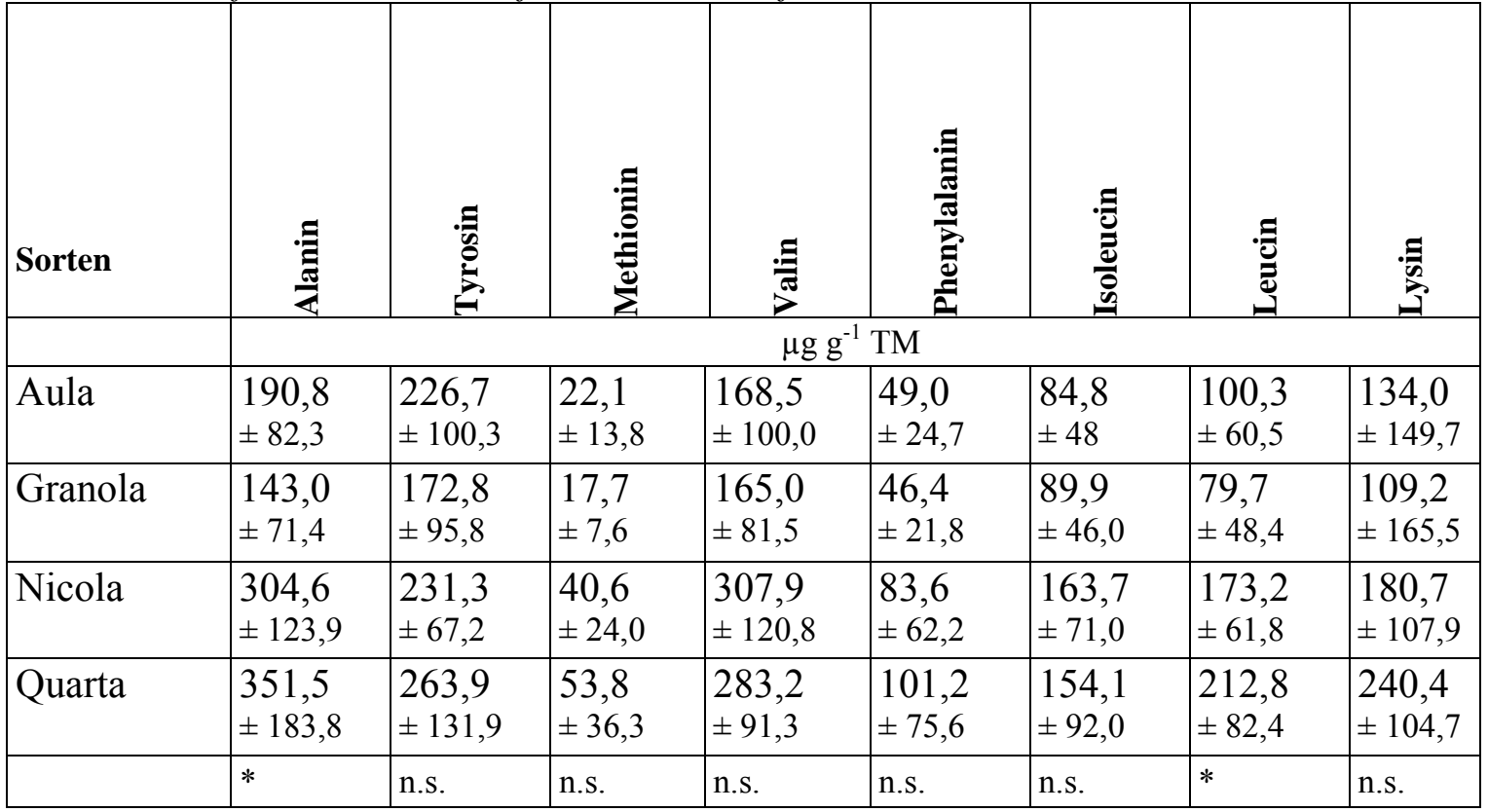

${ }^{*} \mathrm{p}<0,05 ;$ n.s. $=$ nicht signifikant;

In die Betrachtung der Aminosäuren in Abhängigkeit von der spezifischen Dichte sind mit Aula, Granola, Nicola und Quarta alle Sorten eingeflossen. In den nachfolgenden Abbildungen 24a und 24b sind die einzelnen Aminosäuren den drei Dichtefraktionen gegenüber gestellt worden. Die dargestellten Ergebnisse entsprechen den Einzelergebnissen der Sorten. 


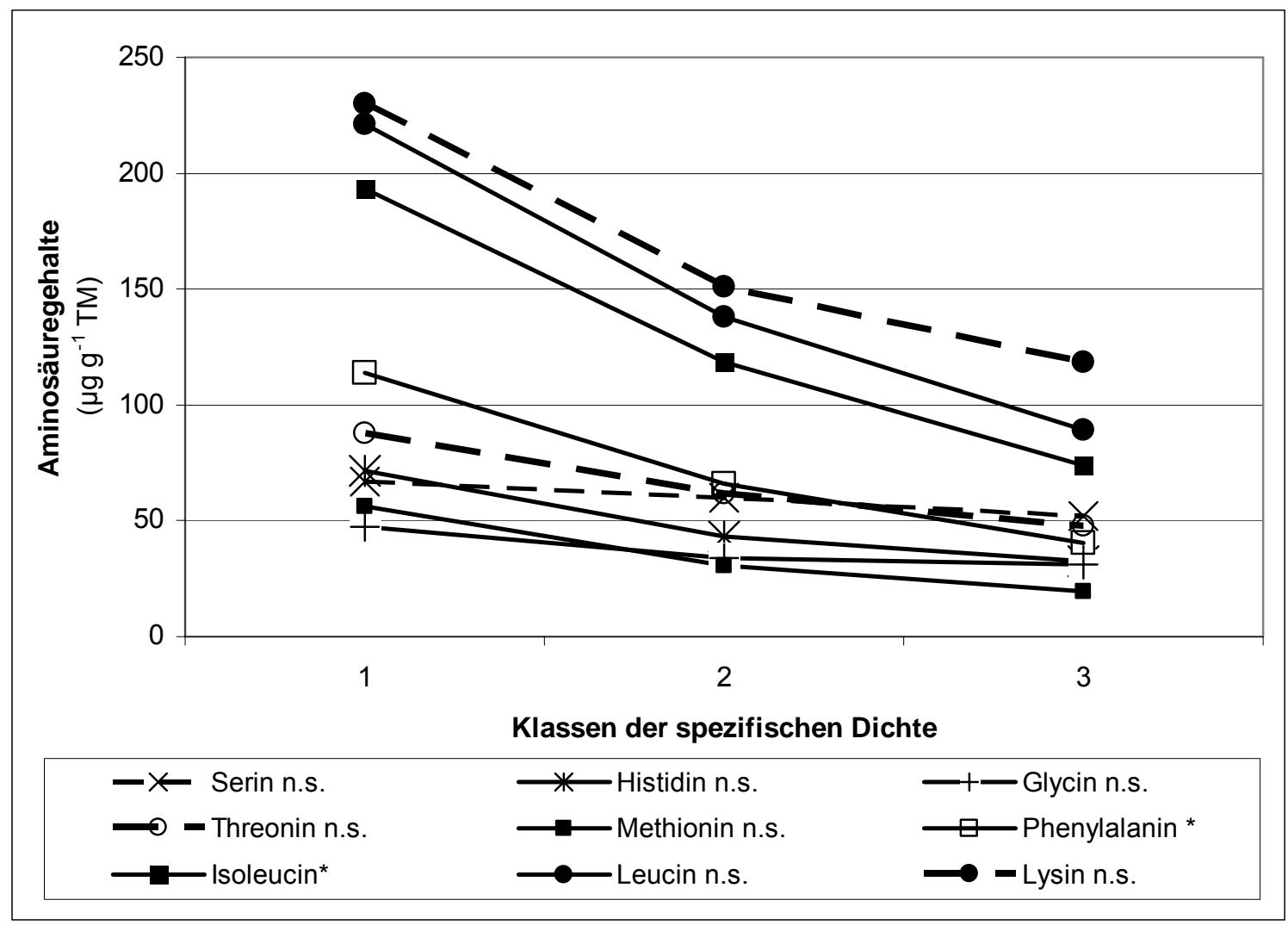

Abb. 24a Beziehung zwischen den freien Aminosäuren und der spezifischen Dichte (im Mittel aller Sorten und Termine)) n.s. $=$ nicht signifikant; ${ }^{*}$ < $<0,05$

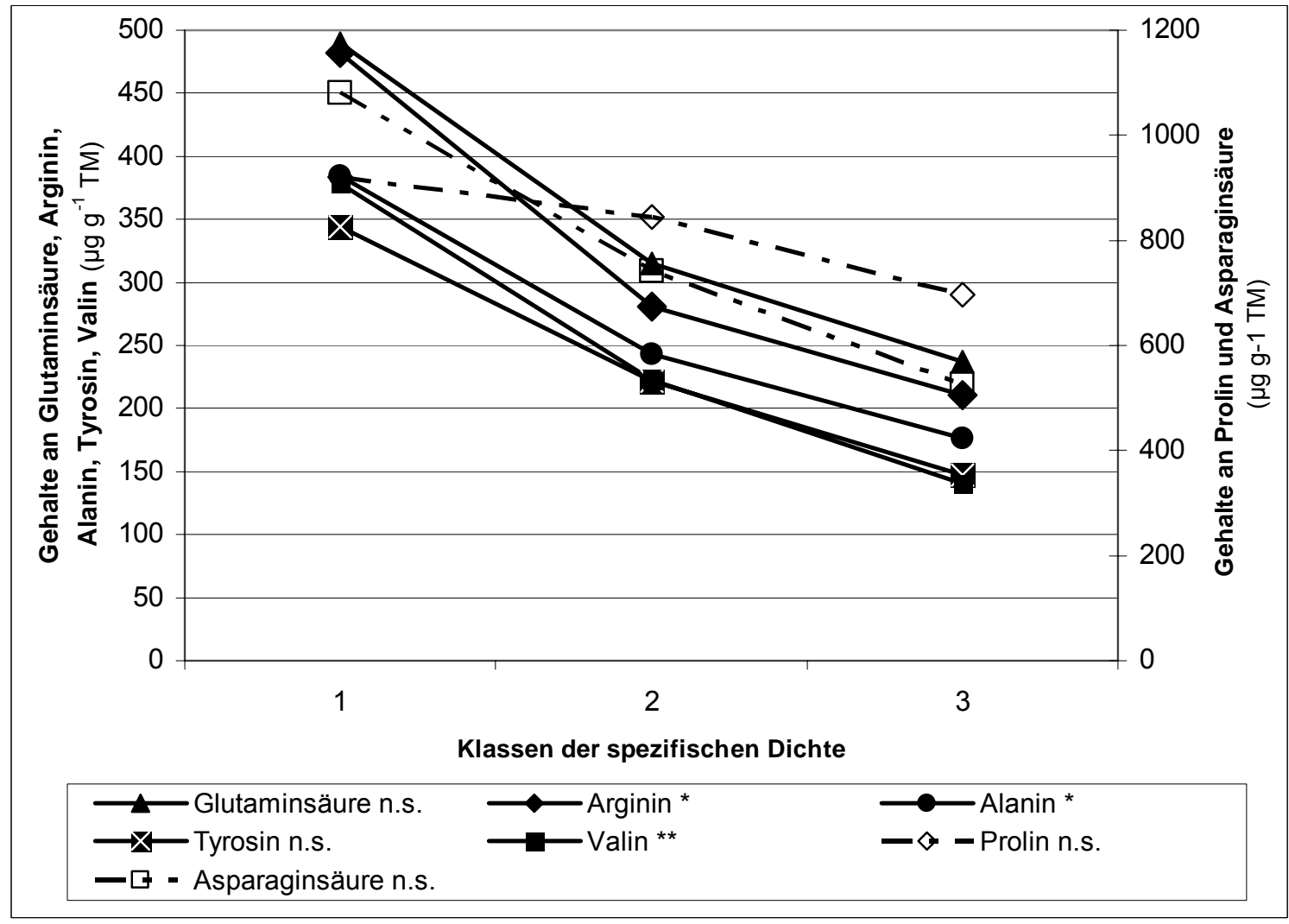

Abb. 24b Beziehung zwischen den freien Aminosäuren und der spezifischen Dichte (im Mittel aller Sorten und Termine) n.s. $=$ nicht signifikant; ${ }^{\mathrm{p}}<0,05 ; * * \mathrm{p}<0,01$ 
Phenylalanin und Isoleucin (Abb. 24a) sowie Arginin, Alanin und Valin (Abb. 24b) gehen mit zunehmender spezifischer Dichte in ihren Gehalten zurück. Bei den übrigen Aminosäuren ist diese Entwicklung tendenziell erkennbar.

Aufgrund des Probenvolumens sind die Aminosäuren im Gegensatz zu den übrigen Inhaltsstoffen nur vor Beginn und nach 8 Monaten Lagerung bestimmt worden (Tab.37a\& b).

Die Gehalte an Prolin und Serin nehmen bis zum Ende der Lagerung signifikant zu, während Glutaminsäure, Threonin, Methionin und Lysin zurückgehen.

Die übrigen Aminosäuren verändern sich nicht signifikant.

Tab. 37a Veränderung der Aminosäuregehalte während der Lagerung (alle Sorten)

\begin{tabular}{|c|c|c|c|c|c|c|c|c|}
\hline Termin & 祭 & 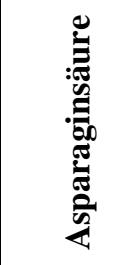 & 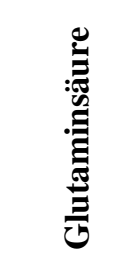 & 蒁 & 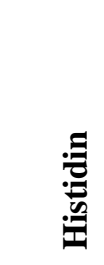 & 㤩 & $\frac{\Xi}{0}$ & 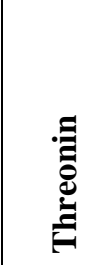 \\
\hline & \multicolumn{8}{|c|}{$\mu \mathrm{g} \mathrm{g}^{-1} \mathrm{TM}$} \\
\hline $\begin{array}{l}\text { Vor der } \\
\text { Lagerung }\end{array}$ & $\begin{array}{l}654,4 \\
\pm 176,9\end{array}$ & $\begin{array}{l}894,9 \\
\pm 779,4\end{array}$ & $\begin{array}{l}440,0 \\
\pm 26,8\end{array}$ & $\begin{array}{l}51,2 \\
\pm 32,2\end{array}$ & $\begin{array}{l}59,0 \\
\pm 20,8\end{array}$ & $\begin{array}{l}371,0 \\
\pm 159,0\end{array}$ & $\begin{array}{l}39,7 \\
\pm 6,7\end{array}$ & $\begin{array}{l}84,1 \\
\pm 40,5\end{array}$ \\
\hline $\begin{array}{l}8 \text { Monate } \\
\text { Lagerung }\end{array}$ & $\begin{array}{l}997,0 \\
\pm 167,9\end{array}$ & $\begin{array}{l}601,1 \\
\pm 304,5\end{array}$ & $\begin{array}{l}212,3 \\
\pm 118,8\end{array}$ & \begin{tabular}{|l|}
68,1 \\
$\pm 29,9$
\end{tabular} & $\begin{array}{l}34,3 \\
\pm 19,8\end{array}$ & $\begin{array}{l}256,3 \\
\pm 70,6\end{array}$ & $\begin{array}{l}34,1 \\
\pm 13,3\end{array}$ & $\begin{array}{l}43,1 \\
\pm 26,9\end{array}$ \\
\hline & $* * *$ & n.s. & * & $*$ & n.s. & n.s. & n.s. & $*$ \\
\hline
\end{tabular}

n.s. $=$ nicht signifikant; ${ }^{*} \mathrm{p}<0,05 ; * * * \mathrm{p}<0,001$

Tab. 37b Veränderung der Aminosäuregehalte während der Lagerung (alle Sorten)

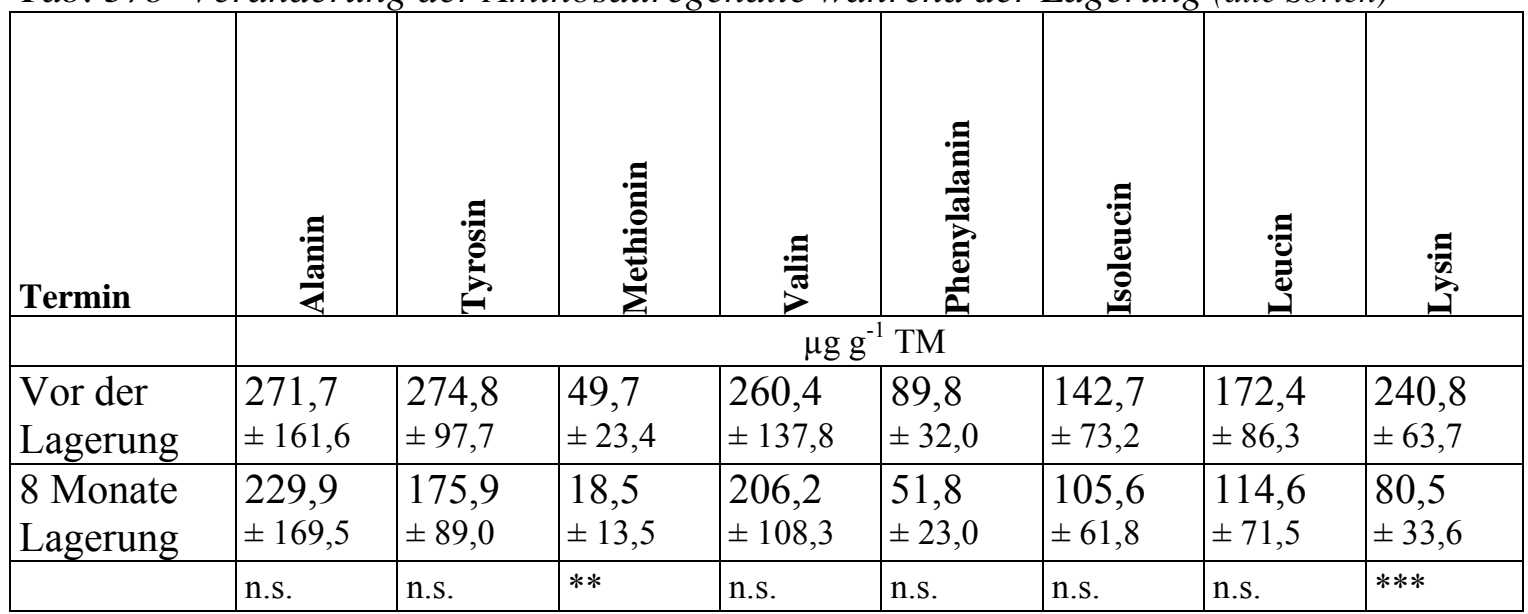

n.s. $=$ nicht signifikant; $* * \mathrm{p}<0,01 ; * * * \mathrm{p}<0,001$; 


\subsubsection{Gehalt an organischen Säuren in Abhängigkeit von der Sorte, der spezifischen Dichte und der Lagerung}

Die Gehalte der organischen Säuren, mit Ausnahme von Maleinsäure und Ascorbinsäure, variieren in den 4 Sorten des Hauptversuches. Während Quarta die höchsten Gehalte an Weinsäure aufweist, sind die höchsten Äpfelsäuregehalte in Granola und die höchsten Zitronensäuregehalte in Nicola nachweisbar. Die Ergebnisse zeigen, dass die Zusammensetzung der organischen Säuren zwischen den einzelnen Sorten stark variiert (Tab.38).

Tab. 38 Einfluss der Sorte auf den Gehalt an organischen Säuren

\begin{tabular}{|c|c|c|c|c|c|c|c|}
\hline Sorten & 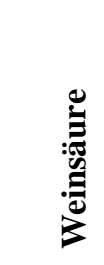 & 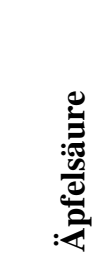 & 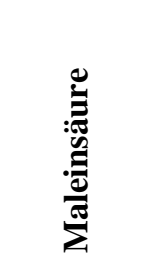 & 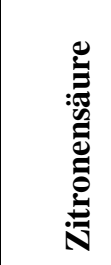 & 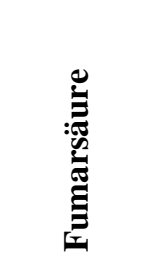 & 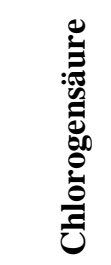 & 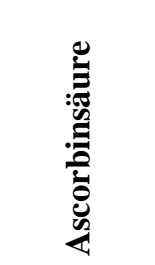 \\
\hline & \multicolumn{7}{|c|}{$\mathrm{g} \mathrm{kg}^{-1} \mathrm{TM}$} \\
\hline Aula & $\begin{array}{l}1,61 \\
\pm 0,59 \\
\end{array}$ & $\begin{array}{l}6,48 \\
\pm 3,03\end{array}$ & $\begin{array}{l}0,0078 \\
\pm 0,004\end{array}$ & $\begin{array}{l}14,83 \\
\pm 3,12\end{array}$ & $\begin{array}{l}0,0364 \\
\pm 0,0194\end{array}$ & $\begin{array}{l}0,59 \\
\pm 0,17\end{array}$ & $\begin{array}{l}0,65 \\
\pm 0,19\end{array}$ \\
\hline Granola & $\begin{array}{l}1,85 \\
\pm 0,53\end{array}$ & $\begin{array}{l}9,30 \\
\pm 4,22\end{array}$ & $\begin{array}{l}0,0110 \\
\pm 0,0042\end{array}$ & $\begin{array}{l}14,40 \\
\pm 2,90\end{array}$ & $\begin{array}{l}0,0197 \\
\pm 0,0055\end{array}$ & $\begin{array}{l}0,87 \\
\pm 0,19\end{array}$ & $\begin{array}{l}\text { liegt nicht } \\
\text { vor }\end{array}$ \\
\hline Nicola & $\begin{array}{l}1,76 \\
\pm 0,56\end{array}$ & $\begin{array}{l}7,46 \\
\pm 1,83\end{array}$ & $\begin{array}{l}0,0085 \\
\pm 0,0037\end{array}$ & $\begin{array}{l}19,00 \\
\pm 2,67\end{array}$ & $\begin{array}{l}0,0241 \\
\pm 0,0084\end{array}$ & $\begin{array}{l}1,09 \\
\pm 0,22\end{array}$ & $\begin{array}{l}\text { liegt nicht } \\
\text { vor }\end{array}$ \\
\hline \multirow[t]{2}{*}{ Quarta } & $\begin{array}{l}2,27 \\
\pm 0,59\end{array}$ & $\begin{array}{l}9,10 \\
\pm 3,28\end{array}$ & $\begin{array}{l}0,0102 \\
\pm 0,0049\end{array}$ & $\begin{array}{l}16,29 \\
\pm 2,87\end{array}$ & $\begin{array}{l}0,0295 \\
\pm 0,0132\end{array}$ & $\begin{array}{l}0,762 \\
\pm 0,26\end{array}$ & $\begin{array}{l}0,63 \\
\pm 0,21\end{array}$ \\
\hline & $* * *$ & $* *$ & n.s. & $* * *$ & $* * *$ & $* * *$ & n.s. \\
\hline
\end{tabular}

Neben den sortenspezifischen Unterschieden bestehen Unterschiede in Abhängigkeit der Klassen der spezifischen Dichte (Abb.25).

Weinsäure, Zitronensäure und Äpfelsäure sind bei zunehmender spezifischer Dichte in geringeren Konzentrationen nachweisbar. Dieses Ergebnis ist in jeder Einzelsorte nachweisbar. 


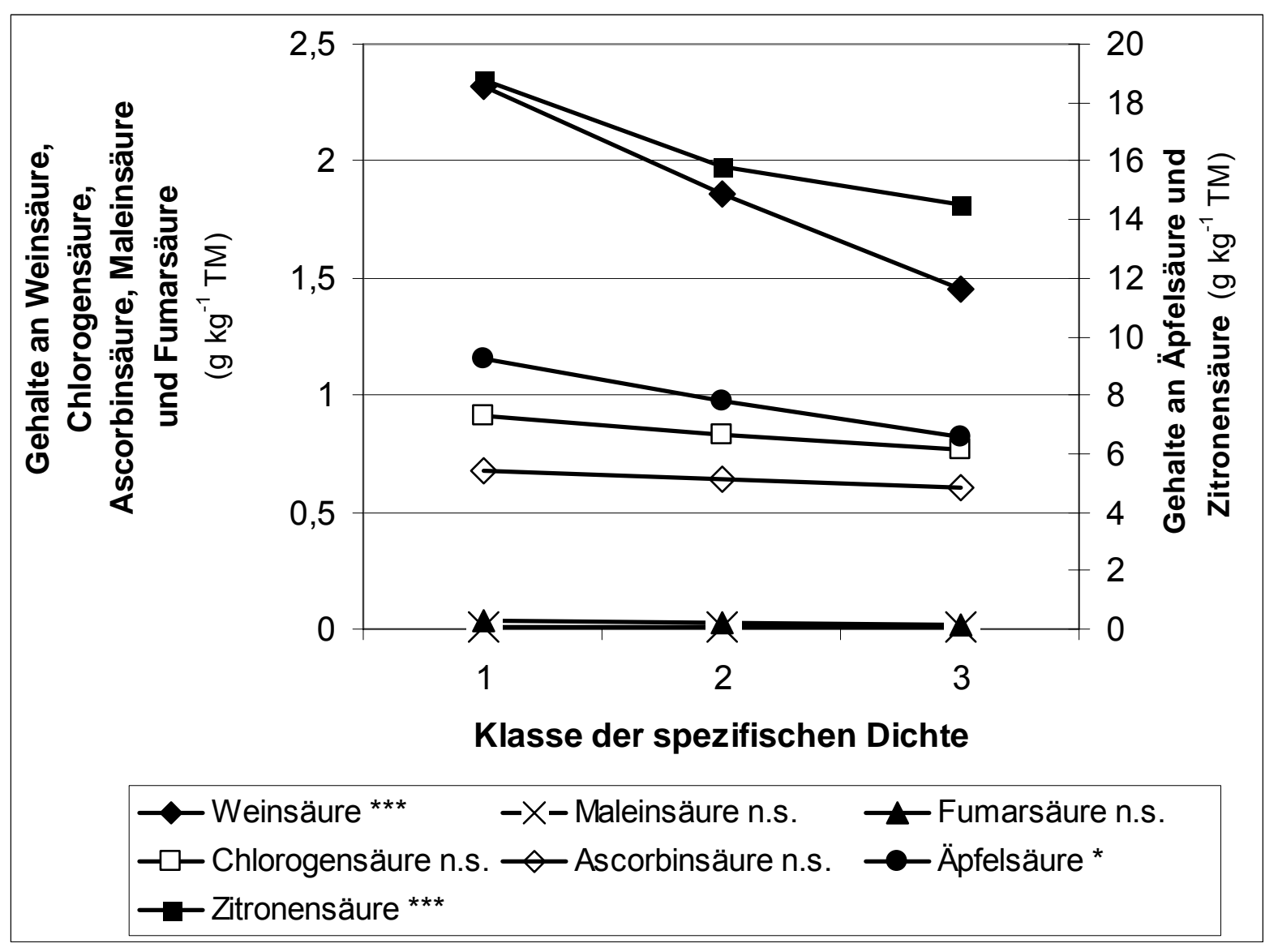

Abb. 25 Beziehung zwischen den organischen Säuren und der spezifischen Dichte (im Mittel aller Sorten und Termine) n.s. $=$ nicht signifikant; ${ }^{\mathrm{p}}<0,05 ; * * * \mathrm{p}<0,001$

Während der Lagerung kommt es zu Veränderungen in den Gehalten der organischen Säuren (Tab.39). Die Weinsäure-, Maleinsäure- und Chlorogensäuregehalte nehmen zu, während die Konzentrationen an Fumarsäure und Ascorbinsäure abnehmen.

Tab. 39 Veränderung der Gehalte der organischen Säuren während der Lagerung (alle Sorten)

\begin{tabular}{|c|c|c|c|c|c|c|c|}
\hline Termin & 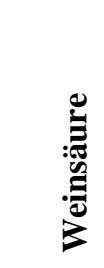 & 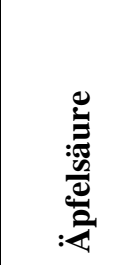 & 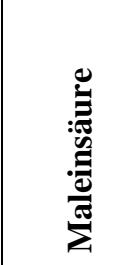 & 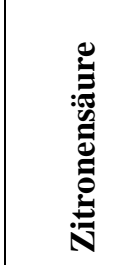 & 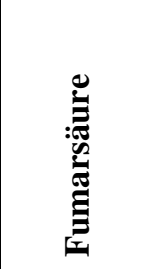 & 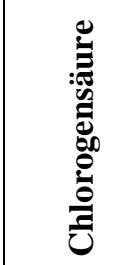 & 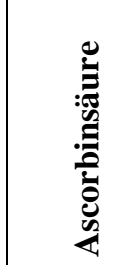 \\
\hline & \multicolumn{7}{|c|}{$\mathrm{g} \mathrm{kg}^{-1} \mathrm{TM}$} \\
\hline $\begin{array}{l}\text { Vor der } \\
\text { Lagerung }\end{array}$ & $\begin{array}{l}1,74 \\
\pm 0,57\end{array}$ & \begin{tabular}{|l|}
8,23 \\
$\pm 3,775$
\end{tabular} & $\begin{array}{l}0,0075 \\
\pm 0,0039\end{array}$ & $\begin{array}{l}16,85 \\
\pm 3,73\end{array}$ & \begin{tabular}{|l}
0,035 \\
$\pm 0,0191$
\end{tabular} & $\begin{array}{l}0,64 \\
\pm 0,18\end{array}$ & $\begin{array}{l}0,91 \\
\pm 0,052\end{array}$ \\
\hline $\begin{array}{l}4 \text { Monate } \\
\text { Lagerung }\end{array}$ & $\begin{array}{l}1,78 \\
\pm 0,66\end{array}$ & $\begin{array}{l}7,87 \\
\pm 3,23\end{array}$ & $\begin{array}{l}0,0101 \\
\pm 0,0054\end{array}$ & $\begin{array}{l}15,59 \\
\pm 3,88\end{array}$ & $\begin{array}{l}0,025 \\
\pm 0,0102\end{array}$ & $\begin{array}{l}0,84 \\
\pm 0,26\end{array}$ & $\begin{array}{l}0,52 \\
\pm 0,049\end{array}$ \\
\hline $\begin{array}{l}8 \text { Monate } \\
\text { Lagerung }\end{array}$ & $\begin{array}{l}2,12 \\
\pm 0,54\end{array}$ & $\begin{array}{l}8,01 \\
\pm 3,03\end{array}$ & $\begin{array}{l}0,0111 \\
\pm 0,0024\end{array}$ & $\begin{array}{l}16,17 \\
\pm 2,25\end{array}$ & $\begin{array}{l}0,023 \\
\pm 0,0072\end{array}$ & $\begin{array}{l}1,01 \\
\pm 0,27\end{array}$ & $\begin{array}{l}0,47 \\
\pm 0,050\end{array}$ \\
\hline & * & n.s. & * & n.s. & ** & $* * *$ & $* * *$ \\
\hline
\end{tabular}




\subsubsection{Mineralstoffgehalte in Abhängigkeit von der Sorte, der spezifischen Dichte und der Lagerung}

Die Mineralstoffzusammensetzung in den Sorten Aula, Granola, Nicola und Quarta variiert sortenspezifisch. Es zeigt sich, dass Aula im Vergleich zu den übrigen drei Sorten die geringsten Kalium-, Calcium- und Eisengehalte aufweist. Die geringsten Magnesiumgehalte sind in der Sorte Granola nachweisbar, die geringsten Phosphorgehalte in der Sorte ,Quarta'. Bei Natrium, Zink, Kupfer und Mangan gibt es nur tendenziell Sortenunterschiede (Tab.40).

Tab. 40 Einfluss der Sorte auf den Mineralstoffgehalt

\begin{tabular}{|c|c|c|c|c|c|c|c|c|c|}
\hline Sorten & 声 & 志 & 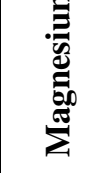 & 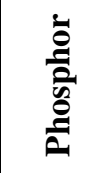 & $\begin{array}{l}\text { 咅 } \\
\text { 营 }\end{array}$ & $\begin{array}{l}\text { 离 } \\
\text { 言 }\end{array}$ & 范 & 总 & 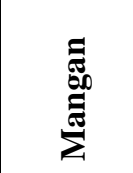 \\
\hline & \multicolumn{9}{|c|}{$\mathrm{g} \mathrm{kg}^{-1} \mathrm{TM}$} \\
\hline Aula & $\begin{array}{l}21,49 \\
\pm 2,15\end{array}$ & $\begin{array}{l}0,15 \\
\pm 0,03\end{array}$ & \begin{tabular}{|l}
1,04 \\
$\pm 0,22$
\end{tabular} & \begin{tabular}{|l}
2,40 \\
$\pm 0,30$
\end{tabular} & $\begin{array}{l}0,10 \\
\pm 0,05\end{array}$ & $\begin{array}{l}0,024 \\
\pm 0,005\end{array}$ & $\begin{array}{l}0,017 \\
\pm 0,019\end{array}$ & $\begin{array}{l}0,0079 \\
\pm 0,0072\end{array}$ & $\begin{array}{l}0,0080 \\
\pm 0,011\end{array}$ \\
\hline Granola & $\begin{array}{l}23,75 \\
\pm 3,19\end{array}$ & $\begin{array}{l}0,20 \\
\pm 0,04\end{array}$ & $\begin{array}{l}0,94 \\
\pm 0,11\end{array}$ & $\begin{array}{l}2,69 \\
\pm 0,57\end{array}$ & $\begin{array}{l}0,11 \\
\pm 0,04\end{array}$ & $\begin{array}{l}0,031 \\
\pm 0,009\end{array}$ & $\begin{array}{l}0,012 \\
\pm 0,0032\end{array}$ & $\begin{array}{l}0,0106 \\
\pm 0,0142\end{array}$ & \begin{tabular}{|l|}
0,0058 \\
$\pm 0,0018$
\end{tabular} \\
\hline Nicola & $\begin{array}{l}24,34 \\
\pm 3,25\end{array}$ & $\begin{array}{l}0,16 \\
\pm 0,05\end{array}$ & \begin{tabular}{|l|}
1,09 \\
$\pm 0,20$
\end{tabular} & \begin{tabular}{|l|}
2,77 \\
$\pm 0,87$
\end{tabular} & $\begin{array}{l}0,27 \\
\pm 0,46\end{array}$ & $\begin{array}{l}0,035 \\
\pm 0,010\end{array}$ & $\begin{array}{l}0,013 \\
\pm 0,0019\end{array}$ & $\begin{array}{l}0,0065 \\
\pm 0,0048\end{array}$ & \begin{tabular}{|l|}
0,0063 \\
$\pm 0,0020$
\end{tabular} \\
\hline Quarta & $\begin{array}{l}23,61 \\
\pm 3,50 \\
\end{array}$ & \begin{tabular}{|l|l}
0,19 \\
$\pm 0,04$ \\
\end{tabular} & \begin{tabular}{|l|}
1,03 \\
$\pm 0,13$ \\
\end{tabular} & $\begin{array}{l}1,92 \\
\pm 0,50 \\
\end{array}$ & $\begin{array}{l}0,17 \\
\pm 0,15 \\
\end{array}$ & \begin{tabular}{|l|}
0,031 \\
$\pm 0,011$ \\
\end{tabular} & \begin{tabular}{|l}
0,015 \\
$\pm 0,0029$ \\
\end{tabular} & \begin{tabular}{|l|l}
0,0055 \\
$\pm 0,0028$ \\
\end{tabular} & \begin{tabular}{|l|}
0,0092 \\
$\pm 0,0100$ \\
\end{tabular} \\
\hline & $* *$ & $* * *$ & $*$ & $* * *$ & n.s. & $* * *$ & n.s. & n.s. & \begin{tabular}{|l|} 
n.s. \\
\end{tabular} \\
\hline
\end{tabular}

Neben der sortenspezifischen Abhängigkeit sind die Mineralstoffgehalte auch von der spezifischen Dichte abhängig.

Die Gehalte an Kalium, Magnesium, Phosphor (Abb. 26a) sowie Eisen (Abb. 26b) gehen in allen Einzelsorten mit zunehmender spezifischer Dichte zurück. 


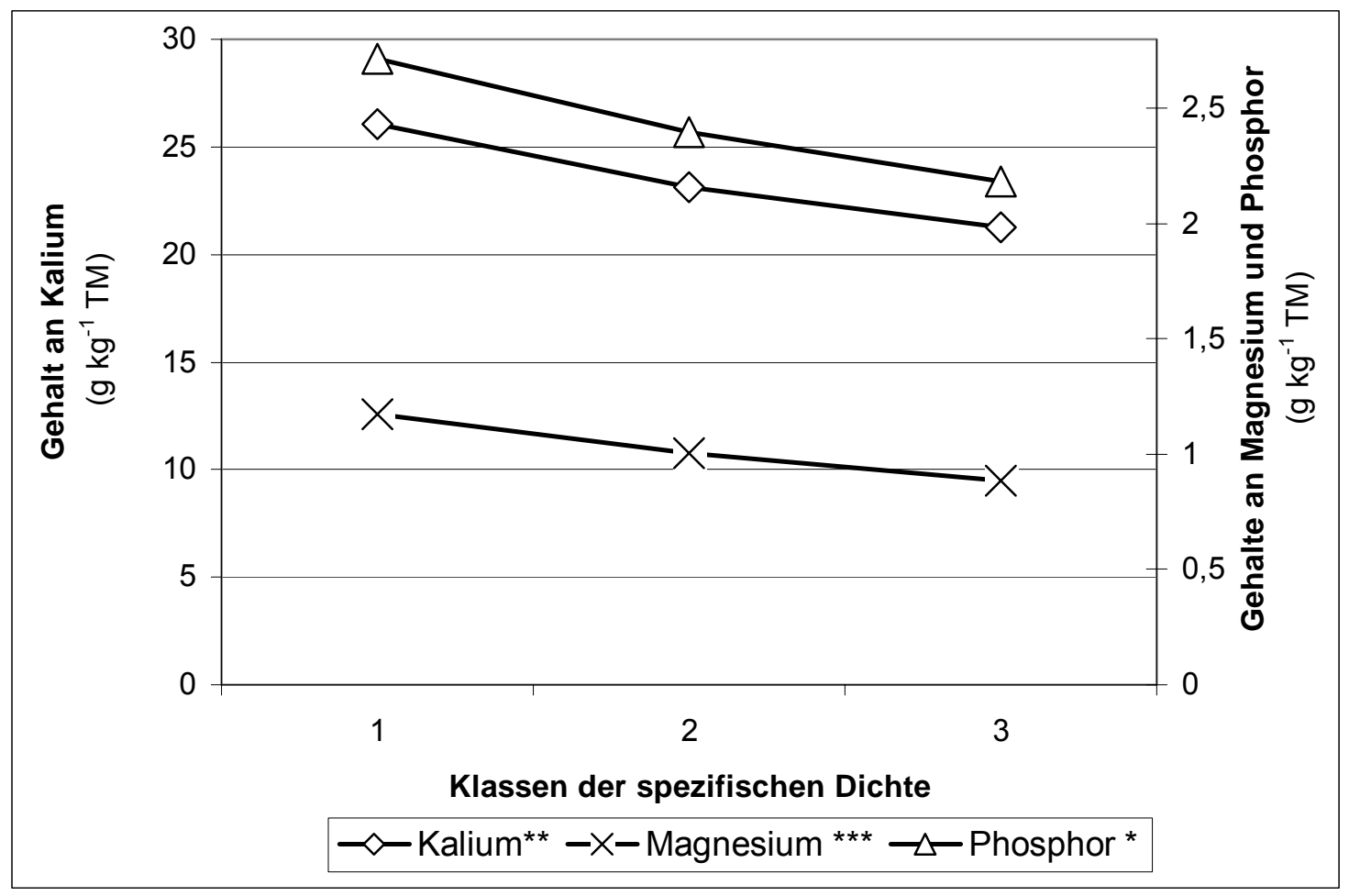

Abb. 26a Beziehung zwischen Mineralstoffen und der spezifischen Dichte (im Mittel aller Sorten und Termine)

${ }^{*} \mathrm{p}<0,05 ; * * \mathrm{p}<0,01 ;{ }^{* * *} \mathrm{p}<0,001$

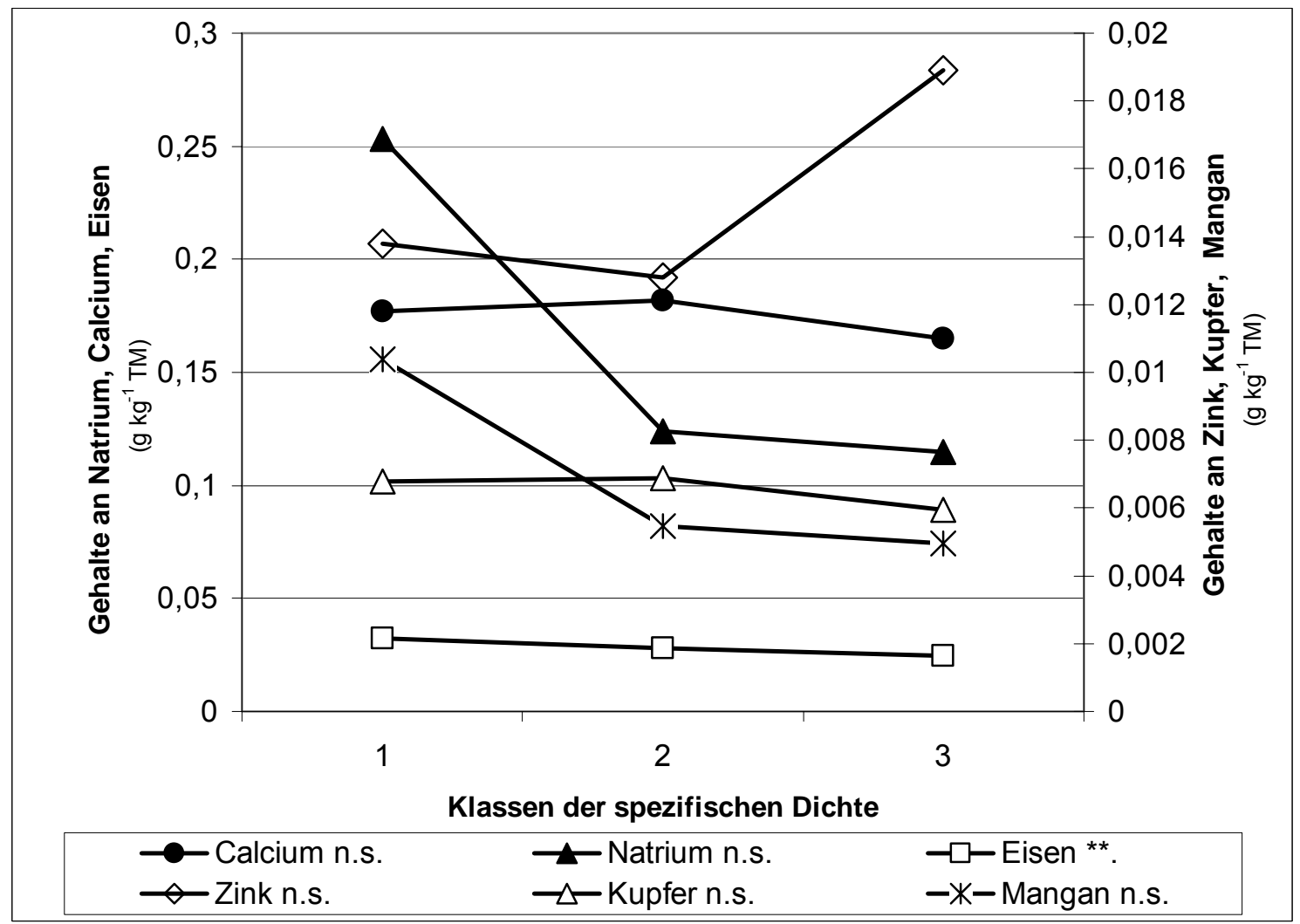

Abb. $26 b$ Beziehung zwischen Mineralstoffen und der spezifischen Dichte (im Mittel aller Sorten und Termine)

n.s. $=$ nicht signifikant; $* * \mathrm{p}<0,01$ 
Während der Lagerung kommt es lediglich zu einem leichten Anstieg der Magnesiumgehalte. Die übrigen Mineralstoffe verändern sich während der 8-monatigen Lagerung nicht (Tab.41).

Tab. 41 Veränderung der Mineralstoffgehalte während der Lagerung (alle Sorten)

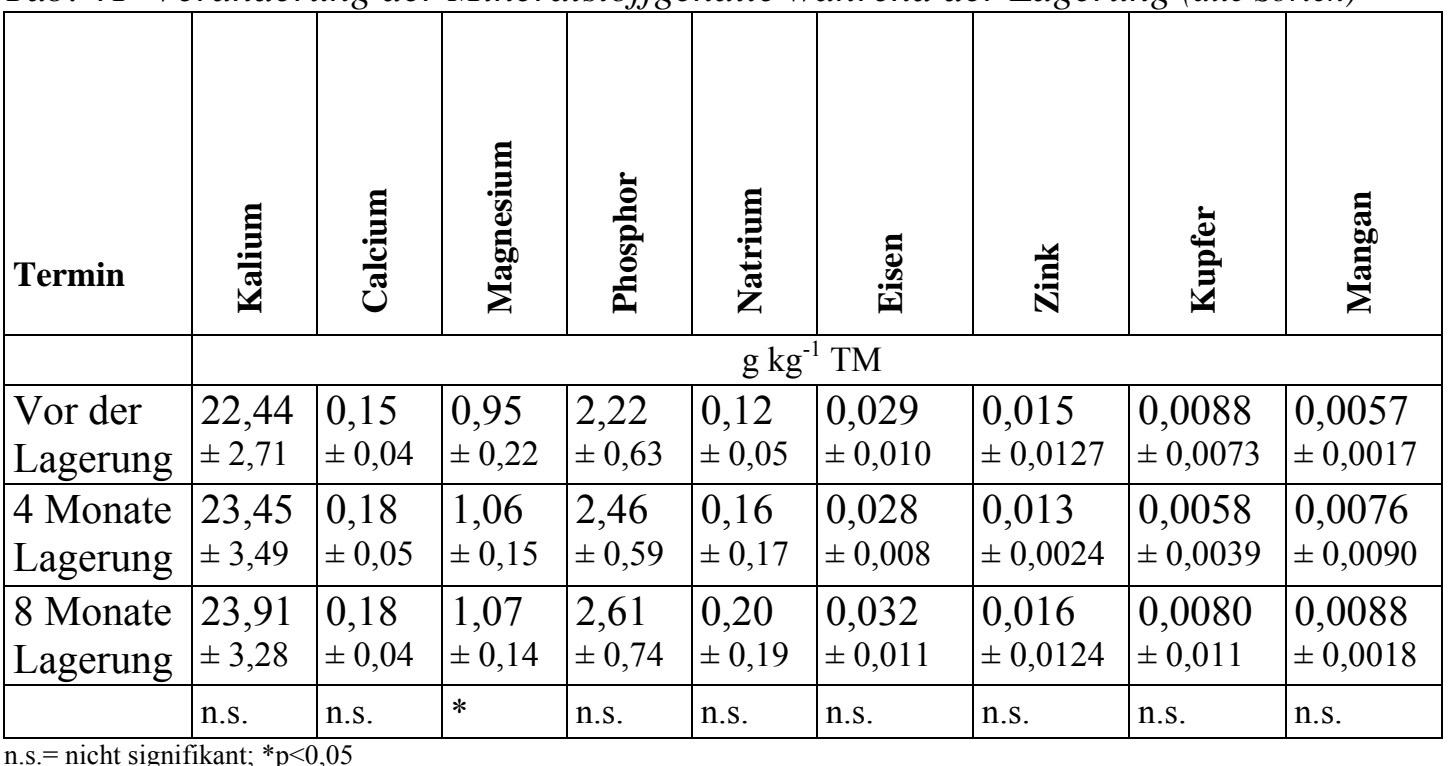

\subsubsection{Zusammenfassung der Ergebnisse aus dem Hauptversuch}

Aus den bereits dargestellten Einzelergebnissen lassen sich nachfolgende Zusammenfassungen bzw. Verknüpfungen erstellen.

In Tab.42 sind die Summen der freien Aminosäuren, der untersuchten organischen Säuren und der analysierten Mineralstoffe dargestellt. Aula als Sorte stärkster Schwarzfleckigkeitsneigung weist die geringsten Gesamtgehalte an organischen Säuren und Mineralstoffen auf, bei den freien Aminosäuren ist es Granola. Die größte Summe an freien Aminosäuren befindet sich in der Sorte Quarta, der Sorte mit der geringsten Schwarzfleckigkeitsneigung. Bei den organischen Säuren und den Mineralstoffen zeigt die Sorte Nicola die größte Summe.

Tab. 42 Summe einzelner Inhaltsstoffe in den Sorten des Hauptversuches

\begin{tabular}{|l|c|c|c|}
\hline \multirow{2}{*}{ Sorte } & \multicolumn{3}{|c|}{ Summe } \\
\cline { 2 - 4 } & Freie Aminosäuren & Organischen Säuren & Mineralstoffe \\
\cline { 2 - 4 } & $\mu \mathrm{g} \mathrm{g}^{-1} \mathrm{TM}$ & \multicolumn{2}{c|}{$\mathrm{g} \mathrm{kg}^{-1} \mathrm{TM}$} \\
\hline Aula & $2983,6 \pm 720$ & $24,20 \pm 3,6$ & $25,24 \pm 0,9$ \\
\hline Granola & $2831,7 \pm 890$ & $26,45 \pm 2,1$ & $27,75 \pm 2,7$ \\
\hline Nicola & $4013,6 \pm 280$ & $29,09 \pm 1,9$ & $28,69 \pm 1,6$ \\
\hline Quarta & $4747,5 \pm 694$ & $29,34 \pm 1,4$ & $26,98 \pm 2,4$ \\
\hline & $* * *$ & $*$ & $*$ \\
\hline${ }_{*}^{*}<0,05 ; * * \mathrm{p}<0,01$ & & & $*$ \\
\hline
\end{tabular}


Betrachtet man die Summe der freien Aminosäuren genauer, fällt der zwischen den Sorten differierende prozentuale Anteil des Tyrosins an freien Aminosäuren auf (Tab.43).

Den höchsten prozentualen Anteil des Tyrosins findet man mit 7,6\% in der Sorte Aula. Quarta erreicht mit 5,56\% den geringsten Prozentsatz.

Tab. 43 Prozentualer Anteil des Tyrosins an der Summe der freien Aminosäuren in Abhängigkeit von der Sorte

\begin{tabular}{|l|c|}
\hline \multicolumn{1}{|c|}{ Sorte } & $\begin{array}{c}\text { Prozentualer Anteil } \\
\text { Tyrosin } \\
\text { an den freien Aminosäuren }\end{array}$ \\
\hline Aula & $\%$ \\
\hline Granola & 7,60 \\
\hline Nicola & 6,10 \\
\hline Quarta & 5,76 \\
\hline & 5,56 \\
\hline$* * * p<0,001$ & $* * *$ \\
\hline
\end{tabular}

Neben der sortenspezifischen Inhaltsstoffzusammensetzung gibt es auch Unterschiede in Abhängigkeit von den Klassen der spezifischen Dichte. In der Dichtefraktion 3 befindet sich nicht nur die geringste Gesamtsumme freier Aminosäuren, sondern auch die geringste Summe an organischen Säuren und an Mineralstoffen (Tab.44).

Tab. 44 Summe einzelner Inhaltsstoffe in Abhängigkeit von der spezifischen Dichte

\begin{tabular}{|c|c|c|c|}
\hline \multirow{2}{*}{$\begin{array}{c}\text { Klassen der } \\
\text { Spezifischen Dichte }\end{array}$} & \multicolumn{3}{|c|}{ Summe der } \\
\cline { 2 - 4 } & Freie Aminosäuren & Organischen Säuren & Mineralstoffe \\
\cline { 2 - 4 } & $\mu \mathrm{g} \mathrm{g}^{-1} \mathrm{TM}$ & $31,96 \pm 5,2$ & $\mathrm{~g} \mathrm{~kg}^{-1} \mathrm{TM}$ \\
\hline 1 & $5169,30 \pm 1100$ & $26,94 \pm 2,9$ & $26,90 \pm 2,44,8$ \\
\hline 2 & $3573,12 \pm 890$ & $23,90 \pm 2,7$ & $24,69 \pm 3,2$ \\
\hline 3 & $2640,26 \pm 630$ & $* * *$ & $* *$ \\
\hline
\end{tabular}

Den größten prozentualen Anteil des Tyrosins an den freien Aminosäuren findet man ebenfalls in der Dichtefraktion 3 (Tab.45).

Tab. 45 Prozentualer Anteil des Tyrosins an der Summe der freien Aminosäuren in Abhängigkeit von der Sorte

\begin{tabular}{|c|c|}
\hline $\begin{array}{c}\text { Klassen der } \\
\text { Spezifischen Dichte }\end{array}$ & $\begin{array}{c}\text { Prozentualer Anteil } \\
\text { Tyrosin } \\
\text { an den freien Aminosäuren }\end{array}$ \\
\hline 1 & $\%$ \\
\hline 2 & 6,65 \\
\hline 3 & 6,20 \\
\hline & 5,57 \\
\hline${ }^{*} \mathrm{p}<0,05$ & $*$ \\
\hline
\end{tabular}


Ergänzend $\mathrm{zu}$ der Einzeldarstellung der organischen Säuren ist in der Abb.27 das Chlorogensäure- Zitronensäure- Verhältnis in Beziehung zum SF- Index gesetzt.

Sorten mit geringem SF- Index wie Quarta und Nicola haben ein geringes ChlorogensäureZitronensäure-Verhältnis $(\mathrm{p}<0,05)$. Zwischen Granola und Aula lässt sich trotz der signifikanten Unterschiede im SF- Index kein Unterschied im Chlorogensäure- ZitronensäureVerhältnis ermitteln.

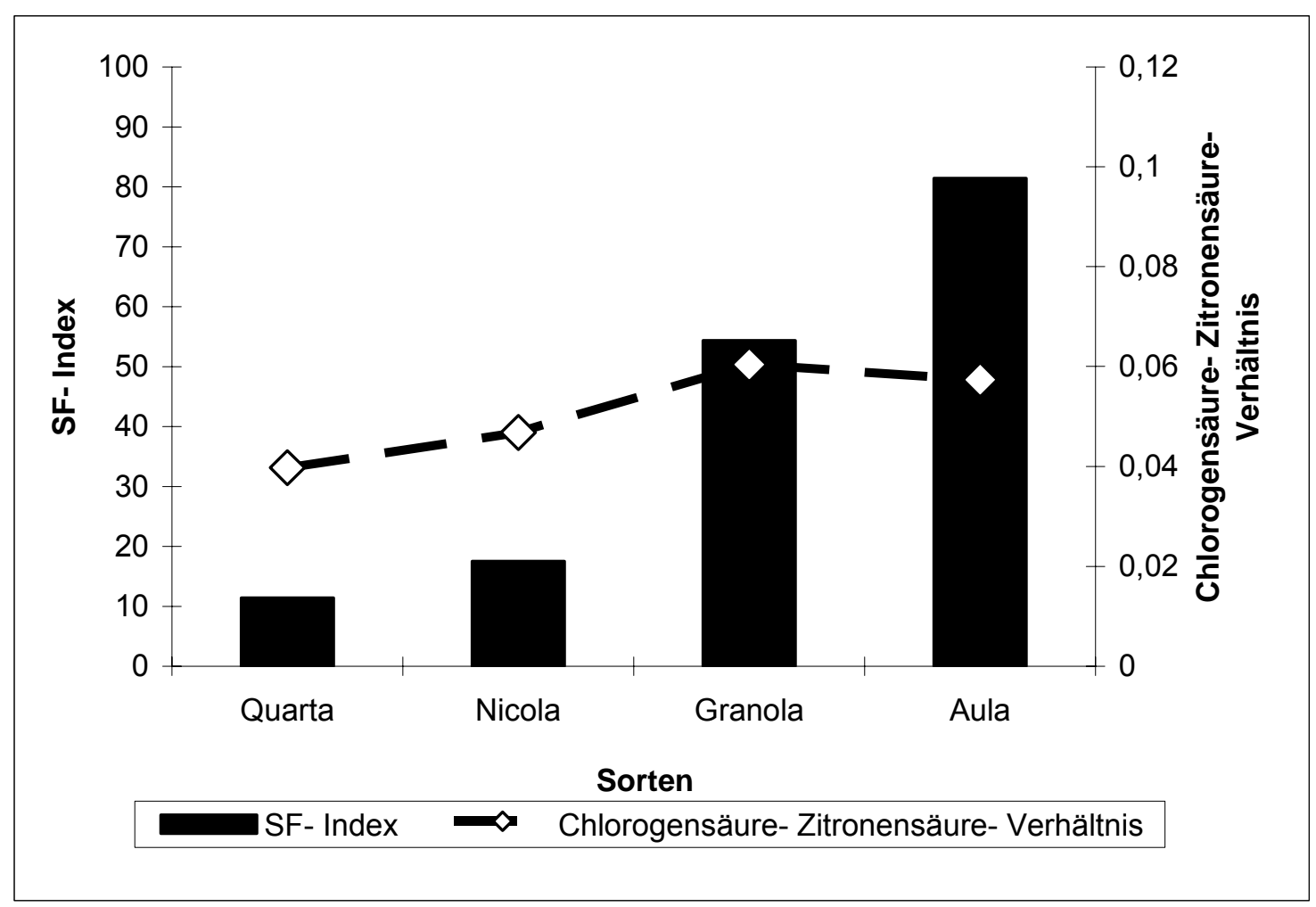

Abb. 27 Beziehung zwischen dem Chlorogensäure- Zitronensäure-Verhältnis und dem SFIndex

Als Abschluss der Zusammenfassung der Ergebnisse des Hauptversuches ist noch die positive Korrelation zwischen dem SF- Index und der PPO $\mathrm{zu}$ ergänzen $\left(\mathrm{r}=0,795^{* * *}\right)$. Weitere Korrelationen zwischen dem SF- Index und Inhaltsstoffen sowie unter einzelnen Inhaltsstoffen bestehen nicht. 


\section{DISKUSSION}

\subsection{Rolle der spezifischen Dichte bei der Ausprägung der Schwarzfleckigkeit}

Der Versuch basierte auf der Gradierung der Kartoffeln in drei Dichtefraktionen, da nur die Gesamtbetrachtung der Trockenmasse, die durch die spezifische Dichte repräsentiert wird, Rückschlüsse auf die Schwarzfleckigkeit zulässt. Sowohl der Vorversuch (Abb.4) als auch der Hauptversuch (Abb.16) zeigten, dass mit zunehmender spezifischer Dichte ein Anstieg der SF- Indices einhergegangen ist.

Aus unserer Sicht ist jedoch entscheidend, dass sich dieser Zusammenhang, den Wright et al. im Jahr 2005 ebenfalls nachgewiesen haben, in allen Sorten wieder findet (Abb. 5 \& 17).

Darüber hinaus zeigen die untersuchten Sorten, dass die Ausprägung der SF- Indices sortenspezifisch variiert. Damit unterstreichen die Ergebnisse die Aussage von Baumgartner (1982), der dem Faktor ,Sorte' eine entscheidende Rolle bei der Ausprägung der Schwarzfleckigkeit beimisst. Aeppli (1979) spricht sogar von einer genetischen Fixierung der Schwarzfleckigkeit in der Größenordnung von 32 bis $40 \%$.

Dean et al. (1993) ergänzen, dass neben dem Faktor Sorte auch Umwelteinflüsse (Wetter und Anbaubedingungen) eine Rolle spielen können, diese dem Sorteneinfluss jedoch unterzuordnen seien.

Im Vorversuch ist dieser Umwelteinfluss aufgrund ähnlicher Witterungsbedingungen und annähernd gleichen SF- Indices in beiden Jahren praktisch nicht gegeben.

Im Hauptversuch ist dagegen eine durch die Witterung bedingte Beeinflussung der Schwarzfleckigkeitsintensität denkbar. Der SF- Index im Versuchsjahr 2002 war bei allen Untersuchungsterminen höher als im Jahr 2003. Im Jahr 2002 gab es einen extrem niederschlagsreichen, nassen Sommer, während der Sommer im Jahr 2003 heiß und niederschlagsarm war (Kapitel 10.8. Wetterdaten). Damit kann angenommen werden, dass eine hohe Niederschlagsintensität eine höhere Schwarzfleckigkeit bedingt, was auf eine erhöhte Auswaschung des Kaliums aus dem Boden zurückzuführen ist (Anhang 10.6. Mineralstoffe).

Insgesamt gesehen treten damit die Witterungseinflüsse aufgrund der Unterschiede im Vorund Hauptversuch hinter den Sorteneinfluss zurück, so dass die Sorte als der entscheidende Einflussfaktor bei der Ausprägung der Schwarzfleckigkeit angesehen werden kann. 


\subsection{Enzymaktivitäten und ihre Rolle bei der Ausprägung der Schwarzfleckigkeit}

\subsubsection{Aktivitäten der CAT, POD, SOD und LOX und ihre Rolle bei der Ausprägung der Schwarzfleckigkeit}

Basis der Untersuchung der Aktivitäten der Enzyme in Abhängigkeit von den Sorten, der spezifischen Dichte sowie der Lagerung war die Hypothese, dass durch die mechanische Belastung der Kartoffelknollen Veränderungen im antioxidativen Status der Kartoffeln einsetzen. Zusätzlich erschien eine Unterscheidung in freie und membranassoziierte Enzyme sinnvoll, da aufgrund der abnehmenden subzellulären Integrität in der Kartoffelknolle Reaktionen der unterschiedlichen Enzymfraktionen zu erwarten sind.

Die Versuchsergebnisse ergaben jedoch zunächst einmal einen Unterschied des Vor- und Hauptversuches in der Aktivität in Abhängigkeit von den Sorten.

Im Vorversuch zeigte sich eine deutliche sortenspezifische Aktivität. Darüber hinaus zeigte die für Schwarzfleckigkeit und Beschädigungen empfindlichste Sorte Ponto bei allen Enzymen mit Ausnahme der freien POD, bei der Cilena die höchsten hatte, stets die höchste Aktivität (Tab.5, 7, 9 \& 11), während Solara stets die geringsten bzw. tendenziell geringsten Aktivitäten zeigte. Damit konnte für die untersuchten Sorten eine Beziehung zwischen sortenspezifischer Aktivität und Schwarzfleckigkeitsneigung nachgewiesen werden.

Diese Deutlichkeit der Ergebnisse findet man jedoch nicht in dem Hauptversuch wieder. Nur bei MA CAT und MA LOX sowie der freien LOX sind klare Sortenunterschiede erkennbar. Außerdem wies Aula als Sorte höchster Schwarzfleckigkeitsneigung bei den genannten Enzymen stets die geringste bzw. tendenziell die geringste Aktivität auf, so dass sich eine Beziehung zwischen der sortenspezifischen Aktivität und der Schwarzfleckigkeitsneigung, nicht herstellen lässt.

Es ist anzunehmen, dass diese Unterschiede darauf zurückzuführen sind, dass im Vorversuch Sorten mit unterschiedlichem Stärkegehalt verwendet wurden, so dass die Unterschiede in den Aktivitäten aufgrund der großen Differenzen zwischen den Sorten ausgeprägter als im Hauptversuch waren. Dennoch lässt sich für beide Versuchsabschnitte festhalten, dass zwischen den freien bzw. MA Enzymen bei CAT, SOD und LOX ein Aktivitätsunterschied besteht. MA Enzyme weisen eine mehr als doppelt so hohe Aktivität als die freien Enzyme auf.

Diese erhöhte Aktivität der MA Enzyme spricht für die Bedeutung dieser Enzyme in der Pflanze. Mizuno et al. (1998), Dipierro \& De Leonardis (1997) und Lulai (1988) ermittelten, dass MA Enzyme grundsätzlich eine erhöhte Aktivität aufweisen, um z.B. nach Beschädigungen einen Schutz vor zellulär weit reichenden Veränderungen zu gewährleisten. 
Auch wenn in diesem Versuch kein Unterschied der Enzymfraktionen bei der POD messbar war, ist dieser Zusammenhang auch für POD zu vermuten, da dieser bei früheren Versuchen an Kohl und Gerste ebenfalls nachgewiesen worden ist (Hallaway et al., 1970).

Bei der Betrachtung der spezifischen Dichte ergab sich lediglich bei der MA SOD (Vor- und Hauptversuch) sowie bei der MA POD des Vorversuches ein Anstieg der Aktivität mit zunehmender spezifischer Dichte (Abb. 8, 10 \& 22). Damit lässt sich auf Basis der Enzymaktivitäten in Abhängigkeit von der spezifischen Dichte, die als indirektes Bindeglied zur Schwarzfleckigkeitsneigung (Abb. 5 \&16) angesehen werden kann, kein Zusammenhang zwischen den Aktivitäten einzelner Enzyme und der Ausprägung der Schwarzfleckigkeit herstellen.

Aufgrund dieses Ergebnisses, was zu Beginn der Untersuchungen nicht zu erwarten war, stellte sich nachträglich die Frage, ob die Aktivität der unterschiedlichen Enzyme durch die Aufbereitung negativ beeinflusst worden sein könnte.

Grundsätzlich gilt die Gefriertrocknung als das schonendste Trocknungsverfahren, bei dem kaum Produktveränderungen auftreten. Jedoch wurde nachgewiesen, dass Phenolasen nach Gefriertrocknung ein Jahr stabil und in etwa konstant bleiben, während Katalase und Peroxidasen an Aktivität verlieren kann. Bei Katalase handelt es sich um einen nach 8 Wochen Lagerdauer einsetzenden bis zu 60\%-igen Aktivitätsverlust. Peroxidasen blieben nur 3 Wochen stabil und verloren im Ablauf eines Jahres bis zu 90\% ihrer Aktivität (Weaver \& Hautala, 1969). Daher sollte aus unseren Erfahrungen heraus in bei zukünftigen Untersuchungen die Bestimmung der Enzyme an Frischmaterial durchgeführt werden, um möglichen Veränderungen vorzubeugen.

Diese Untersuchung an Frischmaterial konnte in unserem Versuch leider nicht erfolgen, da das Knollenmaterial erst nach Abschluss des Feldversuches analysiert werden konnte.

Weiterhin ist zu beachten, dass auch bei Verwendung von Frischmaterial Aktivitätsverluste auftreten können. Untersuchungen von Fretzdorff \& Bergthaller (1989) zeigen, dass sich rohe Kartoffelwürfel nicht für längerfristige Tiefgefrierlagerung eignen, denn POD und CAT verlieren nach 180 Tagen bis zu 30\% ihrer Aktivität, während LOX in den ersten 14 Tagen Lagerung mit einem Anstieg der Aktivität und anschließend mit einer kontinuierlichen Aktivitätsabnahme reagierten. Damit bedarf es selbst bei Frischmaterial einer zeitnahen Untersuchung der Proben nach der Aufbereitung. 
Im Vorversuch konnten in Abhängigkeit von der Lagerung (Kapitel 5.1.2.) keine Aktivitätsveränderungen bei den untersuchten Enzymen ermittelt werden. Damit lässt sich im Vorversuch auch keine Beziehung zwischen den Enzymaktivitäten und der Schwarzfleckigkeitsneigung herstellen, da die Schwarzfleckigkeit während der Lagerung bei allen Sorten während der ersten vier Monate Lagerung anstieg (Abb.6), während sich die Enzymaktivitäten nicht veränderten. Im Hauptversuch kam es bei der freien und MA SOD zunächst bis zum vierten Lagermonat zu einem Rückgang der Aktivität, bis zum Ende der Lagerung stieg jedoch die Aktivität auf Bereiche oberhalb des Ausgangsniveaus an (Tab.33). Bei der freien LOX zeigte sich über alle Lagermonate eine kontinuierliche Abnahme der Aktivität (Tab.31), während die Aktivität der freie CAT nur bis zum 4. Lagermonat zurückging, ehe die Aktivität bis zum Ende der Lagerung wieder fast das Ausgangsniveau erreicht hat (Tab.27). Dieser Verlauf der Aktivitäten der Enzyme verhält sich vollkommen gegenläufig zu dem der Schwarzfleckigkeitsneigung (Abb.18), so dass von einer aktiven Beeinflussung der Schwarzfleckigkeit durch die einzelnen Enzyme ebenfalls nicht ausgegangen werden kann.

Mit der Veränderung der Aktivität in Abhängigkeit von der Lagerung haben sich auch Kawakami et al. (2000) beschäftigt. Bei ihren Untersuchungen während einer 15- wöchigen Lagerung bei $1{ }^{\circ} \mathrm{C}$ und bei $20^{\circ} \mathrm{C}$ gab es analog zum Vorversuch keine Unterschiede der Aktivitäten. Spychalla \& Desborough (1990) ermittelten bei $3^{\circ} \mathrm{C}$ eine höhere SOD- Aktivität als bei $9^{\circ} \mathrm{C}$ Lagertemperatur. Im Verlauf der 40- wöchigen Lagerung nahm die SODAktivität zunächst über 16 Wochen zu, blieb anschließend konstant und nahm zum Ende wieder ab, was vollkommen gegensätzlich zu den Ergebnissen des Hauptversuches ist.

Ebenso wie bei der SOD gibt es deutlich differierende Versuchsergebnisse bei der freien LOX. Berkeley \& Galliard (1974) untersuchten die LOX- Aktivität bei sechs Sorten während einer sechsmonatigen Lagerung bei $5^{\circ} \mathrm{C}$. Dabei zeigten die Sorten insgesamt eine konstante LOXAktivität. Dem gegenüber stehen die Ergebnisse von Petersen et al. (2003). In dieser Untersuchung an der Sorte Bintje wurde die LOX- Aktivität während einer Lagerung von acht Monaten ermittelt. Dabei blieb die Aktivität in den ersten Monaten nach Lagerung gleich und nahmen nach vier Monaten stark zu.

Lediglich bei der freien CAT gibt es mit unseren Ergebnissen des Hauptversuches klar übereinstimmende Ergebnisse. Mizuno et al. (1998) zeigen ebenfalls, dass die CAT-Aktivität nach anfänglicher Abnahme mit zunehmender Lagerdauer wieder ansteigt (Mizuno et al., 1998). Ursache dafür könnte das Ende der Ruheperiode der Kartoffelknolle sein, wobei der Zeitpunkt der beginnenden Keimbereitschaft in unserem Fall nicht quantifizierbar ist, sondern 
nur auf einer Annahme aufgrund der 8-monatigen Lagerdauer ohne Behandlung mit einem Keimhemmungsmittel beruht. Hintergrund dieser Annahme ist die Erkenntnis, dass die CATAktivität bei Keimbeginn der Knollen speziell im Gewebe um die Augen herum ansteigt (Kröner \&Völksen, 1950).

Abschließend bleibt festzuhalten, dass die zum Teil widersprüchlichen Versuchsergebnisse während der Lagerung nicht nur den noch bestehenden Untersuchungsbedarf, sondern in viel größerem Maße den Einfluss der Sorte auf die Aktivität einzelner Enzyme unterstreichen.

\subsubsection{Aktivität der PPO und ihre Rolle bei der Ausprägung der Schwarzfleckigkeit}

Aus Sicht der Pflanze unterstützt PPO die Eigenabwehr der Pflanze gegen Pathogene und Schädlinge (Miller, 1996) und ist am Sekundärstoffwechsel (Ligninabbau) sowie möglicherweise an der Atmung beteiligt (Haeseler, 1980).

Darüber hinaus spielt die PPO eine entscheidende Rolle in den biochemischen Prozessen der Schwarzfleckigkeitsreaktion (Cobb, 1999).

Aus diesem Grund haben Zuchtunternehmen Versuche mit transgenen Pflanzen durchgeführt, bei denen funktionierende PPO durch Genblockade inaktiviert wurde (Miller, 1996). Bei einer Gentrasformierung ist jedoch nicht kalkulierbar, wie sich die Ausgangssorte hinsichtlich ihres Wachstums oder Ertrages verändert (Corsini et al., 1999).

Bei den verwendeten Kartoffelsorten kam es zu einer deutlichen Ertragsdepression und einem Rückgang der Knollengrößen (Miller, 1996).

Die Bedeutung der PPO für den Schwarzfleckigkeitsprozess hat sich sowohl im Vor- als auch im Hauptversuch, in denen die am stärksten zur Schwarzfleckigkeit neigenden Sorten (Vorversuch: Ponto [Tab.13], Hauptversuch: Aula [Tab.34]) die signifikant höchste PPOAktivität aufwiesen, bestätigt.

Unter Berücksichtigung der spezifischen Dichte zeigt sich trotz der hoch signifikanten positiven Korrelationen zwischen dem Schwarzfleckigkeitsindex und der PPO- Aktivität kein Unterschied zwischen den Dichtefraktionen. Selbst eine Einzelbetrachtung der Sorten bestätigte dieses Ergebnis, das auch Buta \& Moline (2001) ermittelt hatten. Sie sehen darin eine Bestätigung, dass es bei der Ausprägung der Verfärbung nicht auf die PPO- Aktivität, sondern vielmehr auf den Gehalt an phenolischen Verbindungen in der Kartoffelknolle ankommt.

Während der Lagerung ist in keinem Versuchsabschnitt eine Veränderung der PPO- Aktivität beobachtet worden. Damit ist die erhöhte Schwarzfleckigkeitsneigung von Kartoffeln nach 
der Lagerung nicht auf eine Veränderung der PPO- Aktivität zurückzuführen, sondern u.a. auf die von Effmert et al (1980) beschriebenen Wasserverluste bzw. die bei der Einlagerung erfolgten Beschädigungen (Wirsing, 1997).

Buta \& Moline (2001) weisen daraufhin, dass eine durch PPO bedingte Verfärbung von Kartoffelscheiben bei Lagerung unter modifizierten atmosphärischen Bedingungen (veränderte $\mathrm{O}_{2} / \mathrm{CO}_{2^{-}}$Konzentrationen) durch Zugabe von Kaliumphosphat und Calciumchlorid in Verbindung mit Zitronensäure verhindert werden kann. Darüber hinaus wirken schwefelhaltige Aminosäuren wie Cystein in Verbindung mit Zitronensäure bei modifizierter Lagerung PPO hemmend, während sich Ascorbinsäure als uneffektiv erwiesen hat.

Damit existiert eine Beeinflussung der PPO- Aktivität durch organische Säuren, was durch die negative Korrelation zwischen Zitronensäure und PPO (Tab.25) bestätigt worden ist.

\subsection{Aminosäuregehalte und deren Verbindung zur Schwarzfleckigkeit}

Die Aminosäurezusammensetzung in der Kartoffel ist entscheidend von der Sorte abhängig. In beiden Versuchsabschnitten wurde deutlich, dass nicht nur die Summe der freien Aminosäuren (Tab. $21 \&$ 42) sortenspezifisch variiert, sondern auch der Anteil einzelner Aminosäuren (Tab.22 \& 43). Amrein et al. (2003) zeigen mit ihren Ergebnissen für Glutaminsäure und Asparaginsäure starke Sortenunterschiede. Darüber hinaus weisen die Autoren darauf hin, dass Aminosäuregehalte zudem jahresbedingt schwanken können, was sich auch in unserem Versuch anhand der einzelnen Jahresergebnisse zeigt (Anhang 10.5.1). Das Alter einer Kartoffelknolle beeinflusst die Aminosäuregehalte jedoch nicht (Amrein et al., 2003).

Im Vorversuch weist die Aminosäure Tyrosin, die am Schwarzfleckigkeitsprozess beteiligt ist (Dean et al., 1993), den absolut höchsten Gehalt in der Sorte Cilena (Tab.15b) auf. Betrachtet man Tyrosin jedoch im Kontext der Gesamtheit aller freien Aminosäuren, so enthält Ponto als Sorte größter Schwarzfleckigkeitsneigung mit 7,38\% den höchsten prozentualen Anteil des Tyrosins an den freien Aminosäuren. Im Hauptversuch verhielten sich die Sorten entsprechend. Quarta, die Sorte geringster Schwarzfleckigkeitsneigung, hat zwar mengenmäßig den größten Gehalt an Tyrosin, dennoch hat die schwarzfleckigkeitsanfällige Sorte Aula mit 7,60\% den höchsten prozentualen Anteil des Tyrosins an der Gesamtheit aller freien Aminosäuren.

Damit wird deutlich, dass nicht die absoluten Gehalte einzelner freier Aminosäuren relevant sind, sondern ihr Anteil am Gesamtpool aller freien Aminosäuren. Auch Brown et al. (1999) 
sehen darin eine mögliche Erklärung für die unterschiedliche Ausprägung der Schwarzfleckigkeit bei unterschiedlichen Sorten.

Darüber hinaus wird die Schwarzfleckigkeitsneigung einer Sorte durch die stark sortenspezifische Nutzung einzelner Aminosäuren in der Proteinbiosynthese bestimmt (Corsini et al., 1992). Daher kann Cilena trotz mengenmäßig größtem Anteil an Tyrosin eine geringere Schwarzfleckigkeitsneigung als vergleichsweise Ponto haben. Wie stark Tyrosin in der Proteinbiosynthese genutzt wird, ist genetisch fixiert (Corsini et al., 1992).

Die Untersuchung der Aminosäuregehalte in Abhängigkeit von der spezifischen Dichte ergab in dem Vor- und Hauptversuch nur die übereinstimmende Abnahme der Isoleucin- und Valingehalte mit zunehmender spezifischer Dichte. Unter Berücksichtigung der Ergebnisse des Kapitels 5.1.1 bzw. 5.2.1 ist daher davon auszugehen, dass Isoleucin und Valin keinen Einfluss auf die Schwarzfleckigkeit nehmen. Da dieses Ergebnis auf zwei Versuchsabschnitten mit 7 verschiedenen Sorten beruht und es sich bei den Gehalten um Größenordnungen wie bei der Aminosäure Tyrosin handelt, ist eine Fehlerhaftigkeit der Ergebnisse aufgrund kleiner Probenzahl bzw. geringer Aminosäuregehalte auszuschließen. Literaturhinweise über die Bedeutung dieser Aminosäuren im Schwarzfleckigkeitsprozess existieren bisher nicht.

Während der Lagerung sind in beiden Versuchsabschnitten die Aminosäuren Prolin, Serin, Threonin und Lysin signifikant angestiegen. Der Anstieg dieser Aminosäuren kann auf den während der Lagerung einsetzenden Proteinabbau, der besonders durch kalte Lagertemperaturen gefördert wird, zurückgeführt werden (Sabba \& Dean, 1996).

Die Ergebnisse zu Tyrosin während der Lagerung erwiesen sich zwischen dem Vor- und Hauptversuch als gegenläufig. Während im Vorversuch ein signifikanter Anstieg der Tyrosingehalte in allen Sorten ermittelt wurde, nahmen die Gehalte im Hauptversuch tendenziell in allen Sorten ab (Anhang 10.5.2.).

Dean et al. (1993) hatten analog zu unserem Vorversuch ein Anstieg freien Tyrosins in den Knollen während der Lagerung ermittelt und dies als Ursache erhöhter Schwarzfleckigkeitsanfälligkeit nach der Lagerung gesehen. Aus unserer Sicht unterstreichen die Ergebnisse des Vor- und Hauptversuches, dass die Schwarzfleckigkeitsreaktion nicht ausschließlich von Tyrosin, sondern von verschiedenen phenolischen Verbindungen bedingt wird. Dafür sprechen besonders die Chlorogensäuregehalte im Hauptversuch (Tab.39), bei denen über die Lagerdauer von 8 Monaten ein deutlicher Anstieg zu beobachten war. Es konnte demnach trotz tendenziell abnehmender Tyrosingehalte auch deshalb zum Anstieg der 
Neigung zur Schwarzfleckigkeit mit zunehmender Lagerdauer kommen, da der PPO durch die Chlorogensäure ausreichend Substrat zur Verfügung gestanden hat.

\subsection{Organische Säuren und ihre Rolle bei der Ausprägung der Schwarzfleckigkeit}

Die Bedeutung der organischen Säuren liegt in ihrer zentralen Stellung im Stoffwechsel. Der Zitronensäurezyklus übernimmt die Rolle der Schaltstelle der biochemischen Reaktionen, zum einen bei der Energiegewinnung, zum anderen beim Kohlenhydrat-, Fett- und Proteinabbau (Schlegel, 1992). Die organischen Säuren sind weitgehend in der Rindenschicht der Knolle lokalisiert, dabei befindet sich eine höhere Konzentration organischer Säuren am Kronenende als am Nabelende der Knolle (Schick \& Klinkowski, 1961).

Die Ergebnisse des Vor- sowie Hauptversuches haben gezeigt, dass die Gehalte einzelner organischer Säuren in Kartoffeln sortenspezifisch variieren (Tab. 17 \& 38).

In einer Vielzahl früherer Veröffentlichungen (u.a. Kolbe, 1996; Baumgartner, 1982; Müller, 1975) wird die farbstabilisierende Wirkung einzelner organischer Säuren, vor allem der Zitronensäure und der Äpfelsäure, beschrieben. Ihre Wirkung wird in der Absenkung des pHWertes gesehen (Müller, 1977). Baumgartner (1982) begründet die durch die Erhöhung der Azidität verminderte Schwarzfleckigkeitsneigung mit einer einsetzenden Hemmung der PPOAktivität.

Die Konzentration einzelner organischer Säuren ist damit für die Ausprägung der Schwarzfleckigkeit entscheidend, wie sich auch deutlich im Vorversuch zeigte. Die am stärksten zur Schwarzfleckigkeit neigende Sorte Ponto hatte sowohl die geringsten Zitronensäuregehalte, als auch die geringsten Äpfelsäure- und Weinsäuregehalte (Tab.17). Darüber hinaus konnte nicht nur eine hoch signifikante negative Korrelation zwischen Zitronensäure und dem Schwarzfleckigkeitsindex, sondern auch eine negative Korrelation zwischen Zitronensäure und der PPO ermittelt werden (Tab.25).

Im Hauptversuch ist das Ergebnis jedoch nicht ganz so eindeutig.

Es existiert zwar eine negative Korrelation zwischen Schwarzfleckigkeitsindex und Zitronensäure, jedoch enthielt nicht zwangsläufig die Sorte mit geringster Schwarzfleckigkeitsneigung die höchsten Säuregehalte.

Aussagekraft gewinnen die Ergebnisse des Hauptversuches erst durch die Zusammenfassung aller organischen Säuren (Tab.42). Das bedeutet, dass die gering anfällige Sorte Quarta den mengenmäßig größten Anteil an organischen Säuren enthält. 
Damit kommt es bei der Beurteilung der Wirksamkeit organischer Säuren im Schwarzfleckigkeitsprozess nicht nur auf einzelne organische Säuren, sondern auf die Summe aller organischen Säuren an.

Bei der Betrachtung der organischen Säuren in Abhängigkeit von der spezifischen Dichte wurde die bereits beschriebene grundlegende Bedeutung der organischen Säuren deutlich. Zitronensäure, Weinsäure und Äpfelsäure (nur im Hauptversuch) nehmen mit zunehmender spezifischer Dichte bei gleichzeitiger Zunahme der Schwarzfleckigkeitsneigung ab (Abb.13\& 25).

Die Bedeutung der Äpfelsäure und der Zitronensäure für den Schwarzfleckigkeitsprozess ist besonders hervorzuheben.

Äpfelsäure- Ionen werden gemeinsam mit $\mathrm{K}^{+}$- Ionen als osmotisch wirksame Substanzen in der Vakuole angereichert, so dass Wasser osmotisch nachströmt und der Zellturgor erhöht wird (Lüttge et al., 1999). Kolbe \& Haase (1997) bestätigen, dass geringe Turgeszenz eine hohe Schwarzfleckigkeitsneigung zur Folge hat. Damit trägt auch die Äpfelsäure zur Verringerung der Schwarzfleckigkeitsanfälligkeit bei, was sich in unserem Versuch zeigte. Ponto und Aula, die Sorten mit hoher Schwarzfleckigkeitsneigung, haben deutlich geringere Äpfelsäuregehalte als die übrigen Sorten.

Die Zitronensäure ist nicht nur durch ihre direkte, bereits beschriebene Wirkung, sondern auch durch ihre indirekte Wirkung auf Schwarzfleckigkeitsausprägung bedeutsam: Zitronensäure sorgt für eine Stabilisierung des für die Knolle wichtigen Redoxsystems Ascorbinsäure- Dehydroascorbinsäure (Müller, 1975).

Ascorbinsäure ist in der Lage, bereits gebildete Quinone in farblose Verbindungen umzuwandeln (Baumgartner, 1982). Diese Umsetzung erfolgt mittels Redoxsystems Ascorbinsäure- Dehydroascorbinsäure, wobei Ascorbinsäure oxidiert wird.

Damit verhindert die Ascorbinsäure eine Bildung der für die Ausprägung der Schwarzfleckigkeit notwendigen Melanine. Das bedeutet, dass bei geringerem Ascorbinsäuregehalt die Schwarzfleckigkeit deutlich ansteigt. Diese Wirkung zeigt sich sowohl im Vor- als auch im Hauptversuch nach der Lagerung:

Unterstrichen wird dieses Ergebnis durch die negative Korrelation zwischen SF- Index und Ascorbinsäure (Tab.25).

Die beschriebene Ascorbinsäurewirkung ist jedoch bei der Betrachtung der einzelnen Sorten und der Beziehung zur spezifischen Dichte nicht statistisch abzusichern. 
Bei Chlorogensäure handelt es sich um eine tanninartige Substanz, aus je einem Molekül Kaffeesäure und Chinasäure (Brockhaus, 1989). Phytopathologisch gesehen wirkt Chlorogensäure insektizid (Griffith et al., 1992) und anti- phytopathogen (Müller, 1975). Der Einfluss der Chlorogensäure auf die Verfärbungsneigung der Kartoffel ist umstritten. Während Baumgartner (1982) eine enge Korrelation zwischen Schwarzfleckigkeit und Chlorogensäure nachweisen konnte, spricht Dean (1997) von einer eher untergeordneten Rolle der Chlorogensäure als Substrat der PPO. Dieser von beiden Autoren geschilderte Unterschied könnte auf das unterschiedliche Sortenspektrum in beiden Versuchen zurückzuführen sein, wobei diese Vermutung aufgrund fehlender Angaben bei Dean (1997) nicht zu überprüfen ist.

Unsere Ergebnisse aus dem Vor- und dem Hauptversuch zeigen deutlich, dass die Chlorogensäuregehalte stark zwischen den Sorten variieren.

Im Vorversuch enthielt zusätzlich die am stärksten zur Schwarzfleckigkeit neigende Sorte Ponto die höchsten Chlorogensäuregehalte (Tab.17). Im Hauptversuch konnte trotz sortenspezifischer Chlorogensäuregehalte keine Beziehung zur Schwarzfleckigkeit hergestellt werden.

Während der Lagerung kam es im Vor- und Hauptversuch trotz steigender Schwarzfleckigkeitsneigung zu gegensätzlichen Entwicklungen der Chlorogensäuregehalte. Im Vorversuch veränderten sich die Chlorogensäuregehalte nicht (Tab.18), während sie im Hauptversuch bis zum Ende der Lagerung signifikant anstiegen (Tab.39). In Verbindung mit Kapitel 5.3. unterstreicht das Ergebnis des Hauptversuches, dass Chlorogensäure an der Ausprägung der Schwarzfleckigkeit beteiligt ist.

Insgesamt gesehen haben sich damit sowohl im Vorversuch als auch im Hauptversuch Hinweise ergeben, dass Chlorogensäure ein Einflussfaktor im multifaktoriellen Prozess der Schwarzfleckigkeit ist, jedoch lässt sich die Bedeutung der Chlorogensäure erst beurteilen, wenn man sie im Gesamtkontext aller Einflussfaktoren betrachtet.

Interessant für die Bewertung der Rolle der Chlorogensäure bei der Ausprägung der Schwarzfleckigkeit erscheint auch eine von Amberger und Schaller (1975) aufgestellte These. Sie gehen davon aus, dass die Farbausprägung im Schwarzfleckigkeitsprozess von der aus der Kochdunklung bekannten, nicht- enzymatischen Verfärbungsreaktion begleitet wird.

Bisher geht man davon aus, dass es sich bei der Kochdunklung und der Schwarzfleckigkeit um von einander unabhängige Verfärbungsreaktionen handelt. Amberger und Schaller (1975) sind jedoch der Meinung, dass parallel zur enzymatischen Reaktion auch die rein chemischen Prozesse in der Knolle weiterhin ablaufen, d.h., dass sich die für die Kochdunklung bekannten 
grün bis blau- grauen Eisenphenolate auch im Schwarzfleckigkeitsprozess bilden und die Ausprägung der Verfärbung, die letztendlich nur der enzymatischen Reaktion zugeschrieben wird, verstärken. In eigenen Untersuchungen zum Thema Kochdunklung (Schulze, 2004) wurde deutlich, dass das Chlorogensäure- Zitronensäure- Verhältnis für die Farbintensität von Bedeutung ist. Um der These von Amberger und Schaller (1975) nachzugehen, wurde in Abb.14 bzw. Abb.25 das Chlorogensäure- Zitronensäure-Verhältnis der Schwarzfleckigkeit gegenübergestellt.

Es ist auffällig, dass sowohl im Vorversuch als auch im Hauptversuch die für Schwarzfleckigkeit gering anfällige Sorte ein signifikant niedrigeres ChlorogensäureZitronensäure-Verhältnis als eine anfällige Sorte aufweist. Unter Berücksichtigung der Aussage Hofferberts (1986), dass die Kochdunklungsneigung mit größer werdendem Chlorogensäure- Zitronensäure-Verhältnis ansteigt, könnte es daher durchaus sein, dass neben dem enzymatischen Schwarzfleckigkeitsprozess die rein chemischen Prozesse der Kochdunklung ablaufen und die Verfärbung verstärken. Für zukünftige Untersuchungen wäre es daher interessant, versuchsbegleitende Farbhelligkeitstest durchzuführen.

\subsection{Mineralstoffgehalte und deren Verbindung zur Schwarzfleckigkeit}

Die Mineralstoffe sind in der Kartoffelknolle unregelmäßig verteilt. Die Gehalte nehmen von der Rindenschicht zur Mitte hin ab. Der überwiegende Teil der Mineralstoffe ist im Bereich des Gefäßbündelringes lokalisiert (Adler, 1971). Dieses Wissen um die Verteilung der Mineralstoffe in der Knolle ist für das Verständnis der Ergebnisse und die Erklärung der Zusammenhänge erforderlich, da sich die Schwarzfleckigkeit ebenfalls überwiegend im Bereich des Gefäßbündelringes ausprägt (Kolbe \& Haase, 1997).

In unserer Untersuchung wurde deutlich, dass die Kalium-, Magnesium- und Phosphorgehalte einerseits sortenspezifisch variieren, andererseits mit zunehmender spezifischer Dichte und signifikant zunehmender Schwarzfleckigkeitsneigung abnehmen (Abb. 14 bzw. 26).

Damit zeigte sich der grundlegende Zusammenhang ,Je mehr Kalium und Magnesium in der Knolle sind, desto geringer ist die Neigung zur Schwarzfleckigkeit' (MacNabnay et al., 1999, Hofferbert, 1986, Baumgartner, 1982). Beiden Makronährstoffen gemeinsam ist ihre allgemeine Ionenwirkung, wobei Kalium das wichtigste Ion bei der Erhöhung des osmotischen Druckes und des Quellungszustandes in der Pflanze ist (Finck, 1991).

Grundsätzlich besteht ein Antagonismus in der Aufnahme von Kalium- und Magnesiumionen aus der Bodenlösung (Schuhmann, 1999), aber Feldversuchsergebnisse haben gezeigt, dass Magnesiumdüngung nicht nur eine Erhöhung des Magnesiumgehaltes in der Knolle bewirkt, 
sondern zusätzlich zu einer deutlichen Anhebung der Kaliumgehalte in der Knolle führt (Kolbe, 1995).

Eine besondere Bedeutung kommt Magnesium und Kalium in der Aktivierung des AcetylCoA, welches eine Schlüsselstellung zwischen Kohlenhydrat- und Fettsäurestoffwechsels einnimmt, zu. Das bedeutet, dass beispielsweise bei auftretendem Kaliummangel der Zitronensäuregehalt absinkt (Amberger, 1996).

Wie bereits erwähnt, nahm neben Kalium und Magnesium auch Phosphor mit zunehmender spezifischer Dichte ab. Phosphor hat in der Pflanze eine Schlüsselfunktion im Aufbau von Biomembranen, wichtigen Coenzymen (Amberger, 1997) sowie im Energiestoffwechsel (Schuhmann, 1999). Phospholipide sind wichtige Strukturelemente der Zellmembranen und sorgen für die Funktionalität der Lipidschicht (Amberger, 1997).

Phosphormangel führt daher zur Einschränkung der Funktionalität der Zellmembranen, so dass potentiell eine erhöhte Belastungsempfindlichkeit und damit erhöhte Neigung zur Schwarzfleckigkeit gegeben ist.

Bei den Calciumgehalten waren weder im Vor- noch im Hauptversuch Unterschiede zwischen den Klassen der spezifischen Dichte erkennbar, dennoch fiel auf, dass sich im Hauptversuch die Calciumgehalte sortenspezifisch deutlich unterschieden (Tab.40). Calcium, das als Stabilisator des Plasmalemmas, der Endomembranen und der Zellwand bekannt ist (Davies, 1998), könnte daher über die sortenspezifischen Gehalte die Beschädigungsempfindlichkeit und damit die Schwarzfleckigkeitsneigung der einzelnen Sorten beeinflussen.

Bei eingeschränktem Calciumangebot in der Knolle kann laut Davies (1998) ein subzellulärer Abbau einsetzen, der eine Freilegung der Membranlipide hervorruft und damit für Lipasen oder Lipoxygenasen zugänglich macht, wodurch eine Labilität von Membranen hervorgerufen wird.

Während der Lagerung gab es lediglich im Vorversuch einen Anstieg der Kupfergehalte bzw. im Hauptversuch einen Anstieg der Magnesiumgehalte, was jedoch keine grundsätzliche Aussage über die Veränderung der Mineralstoffgehalte während der Lagerung zulässt.

Wesentlich entscheidender ist die Tatsache, dass sowohl im Vorversuch mit der Sorte Ponto als auch im Hauptversuch mit Aula die am stärksten zur Schwarzfleckigkeit neigenden Sorten die geringsten Gesamtmineralstoffgehalte aufweisen (Tab. 21\& 42), was nicht zuletzt durch Kalium als mengenmäßig stärksten Mineralstoff hervorgerufen wird. Unterstrichen wird dieser Zusammenhang durch die Abnahme der Gesamtmineralstoffgehalte mit zunehmender spezifischer Dichte (Tab.23\& 44). Damit wird klar, dass Kalium eine dominierende Stellung 
bei der Verhinderung der Schwarzfleckigkeit einnimmt, gefolgt von Magnesium und Phosphor.

\subsection{Osmotisch wirksame Substanzen}

Auf Basis der Aminosäureergebnisse (mit Ausnahme des Tyrosins), der Ergebnisse der organischen Säuren Äpfelsäure, Zitronensäure und Ascorbinsäure sowie der Mineralstoffe Kalium, Calcium, Magnesium sowie Natrium erfolgte die Ermittlung der osmotisch wirksamen Substanzen.

Hintergrund ist, dass Aminosäuren gemeinsam mit anderen organischen sowie anorganischen Osmotika die Regulation des Wasserpotentials in den Zellen übernehmen (Amberger, 1996). Tyrosin wurde nicht berücksichtigt, weil es als Substrat für PPO dient.

Besondere Bedeutung als osmotisch wirksame Substanzen haben vor allem Äpfelsäure sowie Kalium (Amberger, 1996).

Nachfolgend sind in den Abbildungen 28 \& 29 die osmotisch wirksamen Substanzen in Abhängigkeit von den Sorten dargestellt.

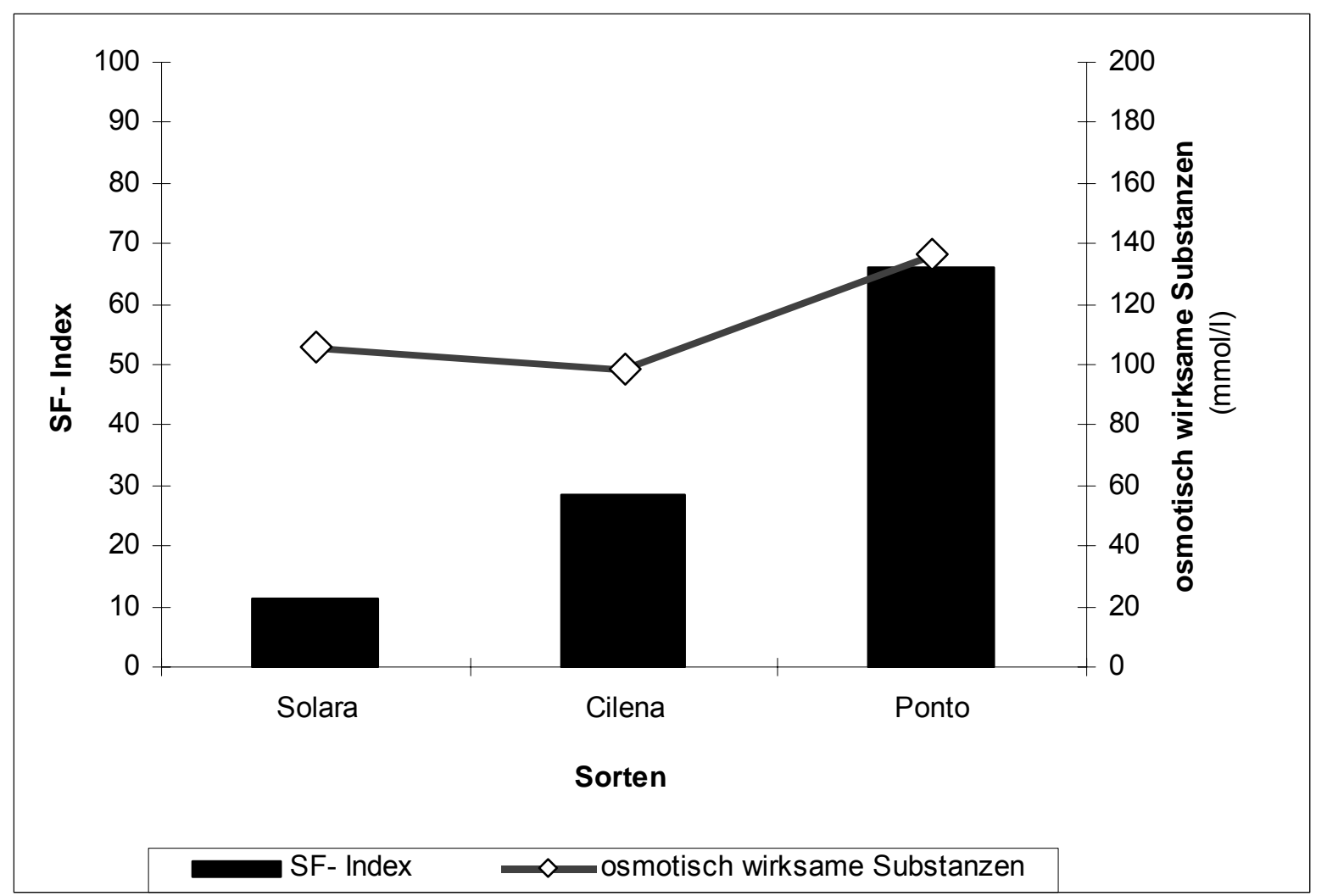

Abb. 28 Summe osmotisch wirksamer Substanzen in Abhängigkeit von den Sorten des Vorversuches und deren Schwarzfleckigkeitsneigung (Vorversuch) 


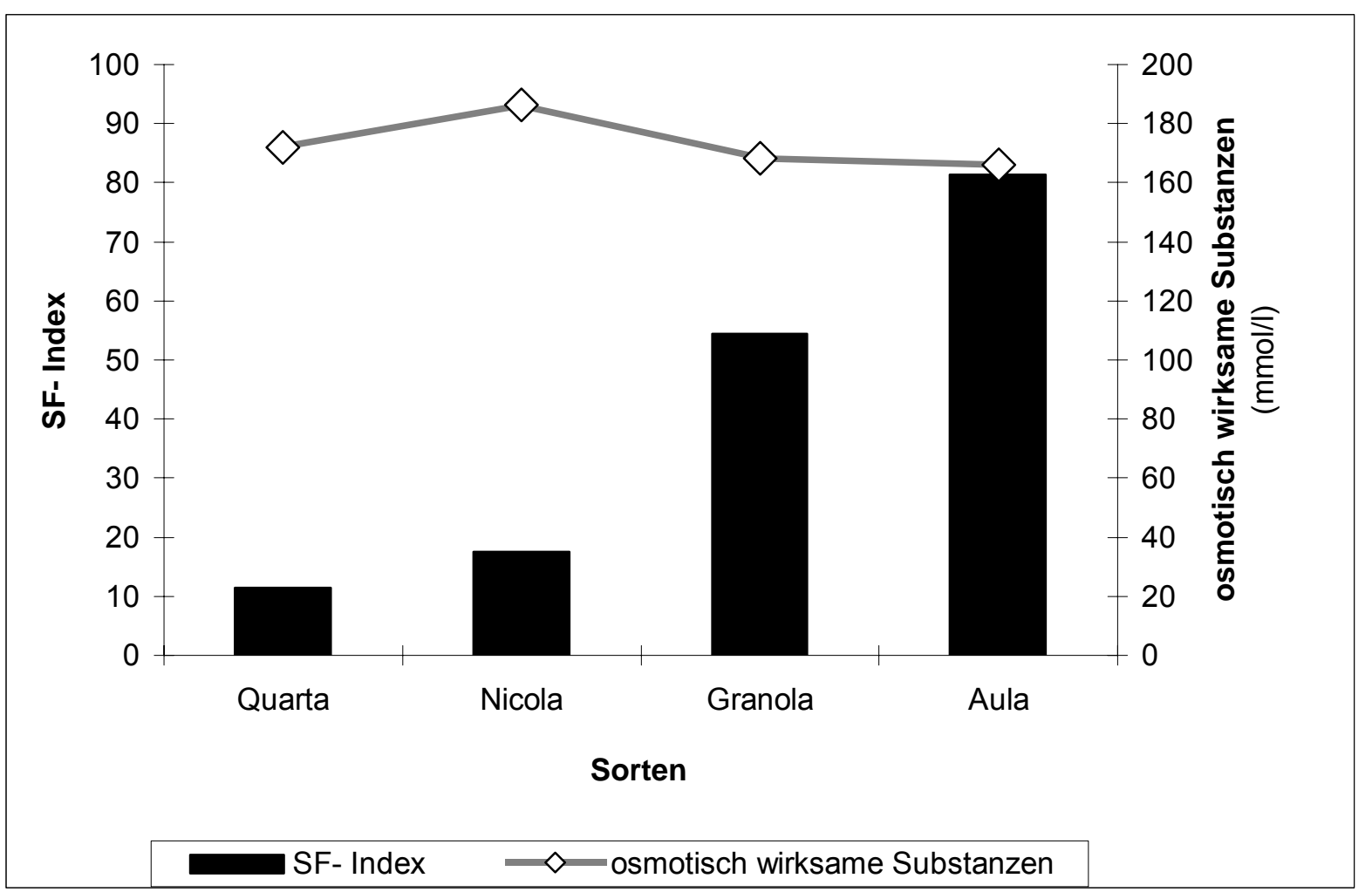

Abb. 29 Summe osmotisch wirksamer Substanzen in Abhängigkeit von den Sorten des Hauptversuches und deren Schwarzfleckigkeitsneigung (Hauptversuch)

Die Betrachtung aller Sorten eines Versuchsabschnittes macht deutlich, dass sortenspezifische Unterschiede in den Gehalten osmotisch wirksamer Substanzen bestehen. Eine klare Verbindung zwischen osmotisch wirksamen Substanzen und der Schwarzfleckigkeitsneigung ist jedoch nicht erkennbar. Während im Vorversuch die für SF- anfällige Sorte Ponto die höchsten Konzentrationen an osmotisch wirksamen Substanzen aufweist $(p<0,01)$, enthalten im Hauptversuch die SF- anfälligen Sorten die geringsten Gehalte $(\mathrm{p}<0,05)$.

Bei der Ermittlung der Beziehung zwischen spezifischer Dichte und der Summe der osmotisch wirksamen Substanzen ist weder im Vorversuch noch im Hauptversuch ein Unterschied zwischen den Klassen der spezifischen Dichte erkennbar (Abb. 30\& 31). 


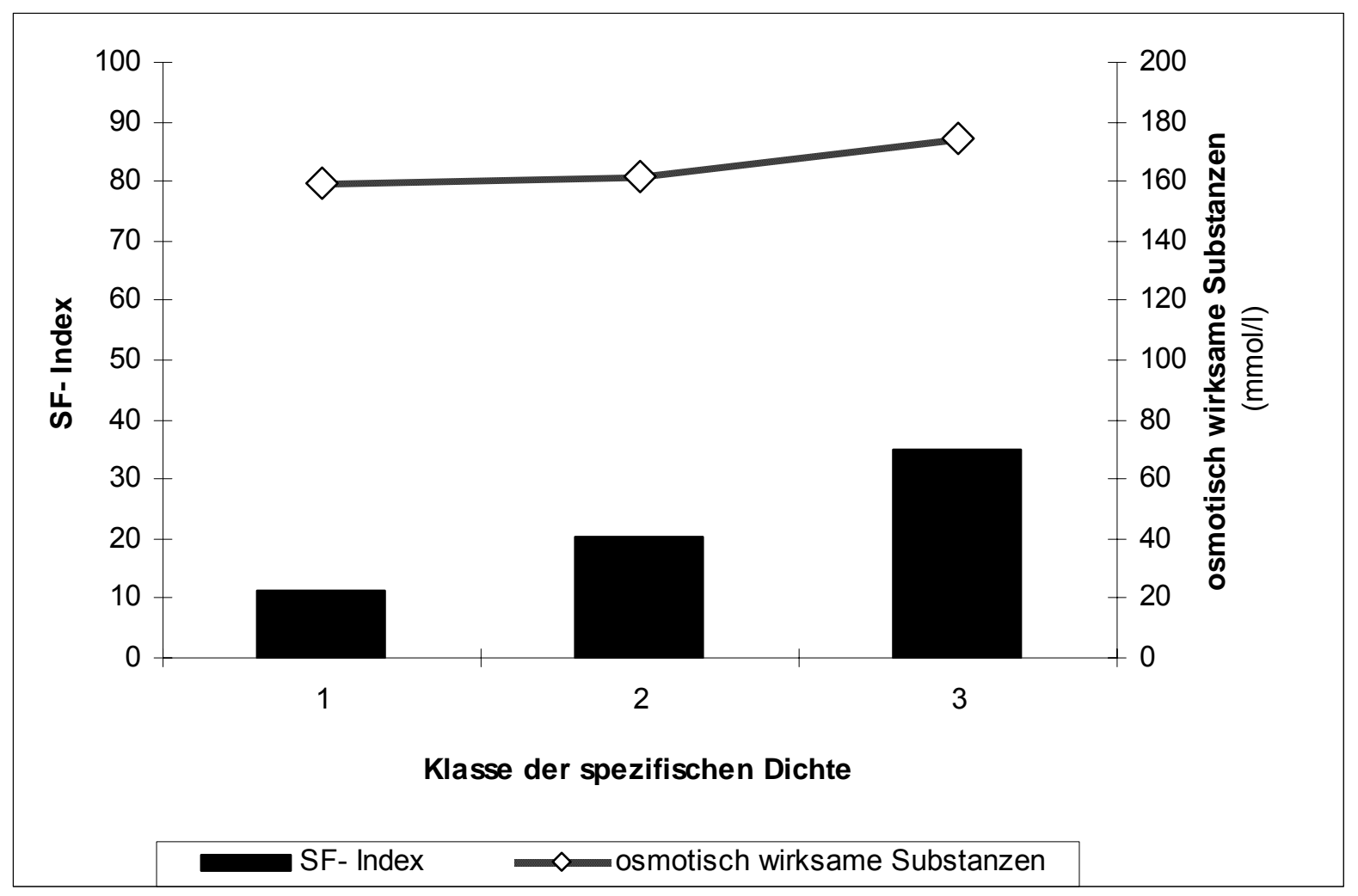

Abb. 30 Summe osmotisch wirksamer Substanzen in Abhängigkeit von der spezifischen Dichte (Vorversuch)

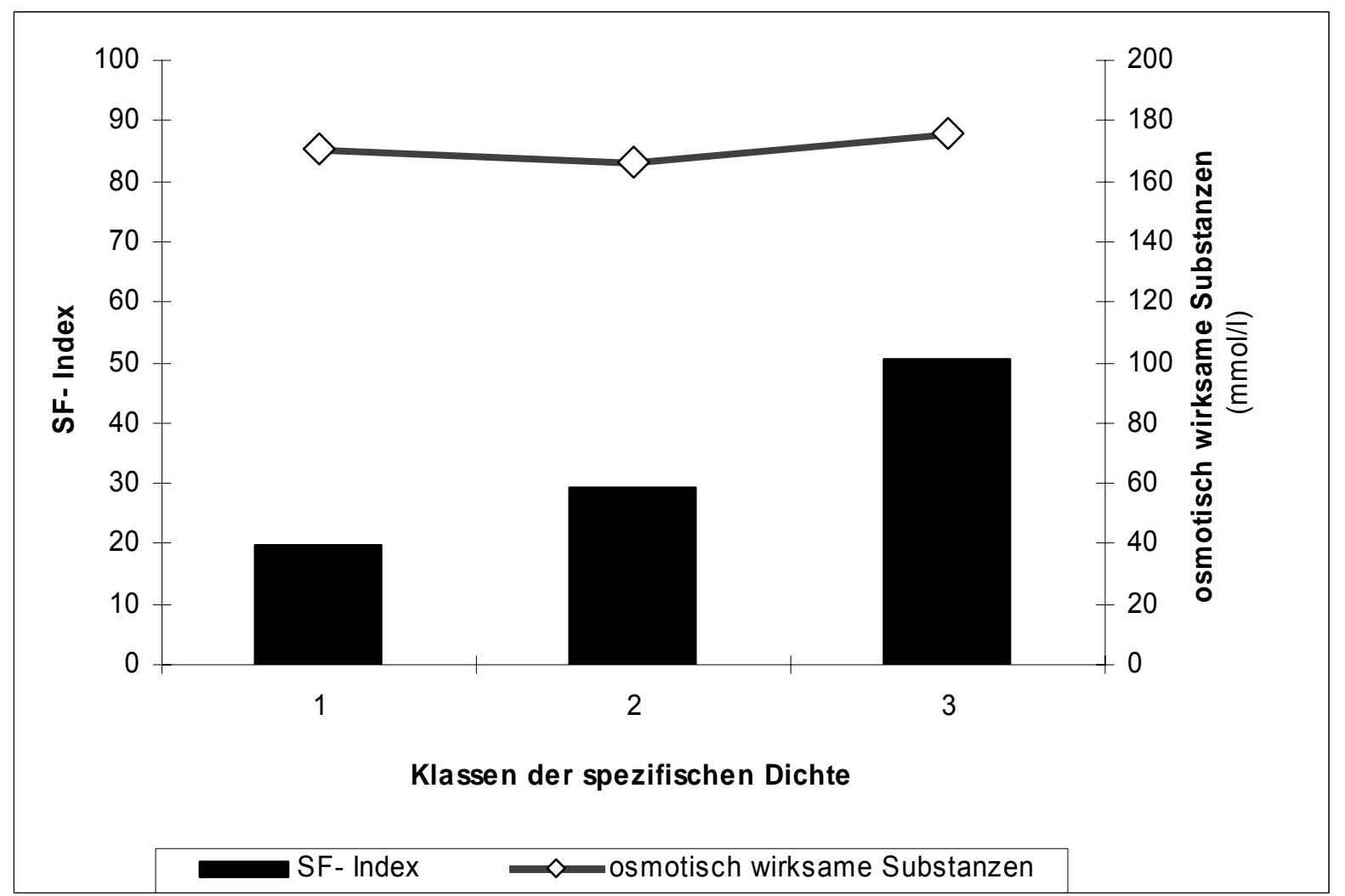

Abb. 31 Summe osmotisch wirksamer Substanzen in Abhängigkeit von der spezifischen Dichte (Hauptversuch) 
Damit kann nicht von der Summe der osmotisch wirksamen Substanzen auf die Neigung bzw. Ausprägung der Schwarzfleckigkeit geschlossen werden. Vielmehr unterstreicht dieses Ergebnis, dass die Schwarzfleckigkeit von einer Vielzahl von Faktoren abhängig ist. Eine Betrachtung von Einzelaspekten kann nur Tendenzen und eine mögliche grundsätzliche Einflussnahme erkennen lassen, aber eine Gesamtbeurteilung der Schwarzfleckigkeitsneigung ist nur unter Berücksichtigung der Sorte und aller übrigen Einflussfaktoren möglich. 


\section{SCHLUSSFOLGERUNGEN}

Mit dieser Arbeit sollte ein Beitrag zur Abklärung folgender Fragen bzw. Hypothesen geleistet werden:

1. Ist es mittels spezifischer Dichte der Knollen möglich, verschiedene Kartoffelsorten bei gleicher Knollengröße in ihrer stofflichen Zusammensetzung zu unterscheiden sowie die unterschiedliche Anfälligkeit gegenüber Schwarzfleckigkeit abzubilden?

2. Gibt es sortenspezifische Unterschiede in der Inhaltsstoffzusammensetzung der Kartoffeln? Lassen sich anhand möglicher Unterschiede Rückschlüsse auf die Ausprägung der Schwarzfleckigkeit ziehen?

a. Wie verändern sich die Gehalte an Aminosäuren, Mineralstoffe und organische Säuren in Abhängigkeit von der Sorte und der spezifischen Dichte?

b. Gibt es Unterschiede in den Enzymaktivitäten in Abhängigkeit von der Sorte und der spezifischen Dichte?

Bereits während der Ergebnisauswertung wurde deutlich, dass die spezifische Dichte die Möglichkeit bietet, indirekte Beziehungen zwischen einzelnen Versuchsgrößen herzustellen, um die Gesamtzusammenhänge genauer beleuchten zu können.

Für zukünftige Untersuchungen sollte damit eine Gradierung in unterschiedliche Klassen spezifischer Dichte bei wissenschaftlichen Untersuchungen zur Regel werden, da dadurch die Bezugsgröße klar formuliert ist und die Vergleichbarkeit gegeben ist.

Die Schwarzfleckigkeit wird durch eine Vielzahl von Faktoren bedingt.

Die Arbeit hat jedoch gezeigt, dass die Kartoffelsorte der entscheidende Einflussfaktor ist. Die sortenspezifischen Unterschiede in der Schwarzfleckigkeitsneigung beruhen auf der unterschiedlichen Inhaltsstoffzusammensetzung der Sorten.

Bei den Aminosäuren existieren nicht nur sortenspezifische Unterschiede im Gesamtgehalt freier Aminosäuren, sondern auch in der Konzentration einzelner Aminosäuren.

Die Bedeutung einzelner Aminosäuren für den Schwarzfleckigkeitsprozess ist nicht an ihrem absoluten Gehalt, sondern nur an ihrem Anteil am Gesamtpool aller freien Aminosäuren erkennbar. Durch diese Betrachtungsweise konnte die Bedeutung von Tyrosin für den Prozess der Schwarzfleckigkeitsentstehung bestätigt werden. 
Am Gesamtmineralstoffgehalt haben Kalium, Phosphor und Magnesium den größten Anteil. Alle drei Mineralstoffe nehmen einerseits mit zunehmender spezifischer Dichte ab, andererseits variieren sie stark sortenspezifisch in ihren Gehalten.

Kalium, Phosphor und Magnesium tragen somit durch ihre physiologisch spezifischen Wirkungen zur Verminderung der Schwarzfleckigkeit bei.

Sortenspezifische Unterschiede existieren auch bei den organischen Säuren. Eine gering zur Schwarzfleckigkeit neigende Sorte enthält höhere Konzentrationen an Zitronensäure, Äpfelsäure und Weinsäure. Die verstärkte Schwarzfleckigkeitsneigung einer Kartoffel nach der Lagerung ist auch mit der Abnahme der Ascorbinsäuregehalte verbunden. Darüber hinaus ist über die spezifische Dichte die Bedeutung der organischen Säuren für den Schwarzfleckigkeitsprozess ablesbar. Mit zunehmender spezifischer Dichte enthält eine Kartoffel geringere Säuregehalte, wodurch die Schwarzfleckigkeitsneigung steigt.

Chlorogensäure ist neben Tyrosin ein Reaktionspartner für die PPO. Nach der Lagerung kam es im Hauptversuch trotz abnehmender Tyrosingehalte zum Anstieg der Schwarzfleckigkeit, da offensichtlich ausreichend Chlorogensäure als Substrat zur Verfügung stand. Sortenunterschiede in den Chlorogensäuregehalten bedingen zusätzlich unterschiedliche Schwarzfleckigkeitsneigung.

Amberger \& Schaller (1975) haben vermutet, dass begleitend zum Schwarzfleckigkeitsprozess der rein chemische Prozess der Kochdunklung abläuft, wodurch eine verstärkte Verfärbungsneigung hervorgerufen wird. Tatsächlich weisen die zur Schwarzfleckigkeit neigenden Sorten ein größeres Chlorogensäure- Zitronensäure- Verhältnis als die übrigen Sorten auf, was potentiell für eine verstärkte Kochdunklungsneigung der Sorten spricht. Damit wäre eine Beeinflussung des Schwarzfleckigkeitsprozesses durch die Kochdunklung durchaus nachvollziehbar. Damit sollten zukünftige Versuche durch Farbhelligkeitstests begleitet werden, um diesem Zusammenhang zu überprüfen.

Die Ergebnisse zu den ermittelten Summen osmotisch wirksamer Substanzen zeigen tendenziell, dass die Schwarzfleckigkeitsneigung einer Kartoffel mit zunehmendem Anteil osmotisch wirksamen Substanzen zurückgeht.

Die PPO ist das für den Schwarzfleckigkeitsprozess maßgebliche Enzym. Eine für Schwarzfleckigkeit anfällige Sorte zeigt die höchste PPO- Aktivität. Unter Berücksichtigung der spezifischen Dichte wird deutlich, dass stets die Knollen mit der höchsten spezifischen Dichte trotz höchster Schwarzfleckigkeitsneigung (unabhängig von der Anfälligkeit einer 
Sorte) die niedrigste PPO- Aktivität aufweisen. Damit kommt es nicht allein auf die PPOAktivität an, sondern auch auf die Verfügbarkeit an Substrat.

Die Untersuchung der Enzyme POD, SOD, CAT, LOX ergab aus den in der Arbeit erläuterten Gründen keine eindeutige Einflussnahme auf den Schwarzfleckigkeitsprozess. Dennoch wurde deutlich, dass die Aktivität membranassoziierter Enzyme im Vergleich zu freien Enzymen größer ist. 


\section{ZUSAMMENFASSUNG}

Die vorliegende Arbeit basiert auf einem gemeinsam durchgeführten Feldversuch des Departments für Nutzpflanzenwissenschaften, Abteilung Qualität, der Universität Göttingen, der Versuchsstation für Kartoffelbau, Dethlingen, und der Bundesanstalt für Ernährung und Lebensmittel (BEL), Detmold. Mit diesem Versuch sollte ein Beitrag zur Klärung der biochemischen Ursachen der Beschädigungsempfindlichkeit einer Kartoffel geleistet werden.

Der vierjährige Versuch ist in zwei Versuchsabschnitte mit je zwei Versuchsjahren unterteilt worden. Als Sorten sind im ersten Versuchsabschnitt die Sorten Solara, Ponto und Cilena und im zweiten Versuchsabschnitt die Sorten Aula, Granola, Nicola und Quarta verwandt worden. Die verschiedenen Sorten eines Versuchsabschnittes unterscheiden sich in ihrer Schwarzfleckigkeitsneigung. Der Sortenwechsel zwischen den Versuchsabschnitten ist erfolgt, um Sorten mit gleicher Verwertungsrichtung und einem vergleichbaren Stärkegehalt prüfen zu können.

Das Kartoffelmaterial ist bis zu 8 Monate bei $4^{\circ} \mathrm{C}$ gelagert worden.

Nach Auslagerung ist die spezifische Dichte ermittelt worden. Anschließend konnte durch die so genannte Waschmaschinenmethode, die Standardmethode des Bundessortenamtes, die für die Schwarzfleckigkeitsreaktion erforderliche mechanische Belastung erzeugt werden. Nach 4- 5 Tagen erfolgte eine Bonitur der mechanisch belasteten Kartoffelknollen.

Kennzeichnend für alle untersuchten Inhaltsstoffe sind die sortenspezifischen Gehalte.

Im Rahmen der Enzymanalyse sind Ascorbat-Peroxidase, Katalase, Superoxiddismutase und Lipoxygenase sowohl in der freien als auch der membrangebundenen Form bestimmt worden. Zwischen diesen vier Enzymen und der Schwarzfleckigkeit besteht keine direkte Beziehung. Es ist dennoch deutlich geworden, dass die membrangebundenen Enzyme eine höhere Aktivität als die freien Enzyme aufweisen.

Außerdem ist das für die Schwarzfleckigkeitsreaktion essentielle Enzym PPO bestimmt worden. Eine für Schwarzfleckigkeit anfällige Sorte zeigt die höchste PPO- Aktivität. Unter Berücksichtigung der spezifischen Dichte wird deutlich, dass stets die Knollen mit der höchsten spezifischen Dichte trotz höchster Schwarzfleckigkeitsneigung (unabhängig von der Anfälligkeit einer Sorte) die niedrigste PPO- Aktivität aufweisen. 
Die Aminosäureuntersuchung ergab, dass die Bedeutung einer Aminosäure für den Schwarzfleckigkeitsprozess nicht am Gehalt der einzelnen Aminosäure ablesbar ist, sondern erst durch den prozentualen Anteil am Gesamtpool aller freien Aminosäuren.

Die Mineralstoffe Kalium, Magnesium und Phosphor leisten ebenso wie die organischen Säuren Zitronensäure, Äpfelsäure, Weinsäure und Ascorbinsäure einen Beitrag zur Verminderung der Schwarzfleckigkeit bei Kartoffeln.

Schwarzfleckigkeit ist ein seit vielen Jahren bekanntes Qualitätsproblem mit gleich bleibender Brisanz für die Wissenschaft, die Landwirte und Verarbeiter. Diese Arbeit hat deutlich gemacht, dass die Schwarzfleckigkeit durch viele Faktoren bedingt wird. Entscheidender Einflussfaktor ist jedoch die Sorte.

Damit ist vor allem die Züchtung gefordert, auf Sorten mit geringer Anfälligkeit zu selektieren. Durch die Vielzahl der inhaltsstofflichen Einflussmerkmale wird die Selektion jedoch kosten- und zeitaufwendig.

Abschließend ist festzuhalten, dass die spezifische Dichte ein geeigneter Parameter ist, um Ergebnisse untereinander zu vergleichen. 


\section{LITERATUR}

Adler, G. (1971): Kartoffeln und Kartoffelerzeugnisse. Paul Parey - Verlag, Berlin, 208 S

Aebi, H. (1967): Berliner Symposium über die Struktur und Funktion von Erythrocyten. Humboldt Universität Berlin, DDR

Aeppli,A. (1979): Einfluss der Sorte, Erntetermin und Standort auf die Blauempfindlichkeit der Kartoffeln sowie Beziehungen zwischen Blaufleckigkeit und Kartoffelrespiration. Dissertation, ETH Zürich, 154 S.

Aeppli, A. \& Keller, E.R. (1979): Einfluss des Standortes auf die Blauempfindlichkeit von Kartoffelknollen. Zeitschrift Acker- und Pflanzenbau, 148, 115- 130

Alscher, R.G., Erturk, N. und Heath, L.S.(2002): Role of superoxide dismutase (SODs) in controlling oxidative stress in plants. J. of Experimental Botany, Vol. 53, No. 372, 1331-1341

Amberger, A. \& Schaller, K. (1975): Der Einfluss von Sorte und Standort auf die an der enzymatischen Verfärbung beteiligten Inhaltsstoffe der Kartoffel. Potato Research, 18, 161-173

Amberger, A. (1996): Pflanzenernährung. 4. Auflage, UTB 846, Eugen Ulmer Verlag, Stuttgart, 180-186, 221-227, 239- 245, 256-261, 295-300

Amrein,T., Bachmann, S., Noti, A., Biedermann, M., Barbosa, M.F., Biederman- Brem, S., Grob, K., Keiser, A., Realini, P., Escher, F. \& Amado,R. (2003): Potential of Acrylamide Formation, Sugars, and Free Asparagine in Potatoes: A Comparison of Cultivars and Farming System. J Agric Food Chem, 51, 5556-5560

Asada, K. (1992): Ascorbate peroxidase- a hydrogen peroxide- scavenging enzyme in plants. Physiologia Plantarum, 85, 235-241

Bachem, C.W.B., Speckmann, G.J., Vanderlinde, P.C.G., VErheggen, F.T.M., Hunt, M.D., Steffens, J.C. \& Zabeau, M. (1994): Antisense expression of polyphenol oxidase inhibits enzymatic browning in potato tubers. Bio- Technology, 12, 1101- 1105

Baumgartner, M. (1982): Modifizierbarkeit der Blauempfindlichkeit verschiedener Kartoffelsorten durch Umweltbedingungen sowie der Einfluss ausgewählter Klimafaktoren auf die Blauempfindlichkeit. Dissertation, ETH Zürich, Nr. 6971, 127 S.

Barka, E. (2001): Protective enzymes aigainst reatice oxygen species during ripening of tomato fruits in response to low amounts of UV-C. Aust.J.Plant Physiol., 28, 785-791

Berkeley, H.D. \& Galliard, T. (1974): Lipids of Potato Tubers. IV. Effect of growth and storage on the lipid- degrading enzymes of the potato tuber. J Sci Food Agric, 25, 869- 873

Beutler, H.O. \& Beinstingl, G. (1980): Bestimmung von L-Ascorbinsäure in Lebensmitteln. Deutsche Lebensmittel- Rundschau 76, 69- 75

Birecka H. \& Miller A. (1974): Cell wall and Protoplast Isoperoxidases in Relation to Injury, Indoleacetic Acid and Ethylene Effects. Plant Physiol 53, 569-574 
Bodin, F.-K. (1984): Kartoffellagerung ohne Qualitätsverluste. KTBL- Schrift 294, KTBLSchriftenvertrieb im Landwirtschaftsverlag, Münster- Hiltrup, 152 S.

Bowler, C., Van Montagu, M. \& Inzé, D. (1992): Superoxide Dismutase and stress tolerance. Annual Review of Plant Physiology and Plant Molecular Biology, 43, 83-116

Bundessortenamt (Ed.)(2001): Beschreibende Sortenliste Kartoffeln 2001. Landbuchverlag Hannover, 21, 36-37

Bundessortenamt (Ed.)(2006): Schwarzfleckigkeit Richtlinie BSA 2006. Landbuchverlag Hannover

Burton, W.G. (1966): Cooking qualitiy. In: The potato. 2. Auflage, Wageningen, Veenman und Zonen Verlag, 183-209

Buta, J.G. \& Moline, H.E. (2001): Prevention of browning of potato slices using polyphenoloxidase inhibitors and organic acids. J Food Quality, 24, 271- 282

Bradford, M.M. (1976): A rapid and sensitive method for the quantification of microgram quantities of protein utilizing the principle of protein-dye binding. Analytical Biochemistry, $72,248-254$

Brockhaus (1989): Enzyklopädie in 24 Bänden. 19. Auflage

Brown, C.R., MacNabnay, M. \& Dean, B. (1999): Genetic characterization of reduced melanin formation in tuber tissue of Solanum hjertingii and hybrids with cultivated diploids. Am J of Potato Res, 76, Nr.1, 37-43

Civello P.M., Martinez G.A., Chave A.R. \& Añón M.C. (1995): Peroxidase from strawberry fruit (Fragaria $\mathrm{x}$ ananassa Duch.): partial purification and dertermination of some properties. $\mathrm{J}$ Agric Food Chem 43, 2596-2601

Cobb, A.H. (1999): A review of the physiology of bruising in potatoes. Proceedings of the 14th Triennal Conference of the EAPR, 198- 199

Cohen, S.A. \& Michaud, D.P. (1993): Synthesis of a fluorescent derivating reagent, 6aminoquinolyl-n-hydroxysuccinidyl carbamate, and its application for the analysis of hydrolysate amino acids via high performance liquid chromatography. Analytical Biochemistry, 211, 279-287

Corsini, D., Pavek, J. \& Dean, B. (1992): Differences in free and protein-bound tyrosine among potato genotypes and Relationship to internal blackspot resistance. Am J of Potato Res, $69,423-435$

Corsini, D., Stark, J. \& Thornton, M. (1999): Factors contributin to the blackspot bruise potential of Idaho potato fields. Am J of Potato Res 76, Nr. 4, 221-226

Davenport, J.R. (2000): Potassium and specific gravity of potato tubers. Better Crops, 94, 4, 14-15 
Davies, H.V. (1998): Physiological mechanisms associated with the development of internal necrotic disorders of potato. Am J of Potato Res 75, Nr. 1, 37- 44

Dean, B.B., Jackowiak, N., Nagle, M., Pavek, J. \& Corsini, D. (1993): Blackspot pigment development of resistant ans susceptible Solanum tuberosum L. Genotypes at harvest ans during storage measured by three methods of evaluation. Am J of Potato Res. 70, 201-217

Dean, B.B. (1997): The chemical nature of blackspot bruising. Spudman, 5, 12-15

Dipierro, S. \& De Leonardis, S. (1997): The ascorbate system and lipid peroxidation in stored potato (Solanum tuberosum L.) tubers. Journal of Experimental Botany, 48, 779- 783

Effmert, B. \& Schüler, K. (1978): Untersuchungen über die Ursachen der Schwarzfleckgkeit. EAPR_Berichte der 7. Dreijahrestagung 1978, Warschau, S.121f

Fauconnier, M.L., Rojas- Beltrán, J., Delcarte, J., Dejaegher, F., Marlier, M. \& du Jardin, P. (2002): Liopxygenase pathway and menbrane permeability and composition during torage of potato tubers (Solanum tuberosum) in different consitions. Plant Biology, 4, 77-85

Fretzdorff, B. \& Bergthaller, W. (1989): Einflüsse des Einfrierens und der Tiefgefrierlagerung auf Enzymaktivitäten in rohen Kartoffelwürfeln. Lebensmittel- und Biotechnologie, 5, 257259

Finck, A. (1991): Pflanzenernährung in Stichworten. 5. Auflage, Hirt Verlag, Stuttgart, 200 S.

Griffiths, D.H., Bain, H. \& Date, M.F.B. (1992): Development of a rapid colorimetric method for determination of chlorogenic acid in freeze- dried potato tuber. J Sci Food Agric, 41-48

Griffiths, D.H. \& Bain, H (1997): Photo- induced changes in the concentrations of individual chlorogenic acid isomers in potato (Solanum tuberosum) tubers and their complexation with ferric irons. Potato Research, 40, 307- 315

Haase, N.U. (1999): Enzymatische Verfärbung der Kartoffelknolle- Labormethoden im Vergleich. In: Bericht über die 21. Kartoffeltagung, Granum-Verlag, Detmold, 42-53

Haeseler, E. (1980): Ursachen und Verlauf der enzymatischen Bräunung von Kartoffelknollen verschiedener Sorten und Reifegrade. Dissertation, FAL Braunschweig, 98S.

Haiger, A. (1978): Biometrische Methoden in der Tierproduktion. Österreichischer Agrarverlag Wien

Hallaway, M., Phtethean, P.D. \& Taggart, J. (1970): A critical study of the intracellular distribution of ascorbate oxidase and a comparison of the kinetics of the soluble and cellwall enzyme. Phytochemistry, 9, 935- 944

Horne, A.S. (1913): Contributions from the Wisley Laboratory. XVI. Bruise in potatoes. J. Roy. Hort. Soc., 38, 40- 50

Hudson, D.E. (1975): The relationship of cell size, intercellular space and specific gravity to bruise depth in potatoes. Am Potato J, 52, 9-14 
Hughes,J.C. \& Mapson L.W. (1967): Chemical and Enzymatic Discloration in Potatoes. Proc. $2^{\text {nd }}$ int. Congr. Food Science Technol. Warschau, 119-135

Hofferbert, H.-R. (1986): Bodenart und Kartoffelqualität. KTBL- Schrift 314, KTBLSchriftenvertrieb im Landwirtschaftsverlag, Münster- Hiltrup, $121 \mathrm{~S}$.

Kawakami, S., Mizuno, M. \& Tsuchida, H. (2000): Comparison of antioxidant enzyme between Solanum tuberosum cultivars Danshaku and Kitaakari during low- temperature storage. J Agric Food Chem, 48, 2117- 2121

Kiefer, M. (2002): Zum antioxidativen Verteidigungssystem bei Mesembryanthenum Crystallinum, Dissertation, Ruprecht- Karls-Universität, Heidelberg, OnlineVeröffentlichung

Kolbe, H. (1995): Die Nährstoffversorgung und Qualität der Kartoffel. 1. Auflage, Severin Verlag, Göttingen, $113 \mathrm{~S}$.

Kolbe, H. (1996): Einflussfaktoren auf die Inhaltsstoffe der Kartoffel - Teil VI: Organische Säuren. Kartoffelbau, 47, Nr.9, 345- 347

Kolbe, H. \& Haase, N.U. (1997): Einflussfaktoren auf die Inhaltsstoffe der Kartoffel. Kartoffelbau, 48, Nr.6, 234- 240

Kröner, W. \& Völksen, W. (1950): Die Kartoffel- Die wichtigsten Eigenschaften der Knolle als Lebensmittel und Rohstoff. Heft 9, aus: Die Ernährung, Barth Verlag Leipzig, 172 S.

Lærke, P.E., Brierley, E.R. \& Cobb, A.H. (2000): Impact- induced blackspots and membrane deterioration in potato (Solanum tuberosum) tubers. J Sci Food Agric, 80, 1332- 1338

Lærke, P.E. (2001): Blackspot in potato tubers, Ph.D. thesis, The Royal Veterinary and Agricultural University, Frederiksberg

Lüttge, U., Kluge, M. \& Bauer, G. (1999): Botanik. 3. Auflage, Wiley-VCH Verlag, Weinheim, 625S.

Lulai, E.C. (1988): Induction of lipoxygenase actvity increases: a response to tuber wounding. Am Potato J, 65, 490

McNabnay, M., Dean, B.B., Bajeman, R.W. \& Hyde, G.M. (1999): The effect of potassium deficiency on chemical, biochemical and physical factors commonly associated with blackspot development in potato tubers. Am J of Potato Res 76, 221- 226

Meixner, S. (1999): Praktikumsmethodensammlung Universität Hamburg, Institut für Biochemie und Lebensmittelchemie, Abteilung Lebensmittelchemie, Bestimmung der Superoxiddismutase (SOD). SOP-Nr. 1999-18

Miller, M. (1996): Gentransfer und Schwarzfleckigkeit. Kartoffelbau, 47, Nr.6, 234- 236

Mizuno, M., Kamei, M. \& Tsuchida, H.(1998): Ascorbate Peroxidase and Catalase cooperate for protection aigainst hydrogen peroxide generated in potato tubers during low-temperature storage. Biochemistry and molecular biology international, No.4, 717-726 
Molema, G.J. \& Bosma, A.H. (1998): Einfluss mehrmaliger Belastung auf Schwarzfleckigkeit bei Speisekartoffeln. Kartoffelbau, 49, Nr.1/2, 20-23

Mondy, N.I. \& Munshi, C.B. (1993): Effect of maturity and storage on Ascorbic acid and Tyrosine concentrations and enzymatic discoloration of potatoes. J Agric Food Chem, 41, $1868-1871$

Müller, K. (1975): Veränderungen wertgebender Inhaltsstoffe in der Kartoffelpflanze und -knolle im Verlauf von Vegetation und Lagerung, ihre Bedeutung für die Qualität der Knolle. Schriftenreihe der Förderungsgemeinschaft der Kartoffelwirtschaft, Band 17, 148 S.

Müller, K. (1977): Chemisch und physiologisch bedingte Ursachen von Blaufleckigkeit, Rohbreiverfärbung und Kochdunklung der Kartoffeln. Kali-Briefe, Fachgebiet 2, 11. Folge, Band 13, 14S.

Ojala, J. (1995): Know what makes blackspot bruise. Potato Grower 24, Nr.6, 22

Orlovius, K. (1996): Kalium- Menge und Form bestimmen den Ertrag und die Qualität. Kartoffelbau, 47, Nr.3, 83- 85

Pawelzik, E. \& Delgado, E. (1999): Wirkung von Trockenstress auf die Verfärbungsneigung von Kartoffelknollen, Kartoffelbau, 50, Nr. 9/10, 524-527

Petersen, M.A., Poll, L. \& Larsen, L.M. (2003): Changes in flavor- affecting aroma compounds during potato storage are not associated with Lipoxygenase activity.

Am J of Potato Res, 80, 397-402

Putz, B. (1998): Kartoffeln- Züchtung- Anbau- Verwertung. 3. Auflage, Behr`s Verlag, Hamburg, $263 \mathrm{~S}$.

Rosahl, S. (1996): Lipoxygenases in Plants. Their role in development and stress response. Zeitung für Naturforschung, 51c, 123-138

Sabba, R.P. \& Dean, B.B. (1996): Effect of cold storage on proteinase and chlorismate mutase activities in Solanum tuberosum genotypes differing in blackspot susceptibility. Am Potato J, $73,113-122$

Schick, R. \& Klinkowski, M. (1961): Die Kartoffel- Ein Handbuch Band 1. VEB Deutscher Landwirtschaftsverlag, Berlin, $1008 \mathrm{~S}$.

Schlegel, H.G. (1992): Allgemeine Mikrobiologie, 7. Auflage, Thieme Verlag, Stuttgart, 634 S.

Schuhmann, P. (1997): Speisefrischkartoffeln, Qualität erzeugen, erfassen, lagern, vermarkten, 1. Auflage, Agri Media im Verlag Alfred Strothe, Holm, 156 S.

Schuhmann, P. (1999): Die Erzeugung von Kartoffeln zur industriellen Verarbeitung, 1. Auflage, Agri Media Verlag, Bergen/Dumme, 208 S. 
Schulze, A. (2004): Physiologisches Alter der Pflanzkartoffel: Einfluss auf Kochdunklung und pflanzenbauliche Merkmale. Kartoffelbau, 55, 5, 184- 187

Siedow, J. (1991): Plant Lipoxygenase: structure and function. Annual Review of Plant Physiology and Plant Molecular Biology, 42, 145 - 188

Spychalla, J.P. \& Desborough, S.L. (1990): Superoxide Dismutase, Catalase and $\alpha$ Tocopherol content of stored potato tubers. Plant Phys., 94, 1214- 1218

Stark, J.C., Corsini, D., Hurley, P.J. \& Dwelle, R.B. (1985): Biochemical characteristics of potato clones differing in blackspot susceptibility. Am Potato J, 62, 657- 666

Stevens, L.H. \& Davelaar, E. (1997): Biochemical potential of potato tubers to synthesize blackspot pigments in relation to their actual blackspot suseptibility. J Agric Food Chem, 45, $4221-4226$

Streubing, L. \& Fangmeier, A. (1992): Pflanzenökologisches Praktikum. Eugen Ulmer Verlag, Stuttgart

Stricker, H.W. (1981): Das Auftreten von Schwarzfleckigkeit in Abhängigkeit von Lagerungsmaßnahmen, vom Anbauort und vom Anbaujahr. Kartoffelbau 32, 12-17

Swain, T., Mapson, L.W. \& Tomalin, A.W. (1964): The enzymatic browning of potatoes, Potato Journal, 7, No.4, 252

Thornton, M. \& Workman, M (1987): Changes in ascorbic acid content of blackspot- resistant and-susceptible potatoes following bruising. HortScience, 22, 455

Thornton, M. (1994): Seven tips to help control bruising, Potato Grower, 35, Nr. 5, 39- 52

VDLUFA (Herausgeber) (1976): Methodenbuch des VDLUFA, III. Chemische Untersuchung von Futtermitteln, Verlag J. Neumann- Neudamm, Melsungen

Weaver, M.L. \& Hautala, E. (1969): Recovery and stability of phenolase, peroxidase and catalase activity in dried potato tissue. J Sci Food Agric, 20, 627- 629

www.wetteronline.de, besucht Mai 2005

Welte, E. \& Müller, K. (1966): Über den Einfluss der Kaliumdüngung auf die Dunkelung von rohem Kartoffelbrei. Potato Journal, 9, 1, 36- 44

Welz, B. (1983): Atomabsorptionsspektrometrie. 3. Auflage, Verlag Chemie GmbH, Weinheim

Willekens, H., Chamnongpol, S., Davey, M., Schrauder, M., Langebartels, C., von Montagu, M., Inzé, D. \& van Camp, W. (1997): Catalase is a sink for $\mathrm{H}_{2} \mathrm{O}_{2}$ and is indispensable for stress defence in $\mathrm{C}_{3}$ plants. The EMBO Journal, 16, 4806- 4816

Wirsing, F. (1997): Einfluss von Stressfaktoren auf Qualitätsmerkmale von Kartoffeln. Kartoffelbau, 48, Nr.6, 272- 277 
Wormanns, G. (1999): Qualitätssicherung von Kartoffeln im Nacherntebereich- Das Problem der Schwarzfleckigkeit und Maßnahmen zu ihrer Vermeidung, Landtechnik, 45, 4, 210- 211

Wright, P.J., Triggs, C.M. \& Anderson, J.A.D. (2005): Effects of specific gravity and cultivar on susceptibility of potato (Solanum tuberosum) tubers to blackspot bruising and bacterial soft rot. New Zealand Journal of Crop and Horticultural Science, 33, 353- 361

Zimmermann, P. \& Zentgraf, U. (2004): Der Zusammenhang zwischen oxidativem Stress und Blattseneszenz während der Entwicklung von Pflanzen, Internet: www.springerlink.com , Stand: Januar 2005 


\section{ANHANG}

10.1. KATALASE ( $\triangle$ Aktivität $10 \mathrm{~min}^{-1} \mathrm{mg}$ Protein)

\begin{tabular}{|c|c|c|c|c|c|}
\hline Termin & Sorte & $S D$ & freie CAT & MA CAT & SF- Index \\
\hline \multirow{12}{*}{$\begin{array}{l}\text { OKTOBER } \\
2000\end{array}$} & \multirow[t]{4}{*}{ Cilena } & ungradiert & 0,65588 & 1,14640 & 10,48 \\
\hline & & $<1,055$ & 0,46142 & 1,10012 & 9,71 \\
\hline & & $<1,065$ & 0,33257 & 1,02034 & 20,29 \\
\hline & & $>1,065$ & 0,51568 & 0,63017 & 27,65 \\
\hline & \multirow[t]{4}{*}{ Ponto } & ungradiert & 0,41305 & 1,06192 & 59,86 \\
\hline & & $<1,085$ & 0,59464 & 0,62024 & 14,48 \\
\hline & & $<1,095$ & 0,45300 & 1,17561 & 42,42 \\
\hline & & $>1,095$ & 0,37891 & 1,62098 & 75,11 \\
\hline & \multirow[t]{4}{*}{ Solara } & ungradiert & 0,59292 & 0,88209 & 5,26 \\
\hline & & $<1,065$ & 0,50994 & 0,69113 & 1,65 \\
\hline & & $<1,075$ & 0,46318 & 0,73243 & 1,42 \\
\hline & & $>1,075$ & 0,28233 & 4,16575 & 6,08 \\
\hline \multirow{12}{*}{$\begin{array}{l}\text { FEBRUAR } \\
2001\end{array}$} & \multirow[t]{4}{*}{ Cilena } & ungradiert & 0,38447 & 0,64529 & 24,05 \\
\hline & & $<1,055$ & 0,40656 & 0,64651 & 12,50 \\
\hline & & $<1,065$ & 0,37044 & 2,68462 & 20,32 \\
\hline & & $>1,065$ & 0,43657 & 0,55943 & 36,79 \\
\hline & \multirow[t]{4}{*}{ Ponto } & ungradiert & 0,43760 & 1,41707 & 92,59 \\
\hline & & $<1,095$ & 0,37753 & 1,73617 & 70,41 \\
\hline & & $<1,105$ & 0,34434 & 0,78792 & 100,00 \\
\hline & & $>1,105$ & 0,69439 & 0,46110 & 100,00 \\
\hline & \multirow[t]{4}{*}{ Solara } & ungradiert & 0,47975 & 0,41927 & 20,32 \\
\hline & & $<1,065$ & 0,30404 & 0,40592 & 4,60 \\
\hline & & $<1,075$ & 0,31872 & 0,45642 & 13,17 \\
\hline & & $>1,075$ & 0,43794 & 0,64140 & 29,28 \\
\hline \multirow{12}{*}{$\begin{array}{l}\text { JUNI } \\
2001\end{array}$} & \multirow[t]{4}{*}{ Cilena } & ungradiert & 0,47343 & 0,75824 & 34,68 \\
\hline & & $<1,055$ & 0,41005 & 0,44345 & 8,48 \\
\hline & & $<1,065$ & 0,39573 & 0,35081 & 24,00 \\
\hline & & $>1,065$ & 0,39573 & 17,27126 & 42,31 \\
\hline & \multirow[t]{4}{*}{ Ponto } & ungradiert & 0,46946 & 0,87511 & 90,71 \\
\hline & & $<1,095$ & 0,39572 & 0,66595 & 51,49 \\
\hline & & $<1,105$ & 0,53528 & 0,80089 & 77,33 \\
\hline & & $>1,105$ & 0,54788 & 1,73376 & 98,52 \\
\hline & \multirow[t]{4}{*}{ Solara } & ungradiert & 0,35867 & 0,45055 & 21,91 \\
\hline & & $<1,065$ & 0,20612 & 0,36516 & 5,99 \\
\hline & & $<1,075$ & 0,34511 & 0,56986 & 9,78 \\
\hline & & $>1,075$ & 0,29982 & 0,98619 & 30,95 \\
\hline
\end{tabular}




\begin{tabular}{|c|c|c|c|c|c|}
\hline Termin & Sorte & $S D$ & freie CAT & MA CAT & SF- Index \\
\hline \multirow{11}{*}{$\begin{array}{l}\text { OKTOBER } \\
2001\end{array}$} & \multirow[t]{3}{*}{ Cilena } & ungradiert & 0,44682 & 0,66846 & 4,70 \\
\hline & & $<1,075$ & 0,48157 & 1,07285 & 8,20 \\
\hline & & $<1,085$ & 0,34762 & 1,77612 & 10,70 \\
\hline & \multirow[t]{4}{*}{ Ponto } & ungradiert & 0,42246 & 3,29314 & 4,20 \\
\hline & & $<1,095$ & 0,42277 & 1,09586 & 13,60 \\
\hline & & $<1,105$ & 0,43870 & 0,84740 & 9,00 \\
\hline & & $>1,105$ & 0,56077 & 1,53389 & 33,10 \\
\hline & \multirow[t]{4}{*}{ Solara } & ungradiert & 0,35218 & 0,71355 & 5,30 \\
\hline & & $<1,075$ & 0,41280 & 0,74810 & 1,70 \\
\hline & & $<1,085$ & 0,33164 & 1,04170 & 9,20 \\
\hline & & $>1,085$ & 0,51513 & 0,91490 & 14,30 \\
\hline \multirow{12}{*}{$\begin{array}{l}\text { FEBRUAR } \\
2002\end{array}$} & \multirow[t]{4}{*}{ Cilena } & ungradiert & 0,40880 & 0,61644 & 29,10 \\
\hline & & $<1,075$ & 0,36695 & 0,52654 & 22,70 \\
\hline & & $<1,085$ & 0,35284 & 0,69138 & 39,80 \\
\hline & & $>1,085$ & 0,35134 & 1,57941 & \\
\hline & \multirow[t]{4}{*}{ Ponto } & ungradiert & 0,44891 & 1,41791 & 81,30 \\
\hline & & $<1,095$ & 0,38305 & 0,60832 & 69,50 \\
\hline & & $<1,105$ & 0,39429 & 0,48421 & 87,00 \\
\hline & & $>1,105$ & 0,41942 & 0,70692 & 93,80 \\
\hline & \multirow[t]{4}{*}{ Solara } & ungradiert & 0,36785 & 0,47464 & 12,50 \\
\hline & & $<1,075$ & 0,42427 & 0,48245 & 7,80 \\
\hline & & $<1,085$ & 0,47756 & 1,01914 & 11,60 \\
\hline & & $>1,085$ & 0,40022 & 1,07070 & 20,80 \\
\hline \multirow{12}{*}{$\begin{array}{l}\text { JUNI } \\
2002\end{array}$} & \multirow[t]{4}{*}{ Cilena } & ungradiert & 0,31786 & 0,83297 & 45,40 \\
\hline & & $<1,075$ & 0,30579 & 0,54612 & 37,10 \\
\hline & & $<1,085$ & 0,37542 & 0,76936 & 44,60 \\
\hline & & $>1,085$ & 0,39983 & 1,13040 & 92,00 \\
\hline & \multirow[t]{4}{*}{ Ponto } & ungradiert & 0,64136 & 0,97513 & 93,10 \\
\hline & & $<1,095$ & 0,45967 & 0,63832 & 66,40 \\
\hline & & $<1,105$ & 0,39842 & 2,15371 & 86,90 \\
\hline & & $>1,105$ & 0,55228 & 0,47952 & 97,50 \\
\hline & \multirow[t]{4}{*}{ Solara } & ungradiert & 0,38946 & 0,84936 & 19,00 \\
\hline & & $<1,075$ & 0,31359 & 0,62292 & 7,40 \\
\hline & & $<1,085$ & 0,29404 & 0,38241 & 15,00 \\
\hline & & $>1,085$ & 0,31365 & 0,50110 & 15,80 \\
\hline
\end{tabular}




\begin{tabular}{|c|c|c|c|c|c|}
\hline Termin & Sorte & $S D$ & freie CAT & MA CAT & SF- Index \\
\hline \multirow{16}{*}{$\begin{array}{l}\text { OKTOBER } \\
2002\end{array}$} & \multirow[t]{4}{*}{ Aula } & ungradiert & 0,44860 & 0,60035 & 94,40 \\
\hline & & $<1,085$ & 0,34519 & 0,49668 & 68,60 \\
\hline & & $<1,095$ & 0,69287 & 0,85648 & 97,10 \\
\hline & & $>1,095$ & 0,46970 & 1,00640 & 98,00 \\
\hline & \multirow[t]{4}{*}{ Granola } & ungradiert & 0,43268 & 2,47455 & 31,20 \\
\hline & & $<1,065$ & 0,45719 & 0,62044 & 20,50 \\
\hline & & $<1,075$ & 0,44210 & 4,95494 & 20,80 \\
\hline & & $>1,075$ & 0,63706 & 1,05601 & 74,50 \\
\hline & \multirow[t]{4}{*}{ Nicola } & ungradiert & 0,47161 & 0,43096 & 2,50 \\
\hline & & $<1,065$ & 0,46187 & 0,68659 & 1,60 \\
\hline & & $<1,075$ & 0,40006 & 0,74426 & 2,50 \\
\hline & & $>1,075$ & 0,67348 & 0,52716 & 8,90 \\
\hline & \multirow[t]{4}{*}{ Quarta } & ungradiert & 0,39490 & 0,39198 & 12,70 \\
\hline & & $<1,065$ & 0,47336 & 0,48305 & 6,70 \\
\hline & & $<1,075$ & 0,27365 & 0,68800 & 7,50 \\
\hline & & $>1,075$ & 0,40701 & 0,38159 & 19,90 \\
\hline \multirow{16}{*}{$\begin{array}{l}\text { FEBRUAR } \\
2003\end{array}$} & \multirow[t]{4}{*}{ Aula } & ungradiert & 0,42667 & 0,46851 & 89,50 \\
\hline & & $<1,085$ & 0,46953 & 0,44135 & 88,30 \\
\hline & & $<1,095$ & 0,43089 & 0,62975 & 96,80 \\
\hline & & $>1,095$ & 0,49060 & 0,57580 & 99,60 \\
\hline & \multirow[t]{4}{*}{ Granola } & ungradiert & 0,47351 & 0,79541 & 66,40 \\
\hline & & $<1,065$ & 0,37002 & 0,35099 & 46,10 \\
\hline & & $<1,075$ & 0,29089 & 0,41396 & 80,90 \\
\hline & & $>1,075$ & 0,52036 & 0,52515 & 94,60 \\
\hline & \multirow[t]{4}{*}{ Nicola } & ungradiert & 0,43563 & 0,26995 & 13,00 \\
\hline & & $<1,065$ & 0,35621 & 0,35597 & 2,70 \\
\hline & & $<1,075$ & 0,38360 & 0,57275 & 11,30 \\
\hline & & $>1,075$ & 0,34137 & 0,30024 & 20,70 \\
\hline & \multirow[t]{4}{*}{ Quarta } & ungradiert & 0,29694 & 0,20471 & 15,70 \\
\hline & & $<1,065$ & 0,43508 & 0,47537 & 4,90 \\
\hline & & $<1,075$ & 0,42247 & 0,47991 & 9,10 \\
\hline & & $>1,075$ & 0,40689 & 0,61578 & 14,00 \\
\hline \multirow{4}{*}{$\begin{array}{l}\text { JUNI } \\
2003\end{array}$} & \multirow[t]{4}{*}{ Aula } & ungradiert & 0,36081 & 0,43350 & 79,00 \\
\hline & & $<1,085$ & 0,42104 & 0,41714 & 92,50 \\
\hline & & $<1,095$ & 0,51168 & 0,92941 & 98,10 \\
\hline & & $>1,095$ & 0,52214 & 0,43144 & 98,90 \\
\hline
\end{tabular}




\begin{tabular}{|c|c|c|c|c|c|}
\hline Termin & Sorte & $S D$ & freie CAT & MA CAT & SF- Index \\
\hline & \multirow[t]{4}{*}{ Granola } & ungradiert & 0,53235 & 1,35137 & 72,60 \\
\hline & & $<1,065$ & 0,49202 & 0,45160 & 37,10 \\
\hline & & $<1,075$ & 0,36875 & 1,38642 & 75,50 \\
\hline & & $>1,075$ & 0,36016 & 1,77563 & 87,40 \\
\hline & \multirow[t]{4}{*}{ Nicola } & ungradiert & 0,39457 & 0,32557 & 13,90 \\
\hline & & $<1,065$ & 0,49507 & 0,25661 & 7,50 \\
\hline & & $<1,075$ & 0,38459 & 0,84147 & 9,70 \\
\hline & & $>1,075$ & 0,43399 & 0,37501 & 16,50 \\
\hline & \multirow[t]{4}{*}{ Quarta } & ungradiert & 0,60115 & 0,63780 & 15,80 \\
\hline & & $<1,065$ & 0,33853 & 0,46625 & 5,00 \\
\hline & & $<1,075$ & 0,39177 & 0,86160 & 8,90 \\
\hline & & $>1,075$ & 0,40136 & 1,01893 & 24,80 \\
\hline \multirow{15}{*}{$\begin{array}{l}\text { OKTOBER } \\
2003\end{array}$} & \multirow[t]{4}{*}{ Aula } & ungradiert & 0,59524 & 0,91817 & 48,80 \\
\hline & & $<1,085$ & 0,40708 & 1,08976 & 18,70 \\
\hline & & $<1,095$ & 0,46508 & 0,41231 & 51,80 \\
\hline & & $>1,095$ & 0,44125 & 0,33546 & 82,70 \\
\hline & \multirow[t]{3}{*}{ Granola } & ungradiert & 0,40950 & 1,56680 & 39,50 \\
\hline & & $<1,075$ & 0,45895 & 1,25397 & 27,00 \\
\hline & & $<1,085$ & 0,62039 & 3,25503 & 52,40 \\
\hline & \multirow[t]{4}{*}{ Nicola } & ungradiert & 0,39986 & 1,05499 & 5,60 \\
\hline & & $<1,075$ & 0,45467 & 0,47965 & 2,10 \\
\hline & & $<1,085$ & 0,39006 & 0,54100 & 6,30 \\
\hline & & $>1,085$ & 0,49792 & 0,49464 & 9,00 \\
\hline & \multirow[t]{4}{*}{ Quarta } & ungradiert & 0,57145 & 0,66644 & 16,10 \\
\hline & & $<1,075$ & 0,38612 & 0,52961 & 2,60 \\
\hline & & $<1,085$ & 0,52055 & 0,61051 & 7,90 \\
\hline & & $>1,085$ & 0,56189 & 0,49585 & 11,90 \\
\hline \multirow{7}{*}{$\begin{array}{l}\text { FEBRUAR } \\
2004\end{array}$} & \multirow[t]{4}{*}{ Aula } & ungradiert & 0,31422 & 0,48646 & 97,10 \\
\hline & & $<1,085$ & 0,41248 & 0,49468 & 72,50 \\
\hline & & $<1,095$ & 0,33672 & 0,70266 & 98,80 \\
\hline & & $>1,095$ & 0,33557 & 0,56827 & 100,00 \\
\hline & \multirow[t]{3}{*}{ Granola } & ungradiert & 0,37750 & 1,11600 & 78,10 \\
\hline & & $<1,075$ & 0,44862 & 1,21854 & 68,90 \\
\hline & & $<1,085$ & 0,45052 & 0,72199 & 89,00 \\
\hline
\end{tabular}




\begin{tabular}{|c|c|c|c|c|c|}
\hline Termin & Sorte & $S D$ & freie CAT & MA CAT & SF- Index \\
\hline & \multirow[t]{4}{*}{ Nicola } & ungradiert & 0,28387 & 0,70853 & 31,50 \\
\hline & & $<1,075$ & 0,30623 & 0,66031 & 23,10 \\
\hline & & $<1,085$ & 0,28253 & 2,89253 & 30,30 \\
\hline & & $>1,085$ & 0,28846 & 2,25973 & 54,20 \\
\hline & \multirow[t]{4}{*}{ Quarta } & ungradiert & 0,41316 & 0,69120 & 13,90 \\
\hline & & $<1,075$ & 0,48510 & 0,68664 & 6,70 \\
\hline & & $<1,085$ & 0,50491 & 0,68731 & 13,60 \\
\hline & & $>1,085$ & 0,34582 & 3,68944 & 19,50 \\
\hline \multirow{15}{*}{$\begin{array}{l}\text { JUNI } \\
2004\end{array}$} & \multirow[t]{4}{*}{ Aula } & ungradiert & 0,37506 & 0,95816 & 98,10 \\
\hline & & $<1,085$ & 0,38228 & 0,72898 & 21,70 \\
\hline & & $<1,095$ & 0,30139 & 0,51947 & 83,50 \\
\hline & & $>1,095$ & 0,51545 & 0,83853 & 98,50 \\
\hline & \multirow[t]{3}{*}{ Granola } & ungradiert & 0,38971 & 3,32963 & 19,70 \\
\hline & & $<1,075$ & 0,55343 & 0,99740 & 13,00 \\
\hline & & $<1,085$ & 0,41659 & 1,62861 & 28,20 \\
\hline & \multirow[t]{4}{*}{ Nicola } & ungradiert & 0,29384 & 0,48736 & 34,90 \\
\hline & & $<1,075$ & 0,33054 & 0,83965 & 23,70 \\
\hline & & $<1,085$ & 0,32845 & 0,95721 & 34,20 \\
\hline & & $>1,085$ & 0,42955 & 0,82077 & 50,70 \\
\hline & \multirow[t]{4}{*}{ Quarta } & ungradiert & 0,41255 & 0,67654 & 9,00 \\
\hline & & $<1,075$ & 0,40414 & 1,20663 & 7,70 \\
\hline & & $<1,085$ & 0,44159 & 2,13396 & 13,50 \\
\hline & & $>1,085$ & 0,49019 & 5,93465 & 20,60 \\
\hline
\end{tabular}


10.2. LIPOXYGENASE ( $\Delta$ Aktivität $\mathrm{mmol} \mathrm{sec}^{-1} \mathrm{mg}$ Protein)

\begin{tabular}{|c|c|c|c|c|}
\hline Termin & Sorte & $S D$ & MA LOX & freie LOX \\
\hline \multirow{12}{*}{$\begin{array}{l}\text { OKTOBER } \\
2000\end{array}$} & \multirow[t]{4}{*}{ Cilena } & ungradiert & 0,07132 & 0,03644 \\
\hline & & $<1,055$ & 0,08763 & 0,02746 \\
\hline & & $<1,065$ & 0,06369 & 0,02677 \\
\hline & & $>1,065$ & 0,03690 & 0,03244 \\
\hline & \multirow[t]{4}{*}{ Ponto } & ungradiert & 0,08236 & 0,02772 \\
\hline & & $<1,085$ & 0,03281 & 0,04853 \\
\hline & & $<1,095$ & 0,06902 & 0,02739 \\
\hline & & $>1,095$ & 0,11229 & 0,03191 \\
\hline & \multirow[t]{4}{*}{ Solara } & ungradiert & 0,07051 & 0,03095 \\
\hline & & $<1,065$ & 0,04139 & 0,02781 \\
\hline & & $<1,075$ & 0,05324 & 0,02987 \\
\hline & & $>1,075$ & 0,36859 & 0,02601 \\
\hline \multirow{12}{*}{$\begin{array}{l}\text { FEBRUAR } \\
2001\end{array}$} & \multirow[t]{4}{*}{ Cilena } & ungradiert & 0,04452 & 0,02738 \\
\hline & & $<1,055$ & 0,05776 & 0,02635 \\
\hline & & $<1,065$ & 0,15218 & 0,02595 \\
\hline & & $>1,065$ & 0,03660 & 0,03667 \\
\hline & \multirow[t]{4}{*}{ Ponto } & ungradiert & 0,09261 & 0,02978 \\
\hline & & $<1,095$ & 0,10198 & 0,02451 \\
\hline & & $<1,105$ & 0,05472 & 0,03375 \\
\hline & & $>1,105$ & 0,02950 & 0,03184 \\
\hline & \multirow[t]{4}{*}{ Solara } & ungradiert & 0,03924 & 0,02940 \\
\hline & & $<1,065$ & 0,03221 & 0,01875 \\
\hline & & $<1,075$ & 0,02881 & 0,03238 \\
\hline & & $>1,075$ & 0,03474 & 0,02826 \\
\hline \multirow{12}{*}{$\begin{array}{l}\text { JUNI } \\
2001\end{array}$} & \multirow[t]{4}{*}{ Cilena } & ungradiert & 0,04271 & 0,03148 \\
\hline & & $<1,055$ & 0,03402 & 0,02467 \\
\hline & & $<1,065$ & 0,02235 & 0,03054 \\
\hline & & $>1,065$ & 0,76499 & 0,02914 \\
\hline & \multirow[t]{4}{*}{ Ponto } & ungradiert & 0,05020 & 0,02966 \\
\hline & & $<1,095$ & 0,04474 & 0,02358 \\
\hline & & $<1,105$ & 0,03725 & 0,03366 \\
\hline & & $>1,105$ & 0,10473 & 0,03264 \\
\hline & \multirow[t]{4}{*}{ Solara } & ungradiert & 0,02979 & 0,02212 \\
\hline & & $<1,065$ & 0,02842 & 0,02238 \\
\hline & & $<1,075$ & 0,03429 & 0,02977 \\
\hline & & $>1,075$ & 0,05726 & 0,02422 \\
\hline
\end{tabular}




\begin{tabular}{|c|c|c|c|c|}
\hline Termin & Sorte & $S D$ & MA LOX & freie LOX \\
\hline \multirow{11}{*}{$\begin{array}{l}\text { OKTOBER } \\
2001\end{array}$} & \multirow[t]{3}{*}{ Cilena } & ungradiert & 0,04925 & 0,03042 \\
\hline & & $<1,075$ & 0,07854 & 0,03220 \\
\hline & & $<1,085$ & 0,12314 & 0,02196 \\
\hline & \multirow[t]{4}{*}{ Ponto } & ungradiert & 0,22837 & 0,02232 \\
\hline & & $<1,095$ & 0,06771 & 0,02644 \\
\hline & & $<1,105$ & 0,05955 & 0,03100 \\
\hline & & $>1,105$ & 0,09640 & 0,04775 \\
\hline & \multirow[t]{4}{*}{ Solara } & ungradiert & 0,05967 & 0,03194 \\
\hline & & $<1,075$ & 0,02608 & 0,01974 \\
\hline & & $<1,085$ & 0,08055 & 0,03240 \\
\hline & & $>1,085$ & 0,06904 & 0,03168 \\
\hline \multirow{12}{*}{$\begin{array}{l}\text { FEBRUAR } \\
2002\end{array}$} & \multirow[t]{4}{*}{ Cilena } & ungradiert & 0,05552 & 0,02977 \\
\hline & & $<1,075$ & 0,03447 & 0,02142 \\
\hline & & $<1,085$ & 0,04836 & 0,02467 \\
\hline & & $>1,085$ & 0,08334 & 0,02828 \\
\hline & \multirow[t]{4}{*}{ Ponto } & ungradiert & 0,09915 & 0,03608 \\
\hline & & $<1,095$ & 0,04044 & 0,02633 \\
\hline & & $<1,105$ & 0,03075 & 0,03258 \\
\hline & & $>1,105$ & 0,06041 & 0,02772 \\
\hline & \multirow[t]{4}{*}{ Solara } & ungradiert & 0,02703 & 0,02898 \\
\hline & & $<1,075$ & 0,03114 & 0,02650 \\
\hline & & $<1,085$ & 0,06788 & 0,02761 \\
\hline & & $>1,085$ & 0,06626 & 0,02859 \\
\hline \multirow{12}{*}{$\begin{array}{l}\text { JUNI } \\
2002\end{array}$} & \multirow[t]{4}{*}{ Cilena } & ungradiert & 0,05402 & 0,02600 \\
\hline & & $<1,075$ & 0,04288 & 0,02033 \\
\hline & & $<1,085$ & 0,05996 & 0,02513 \\
\hline & & $>1,085$ & 0,06664 & 0,01975 \\
\hline & \multirow[t]{4}{*}{ Ponto } & ungradiert & 0,06791 & 0,04227 \\
\hline & & $<1,095$ & 0,04945 & 0,03152 \\
\hline & & $<1,105$ & 0,08504 & 0,02609 \\
\hline & & $>1,105$ & 0,02698 & 0,04313 \\
\hline & \multirow[t]{4}{*}{ Solara } & ungradiert & 0,08207 & 0,02997 \\
\hline & & $<1,075$ & 0,04252 & 0,02986 \\
\hline & & $<1,085$ & 0,02282 & 0,02483 \\
\hline & & $>1,085$ & 0,03764 & 0,02278 \\
\hline
\end{tabular}




\begin{tabular}{|c|c|c|c|c|}
\hline Termin & Sorte & $S D$ & MA LOX & freie LOX \\
\hline \multirow{16}{*}{$\begin{array}{l}\text { OKTOBER } \\
2002\end{array}$} & \multirow[t]{4}{*}{ Aula } & ungradiert & 0,03043 & 0,03057 \\
\hline & & $<1,085$ & 0,03130 & 0,02481 \\
\hline & & $<1,095$ & 0,07565 & 0,03409 \\
\hline & & $>1,095$ & 0,06443 & 0,03009 \\
\hline & \multirow[t]{4}{*}{ Granola } & ungradiert & 0,16835 & 0,02416 \\
\hline & & $<1,065$ & 0,05662 & 0,03071 \\
\hline & & $<1,075$ & 0,30277 & 0,02263 \\
\hline & & $>1,075$ & 0,06629 & 0,07402 \\
\hline & \multirow[t]{4}{*}{ Nicola } & ungradiert & 0,03311 & 0,01842 \\
\hline & & $<1,065$ & 0,05245 & 0,02434 \\
\hline & & $<1,075$ & 0,04596 & 0,01773 \\
\hline & & $>1,075$ & 0,07484 & 0,05227 \\
\hline & \multirow[t]{4}{*}{ Quarta } & ungradiert & 0,04672 & 0,03382 \\
\hline & & $<1,065$ & 0,03489 & 0,02688 \\
\hline & & $<1,075$ & 0,04527 & 0,02687 \\
\hline & & $>1,075$ & 0,05560 & 0,04880 \\
\hline \multirow{16}{*}{$\begin{array}{l}\text { FEBRUAR } \\
2003\end{array}$} & \multirow[t]{4}{*}{ Aula } & ungradiert & 0,03753 & 0,03270 \\
\hline & & $<1,085$ & 0,02558 & 0,02828 \\
\hline & & $<1,095$ & 0,04277 & 0,03032 \\
\hline & & $>1,095$ & 0,04008 & 0,03019 \\
\hline & \multirow[t]{4}{*}{ Granola } & ungradiert & 0,07148 & 0,02827 \\
\hline & & $<1,065$ & 0,04881 & 0,04071 \\
\hline & & $<1,075$ & 0,05451 & 0,03186 \\
\hline & & $>1,075$ & 0,03696 & 0,02973 \\
\hline & \multirow[t]{4}{*}{ Nicola } & ungradiert & 0,03007 & 0,03816 \\
\hline & & $<1,065$ & 0,02075 & 0,02034 \\
\hline & & $<1,075$ & 0,03932 & 0,02216 \\
\hline & & $>1,075$ & 0,04024 & 0,03247 \\
\hline & \multirow[t]{4}{*}{ Quarta } & ungradiert & 0,03156 & 0,04143 \\
\hline & & $<1,065$ & 0,05970 & 0,03978 \\
\hline & & $<1,075$ & 0,05641 & 0,03964 \\
\hline & & $>1,075$ & 0,04106 & 0,01976 \\
\hline \multirow{4}{*}{$\begin{array}{l}\text { JUNI } \\
2003\end{array}$} & \multirow[t]{4}{*}{ Aula } & ungradiert & 0,03185 & 0,02108 \\
\hline & & $<1,085$ & 0,03301 & 0,02864 \\
\hline & & $<1,095$ & 0,06352 & 0,02651 \\
\hline & & $>1,095$ & 0,02841 & 0,03756 \\
\hline
\end{tabular}




\begin{tabular}{|c|c|c|c|c|}
\hline Termin & Sorte & $S D$ & MA LOX & freie LOX \\
\hline & \multirow[t]{4}{*}{ Granola } & ungradiert & 0,14261 & 0,03289 \\
\hline & & $<1,065$ & 0,03579 & 0,03382 \\
\hline & & $<1,075$ & 0,12030 & 0,02810 \\
\hline & & $>1,075$ & 0,17137 & 0,02369 \\
\hline & \multirow[t]{4}{*}{ Nicola } & ungradiert & 0,02642 & 0,02630 \\
\hline & & $<1,065$ & 0,03370 & 0,02634 \\
\hline & & $<1,075$ & 0,06404 & 0,02807 \\
\hline & & $>1,075$ & 0,03472 & 0,03019 \\
\hline & \multirow[t]{4}{*}{ Quarta } & ungradiert & 0,04676 & 0,02961 \\
\hline & & $<1,065$ & 0,05551 & 0,01961 \\
\hline & & $<1,075$ & 0,04743 & 0,02701 \\
\hline & & $>1,075$ & 0,09028 & 0,02075 \\
\hline
\end{tabular}

\begin{tabular}{|c|c|c|c|c|}
\hline OKTOBER & Aula & ungradiert & 0,08225 & 0,03608 \\
\hline 2003 & & $<1,085$ & 0,06449 & 0,02400 \\
\hline & & $<1,095$ & 0,02730 & 0,02825 \\
\hline & & $>1,095$ & 0,03384 & 0,02624 \\
\hline & Granola & ungradiert & 0,12937 & 0,02945 \\
\hline & & $<1,075$ & 0,09056 & 0,04344 \\
\hline & & $<1,085$ & 0,23378 & 0,04493 \\
\hline & Nicola & ungradiert & 0,06463 & 0,03493 \\
\hline & & $<1,075$ & 0,02709 & 0,02635 \\
\hline & & $<1,085$ & 0,04218 & 0,02169 \\
\hline & & $>1,085$ & 0,03223 & 0,02810 \\
\hline & Quarta & ungradiert & 0,05583 & 0,02653 \\
\hline & & $<1,075$ & 0,03814 & 0,02404 \\
\hline & & $<1,085$ & 0,05036 & 0,02717 \\
\hline & & $>1,085$ & 0,04604 & 0,03123 \\
\hline FEBRUAR & Aula & ungradiert & 0,03300 & 0,02020 \\
\hline 2004 & & $<1,085$ & 0,02496 & 0,02030 \\
\hline & & $<1,095$ & 0,04393 & 0,02104 \\
\hline & & $>1,095$ & 0,03127 & 0,01925 \\
\hline & Granola & ungradiert & 0,06343 & 0,02513 \\
\hline & & $<1,075$ & 0,06816 & 0,02398 \\
\hline & & $<1,085$ & 0,04675 & 0,02136 \\
\hline
\end{tabular}




\begin{tabular}{|c|c|c|c|c|}
\hline Termin & Sorte & $S D$ & MA LOX & freie LOX \\
\hline & \multirow[t]{4}{*}{ Nicola } & ungradiert & 0,04614 & 0,01875 \\
\hline & & $<1,075$ & 0,03539 & 0,02003 \\
\hline & & $<1,085$ & 0,16693 & 0,02163 \\
\hline & & $>1,085$ & 0,12463 & 0,02009 \\
\hline & \multirow[t]{4}{*}{ Quarta } & ungradiert & 0,03685 & 0,02262 \\
\hline & & $<1,075$ & 0,04557 & 0,01770 \\
\hline & & $<1,085$ & 0,03762 & 0,01814 \\
\hline & & $>1,085$ & 0,22106 & 0,02071 \\
\hline \multirow{15}{*}{$\begin{array}{l}\text { JUNI } \\
2004\end{array}$} & \multirow[t]{4}{*}{ Aula } & ungradiert & 0,05605 & 0,02184 \\
\hline & & $<1,085$ & 0,03041 & 0,01977 \\
\hline & & $<1,095$ & 0,02711 & 0,01858 \\
\hline & & $>1,095$ & 0,04671 & 0,02736 \\
\hline & \multirow[t]{3}{*}{ Granola } & ungradiert & 0,22449 & 0,01941 \\
\hline & & $<1,075$ & 0,07062 & 0,03284 \\
\hline & & $<1,085$ & 0,10223 & 0,02348 \\
\hline & \multirow[t]{4}{*}{ Nicola } & ungradiert & 0,03208 & 0,01817 \\
\hline & & $<1,075$ & 0,04560 & 0,02005 \\
\hline & & $<1,085$ & 0,05907 & 0,02166 \\
\hline & & $>1,085$ & 0,03141 & 0,02556 \\
\hline & \multirow[t]{4}{*}{ Quarta } & ungradiert & 0,03824 & 0,02118 \\
\hline & & $<1,075$ & 0,05637 & 0,02278 \\
\hline & & $<1,085$ & 0,15543 & 0,02404 \\
\hline & & $>1,085$ & 0,33581 & 0,02200 \\
\hline
\end{tabular}


10.3. ASCORBAT- PEROXIDASE ( $\triangle$ Aktivität $10 \mathrm{~min}^{-1} \mathrm{mg}$ Protein)

\begin{tabular}{|c|c|c|c|c|}
\hline Termin & Sorte & $S D$ & MA POD & freie POD \\
\hline \multirow{12}{*}{$\begin{array}{l}\text { OKTOBER } \\
2000\end{array}$} & \multirow[t]{4}{*}{ Cilena } & ungradiert & 0,00512 & 0,00376 \\
\hline & & $<1,055$ & 0,00547 & 0,00165 \\
\hline & & $<1,065$ & 0,00448 & 0,00215 \\
\hline & & $>1,065$ & 0,00347 & 0,00373 \\
\hline & \multirow[t]{4}{*}{ Ponto } & ungradiert & 0,00549 & 0,00175 \\
\hline & & $<1,085$ & 0,00191 & 0,00266 \\
\hline & & $<1,095$ & 0,00615 & 0,00091 \\
\hline & & $>1,095$ & 0,00701 & 0,00139 \\
\hline & \multirow[t]{4}{*}{ Solara } & ungradiert & 0,00505 & 0,00308 \\
\hline & & $<1,065$ & 0,00235 & 0,00122 \\
\hline & & $<1,075$ & 0,00240 & 0,00218 \\
\hline & & $>1,075$ & 0,01989 & 0,00250 \\
\hline \multirow{12}{*}{$\begin{array}{l}\text { FEBRUAR } \\
2001\end{array}$} & \multirow[t]{4}{*}{ Cilena } & ungradiert & 0,00352 & 0,00291 \\
\hline & & $<1,055$ & 0,00332 & 0,00355 \\
\hline & & $<1,065$ & 0,00793 & 0,00317 \\
\hline & & $>1,065$ & 0,00198 & 0,00147 \\
\hline & \multirow[t]{4}{*}{ Ponto } & ungradiert & 0,00617 & 0,00247 \\
\hline & & $<1,095$ & 0,00614 & 0,00114 \\
\hline & & $<1,105$ & 0,00505 & 0,00202 \\
\hline & & $>1,105$ & 0,00270 & 0,00237 \\
\hline & \multirow[t]{4}{*}{ Solara } & ungradiert & 0,00181 & 0,00244 \\
\hline & & $<1,065$ & 0,00188 & 0,00106 \\
\hline & & $<1,075$ & 0,00196 & 0,00173 \\
\hline & & $>1,075$ & 0,00277 & 0,00246 \\
\hline \multirow{12}{*}{$\begin{array}{l}\text { JUNI } \\
2001\end{array}$} & \multirow[t]{4}{*}{ Cilena } & ungradiert & 0,00313 & 0,00297 \\
\hline & & $<1,055$ & 0,00154 & 0,00277 \\
\hline & & $<1,065$ & 0,00156 & 0,00224 \\
\hline & & $>1,065$ & 0,05661 & 0,00173 \\
\hline & \multirow[t]{4}{*}{ Ponto } & ungradiert & 0,00368 & 0,00160 \\
\hline & & $<1,095$ & 0,00304 & 0,00130 \\
\hline & & $<1,105$ & 0,00436 & 0,00185 \\
\hline & & $>1,105$ & 0,00741 & 0,00217 \\
\hline & \multirow[t]{4}{*}{ Solara } & ungradiert & 0,00198 & 0,00254 \\
\hline & & $<1,065$ & 0,00128 & 0,00114 \\
\hline & & $<1,075$ & 0,00142 & 0,00165 \\
\hline & & $>1,075$ & 0,00307 & 0,00185 \\
\hline
\end{tabular}




\begin{tabular}{|c|c|c|c|c|}
\hline Termin & Sorte & $S D$ & MA POD & freie POD \\
\hline \multirow{11}{*}{$\begin{array}{l}\text { OKTOBER } \\
2001\end{array}$} & \multirow[t]{3}{*}{ Cilena } & ungradiert & 0,00272 & 0,00190 \\
\hline & & $<1,075$ & 0,00452 & 0,00128 \\
\hline & & $<1,085$ & 0,00784 & 0,00179 \\
\hline & \multirow[t]{4}{*}{ Ponto } & ungradiert & 0,01809 & 0,00181 \\
\hline & & $<1,095$ & 0,00404 & 0,00179 \\
\hline & & $<1,105$ & 0,00450 & 0,00198 \\
\hline & & $>1,105$ & 0,00672 & 0,00249 \\
\hline & \multirow[t]{4}{*}{ Solara } & ungradiert & 0,00310 & 0,00199 \\
\hline & & $<1,075$ & 0,00223 & 0,00134 \\
\hline & & $<1,085$ & 0,02245 & 0,00112 \\
\hline & & $>1,085$ & 0,00280 & 0,00188 \\
\hline \multirow{12}{*}{$\begin{array}{l}\text { FEBRUAR } \\
2002\end{array}$} & \multirow[t]{4}{*}{ Cilena } & ungradiert & 0,00253 & 0,00188 \\
\hline & & $<1,075$ & 0,00170 & 0,00146 \\
\hline & & $<1,085$ & 0,00267 & 0,00146 \\
\hline & & $>1,085$ & 0,00782 & 0,00163 \\
\hline & \multirow[t]{4}{*}{ Ponto } & ungradiert & 0,00435 & 0,00174 \\
\hline & & $<1,095$ & 0,00269 & 0,00194 \\
\hline & & $<1,105$ & 0,00170 & 0,00176 \\
\hline & & $>1,105$ & 0,00372 & 0,00134 \\
\hline & \multirow[t]{4}{*}{ Solara } & ungradiert & 0,00190 & 0,00234 \\
\hline & & $<1,075$ & 0,00172 & 0,00141 \\
\hline & & $<1,085$ & 0,00407 & 0,00281 \\
\hline & & $>1,085$ & 0,00405 & 0,00115 \\
\hline \multirow{12}{*}{$\begin{array}{l}\text { JUNI } \\
2002\end{array}$} & \multirow[t]{4}{*}{ Cilena } & ungradiert & 0,00447 & 0,00084 \\
\hline & & $<1,075$ & 0,00291 & 0,00204 \\
\hline & & $<1,085$ & 0,00323 & 0,00216 \\
\hline & & $>1,085$ & 0,00553 & 0,00283 \\
\hline & \multirow[t]{4}{*}{ Ponto } & ungradiert & 0,00473 & 0,00513 \\
\hline & & $<1,095$ & 0,00284 & 0,00147 \\
\hline & & $<1,105$ & 0,01145 & 0,00158 \\
\hline & & $>1,105$ & 0,00336 & 0,00187 \\
\hline & \multirow[t]{4}{*}{ Solara } & ungradiert & 0,00647 & 0,00154 \\
\hline & & $<1,075$ & 0,00192 & 0,00141 \\
\hline & & $<1,085$ & 0,00189 & 0,00169 \\
\hline & & $>1,085$ & 0,00285 & 0,00195 \\
\hline
\end{tabular}




\begin{tabular}{|c|c|c|c|c|}
\hline Termin & Sorte & $S D$ & MA POD & freie POD \\
\hline \multirow{16}{*}{$\begin{array}{l}\text { OKTOBER } \\
2002\end{array}$} & \multirow[t]{4}{*}{ Aula } & ungradiert & 0,00288 & 0,00249 \\
\hline & & $<1,085$ & 0,00205 & 0,00238 \\
\hline & & $<1,095$ & 0,00413 & 0,00315 \\
\hline & & $>1,095$ & 0,00458 & 0,00264 \\
\hline & \multirow[t]{4}{*}{ Granola } & ungradiert & 0,01422 & 0,00267 \\
\hline & & $<1,065$ & 0,00287 & 0,00193 \\
\hline & & $<1,075$ & 0,02897 & 0,00344 \\
\hline & & $>1,075$ & 0,00607 & 0,00773 \\
\hline & \multirow[t]{4}{*}{ Nicola } & ungradiert & 0,00207 & 0,00214 \\
\hline & & $<1,065$ & 0,00450 & 0,00211 \\
\hline & & $<1,075$ & 0,00273 & 0,00187 \\
\hline & & $>1,075$ & 0,00289 & 0,00293 \\
\hline & \multirow[t]{4}{*}{ Quarta } & ungradiert & 0,00228 & 0,00233 \\
\hline & & $<1,065$ & 0,00248 & 0,00240 \\
\hline & & $<1,075$ & 0,00466 & 0,00204 \\
\hline & & $>1,075$ & 0,00234 & 0,00238 \\
\hline \multirow{16}{*}{$\begin{array}{l}\text { FEBRUAR } \\
2003\end{array}$} & \multirow[t]{4}{*}{ Aula } & ungradiert & 0,00250 & 0,00206 \\
\hline & & $<1,085$ & 0,00208 & 0,00322 \\
\hline & & $<1,095$ & 0,00365 & 0,00153 \\
\hline & & $>1,095$ & 0,00402 & 0,00249 \\
\hline & \multirow[t]{4}{*}{ Granola } & ungradiert & 0,00583 & 0,00230 \\
\hline & & $<1,065$ & 0,00225 & 0,00271 \\
\hline & & $<1,075$ & 0,00230 & 0,00255 \\
\hline & & $>1,075$ & 0,00448 & 0,00228 \\
\hline & \multirow[t]{4}{*}{ Nicola } & ungradiert & 0,00119 & 0,00312 \\
\hline & & $<1,065$ & 0,00199 & 0,00287 \\
\hline & & $<1,075$ & 0,00248 & 0,00181 \\
\hline & & $>1,075$ & 0,00161 & 0,00209 \\
\hline & \multirow[t]{4}{*}{ Quarta } & ungradiert & 0,00176 & 0,00287 \\
\hline & & $<1,065$ & 0,00274 & 0,00337 \\
\hline & & $<1,075$ & 0,00236 & 0,00286 \\
\hline & & $>1,075$ & 0,00458 & 0,00242 \\
\hline \multirow{4}{*}{$\begin{array}{l}\text { JUNI } \\
2003\end{array}$} & \multirow[t]{4}{*}{ Aula } & ungradiert & 0,00261 & 0,00162 \\
\hline & & $<1,085$ & 0,00212 & 0,00158 \\
\hline & & $<1,095$ & 0,00486 & 0,00197 \\
\hline & & $>1,095$ & 0,00327 & 0,00297 \\
\hline
\end{tabular}




\begin{tabular}{|c|c|c|c|c|}
\hline Termin & Sorte & $S D$ & MA POD & freie POD \\
\hline & \multirow[t]{4}{*}{ Granola } & ungradiert & 0,00830 & 0,00377 \\
\hline & & $<1,065$ & 0,00245 & 0,00305 \\
\hline & & $<1,075$ & 0,00956 & 0,00208 \\
\hline & & $>1,075$ & 0,00992 & 0,00168 \\
\hline & \multirow[t]{4}{*}{ Nicola } & ungradiert & 0,00227 & 0,00253 \\
\hline & & $<1,065$ & 0,00189 & 0,00270 \\
\hline & & $<1,075$ & 0,00408 & 0,00179 \\
\hline & & $>1,075$ & 0,00223 & 0,00329 \\
\hline & \multirow[t]{4}{*}{ Quarta } & ungradiert & 0,00287 & 0,00374 \\
\hline & & $<1,065$ & 0,00328 & 0,00231 \\
\hline & & $<1,075$ & 0,00514 & 0,00221 \\
\hline & & $>1,075$ & 0,00584 & 0,00530 \\
\hline \multirow{15}{*}{$\begin{array}{l}\text { OKTOBER } \\
2003\end{array}$} & \multirow[t]{4}{*}{ Aula } & ungradiert & 0,00485 & 0,00269 \\
\hline & & $<1,085$ & 0,00463 & 0,00246 \\
\hline & & $<1,095$ & 0,00214 & 0,00210 \\
\hline & & $>1,095$ & 0,00278 & 0,00541 \\
\hline & \multirow[t]{3}{*}{ Granola } & ungradiert & 0,00973 & 0,00231 \\
\hline & & $<1,075$ & 0,00783 & 0,00398 \\
\hline & & $<1,085$ & 0,02014 & 0,00350 \\
\hline & \multirow[t]{4}{*}{ Nicola } & ungradiert & 0,00717 & 0,00240 \\
\hline & & $<1,075$ & 0,00229 & 0,00425 \\
\hline & & $<1,085$ & 0,00294 & 0,00151 \\
\hline & & $>1,085$ & 0,00240 & 0,00253 \\
\hline & \multirow[t]{4}{*}{ Quarta } & ungradiert & 0,00313 & 0,00341 \\
\hline & & $<1,075$ & 0,00318 & 0,00206 \\
\hline & & $<1,085$ & 0,00464 & 0,00264 \\
\hline & & $>1,085$ & 0,00335 & 0,00260 \\
\hline \multirow{7}{*}{$\begin{array}{l}\text { FEBRUAR } \\
2004\end{array}$} & \multirow[t]{4}{*}{ Aula } & ungradiert & 0,00325 & 0,00206 \\
\hline & & $<1,085$ & 0,00407 & 0,00227 \\
\hline & & $<1,095$ & 0,00436 & 0,00378 \\
\hline & & $>1,095$ & 0,00357 & 0,00291 \\
\hline & \multirow[t]{3}{*}{ Granola } & ungradiert & 0,00847 & 0,00278 \\
\hline & & $<1,075$ & 0,01440 & 0,00445 \\
\hline & & $<1,085$ & 0,00556 & 0,00331 \\
\hline
\end{tabular}




\begin{tabular}{|c|c|c|c|c|}
\hline Termin & Sorte & $S D$ & MA POD & freie POD \\
\hline & \multirow[t]{4}{*}{ Nicola } & ungradiert & 0,00520 & 0,00694 \\
\hline & & $<1,075$ & 0,00553 & 0,00557 \\
\hline & & $<1,085$ & 0,01859 & 0,00396 \\
\hline & & $>1,085$ & 0,01160 & 0,00758 \\
\hline & \multirow[t]{4}{*}{ Quarta } & ungradiert & 0,00509 & 0,00871 \\
\hline & & $<1,075$ & 0,00347 & 0,00342 \\
\hline & & $<1,085$ & 0,00405 & 0,00405 \\
\hline & & $>1,085$ & 0,01835 & 0,00485 \\
\hline \multirow{15}{*}{$\begin{array}{l}\text { JUNI } \\
2004\end{array}$} & \multirow[t]{4}{*}{ Aula } & ungradiert & 0,00512 & 0,00269 \\
\hline & & $<1,085$ & 0,00408 & 0,00165 \\
\hline & & $<1,095$ & 0,00448 & 0,00179 \\
\hline & & $>1,095$ & 0,00383 & 0,00287 \\
\hline & \multirow[t]{3}{*}{ Granola } & ungradiert & 0,02524 & 0,00217 \\
\hline & & $<1,075$ & 0,01568 & 0,00287 \\
\hline & & $<1,085$ & 0,01383 & 0,00268 \\
\hline & \multirow[t]{4}{*}{ Nicola } & ungradiert & 0,00351 & 0,00416 \\
\hline & & $<1,075$ & 0,00574 & 0,00219 \\
\hline & & $<1,085$ & 0,00555 & 0,00256 \\
\hline & & $>1,085$ & 0,00585 & 0,00353 \\
\hline & \multirow[t]{4}{*}{ Quarta } & ungradiert & 0,00409 & 0,00200 \\
\hline & & $<1,075$ & 0,00503 & 0,00178 \\
\hline & & $<1,085$ & 0,01314 & 0,00260 \\
\hline & & $>1,085$ & 0,00584 & 0,00530 \\
\hline
\end{tabular}


10.4. SUPEROXIDDISMUTASE ( $\Delta$ Aktivität $\mathrm{mg}^{-1}$ Protein)

\begin{tabular}{|c|c|c|c|c|}
\hline Termin & Sorte & $S D$ & MA SOD & freie SOD \\
\hline \multirow{12}{*}{$\begin{array}{l}\text { OKTOBER } \\
2000\end{array}$} & \multirow[t]{4}{*}{ Cilena } & ungradiert & 11,18115 & 3,09500 \\
\hline & & $<1,055$ & 8,81731 & 4,11232 \\
\hline & & $<1,065$ & 18,90031 & 3,04495 \\
\hline & & $>1,065$ & 5,16350 & 2,99303 \\
\hline & \multirow[t]{4}{*}{ Ponto } & ungradiert & 18,05571 & 7,60222 \\
\hline & & $<1,085$ & 6,78358 & 5,31020 \\
\hline & & $<1,095$ & 20,73855 & 5,61818 \\
\hline & & $>1,095$ & 17,29091 & 4,15056 \\
\hline & \multirow[t]{4}{*}{ Solara } & ungradiert & 6,16342 & 3,19196 \\
\hline & & $<1,065$ & 6,00757 & 6,17777 \\
\hline & & $<1,075$ & 8,60596 & 3,73578 \\
\hline & & $>1,075$ & 10,74493 & 4,84339 \\
\hline \multirow{12}{*}{$\begin{array}{l}\text { FEBRUAR } \\
2001\end{array}$} & \multirow{4}{*}{ Cilena } & ungradiert & 6,77759 & 6,71926 \\
\hline & & $<1,055$ & 12,25291 & 6,80960 \\
\hline & & $<1,065$ & 18,31394 & 7,29209 \\
\hline & & $>1,065$ & 8,88969 & 7,45851 \\
\hline & \multirow[t]{4}{*}{ Ponto } & ungradiert & 18,94747 & 5,29730 \\
\hline & & $<1,095$ & 28,46767 & 5,12321 \\
\hline & & $<1,105$ & 11,94898 & 5,98768 \\
\hline & & $>1,105$ & 3,68790 & 4,60991 \\
\hline & \multirow[t]{4}{*}{ Solara } & ungradiert & 3,27781 & 7,88447 \\
\hline & & $<1,065$ & 5,97488 & 6,52830 \\
\hline & & $<1,075$ & 2,68856 & 0,77676 \\
\hline & & $>1,075$ & 3,15660 & 7,69576 \\
\hline \multirow{12}{*}{$\begin{array}{l}\text { JUNI } \\
2001\end{array}$} & \multirow[t]{4}{*}{ Cilena } & ungradiert & 8,01256 & 5,67011 \\
\hline & & $<1,055$ & 5,24411 & 6,10206 \\
\hline & & $<1,065$ & 1,63189 & 2,20214 \\
\hline & & $>1,065$ & 132,20296 & 7,58522 \\
\hline & \multirow[t]{4}{*}{ Ponto } & ungradiert & 10,71351 & 6,48939 \\
\hline & & $<1,095$ & 12,55963 & 5,35773 \\
\hline & & $<1,105$ & 14,65026 & 5,29699 \\
\hline & & $>1,105$ & 14,93914 & 3,39349 \\
\hline & \multirow[t]{4}{*}{ Solara } & ungradiert & 4,76153 & 2,80086 \\
\hline & & $<1,065$ & 2,39293 & 2,56038 \\
\hline & & $<1,075$ & 0,95289 & 2,50429 \\
\hline & & $>1,075$ & 6,52045 & 6,58942 \\
\hline
\end{tabular}




\begin{tabular}{|c|c|c|c|c|}
\hline Termin & Sorte & $S D$ & MA SOD & freie SOD \\
\hline \multirow{11}{*}{$\begin{array}{l}\text { OKTOBER } \\
2001\end{array}$} & \multirow[t]{3}{*}{ Cilena } & ungradiert & 5,60175 & 8,21576 \\
\hline & & $<1,075$ & 9,95955 & 5,59820 \\
\hline & & $<1,085$ & 9,69159 & 2,95181 \\
\hline & \multirow[t]{4}{*}{ Ponto } & ungradiert & 66,83448 & 3,73276 \\
\hline & & $<1,095$ & 12,35099 & 8,54853 \\
\hline & & $<1,105$ & 11,74327 & 8,13700 \\
\hline & & $>1,105$ & 15,69551 & 5,41761 \\
\hline & \multirow[t]{4}{*}{ Solara } & ungradiert & 6,54494 & 6,00005 \\
\hline & & $<1,075$ & 5,85746 & 4,92693 \\
\hline & & $<1,085$ & 7,36377 & 3,09053 \\
\hline & & $>1,085$ & 11,60170 & 8,24900 \\
\hline \multirow{12}{*}{$\begin{array}{l}\text { FEBRUAR } \\
2002\end{array}$} & \multirow[t]{4}{*}{ Cilena } & ungradiert & 6,33303 & 4,64505 \\
\hline & & $<1,075$ & 4,24504 & 4,67618 \\
\hline & & $<1,085$ & 5,89628 & 8,37765 \\
\hline & & $>1,085$ & 21,61469 & 4,00061 \\
\hline & \multirow[t]{4}{*}{ Ponto } & ungradiert & 22,12487 & 5,07860 \\
\hline & & $<1,095$ & 7,84673 & 5,66523 \\
\hline & & $<1,105$ & 6,44140 & 9,23817 \\
\hline & & $>1,105$ & 14,23343 & 10,30317 \\
\hline & \multirow[t]{4}{*}{ Solara } & ungradiert & 3,68633 & 8,18398 \\
\hline & & $<1,075$ & 3,80488 & 3,67635 \\
\hline & & $<1,085$ & 10,40429 & 4,84891 \\
\hline & & $>1,085$ & 9,19379 & 4,98288 \\
\hline \multirow{12}{*}{$\begin{array}{l}\text { JUNI } \\
2002\end{array}$} & \multirow[t]{4}{*}{ Cilena } & ungradiert & $-4,79105$ & 3,69741 \\
\hline & & $<1,075$ & 4,79103 & 5,57440 \\
\hline & & $<1,085$ & 8,91695 & 4,59604 \\
\hline & & $>1,085$ & 8,34413 & 7,10993 \\
\hline & \multirow[t]{4}{*}{ Ponto } & ungradiert & 11,93141 & 8,30299 \\
\hline & & $<1,095$ & 8,79366 & 5,83995 \\
\hline & & $<1,105$ & 32,98641 & 8,86295 \\
\hline & & $>1,105$ & 10,15264 & 11,93023 \\
\hline & \multirow[t]{4}{*}{ Solara } & ungradiert & 14,39992 & 8,90027 \\
\hline & & $<1,075$ & 6,28157 & 7,77710 \\
\hline & & $<1,085$ & 4,22136 & 5,20345 \\
\hline & & $>1,085$ & 4,33894 & 4,98393 \\
\hline
\end{tabular}




\begin{tabular}{|c|c|c|c|c|}
\hline Termin & Sorte & $S D$ & MA SOD & freie SOD \\
\hline \multirow{16}{*}{$\begin{array}{l}\text { OKTOBER } \\
2002\end{array}$} & \multirow[t]{4}{*}{ Aula } & ungradiert & 8,04423 & 3,44502 \\
\hline & & $<1,085$ & 4,45493 & 3,94316 \\
\hline & & $<1,095$ & 8,85847 & 5,38333 \\
\hline & & $>1,095$ & 9,33152 & 4,97093 \\
\hline & \multirow[t]{4}{*}{ Granola } & ungradiert & 19,99030 & 3,69184 \\
\hline & & $<1,065$ & 9,85319 & 2,48414 \\
\hline & & $<1,075$ & 73,66189 & 6,55594 \\
\hline & & $>1,075$ & 21,39347 & 10,88924 \\
\hline & \multirow[t]{4}{*}{ Nicola } & ungradiert & 8,33766 & 2,92283 \\
\hline & & $<1,065$ & 12,34124 & 5,65727 \\
\hline & & $<1,075$ & 11,37355 & 4,94593 \\
\hline & & $>1,075$ & 17,45844 & 7,08385 \\
\hline & \multirow[t]{4}{*}{ Quarta } & ungradiert & 9,75198 & 4,03640 \\
\hline & & $<1,065$ & 4,90464 & 3,81633 \\
\hline & & $<1,075$ & 7,96766 & 5,90971 \\
\hline & & $>1,075$ & 5,87532 & 4,78509 \\
\hline \multirow{16}{*}{$\begin{array}{l}\text { FEBRUAR } \\
2003\end{array}$} & \multirow[t]{4}{*}{ Aula } & ungradiert & 5,70877 & 4,06064 \\
\hline & & $<1,085$ & 7,84536 & 6,80764 \\
\hline & & $<1,095$ & 8,60601 & 3,22980 \\
\hline & & $>1,095$ & 4,16332 & 7,33153 \\
\hline & \multirow[t]{4}{*}{ Granola } & ungradiert & 11,61596 & 0,65992 \\
\hline & & $<1,065$ & 6,18090 & 2,06391 \\
\hline & & $<1,075$ & 8,52365 & 5,00371 \\
\hline & & $>1,075$ & 10,84082 & 10,29412 \\
\hline & \multirow[t]{4}{*}{ Nicola } & ungradiert & 5,80875 & $-1,13144$ \\
\hline & & $<1,065$ & 5,09657 & 5,07024 \\
\hline & & $<1,075$ & 8,33704 & 4,31148 \\
\hline & & $>1,075$ & 6,21301 & 1,17006 \\
\hline & \multirow[t]{4}{*}{ Quarta } & ungradiert & 5,79565 & 4,05065 \\
\hline & & $<1,065$ & 12,59965 & 2,92195 \\
\hline & & $<1,075$ & 7,48988 & $-0,71408$ \\
\hline & & $>1,075$ & 10,84043 & 3,90986 \\
\hline JUNI & \multirow[t]{4}{*}{ Aula } & ungradiert & 5,23407 & 4,61700 \\
\hline \multirow[t]{3}{*}{2003} & & $<1,085$ & 6,27587 & 2,75476 \\
\hline & & $<1,095$ & 13,10279 & 4,38304 \\
\hline & & $>1,095$ & 6,39661 & 7,10318 \\
\hline
\end{tabular}




\begin{tabular}{|c|c|c|c|c|}
\hline Termin & Sorte & $S D$ & MA SOD & freie SOD \\
\hline & \multirow[t]{4}{*}{ Granola } & ungradiert & 25,28309 & 7,71939 \\
\hline & & $<1,065$ & 11,26850 & 7,86257 \\
\hline & & $<1,075$ & 17,12974 & 5,83661 \\
\hline & & $>1,075$ & 33,37186 & 5,42722 \\
\hline & \multirow[t]{4}{*}{ Nicola } & ungradiert & 6,58359 & 7,09267 \\
\hline & & $<1,065$ & 7,06082 & 7,87701 \\
\hline & & $<1,075$ & 10,55851 & 1,64880 \\
\hline & & $>1,075$ & 6,83879 & 8,02218 \\
\hline & \multirow[t]{4}{*}{ Quarta } & ungradiert & 7,70396 & 7,31340 \\
\hline & & $<1,065$ & 9,42048 & 4,61736 \\
\hline & & $<1,075$ & 18,17753 & 3,99537 \\
\hline & & $>1,075$ & 20,20119 & 5,58178 \\
\hline
\end{tabular}

\begin{tabular}{|c|c|c|c|c|}
\hline \multirow{15}{*}{$\begin{array}{l}\text { OKTOBER } \\
2003\end{array}$} & \multirow[t]{4}{*}{ Aula } & ungradiert & 8,48352 & 5,59708 \\
\hline & & $<1,085$ & 14,32975 & 3,51675 \\
\hline & & $<1,095$ & 4,02882 & 2,39812 \\
\hline & & $>1,095$ & 5,06481 & 4,88893 \\
\hline & \multirow[t]{3}{*}{ Granola } & ungradiert & 34,88715 & 3,81177 \\
\hline & & $<1,075$ & 27,61945 & 6,92498 \\
\hline & & $<1,085$ & 64,57546 & 5,93320 \\
\hline & \multirow[t]{4}{*}{ Nicola } & ungradiert & 20,74784 & 6,63884 \\
\hline & & $<1,075$ & 7,78063 & 4,85519 \\
\hline & & $<1,085$ & 11,08298 & 4,37504 \\
\hline & & $>1,085$ & 6,65190 & 4,41020 \\
\hline & \multirow[t]{4}{*}{ Quarta } & ungradiert & 7,34280 & 6,72510 \\
\hline & & $<1,075$ & 10,97078 & 6,21453 \\
\hline & & $<1,085$ & 7,57290 & 5,90396 \\
\hline & & $>1,085$ & 9,90585 & 8,22154 \\
\hline \multirow{7}{*}{$\begin{array}{l}\text { FEBRUAR } \\
2004\end{array}$} & \multirow[t]{4}{*}{ Aula } & ungradiert & 4,43496 & 7,76211 \\
\hline & & $<1,085$ & 9,02780 & 6,82614 \\
\hline & & $<1,095$ & 16,54787 & 6,31545 \\
\hline & & $>1,095$ & 12,19225 & 6,55750 \\
\hline & \multirow[t]{3}{*}{ Granola } & ungradiert & 18,96403 & 7,55698 \\
\hline & & $<1,075$ & 14,84770 & 1,31567 \\
\hline & & $<1,085$ & 12,53064 & 5,64918 \\
\hline
\end{tabular}




\begin{tabular}{|c|c|c|c|c|}
\hline Termin & Sorte & $S D$ & MA SOD & freie SOD \\
\hline & \multirow[t]{4}{*}{ Nicola } & ungradiert & 14,64075 & 6,00035 \\
\hline & & $<1,075$ & 9,01903 & 5,85060 \\
\hline & & $<1,085$ & 52,24243 & 6,88607 \\
\hline & & $>1,085$ & 45,82905 & 6,30938 \\
\hline & \multirow[t]{4}{*}{ Quarta } & ungradiert & 14,12012 & 8,38858 \\
\hline & & $<1,075$ & 7,16431 & 6,67946 \\
\hline & & $<1,085$ & 8,26410 & 6,10620 \\
\hline & & $>1,085$ & 0,29365 & 8,84065 \\
\hline \multirow{15}{*}{$\begin{array}{l}\text { JUNI } \\
2004\end{array}$} & \multirow[t]{4}{*}{ Aula } & ungradiert & 12,62026 & 7,98811 \\
\hline & & $<1,085$ & 8,96484 & 7,14245 \\
\hline & & $<1,095$ & 10,37126 & 5,60992 \\
\hline & & $>1,095$ & 16,10533 & 10,27733 \\
\hline & \multirow[t]{3}{*}{ Granola } & ungradiert & 70,43460 & 8,29786 \\
\hline & & $<1,075$ & 17,30684 & 10,37949 \\
\hline & & $<1,085$ & 29,51595 & 4,97028 \\
\hline & \multirow[t]{4}{*}{ Nicola } & ungradiert & 8,50467 & 6,29642 \\
\hline & & $<1,075$ & 11,64291 & 6,34395 \\
\hline & & $<1,085$ & 9,16652 & 8,41687 \\
\hline & & $>1,085$ & 13,09302 & 10,25506 \\
\hline & \multirow[t]{4}{*}{ Quarta } & ungradiert & 12,53806 & 7,54805 \\
\hline & & $<1,075$ & 9,17005 & 8,04065 \\
\hline & & $<1,085$ & 23,93499 & 6,45280 \\
\hline & & $>1,085$ & 133,93942 & 8,55343 \\
\hline
\end{tabular}




\begin{tabular}{|c|c|c|c|c|c|c|c|c|c|c|c|}
\hline \multicolumn{3}{|c|}{ 10.5.1. AMINOSÄUREN I } & \multirow[b]{2}{*}{ Prolin } & \multirow[b]{2}{*}{$\begin{array}{c}\text { Asparagin- } \\
\text { säure }\end{array}$} & \multirow[b]{2}{*}{$\begin{array}{l}\text { Glutamin- } \\
\text { säure }\end{array}$} & \multirow[b]{2}{*}{ Serin } & \multirow[b]{2}{*}{ Histidin } & \multirow[b]{2}{*}{ Arginin } & \multirow[b]{2}{*}{ Glycin } & \multirow[b]{2}{*}{ Threonin } & \multirow[b]{2}{*}{ Alanin } \\
\hline Termin & Sorte & $S D$ & & & & & & & & & \\
\hline & & & \multicolumn{9}{|c|}{$\mu \mathrm{g} / \mathrm{g}$ TM } \\
\hline OKTOBER & Cilena & ungradiert & 1080,63 & 900,68 & 491,18 & 75,49 & 36,44 & 304,81 & 94,02 & 74,05 & 336,39 \\
\hline \multirow[t]{7}{*}{2000} & & $<1,055$ & 1252,04 & 1430,28 & 732,12 & 116,17 & 67,61 & 529,46 & 154,26 & 116,31 & 570,31 \\
\hline & & $>1,065$ & 851,19 & 651,21 & 323,05 & 80,61 & 17,10 & 191,01 & 54,81 & 43,33 & 234,83 \\
\hline & Ponto & ungradiert & 332,65 & 392,67 & 155,37 & 92,53 & 7,25 & 114,69 & 38,38 & 32,60 & 119,15 \\
\hline & & $<1,085$ & 859,59 & 609,97 & 244,62 & 95,52 & 17,58 & 215,56 & 59,64 & 51,26 & 220,71 \\
\hline & & $<1,095$ & 412,04 & 510,43 & 205,18 & 101,81 & 12,38 & 174,09 & 49,19 & 41,91 & 166,94 \\
\hline & & $>1,095$ & 294,92 & 284,02 & 105,90 & 66,18 & 9,20 & 136,23 & 31,69 & 28,58 & 103,79 \\
\hline & & $>1,075$ & & 419,48 & 187,95 & 68,44 & 6,10 & 131,78 & 40,80 & 29,84 & 127,87 \\
\hline JUNI & Cilena & ungradiert & 1257,85 & 1060,95 & 531,16 & 94,18 & 46,22 & 444,18 & 124,70 & 86,91 & 443,08 \\
\hline \multirow[t]{6}{*}{2001} & & $<1,055$ & 1259,67 & 1174,53 & 617,96 & 148,12 & 70,77 & 588,02 & 150,19 & 102,33 & 626,00 \\
\hline & & $<1,065$ & 1202,88 & 797,79 & 453,12 & 109,02 & 51,02 & 427,58 & 112,88 & 75,49 & 421,22 \\
\hline & & $>1,065$ & 1244,88 & 825,32 & 391,12 & 131,43 & 36,85 & 292,40 & 93,13 & 67,81 & 403,89 \\
\hline & Ponto & ungradiert & 1047,96 & 282,23 & 112,51 & 101,13 & 23,29 & 133,21 & 40,67 & 33,81 & 147,17 \\
\hline & & $<1,095$ & 1178,14 & 578,08 & 206,90 & 153,54 & 33,26 & 307,05 & 51,39 & 64,27 & 289,89 \\
\hline & & $<1,105$ & 1003,69 & 468,90 & 187,19 & 132,56 & 31,39 & 218,78 & 40,26 & 57,01 & 212,94 \\
\hline
\end{tabular}


- 116 -

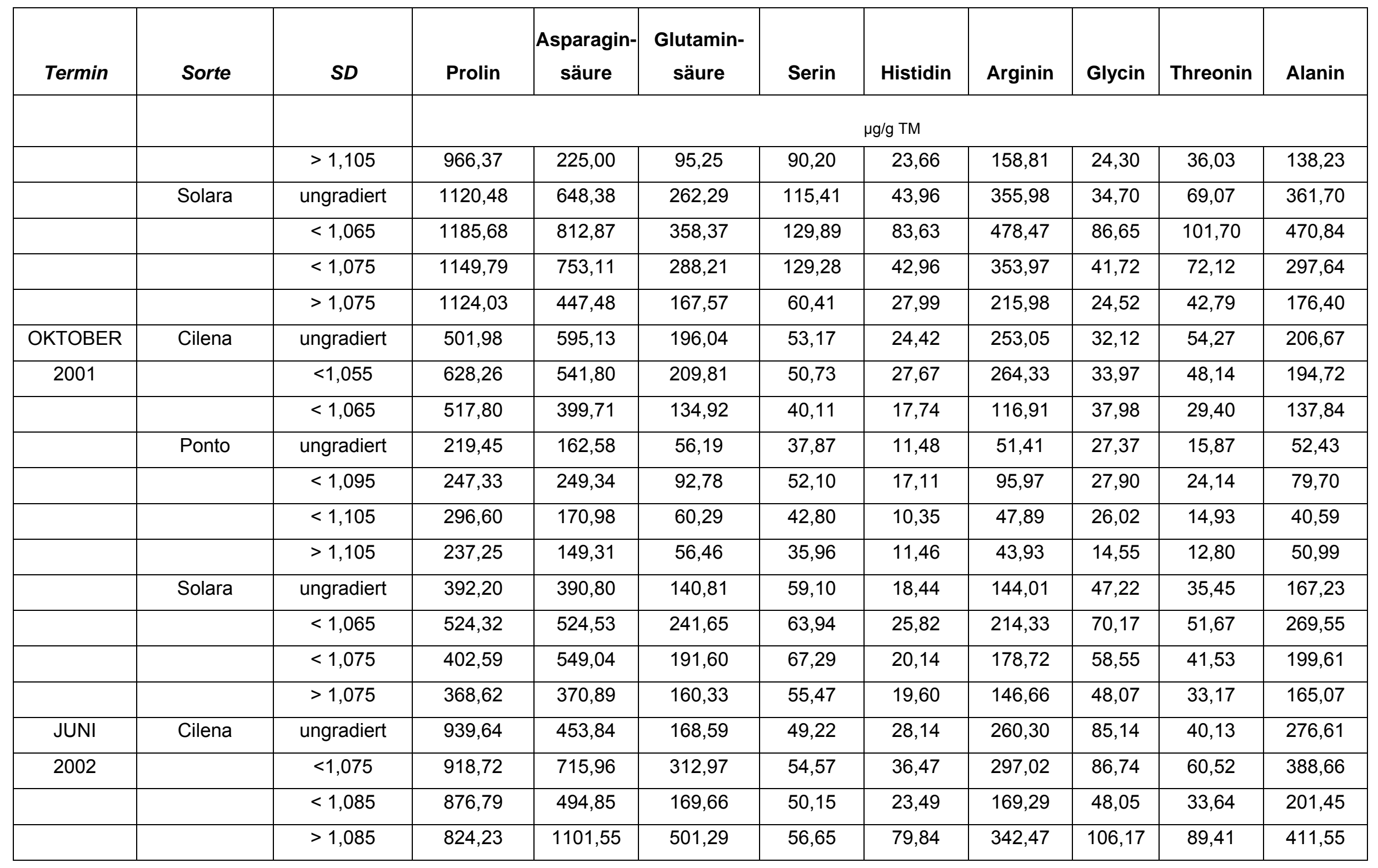


- 117 -

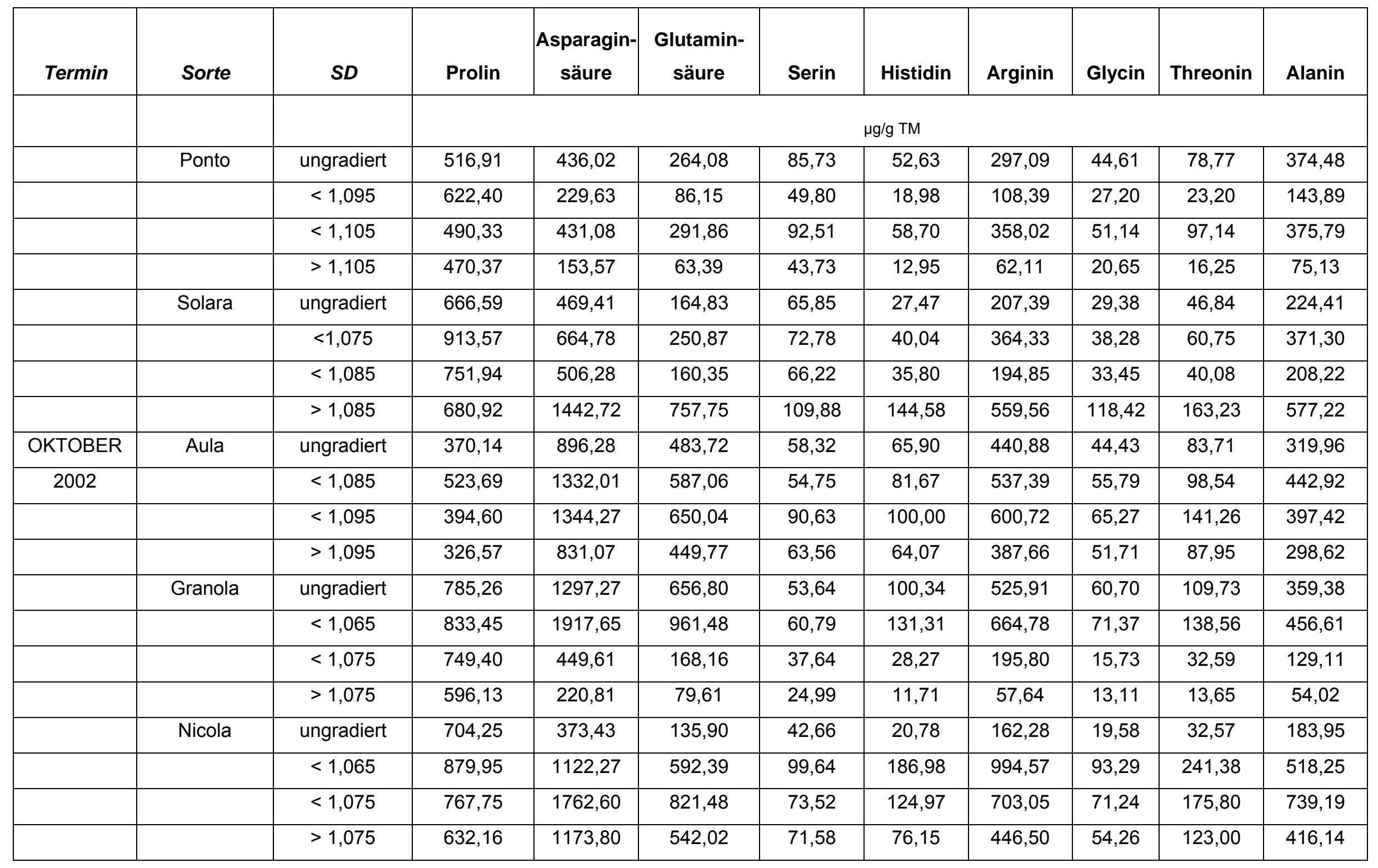


- 118 -

\begin{tabular}{|c|c|c|c|c|c|c|c|c|c|c|c|}
\hline Termin & Sorte & $S D$ & Prolin & $\begin{array}{l}\text { Asparagin- } \\
\text { säure }\end{array}$ & $\begin{array}{l}\text { Glutamin- } \\
\text { säure }\end{array}$ & Serin & Histidin & Arginin & Glycin & Threonin & Alanin \\
\hline & & & \multicolumn{9}{|c|}{$\mu \mathrm{g} / \mathrm{g} \mathrm{TM}$} \\
\hline & Quarta & ungradiert & 597,28 & 919,37 & 602,60 & 101,74 & 152,06 & 878,67 & 86,13 & 223,55 & 289,43 \\
\hline & & $<1,065$ & 784,74 & 3963,23 & 2549,42 & 149,52 & 285,57 & 1521,53 & 162,07 & 365,68 & 1172,11 \\
\hline & & $<1,075$ & 702,67 & 2210,40 & 1379,13 & 104,39 & 152,06 & 925,46 & 100,16 & 229,61 & 740,14 \\
\hline & & $>1,075$ & 498,16 & 1416,31 & 1009,40 & 75,96 & 138,42 & 705,10 & 76,48 & 196,40 & 510,70 \\
\hline JUNI & Aula & ungradiert & 779,17 & 300,24 & 93,13 & 55,24 & 13,07 & 96,66 & 28,27 & 24,88 & 71,86 \\
\hline \multirow[t]{15}{*}{2003} & & $<1,085$ & 976,72 & 387,95 & 117,84 & 45,64 & 17,91 & 143,58 & 20,31 & 24,86 & 157,99 \\
\hline & & $<1,095$ & 851,18 & 347,54 & 117,59 & 36,93 & 13,69 & 96,56 & 11,98 & 17,22 & 124,52 \\
\hline & & $>1,095$ & 761,04 & 123,99 & 39,10 & 22,07 & 9,03 & 62,95 & 11,90 & 9,99 & 33,07 \\
\hline & Granola & ungradiert & 1030,66 & 308,75 & 99,49 & 27,42 & 16,16 & 127,92 & 16,01 & 15,09 & 83,55 \\
\hline & & $<1,065$ & 1105,84 & 580,39 & 225,41 & 36,16 & 36,77 & 277,91 & 19,77 & 29,35 & 197,99 \\
\hline & & $<1,075$ & 1065,57 & 282,98 & 78,15 & 24,46 & 20,72 & 58,25 & 17,30 & 16,78 & 75,36 \\
\hline & & $>1,075$ & 934,85 & 331,88 & 97,50 & 28,71 & 18,18 & 105,12 & 17,93 & 14,74 & 77,47 \\
\hline & Nicola & ungradiert & 1328,42 & 467,43 & 167,09 & 55,89 & 23,44 & 237,61 & 27,51 & 38,10 & 230,45 \\
\hline & & $<1,065$ & 1364,72 & 1539,85 & 582,77 & 76,56 & 61,02 & 774,86 & 64,43 & 73,32 & 821,16 \\
\hline & & $<1,075$ & 1200,49 & 499,03 & 174,43 & 53,55 & 28,30 & 219,20 & 26,75 & 37,19 & 240,49 \\
\hline & & $>1,075$ & 1091,81 & 361,74 & 145,91 & 51,94 & 17,63 & 150,69 & 25,22 & 25,73 & 155,50 \\
\hline & Quarta & ungradiert & 990,64 & 736,17 & 280,87 & 42,34 & 27,16 & 346,95 & 27,26 & 50,18 & 280,73 \\
\hline & & $<1,065$ & 1161,69 & 1030,93 & 354,20 & 45,60 & 56,78 & 603,74 & 40,19 & 59,20 & 491,76 \\
\hline & & $<1,075$ & 967,39 & 832,30 & 296,48 & 65,01 & 32,71 & 334,27 & 32,15 & 57,00 & 276,73 \\
\hline & & $>1,075$ & 493,72 & 509,24 & 173,26 & 42,85 & 20,11 & 218,11 & 25,67 & 33,51 & 174,98 \\
\hline
\end{tabular}


- 119 -

\begin{tabular}{|c|c|c|c|c|c|c|c|c|c|c|c|}
\hline Termin & Sorte & $S D$ & Prolin & $\begin{array}{l}\text { Asparagin- } \\
\text { säure }\end{array}$ & $\begin{array}{l}\text { Glutamin- } \\
\text { säure }\end{array}$ & Serin & Histidin & Arginin & Glycin & Threonin & Alanin \\
\hline & & & \multicolumn{9}{|c|}{$\mu \mathrm{g} / \mathrm{g}$ TM } \\
\hline OKTOBER & Aula & ungradiert & 854,26 & 243,66 & 62,90 & 19,97 & 9,08 & 54,81 & 12,58 & 9,19 & 43,94 \\
\hline \multirow[t]{14}{*}{2003} & & $<1,085$ & 989,91 & 381,41 & 95,47 & 17,70 & 7,14 & 124,89 & 18,78 & 12,66 & 103,74 \\
\hline & & $<1,095$ & 734,35 & 513,96 & 153,52 & 34,80 & 10,46 & 131,51 & 16,38 & 21,73 & 100,13 \\
\hline & & $>1,095$ & 649,59 & 335,38 & 87,64 & 24,63 & 5,96 & 72,15 & 10,75 & 12,67 & 53,05 \\
\hline & Granola & ungradiert & 757,43 & 383,92 & 119,73 & 18,24 & 7,93 & 97,40 & 9,74 & 15,53 & 66,58 \\
\hline & & $<1,065$ & 753,61 & 294,94 & 73,50 & 11,96 & 2,06 & 94,09 & 6,32 & 7,13 & 55,87 \\
\hline & & $<1,075$ & 840,67 & 326,10 & 94,37 & 17,44 & 3,87 & 70,30 & 7,62 & 10,73 & 53,00 \\
\hline & Nicola & ungradiert & 626,42 & 678,07 & 179,34 & 46,88 & 13,34 & 151,79 & 19,21 & 38,82 & 164,69 \\
\hline & & $<1,065$ & 744,90 & 440,86 & 110,77 & 27,15 & 5,29 & 125,66 & 16,70 & 20,82 & 133,54 \\
\hline & & $<1,075$ & 863,09 & 480,27 & 137,07 & 37,52 & 7,03 & 129,95 & 11,55 & 26,51 & 107,80 \\
\hline & & $>1,075$ & 561,23 & 358,15 & 96,44 & 28,95 & 3,95 & 85,25 & 8,95 & 14,88 & 72,42 \\
\hline & Quarta & ungradiert & 377,97 & 619,91 & 255,89 & 43,64 & 11,75 & 188,85 & 11,49 & 39,87 & 128,61 \\
\hline & & $<1,065$ & 590,45 & 566,57 & 224,40 & 32,03 & 11,95 & 208,80 & 19,64 & 33,19 & 153,61 \\
\hline & & $<1,075$ & 434,98 & 483,16 & 161,16 & 32,30 & 6,02 & 112,96 & 12,19 & 29,67 & 90,10 \\
\hline & & $>1,075$ & 360,77 & 406,90 & 119,52 & 29,64 & 2,94 & 105,59 & 8,07 & 19,92 & 68,79 \\
\hline \multirow[t]{4}{*}{ JUNI 2004} & Aula & ungradiert & 951,66 & 695,20 & 224,85 & 112,52 & 25,35 & 268,96 & 49,75 & 34,85 & 226,64 \\
\hline & & $<1,085$ & 991,09 & 931,01 & 330,09 & 108,77 & 61,80 & 341,87 & 37,41 & 69,13 & 336,38 \\
\hline & & $<1,095$ & 1027,57 & 715,58 & 229,78 & 104,63 & 34,83 & 215,47 & 41,73 & 47,84 & 215,75 \\
\hline & & $>1,095$ & 894,45 & 394,58 & 126,16 & 78,89 & 18,93 & 135,56 & 45,31 & 21,85 & 126,69 \\
\hline
\end{tabular}




\begin{tabular}{|c|c|c|c|c|c|c|c|c|c|c|c|c|}
\hline \multirow{2}{*}{ Termin } & Sorte & SD & Prolin & $\begin{array}{c}\text { Asparagin- } \\
\text { säure }\end{array}$ & $\begin{array}{c}\text { Glutamin- } \\
\text { säure }\end{array}$ & Serin & Histidin & Arginin & Glycin & Threonin & Alanin \\
\hline & & & \multicolumn{7}{|c|}{ Mg/g TM } \\
\hline JUNI 2004 & Granola & ungradiert & 1015,11 & 537,84 & 183,34 & 56,91 & 35,79 & 160,42 & 31,72 & 27,21 & 138,41 \\
\hline & & $<1,075$ & 951,37 & 564,32 & 173,95 & 75,04 & 33,51 & 156,55 & 43,42 & 28,64 & 146,43 \\
\hline & & $<1,085$ & 887,74 & 529,09 & 164,45 & 68,00 & 28,63 & 138,68 & 39,28 & 24,77 & 108,39 \\
\hline & & $>1,085$ & 1129,62 & 536,89 & 184,90 & 98,63 & 29,10 & 264,49 & 44,58 & 39,79 & 232,17 \\
\hline & Nicola & ungradiert & 1141,24 & 1119,80 & 382,24 & 131,46 & 72,35 & 512,83 & 46,14 & 78,91 & 454,53 \\
\hline & & $<1,075$ & 1129,71 & 518,26 & 173,99 & 85,84 & 38,04 & 254,92 & 38,65 & 38,60 & 230,08 \\
\hline & & $<1,085$ & 1057,87 & 368,42 & 139,99 & 98,68 & 21,64 & 182,03 & 45,40 & 32,51 & 173,25 \\
\hline & Quarta & ungradiert & 886,51 & 849,33 & 287,98 & 98,18 & 45,38 & 292,34 & 59,42 & 97,09 & 228,25 \\
\hline & & $<1,075$ & 944,91 & 1127,99 & 476,77 & 100,07 & 91,26 & 632,84 & 45,84 & 126,50 & 502,79 \\
\hline & & $<1,085$ & 889,49 & 576,08 & 242,54 & 94,32 & 64,18 & 304,58 & 37,28 & 79,54 & 266,67 \\
\hline & & $>1,085$ & 904,84 & 530,75 & 216,39 & 89,16 & 48,81 & 228,58 & 39,49 & 62,96 & 249,07 \\
\hline
\end{tabular}


10.5.2. AMINOSÄUREN II

\begin{tabular}{|c|c|c|c|c|c|c|c|c|c|}
\hline Termin & Sorte & $S D$ & Tyrosin & Methionin & Valin & Phenylalanin & Isoleucin & Leucin & Lysin \\
\hline & & & \multicolumn{7}{|c|}{$\mu \mathrm{g} / \mathrm{g} \mathrm{TM}$} \\
\hline OKTOBER & Cilena & ungradiert & 222,68 & 59,43 & 29,67 & 106,11 & 175,16 & 206,58 & 137,32 \\
\hline \multirow[t]{11}{*}{2000} & & $<1,055$ & 380,28 & 103,95 & 551,43 & 196,39 & 287,19 & 319,32 & 209,19 \\
\hline & & $<1,065$ & 206,46 & 50,45 & 280,58 & 98,13 & 162,00 & 183,27 & 114,99 \\
\hline & & $>1,065$ & 174,22 & 25,49 & 200,72 & 65,31 & 105,80 & 122,40 & 88,63 \\
\hline & Ponto & ungradiert & 149,37 & 9,25 & 78,04 & 35,32 & 45,38 & 71,47 & 74,74 \\
\hline & & $<1,085$ & 204,26 & 25,19 & 209,09 & 71,08 & 113,89 & 137,27 & 102,73 \\
\hline & & $<1,095$ & 185,80 & 10,88 & 124,54 & 40,68 & 66,88 & 102,00 & 89,45 \\
\hline & & $>1,095$ & 101,21 & 9,22 & 70,00 & 31,29 & 52,35 & 69,30 & 60,03 \\
\hline & Solara & ungradiert & 206,53 & 39,90 & 259,56 & 88,35 & 133,62 & 179,07 & 105,73 \\
\hline & & $<1,065$ & 275,48 & 62,29 & 378,22 & 130,11 & 198,97 & 265,06 & 118,81 \\
\hline & & $<1,075$ & 218,90 & 22,24 & 185,06 & 59,62 & 75,23 & 118,05 & 104,09 \\
\hline & & $>1,075$ & 109,37 & 11,36 & 98,01 & 28,43 & 44,03 & 64,73 & 53,83 \\
\hline JUNI & Cilena & ungradiert & 344,47 & 62,53 & 354,91 & 130,95 & 200,35 & 261,30 & 175,68 \\
\hline \multirow[t]{7}{*}{2001} & & $<1,055$ & 491,23 & 78,06 & 521,38 & 176,43 & 253,03 & 323,14 & 218,52 \\
\hline & & $<1,065$ & 304,64 & 51,84 & 381,59 & 119,73 & 201,03 & 253,03 & 141,36 \\
\hline & & $>1,065$ & 273,13 & 28,83 & 269,31 & 78,13 & 126,53 & 179,58 & 116,33 \\
\hline & Ponto & Ausgang & 152,03 & 8,73 & 85,40 & 27,55 & 51,04 & 76,90 & 64,60 \\
\hline & & $<1,095$ & 288,48 & 26,77 & 197,76 & 72,86 & 112,54 & 159,88 & 112,57 \\
\hline & & $<1,105$ & 206,58 & 16,89 & 117,50 & 42,05 & 63,71 & 105,44 & 95,87 \\
\hline & & $>1,105$ & 145,87 & 7,26 & 70,95 & 24,74 & 42,68 & 66,47 & 63,62 \\
\hline
\end{tabular}




\begin{tabular}{|c|c|c|c|c|c|c|c|c|c|}
\hline Termin & Sorte & $S D$ & Tyrosin & Methionin & Valin & Phenylalanin & Isoleucin & Leucin & Lysin \\
\hline & & & \multicolumn{7}{|c|}{$\mu \mathrm{g} / \mathrm{g} \mathrm{TM}$} \\
\hline & Solara & ungradiert & 170,39 & 31,19 & 204,41 & 68,70 & 116,88 & 194,06 & 98,57 \\
\hline & & $<1,065$ & 249,76 & 56,18 & 339,21 & 123,12 & 191,86 & 322,00 & 137,85 \\
\hline & & $<1,075$ & 173,18 & 30,69 & 211,09 & $\begin{array}{l}4,78 \\
\end{array}$ & 115,17 & 190,60 & 102,40 \\
\hline & & $>1,075$ & 50,84 & 13,73 & 114,54 & 33,85 & 56,24 & 95,29 & 62,68 \\
\hline OKTOBER & Cilena & ungradiert & 149,06 & 21,39 & 167,80 & 46,67 & 84,86 & 108,89 & 94,58 \\
\hline \multirow[t]{10}{*}{2001} & & $<1,055$ & 147,94 & 27,26 & 174,78 & 54,97 & 81,09 & 119,47 & 90,38 \\
\hline & & $<1,065$ & 109,56 & 12,24 & 103,07 & 32,80 & 58,86 & 68,50 & 65,60 \\
\hline & Ponto & ungradiert & 39,94 & 2,54 & 29,88 & 8,76 & 31,92 & 24,63 & 35,58 \\
\hline & & $<1,095$ & 70,56 & 4,63 & 47,85 & 18,15 & 48,12 & 40,01 & 53,63 \\
\hline & & $<1,105$ & 39,00 & 2,14 & 22,67 & 8,49 & 31,00 & 19,90 & 34,55 \\
\hline & & $>1,105$ & 49,79 & 2,14 & 23,13 & 9,11 & 33,20 & 20,68 & 37,00 \\
\hline & Solara & ungradiert & 134,46 & 11,88 & 106,07 & 31,78 & 65,37 & 81,56 & 72,86 \\
\hline & & $<1,065$ & 174,80 & 29,46 & 204,97 & 63,09 & 83,03 & 140,25 & 92,53 \\
\hline & & $<1,075$ & 156,73 & 15,92 & 133,82 & 40,03 & 74,49 & 96,45 & 83,02 \\
\hline & & $>1,075$ & 141,65 & 16,32 & 130,90 & 41,87 & 58,52 & 90,21 & 65,23 \\
\hline JUNI & Cilena & ungradiert & 185,09 & 24,97 & 204,20 & 54,61 & 70,20 & 130,65 & $\begin{array}{l}78,24 \\
\end{array}$ \\
\hline \multirow[t]{6}{*}{2002} & & $<1,075$ & 235,09 & 42,47 & 320,20 & 90,07 & 175,60 & 208,37 & 110,97 \\
\hline & & $<1,085$ & 141,47 & 13,13 & 155,50 & 37,69 & 82,25 & 90,33 & 73,08 \\
\hline & & $>1,085$ & 577,10 & 41,87 & 254,31 & 95,02 & 113,04 & 176,43 & 317,23 \\
\hline & Ponto & ungradiert & 312,68 & 23,14 & 163,67 & 67,80 & 95,16 & 159,55 & 218,81 \\
\hline & & $<1,095$ & 82,71 & 5,38 & 72,92 & 21,86 & 49,22 & 57,19 & 56,95 \\
\hline & & $<1,105$ & 355,36 & 29,57 & 187,67 & 84,51 & 124,08 & 204,95 & 268,14 \\
\hline
\end{tabular}




\begin{tabular}{|c|c|c|c|c|c|c|c|c|c|}
\hline Termin & Sorte & $S D$ & Tyrosin & Methionin & Valin & Phenylalanin & Isoleucin & Leucin & Lysin \\
\hline & & & \multicolumn{7}{|c|}{$\mu g / g$ TM } \\
\hline & & $>1,105$ & 69,94 & 1,77 & 32,13 & 9,12 & 25,14 & 31,19 & 44,08 \\
\hline & Solara & ungradiert & 114,66 & 17,08 & 145,81 & 46,85 & 92,26 & 122,36 & 84,47 \\
\hline & & $<1,075$ & 184,85 & 31,89 & 247,85 & 81,15 & 145,80 & 208,90 & 115,41 \\
\hline & & $<1,085$ & 115,37 & 16,97 & 140,27 & 47,42 & 90,04 & 116,62 & 79,07 \\
\hline & & $>1,085$ & 545,83 & 57,64 & 318,58 & 142,04 & 177,67 & 316,00 & 486,20 \\
\hline OKTOBER & Aula & ungradiert & 513,95 & 46,52 & 252,11 & 89,06 & 122,07 & 169,19 & 313,46 \\
\hline \multirow[t]{15}{*}{2002} & & $<1,085$ & 574,35 & 70,61 & 426,32 & 131,38 & 177,39 & 228,49 & 348,10 \\
\hline & & $<1,095$ & 575,75 & 69,62 & 347,16 & 127,46 & 190,52 & 260,30 & 444,75 \\
\hline & & $>1,095$ & 458,91 & 43,03 & 226,70 & 87,91 & 109,26 & 164,20 & 331,72 \\
\hline & Granola & ungradiert & 569,90 & 68,12 & 397,67 & 140,26 & 204,13 & 213,10 & 461,47 \\
\hline & & $<1,065$ & 676,07 & 93,85 & 543,18 & 185,36 & 259,20 & 292,78 & 577,48 \\
\hline & & $<1,075$ & 123,36 & 14,32 & 177,03 & 40,31 & 108,12 & 79,38 & 84,88 \\
\hline & & $>1,075$ & 61,47 & 4,62 & 67,81 & 9,46 & 38,13 & 26,73 & 40,10 \\
\hline & Nicola & ungradiert & 58,80 & 22,28 & 206,05 & 41,09 & 108,71 & 94,98 & 56,01 \\
\hline & & $<1,065$ & 291,01 & 207,91 & 503,09 & 323,76 & 545,25 & 645,87 & 691,98 \\
\hline & & $<1,075$ & 541,18 & 124,33 & 734,18 & 206,63 & 330,42 & 412,51 & 470,42 \\
\hline & & $>1,075$ & 387,06 & 65,01 & 360,72 & 108,49 & 179,03 & 222,21 & 314,46 \\
\hline & Quarta & ungradiert & 107,15 & 139,72 & 230,69 & 205,56 & 276,16 & 416,21 & 578,81 \\
\hline & & $<1,065$ & 1314,83 & 237,72 & 1094,31 & 409,68 & 493,16 & 701,58 & 1014,74 \\
\hline & & $<1,075$ & 789,76 & 142,89 & 597,07 & 237,77 & 302,55 & 458,62 & 610,77 \\
\hline & & $>1,075$ & 216,79 & 92,34 & 371,43 & 148,30 & 197,55 & 304,80 & 479,58 \\
\hline
\end{tabular}




\begin{tabular}{|c|c|c|c|c|c|c|c|c|c|}
\hline Termin & Sorte & $S D$ & Tyrosin & Methionin & Valin & Phenylalanin & Isoleucin & Leucin & Lysin \\
\hline & & & \multicolumn{7}{|c|}{$\mu \mathrm{g} / \mathrm{g} \mathrm{TM}$} \\
\hline JUNI & Aula & ungradiert & 66,65 & 7,00 & 42,86 & 16,83 & 33,37 & 43,84 & 61,18 \\
\hline \multirow[t]{15}{*}{2003} & & $<1,085$ & 101,60 & 9,93 & 126,52 & 22,23 & 67,69 & 68,75 & 50,94 \\
\hline & & $<1,095$ & 101,93 & 4,94 & 86,51 & 12,63 & 36,84 & 39,93 & 40,48 \\
\hline & & $>1,095$ & 20,47 & 4,17 & 16,14 & 7,67 & 23,26 & 19,29 & 29,11 \\
\hline & Granola & ungradiert & 60,85 & 4,73 & 82,62 & 16,55 & 42,90 & 37,44 & 45,04 \\
\hline & & $<1,065$ & 91,15 & 14,71 & 239,55 & 47,37 & 111,67 & 93,29 & 85,44 \\
\hline & & $<1,075$ & 57,89 & 9,91 & 67,85 & 30,23 & 60,98 & 57,27 & 55,81 \\
\hline & & $>1,075$ & 65,78 & 6,90 & 74,25 & 17,22 & 43,54 & 36,03 & 43,66 \\
\hline & Nicola & ungradiert & 159,19 & 19,05 & 226,58 & 50,80 & 118,27 & 119,23 & 67,11 \\
\hline & & $<1,065$ & 609,99 & 46,10 & 826,85 & 123,55 & 263,46 & 277,22 & 138,04 \\
\hline & & $<1,075$ & 142,11 & 20,76 & 251,80 & 51,21 & 130,22 & 124,38 & 63,34 \\
\hline & & $>1,075$ & 126,89 & 10,48 & 120,67 & 26,24 & 54,49 & 59,21 & 59,84 \\
\hline & Quarta & ungradiert & 169,34 & 22,03 & 213,15 & 51,89 & 105,15 & 131,46 & 74,21 \\
\hline & & $<1,065$ & 318,18 & 41,27 & 410,58 & 97,21 & 198,09 & 242,31 & 125,90 \\
\hline & & $<1,075$ & 146,58 & 20,66 & 183,49 & 57,66 & 100,27 & 136,89 & 127,97 \\
\hline & & $>1,075$ & 70,85 & 13,14 & 110,33 & 30,39 & 61,72 & 75,55 & 57,77 \\
\hline OKTOBER & Aula & ungradiert & 25,17 & 3,05 & 41,57 & 5,49 & 20,80 & 16,87 & 26,54 \\
\hline \multirow[t]{5}{*}{2003} & & $<1,085$ & 77,57 & 7,43 & 128,01 & 18,65 & 54,26 & 43,22 & 32,13 \\
\hline & & $<1,095$ & 108,05 & 7,65 & 117,56 & 19,35 & 60,45 & 50,83 & 48,90 \\
\hline & & $>1,095$ & 77,05 & 1,74 & 64,34 & 10,51 & 36,66 & 27,29 & 34,01 \\
\hline & Granola & ungradiert & 90,12 & 3,24 & 108,79 & 17,58 & 59,76 & 33,20 & 46,49 \\
\hline & & $<1,065$ & 72,34 & 0,41 & 81,96 & 12,51 & 37,45 & 21,13 & 35,76 \\
\hline
\end{tabular}




\begin{tabular}{|c|c|c|c|c|c|c|c|c|c|}
\hline Termin & Sorte & $S D$ & Tyrosin & Methionin & Valin & Phenylalanin & Isoleucin & Leucin & Lysin \\
\hline & & & \multicolumn{7}{|c|}{$\mu \mathrm{g} / \mathrm{g} \mathrm{TM}$} \\
\hline & & $<1,075$ & 69,85 & 1,44 & 67,68 & 13,85 & 45,44 & 22,57 & 37,30 \\
\hline & Nicola & ungradiert & 170,62 & 16,58 & 182,78 & 42,95 & 95,02 & 83,63 & 74,25 \\
\hline & & $<1,065$ & 89,49 & 9,19 & 152,41 & 25,18 & 72,28 & 57,10 & 38,57 \\
\hline & & $<1,075$ & 120,51 & 6,08 & 119,15 & 23,03 & 57,18 & 52,65 & 49,66 \\
\hline & & $>1,075$ & 69,29 & 2,83 & 85,29 & 10,41 & 43,37 & 30,24 & 32,19 \\
\hline & Quarta & ungradiert & 91,09 & 14,26 & 115,72 & 33,41 & 59,54 & 66,72 & 63,90 \\
\hline & & $<1,065$ & 86,98 & 16,49 & 156,91 & 34,78 & 78,40 & 76,59 & 47,55 \\
\hline & & $<1,075$ & 58,80 & 5,10 & 69,01 & 15,20 & 39,82 & 44,49 & 41,14 \\
\hline & & $>1,075$ & 51,04 & 1,19 & 45,93 & 8,92 & 21,50 & 25,56 & 36,59 \\
\hline \multirow[t]{13}{*}{ JUNI 2004} & Aula & ungradiert & 257,64 & 14,15 & 188,91 & 46,51 & 76,78 & 90,72 & 74,12 \\
\hline & & $<1,085$ & 328,65 & 39,65 & 321,86 & 105,17 & 184,69 & 206,13 & 118,04 \\
\hline & & $<1,095$ & 223,51 & 19,31 & 201,46 & 59,92 & 110,14 & 122,56 & 83,57 \\
\hline & & $>1,095$ & 115,62 & 4,78 & 107,89 & 22,93 & 51,91 & 53,15 & 45,74 \\
\hline & Granola & ungradiert & 180,57 & 10,78 & 150,39 & 46,49 & 89,51 & 74,90 & 72,87 \\
\hline & & $<1,075$ & 163,97 & 8,50 & 144,26 & 42,06 & 91,25 & 73,80 & 70,45 \\
\hline & & $<1,085$ & 136,93 & 5,66 & 107,43 & 30,96 & 65,95 & 54,06 & 61,00 \\
\hline & & $>1,085$ & 182,74 & 19,09 & 247,21 & 66,71 & 140,23 & 125,36 & 82,05 \\
\hline & Nicola & ungradiert & 395,49 & 49,29 & 486,94 & 133,74 & 258,82 & 250,81 & 159,04 \\
\hline & & $<1,075$ & 158,16 & 20,63 & 262,77 & 62,42 & 138,85 & 128,89 & 73,28 \\
\hline & & $<1,085$ & 198,21 & 10,28 & 160,59 & 41,86 & 83,27 & 86,33 & 76,98 \\
\hline & Quarta & ungradiert & 161,76 & 29,77 & 195,80 & 73,89 & 125,68 & 179,16 & 110,59 \\
\hline & & $<1,075$ & 309,34 & 48,98 & 405,61 & 109,59 & 199,03 & 261,02 & 144,47 \\
\hline
\end{tabular}


$-126-$

\begin{tabular}{|c|c|c|c|c|c|c|c|c|c|c|}
\hline \multirow{2}{*}{ Termin } & Sorte & SD & Tyrosin & Methionin & Valin & Phenylalanin & Isoleucin & Leucin & Lysin \\
\hline & & & \multicolumn{7}{|c|}{$\mu \mathrm{g} / \mathrm{g} \mathrm{TM}$} \\
\hline & & $<1,085$ & 190,31 & 20,82 & 178,09 & 66,51 & 114,92 & 162,58 & 120,25 \\
\hline & & $>1,085$ & 139,71 & 14,66 & 153,67 & 37,89 & 91,79 & 120,51 & 78,27 \\
\hline
\end{tabular}


10.6. MINERALSTOFFE

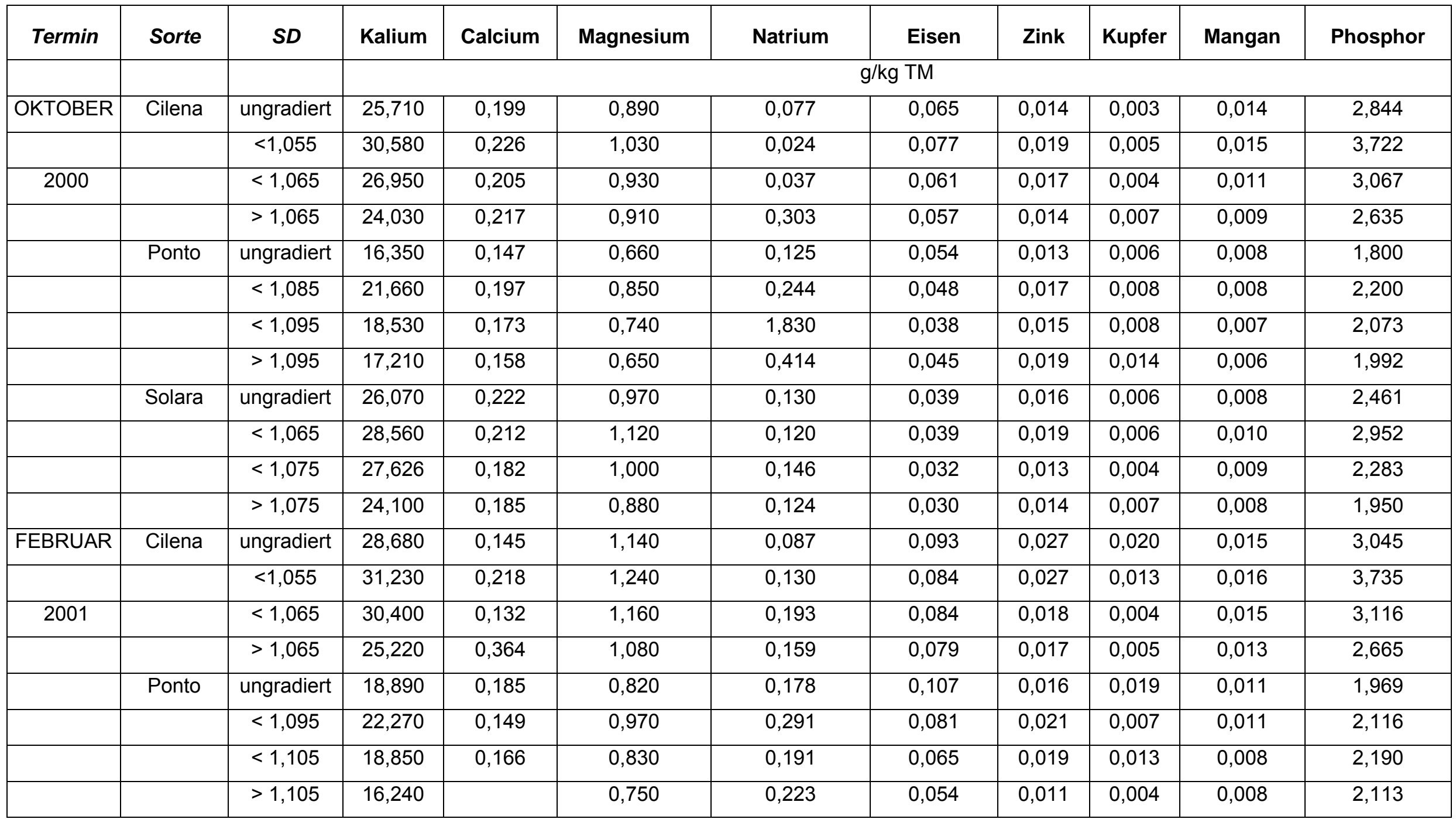




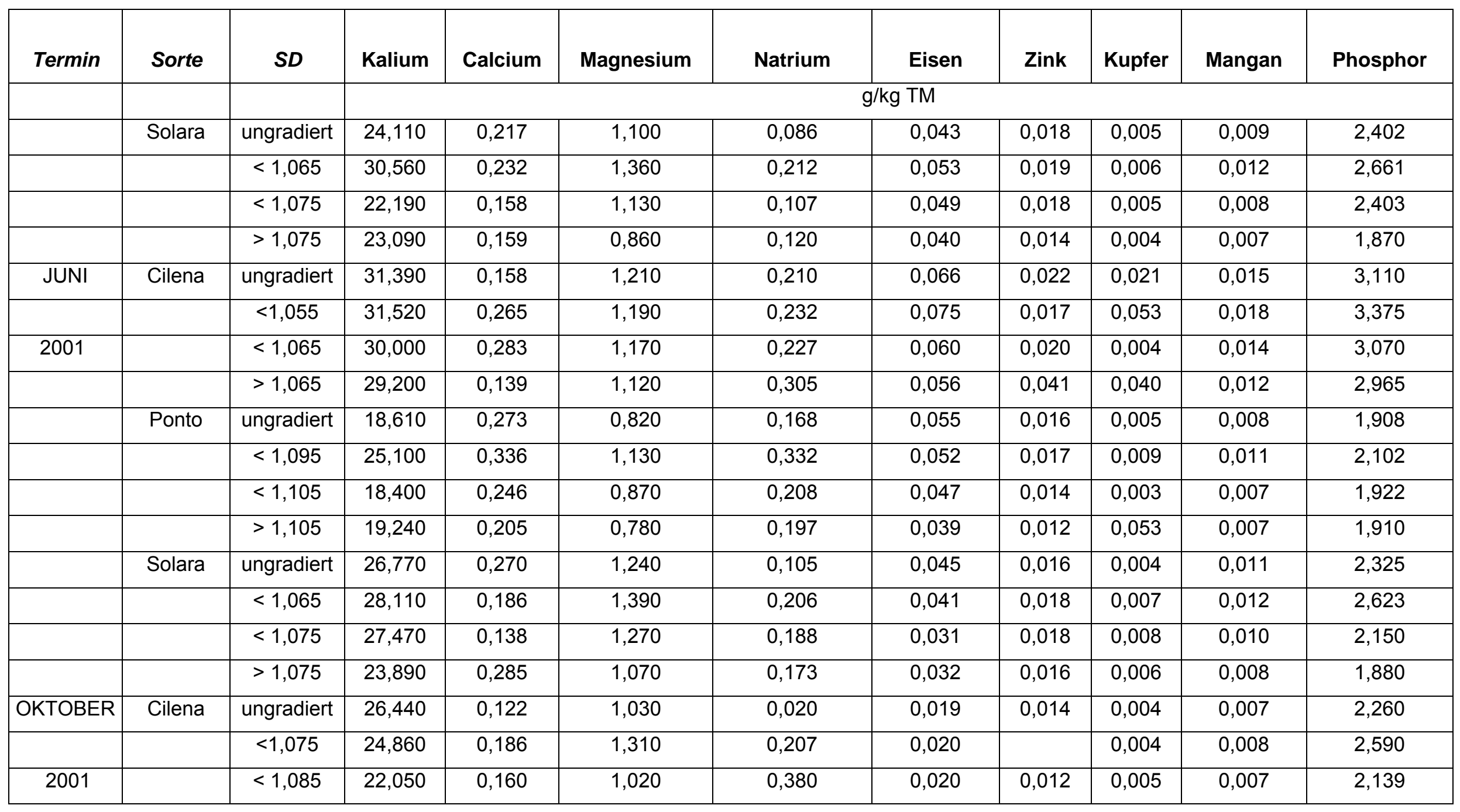




\begin{tabular}{|c|c|c|c|c|c|c|c|c|c|c|c|}
\hline Termin & Sorte & $S D$ & Kalium & Calcium & Magnesium & Natrium & Eisen & Zink & Kupfer & Mangan & Phosphor \\
\hline & & & \multicolumn{9}{|c|}{ g/kg TM } \\
\hline & Ponto & ungradiert & 19,820 & 0,148 & 0,750 & 0,090 & 0,012 & 0,009 & 0,005 & 0,004 & 2,247 \\
\hline & & $<1,095$ & 25,520 & 0,160 & 0,800 & 0,314 & 0,017 & 0,010 & 0,010 & 0,006 & 2,264 \\
\hline & & $<1,105$ & 22,000 & 0,146 & 0,740 & 0,225 & 0,014 & 0,012 & 0,004 & 0,005 & 2,249 \\
\hline & & $>1,105$ & 18,550 & 0,104 & 0,610 & 0,318 & 0,014 & 0,013 & 0,003 & 0,005 & 2,082 \\
\hline & & $<1,075$ & 24,040 & 0,143 & 1,200 & 0,173 & 0,027 & 0,015 & 0,009 & 0,007 & 2,121 \\
\hline & & $<1,085$ & 20,750 & 0,137 & 1,040 & 0,372 & 0,018 & 0,012 & 0,007 & 0,006 & 2,084 \\
\hline & & $>1,085$ & 21,840 & 0,247 & 0,950 & 0,276 & 0,018 & 0,010 & 0,012 & 0,005 & 1,848 \\
\hline \multirow[t]{2}{*}{ FEBRUAR } & Cilena & ungradiert & 25,100 & 0,189 & 1,070 & 0,039 & 0,030 & 0,017 & 0,024 & 0,008 & 2,423 \\
\hline & & $<1,075$ & 25,520 & 0,152 & 1,250 & 0,086 & 0,026 & 0,012 & 0,004 & 0,009 & 2,469 \\
\hline \multirow{7}{*}{2002} & & $<1,095$ & 23,800 & 0,130 & 1,040 & 0,082 & 0,019 & 0,011 & 0,006 & 0,006 & 2,421 \\
\hline & & $<1,105$ & 21,520 & 0,134 & 0,809 & 0,194 & 0,015 & 0,012 & 0,011 & 0,005 & 2,455 \\
\hline & & $>1,105$ & 19,940 & 0,161 & 0,660 & 0,108 & 0,019 & 0,010 & 0,005 & 0,004 & 2,101 \\
\hline & Solara & ungradiert & 22,280 & 0,152 & 1,000 & 0,051 & 0,024 & 0,013 & 0,042 & 0,006 & 2,036 \\
\hline & & $<1,075$ & 25,590 & 0,184 & 1,050 & 0,126 & 0,230 & 0,014 & 0,004 & 0,006 & 2,410 \\
\hline & & $<1,085$ & 23,750 & 0,161 & 1,050 & 0,052 & 0,023 & 0,013 & 0,005 & 0,006 & 2,076 \\
\hline & & $>1,085$ & 21,980 & 0,139 & 0,930 & 0,115 & 0,018 & 0,014 & 0,010 & 0,005 & 1,980 \\
\hline
\end{tabular}




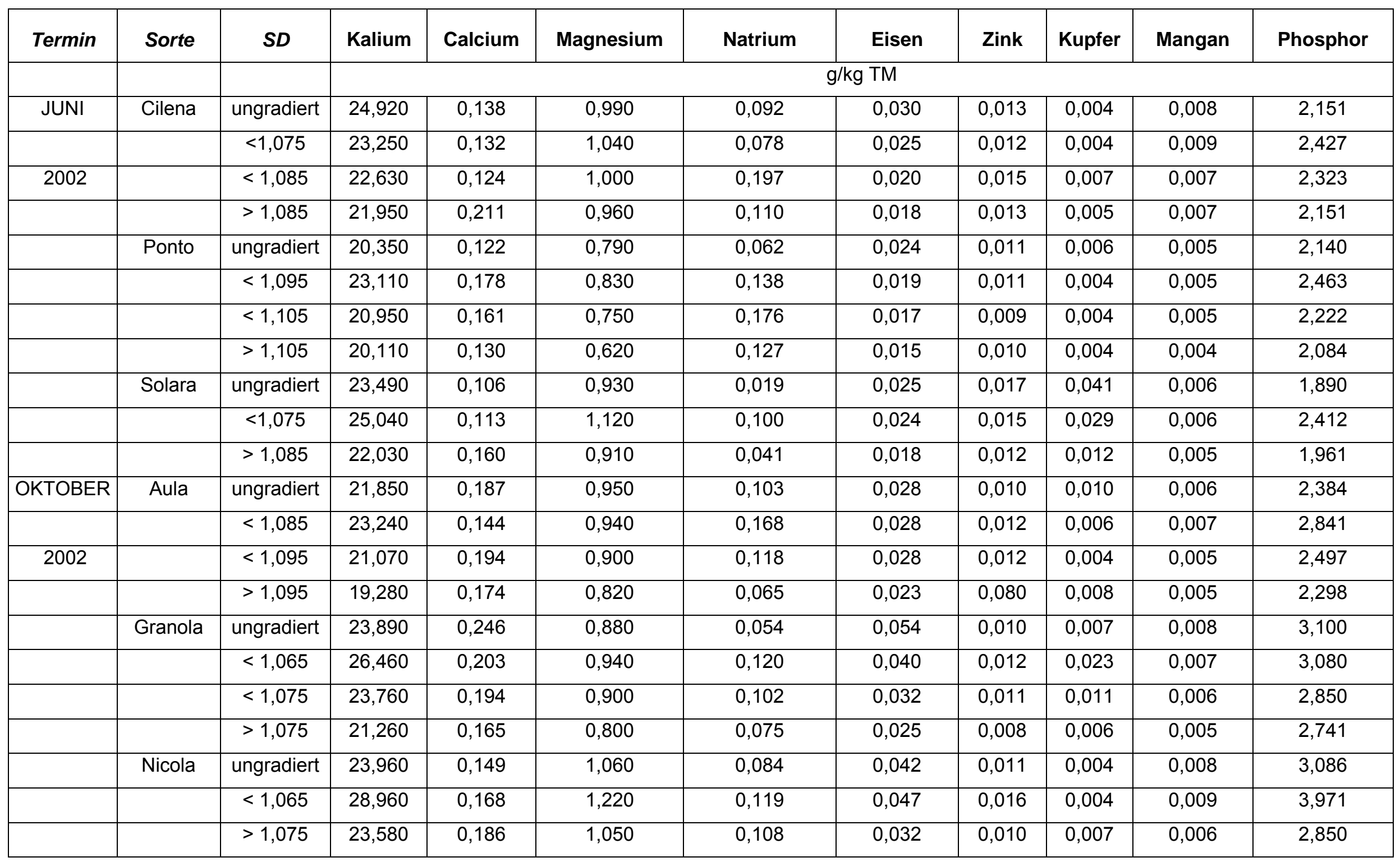




\begin{tabular}{|c|c|c|c|c|c|c|c|c|c|c|c|}
\hline Termin & Sorte & $S D$ & Kalium & Calcium & Magnesium & Natrium & Eisen & Zink & Kupfer & Mangan & Phosphor \\
\hline & & & \multicolumn{9}{|c|}{$\mathrm{g} / \mathrm{kg}$ TM } \\
\hline & Quarta & ungradiert & 21,870 & 0,189 & 0,960 & 0,068 & 0,040 & 0,013 & 0,008 & 0,008 & 2,033 \\
\hline & & $<1,065$ & 26,960 & 0,216 & 1,060 & 0,180 & 0,046 & 0,017 & 0,010 & 0,008 & 2,455 \\
\hline & & $<1,075$ & 26,740 & 0,174 & 0,990 & 0,144 & 0,041 & 0,015 & 0,007 & 0,006 & 2,159 \\
\hline & & $>1,075$ & 25,020 & 0,171 & 0,910 & 0,079 & 0,031 & 0,012 & 0,003 & 0,005 & 1,829 \\
\hline FEBRUAR & Aula & ungradiert & 21,140 & 0,129 & 0,900 & 0,017 & 0,028 & 0,012 & 0,004 & 0,057 & 2,531 \\
\hline \multirow[t]{11}{*}{2003} & & $<1,095$ & 21,850 & 0,149 & 0,960 & 0,110 & 0,024 & 0,010 & 0,004 & 0,005 & 2,594 \\
\hline & & $>1,095$ & 20,750 & 0,159 & 0,860 & 0,108 & 0,022 & 0,010 & 0,003 & 0,006 & 2,303 \\
\hline & Granola & ungradiert & 24,300 & 0,175 & 0,870 & 0,168 & 0,041 & 0,013 & 0,011 & 0,008 & 3,020 \\
\hline & & $<1,065$ & 29,170 & 0,192 & 0,940 & 0,088 & 0,032 & 0,012 & 0,004 & 0,008 & 3,447 \\
\hline & & $<1,075$ & 26,180 & 0,311 & 0,840 & 0,112 & 0,025 & 0,011 & 0,004 & 0,006 & 3,031 \\
\hline & & $<1,075$ & 30,100 & 0,333 & 1,170 & 0,180 & 0,044 & 0,011 & 0,024 & 0,008 & 3,411 \\
\hline & & $>1,075$ & 23,260 & 0,146 & 0,910 & 0,080 & 0,026 & 0,010 & 0,008 & 0,006 & 2,864 \\
\hline & Quarta & ungradiert & 27,170 & 0,154 & 1,030 & 0,197 & 0,044 & 0,013 & 0,004 & 0,008 & 2,182 \\
\hline & & $<1,065$ & 29,920 & 0,158 & 1,060 & 0,145 & 0,042 & 0,019 & 0,005 & 0,008 & 2,548 \\
\hline & & $<1,075$ & 24,542 & 0,187 & 1,000 & 0,153 & 0,039 & 0,019 & 0,004 & 0,006 & 2,348 \\
\hline & & $>1,075$ & 23,000 & & 1,030 & 0,300 & 0,027 & 0,011 & 0,009 & 0,005 & 1,909 \\
\hline
\end{tabular}


- 132 -

\begin{tabular}{|c|c|c|c|c|c|c|c|c|c|c|c|}
\hline Termin & Sorte & $S D$ & Kalium & Calcium & Magnesium & Natrium & Eisen & Zink & Kupfer & Mangan & Phosphor \\
\hline JUNI & Aula & ungradiert & 22,310 & 0,150 & 0,980 & 0,020 & 0,033 & 0,011 & 0,007 & 0,006 & 2,541 \\
\hline \multirow[t]{9}{*}{2003} & & $<1,095$ & 22,760 & 0,144 & 0,970 & 0,142 & 0,026 & 0,011 & 0,007 & 0,006 & 2,678 \\
\hline & & $>1,095$ & 20,060 & 0,163 & 0,850 & 0,075 & 0,022 & 0,080 & 0,005 & 0,005 & 2,368 \\
\hline & & $<1,075$ & 25,870 & & 0,940 & 0,103 & 0,038 & 0,013 & 0,009 & 0,008 & 3,396 \\
\hline & & $>1,075$ & 22,700 & 0,261 & 0,880 & 0,174 & 0,031 & 0,019 & 0,005 & 0,006 & 3,068 \\
\hline & Nicola & ungradiert & 24,620 & 0,172 & 1,060 & 0,041 & 0,063 & & 0,006 & 0,009 & 4,018 \\
\hline & & $<1,065$ & 30,400 & 0,189 & 1,230 & 2,210 & 0,051 & 0,013 & 0,009 & 0,010 & 4,183 \\
\hline & & $<1,075$ & 26,170 & 0,156 & 1,050 & 0,194 & 0,042 & 0,014 & 0,003 & 0,008 & 4,067 \\
\hline & & $<1,075$ & 23,240 & 0,217 & 0,980 & 0,050 & 0,036 & 0,012 & 0,004 & 0,007 & 2,494 \\
\hline & & $>1,075$ & 25,360 & 0,182 & 0,940 & 0,119 & 0,037 & 0,018 & 0,003 & 0,006 & 2,216 \\
\hline \multirow[t]{2}{*}{ OKTOBER } & Aula & ungradiert & 20,300 & 0,084 & 0,850 & 0,046 & 0,021 & 0,011 & 0,040 & 0,005 & 1,941 \\
\hline & & $<1,085$ & 24,580 & 0,190 & 1,850 & 0,209 & 0,020 & 0,014 & 0,011 & 0,010 & 2,311 \\
\hline \multirow[t]{2}{*}{2003} & & $<1,095$ & 22,010 & 0,128 & 0,880 & 0,118 & 0,016 & 0,010 & 0,010 & 0,004 & 2,044 \\
\hline & & $>1,095$ & 19,670 & 0,080 & 0,810 & 0,011 & 0,013 & 0,009 & 0,009 & 0,004 & 1,874 \\
\hline
\end{tabular}




\begin{tabular}{|c|c|c|c|c|c|c|c|c|c|c|c|}
\hline & Granola & ungradiert & 21,040 & 0,129 & 0,830 & 0,046 & 0,028 & 0,009 & 0,005 & 0,004 & 1,963 \\
\hline & & $<1,085$ & 19,640 & 0,142 & 0,750 & 0,086 & 0,019 & 0,020 & 0,005 & 0,004 & 1,776 \\
\hline & Nicola & ungradiert & 21,160 & 0,136 & 0,870 & 0,152 & 0,032 & 0,012 & 0,003 & 0,005 & 1,737 \\
\hline & & $>1,085$ & 20,650 & 0,096 & 0,620 & 0,170 & 0,026 & 0,015 & 0,003 & 0,004 & 1,634 \\
\hline & Quarta & ungradiert & 17,910 & 0,120 & 0,870 & 0,078 & 0,031 & 0,011 & 0,003 & 0,005 & 1,300 \\
\hline & & $<1,075$ & 23,060 & 0,156 & 1,090 & 0,179 & 0,021 & 0,013 & 0,004 & 0,005 & 1,416 \\
\hline & & $<1,085$ & 20,500 & 0,120 & 0,930 & 0,199 & 0,017 & 0,015 & 0,006 & 0,005 & 1,345 \\
\hline & & $>1,085$ & 17,980 & 0,121 & 0,740 & 0,239 & 0,017 & 0,012 & 0,015 & 0,004 & 1,264 \\
\hline & & $>1,095$ & 16,463 & 0,140 & 0,940 & 0,085 & 0,019 & 0,012 & 0,006 & 0,004 & 2,123 \\
\hline & Granola & ungradiert & 22,545 & 0,184 & 1,100 & 0,093 & 0,026 & 0,014 & 0,005 & 0,005 & 2,254 \\
\hline & & $<1,075$ & 22,302 & 0,161 & 1,130 & 0,119 & 0,026 & 0,011 & 0,006 & 0,004 & 2,293 \\
\hline & & $<1,085$ & 18,577 & 0,214 & 1,020 & 0,111 & 0,027 & 0,011 & 0,005 & 0,004 & 2,088 \\
\hline & Nicola & ungradiert & 23,297 & 0,121 & 1,260 & 0,750 & 0,024 & 0,015 & 0,006 & 0,005 & 2,097 \\
\hline & & $<1,075$ & 25,039 & 0,206 & 1,440 & 0,860 & 0,035 & 0,014 & 0,003 & 0,005 & 2,371 \\
\hline & & $<1,085$ & 22,421 & 0,159 & 1,160 & 0,083 & 0,029 & 0,014 & 0,007 & 0,005 & 2,223 \\
\hline & & $>1,085$ & 21,710 & 0,151 & 0,940 & 0,099 & 0,028 & 0,014 & 0,005 & 0,004 & 1,939 \\
\hline
\end{tabular}




\begin{tabular}{|c|c|c|c|c|c|c|c|c|c|c|c|}
\hline Termin & Sorte & $S D$ & Kalium & Calcium & Magnesium & Natrium & Eisen & Zink & Kupfer & Mangan & Phosphor \\
\hline & & & \multicolumn{9}{|c|}{$\mathrm{g} / \mathrm{kg}$ TM } \\
\hline & Quarta & ungradiert & 19,848 & 0,205 & 1,050 & 0,095 & 0,019 & 0,014 & 0,004 & 0,005 & 1,543 \\
\hline & & $<1,075$ & 25,921 & 0,261 & 1,390 & 0,122 & 0,027 & 0,012 & 0,004 & 0,005 & 1,757 \\
\hline & & $<1,085$ & 23,859 & 0,215 & 1,170 & 0,103 & 0,018 & 0,012 & 0,005 & 0,005 & 1,665 \\
\hline & & $>1,085$ & 19,260 & 0,198 & 0,960 & 0,090 & 0,022 & 0,014 & 0,003 & 0,004 & 1,472 \\
\hline JUNI & Aula & ungradiert & 20,546 & 0,146 & 1,160 & 0,080 & 0,031 & 0,010 & 0,007 & 0,005 & 2,257 \\
\hline \multirow[t]{10}{*}{2004} & & $<1,095$ & 23,150 & 0,099 & 1,210 & 0,093 & 0,021 & 0,014 & 0,005 & 0,004 & 2,253 \\
\hline & & $>1,095$ & 21,162 & 0,126 & 1,100 & 0,090 & 0,019 & 0,009 & 0,007 & 0,004 & 2,089 \\
\hline & Granola & ungradiert & 21,857 & 0,229 & 1,110 & 0,109 & 0,027 & 0,014 & 0,068 & 0,004 & 2,220 \\
\hline & & $<1,075$ & 21,897 & 0,181 & 1,110 & 0,164 & 0,025 & 0,015 & 0,003 & 0,004 & 2,277 \\
\hline & & $<1,085$ & 23,448 & 0,201 & 1,020 & 0,118 & 0,030 & 0,013 & 0,003 & 0,004 & 2,018 \\
\hline & & $>1,085$ & 18,589 & 0,128 & 0,830 & 0,115 & 0,022 & 0,011 & 0,003 & 0,004 & 1,863 \\
\hline & Quarta & ungradiert & 23,681 & 0,265 & 1,130 & 0,860 & 0,025 & 0,011 & 0,005 & 0,005 & 1,765 \\
\hline & & $<1,075$ & 29,354 & 0,214 & 1,230 & 0,173 & 0,026 & 0,018 & 0,004 & 0,005 & 1,818 \\
\hline & & $<1,085$ & 23,599 & 0,247 & 1,080 & 0,152 & 0,019 & 0,016 & 0,005 & 0,005 & 1,488 \\
\hline & & $>1,085$ & 19,260 & 0,203 & 0,880 & 0,119 & 0,018 & 0,014 & 0,003 & 0,004 & 1,376 \\
\hline
\end{tabular}


- 135 -

10.7. ORGANISCHE SÄUREN

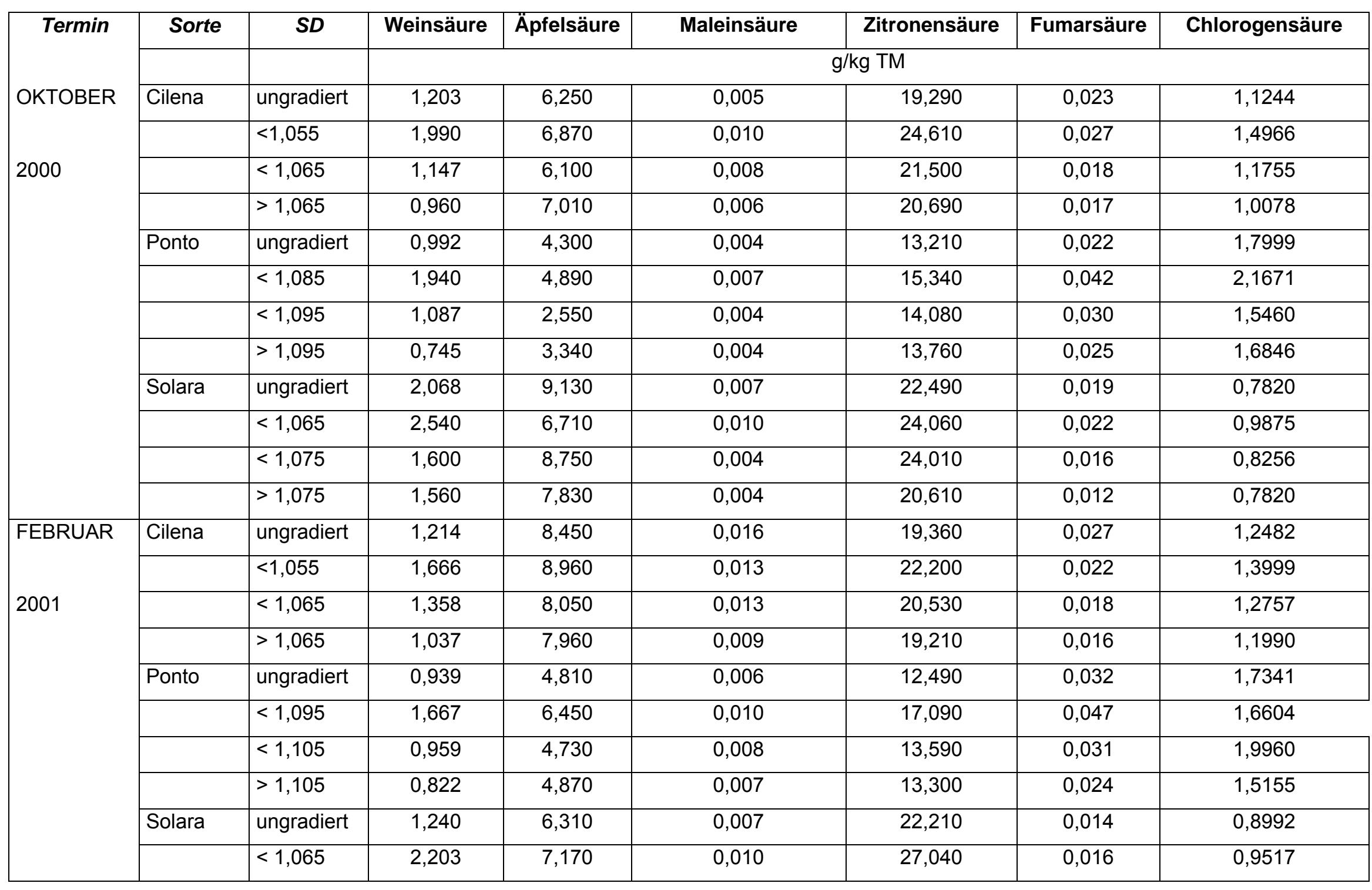


- 136 -

\begin{tabular}{|c|c|c|c|c|c|c|c|c|}
\hline Termin & Sorte & $S D$ & Weinsäure & Äpfelsäure & Maleinsäure & Zitronensäure & Fumarsäure & Chlorogensäure \\
\hline & & & \multicolumn{6}{|c|}{$\mathrm{g} / \mathrm{kg}$ TM } \\
\hline & Solara & $<1,075$ & 1,338 & 6,040 & 0,018 & 24,400 & 0,016 & 0,8522 \\
\hline & & $>1,075$ & 1,213 & 5,130 & 0,014 & 20,500 & 0,013 & 0,8415 \\
\hline \multirow[t]{2}{*}{ JUNI } & Cilena & ungradiert & 1,559 & 9,240 & 0,013 & 21,558 & 0,037 & 1,0970 \\
\hline & & $<1,055$ & 1,660 & 8,080 & 0,012 & 22,640 & 0,036 & 1,3354 \\
\hline \multirow[t]{10}{*}{2001} & & $<1,065$ & 1,500 & 5,590 & 0,011 & 22,010 & 0,033 & 0,9985 \\
\hline & & $>1,065$ & 1,460 & 6,780 & 0,009 & 20,090 & 0,024 & 1,0152 \\
\hline & Ponto & ungradiert & 1,870 & 2,850 & 0,008 & 9,870 & 0,020 & 1,5804 \\
\hline & & $<1,095$ & 1,548 & 3,530 & 0,011 & 15,345 & 0,044 & 1,9076 \\
\hline & & $<1,105$ & 1,000 & 4,560 & 0,010 & 15,610 & 0,026 & 1,4609 \\
\hline & & $>1,105$ & 0,960 & 3,250 & 0,008 & 11,870 & 0,017 & 1,5034 \\
\hline & Solara & ungradiert & 1,690 & 6,830 & 0,014 & 23,640 & 0,022 & 0,8474 \\
\hline & & $<1,065$ & 1,680 & 6,040 & 0,019 & 24,410 & 0,017 & 0,9637 \\
\hline & & $<1,075$ & 1,270 & 5,300 & 0,017 & 20,640 & 0,014 & 0,8271 \\
\hline & & $>1,075$ & 0,860 & 4,230 & 0,009 & 17,230 & 0,011 & 0,8474 \\
\hline \multirow[t]{2}{*}{ OKTOBER } & Cilena & ungradiert & 1,448 & 8,635 & 0,004 & 18,633 & 0,017 & 0,7296 \\
\hline & & $<1,075$ & 1,202 & 11,248 & 0,005 & 25,010 & 0,024 & 0,7904 \\
\hline \multirow[t]{7}{*}{2001} & & $<1,085$ & 1,109 & 9,863 & 0,004 & 23,042 & 0,012 & 0,7919 \\
\hline & Ponto & ungradiert & 0,655 & 7,505 & 0,003 & 22,630 & 0,038 & 1,4636 \\
\hline & & $<1,095$ & 0,909 & 7,453 & 0,003 & 20,018 & 0,039 & 1,2609 \\
\hline & & $<1,105$ & 0,701 & 6,991 & 0,003 & 18,143 & 0,032 & 1,4058 \\
\hline & & $>1,105$ & 0,604 & 7,584 & 0,003 & 17,525 & 0,040 & 1,8461 \\
\hline & Solara & ungradiert & 1,191 & 10,150 & 0,006 & 20,170 & 0,025 & 0,6757 \\
\hline & & $<1,075$ & 1,236 & 11,689 & 0,006 & 24,149 & 0,016 & 0,7080 \\
\hline
\end{tabular}


- 137 -

\begin{tabular}{|c|c|c|c|c|c|c|c|c|}
\hline Termin & Sorte & $S D$ & Weinsäure & Äpfelsäure & Maleinsäure & Zitronensäure & Fumarsäure & Chlorogensäure \\
\hline & & & \multicolumn{6}{|c|}{$\mathrm{g} / \mathrm{kg}$ TM } \\
\hline & Solara & $<1,085$ & 1,073 & 9,580 & 0,004 & 21,675 & 0,011 & 0,6615 \\
\hline & & $>1,085$ & 0,894 & 8,529 & 0,003 & 19,029 & 0,010 & 0,7375 \\
\hline \multirow[t]{2}{*}{ FEBRUAR } & Cilena & ungradiert & 0,907 & 10,823 & 0,010 & 22,898 & 0,031 & 0,9438 \\
\hline & & $<1,075$ & 1,010 & 10,823 & 0,019 & 21,561 & 0,048 & 1,0945 \\
\hline \multirow[t]{10}{*}{2002} & & $<1,085$ & 0,800 & 9,370 & 0,009 & 19,856 & 0,032 & 0,8118 \\
\hline & & $>1,085$ & 0,760 & 9,884 & 0,006 & 15,853 & 0,026 & 0,9292 \\
\hline & Ponto & ungradiert & 0,502 & 8,836 & 0,001 & 18,946 & 0,040 & 1,2518 \\
\hline & & $<1,095$ & 0,697 & 7,123 & 0,001 & 17,712 & 0,018 & 1,3213 \\
\hline & & $<1,105$ & 0,380 & 6,864 & 0,001 & 15,962 & 0,016 & 1,0966 \\
\hline & & $>1,105$ & 0,349 & 8,207 & 0,001 & 15,128 & 0,037 & 1,1781 \\
\hline & Solara & ungradiert & 1,053 & 8,654 & 0,010 & 20,760 & 0,029 & 0,7318 \\
\hline & & $<1,075$ & 1,158 & 9,294 & 0,015 & 22,486 & 0,032 & 0,8269 \\
\hline & & $<1,085$ & 1,142 & 8,570 & 0,013 & 22,128 & 0,026 & 0,5931 \\
\hline & & $>1,085$ & 0,976 & 7,878 & 0,011 & 21,579 & 0,013 & 0,7144 \\
\hline \multirow[t]{2}{*}{ JUNI } & Cilena & ungradiert & 0,937 & 10,947 & 0,006 & 22,583 & 0,030 & 0,8360 \\
\hline & & $<1,075$ & 0,967 & 10,743 & 0,034 & 21,956 & 0,040 & 0,7197 \\
\hline \multirow[t]{6}{*}{2002} & & $<1,085$ & 0,750 & 8,412 & 0,005 & 19,550 & 0,031 & 0,6187 \\
\hline & & $>1,085$ & 0,580 & 8,403 & 0,003 & 15,751 & 0,019 & 0,6052 \\
\hline & Ponto & ungradiert & 0,417 & 8,200 & 0,008 & 18,141 & 0,035 & 1,18999 \\
\hline & & $<1,095$ & 0,755 & 7,412 & 0,009 & 17,058 & 0,023 & 1,3407 \\
\hline & & $<1,105$ & 0,500 & 7,330 & 0,008 & 16,370 & 0,033 & 1,2835 \\
\hline & & $>1,105$ & 0,352 & 7,286 & 0,007 & 15,214 & 0,033 & 1,0187 \\
\hline
\end{tabular}


- 138 -

\begin{tabular}{|c|c|c|c|c|c|c|c|c|}
\hline Termin & Sorte & $S D$ & Weinsäure & Äpfelsäure & Maleinsäure & Zitronensäure & Fumarsäure & Chlorogensäure \\
\hline & & & \multicolumn{6}{|c|}{$\mathrm{g} / \mathrm{kg}$ TM } \\
\hline & Solara & ungradiert & 0,988 & 8,127 & 0,009 & 20,127 & 0,019 & 1,0001 \\
\hline & & $<1,075$ & 1,287 & 8,811 & 0,005 & 23,081 & 0,018 & 0,7155 \\
\hline & & $<1,085$ & 1,106 & 8,437 & 0,008 & 21,792 & 0,018 & 0,6861 \\
\hline & & $>1,085$ & 1,034 & 7,069 & 0,009 & 21,379 & 0,011 & 0,7010 \\
\hline \multirow[t]{2}{*}{ OKTOBER } & Aula & ungradiert & 1,130 & 2,990 & 0,006 & 9,090 & 0,036 & 0,3567 \\
\hline & & $<1,085$ & 1,615 & 6,977 & 0,002 & 16,113 & 0,077 & 0,4102 \\
\hline \multirow[t]{14}{*}{2002} & & $<1,095$ & 1,261 & 6,428 & 0,003 & 14,411 & 0,058 & 0,4263 \\
\hline & & $>1,095$ & 0,500 & 2,140 & 0,004 & 14,000 & 0,023 & 0,5253 \\
\hline & Granola & ungradiert & 0,760 & 15,370 & 0,007 & 19,370 & 0,027 & 0,7577 \\
\hline & & $<1,065$ & 1,910 & 4,190 & 0,011 & 19,370 & 0,018 & 0,9158 \\
\hline & & $<1,075$ & 1,680 & 5,120 & 0,011 & 14,090 & 0,012 & 0,7197 \\
\hline & & $>1,075$ & 1,550 & 6,150 & 0,013 & 11,690 & 0,012 & 0,7564 \\
\hline & Nicola & ungradiert & 1,330 & 3,410 & 0,017 & 17,140 & 0,021 & 0,8886 \\
\hline & & $<1,065$ & 2,144 & 10,238 & 0,006 & 27,054 & 0,034 & 0,9283 \\
\hline & & $<1,075$ & 1,371 & 8,071 & 0,009 & 19,322 & 0,039 & 0,9413 \\
\hline & & $>1,075$ & 1,285 & 6,860 & 0,007 & 18,546 & 0,030 & 0,8612 \\
\hline & Quarta & ungradiert & 2,669 & 12,615 & 0,006 & 18,799 & 0,056 & 0,4925 \\
\hline & & $<1,065$ & 2,564 & 7,026 & 0,003 & 21,672 & 0,059 & 0,5594 \\
\hline & & $<1,075$ & 1,815 & 6,006 & 0,002 & 11,176 & 0,032 & 0,5734 \\
\hline & & $>1,075$ & 1,392 & 13,240 & 0,012 & 10,984 & 0,045 & 0,4690 \\
\hline
\end{tabular}


- 139 -

\begin{tabular}{|c|c|c|c|c|c|c|c|c|}
\hline Termin & Sorte & $S D$ & Weinsäure & Äpfelsäure & Maleinsäure & Zitronensäure & Fumarsäure & Chlorogensäure \\
\hline & & & \multicolumn{6}{|c|}{$\mathrm{g} / \mathrm{kg}$ TM } \\
\hline \multirow[t]{2}{*}{ FEBRUAR } & Aula & ungradiert & 0,589 & 5,437 & 0,009 & 8,113 & 0,024 & 0,4400 \\
\hline & & $<1,085$ & 1,610 & 4,130 & 0,014 & 18,287 & 0,038 & 0,4656 \\
\hline \multirow[t]{14}{*}{2003} & & $<1,095$ & 1,280 & 4,561 & 0,010 & 13,010 & 0,035 & 0,4050 \\
\hline & & $>1,095$ & 1,250 & 4,857 & 0,005 & 9,480 & 0,014 & 0,3796 \\
\hline & Granola & ungradiert & 0,650 & 2,260 & 0,006 & 6,210 & 0,009 & 0,8773 \\
\hline & & $<1,065$ & 1,880 & 5,370 & 0,019 & 15,470 & 0,023 & 0,9433 \\
\hline & & $<1,075$ & 1,530 & 5,550 & 0,016 & 13,220 & 0,020 & 0,6866 \\
\hline & & $>1,075$ & 1,158 & 7,490 & 0,003 & 11,483 & 0,018 & 0,6093 \\
\hline & Nicola & ungradiert & 0,966 & 4,844 & 0,004 & 13,057 & 0,019 & 0,8730 \\
\hline & & $<1,065$ & 1,589 & 6,740 & 0,008 & 23,945 & 0,031 & 1,0851 \\
\hline & & $<1,075$ & 1,330 & 6,450 & 0,003 & 19,161 & 0,030 & 1,0871 \\
\hline & & $>1,075$ & 0,560 & 6,008 & 0,011 & 18,400 & 0,026 & 0,8589 \\
\hline & Quarta & ungradiert & 1,700 & 4,750 & 0,013 & 12,130 & 0,031 & 0,6361 \\
\hline & & $<1,065$ & 3,450 & 6,910 & 0,018 & 18,690 & 0,022 & 0,6497 \\
\hline & & $<1,075$ & 2,530 & 4,230 & 0,016 & 15,900 & 0,059 & 0,5732 \\
\hline & & $>1,075$ & 1,130 & 4,350 & 0,007 & 10,690 & 0,025 & 0,7213 \\
\hline \multirow[t]{2}{*}{ JUNI } & Aula & ungradiert & 1,070 & 3,680 & 0,010 & 13,390 & 0,012 & 0,5878 \\
\hline & & $<1,085$ & 1,934 & 9,391 & 0,010 & 16,665 & 0,038 & 0,7248 \\
\hline \multirow[t]{5}{*}{2003} & & $<1,095$ & 1,190 & 4,560 & 0,011 & 14,000 & 0,025 & 0,5838 \\
\hline & & $>1,095$ & 1,102 & 3,668 & 0,016 & 13,920 & 0,027 & 0,6243 \\
\hline & Granola & ungradiert & 2,528 & 10,690 & 0,008 & 17,190 & 0,024 & 0,7575 \\
\hline & & $<1,065$ & 2,340 & 6,180 & 0,015 & 16,150 & 0,014 & 0,8858 \\
\hline & & $<1,075$ & 1,860 & 4,870 & 0,013 & 14,530 & 0,015 & 0,9417 \\
\hline
\end{tabular}


- 140 -

\begin{tabular}{|c|c|c|c|c|c|c|c|c|}
\hline Termin & Sorte & $S D$ & Weinsäure & Äpfelsäure & Maleinsäure & Zitronensäure & Fumarsäure & Chlorogensäure \\
\hline & & & \multicolumn{6}{|c|}{$\mathrm{g} / \mathrm{kg} \mathrm{TM}$} \\
\hline & Granola & $>1,075$ & 1,680 & 4,640 & 0,011 & 13,990 & 0,016 & \multirow{2}{*}{$\begin{array}{l}0,7575 \\
1,3621\end{array}$} \\
\hline & Nicola & ungradiert & 2,210 & 8,030 & 0,009 & 20,388 & 0,025 & \\
\hline & & $<1,065$ & 2,260 & 7,630 & 0,012 & 20,582 & 0,014 & 1,3626 \\
\hline & & $<1,075$ & 2,161 & 5,594 & 0,009 & 18,290 & 0,022 & 1,1836 \\
\hline & & $>1,075$ & 1,199 & 4,460 & 0,007 & 17,448 & 0,020 & 1,1369 \\
\hline & Quarta & ungradiert & 2,600 & 6,060 & 0,011 & 17,500 & 0,020 & 0,8862 \\
\hline & & $<1,065$ & 3,130 & 5,050 & 0,013 & 18,320 & 0,038 & 1,4889 \\
\hline & & $<1,075$ & 2,620 & 6,110 & 0,012 & 16,530 & 0,019 & 1,3132 \\
\hline & & $>1,075$ & 2,250 & 5,150 & 0,010 & 14,570 & 0,014 & 0,8005 \\
\hline \multirow[t]{2}{*}{ OKTOBER } & Aula & ungradiert & 2,506 & 7,001 & 0,006 & 18,101 & 0,067 & 0,4633 \\
\hline & & $<1,085$ & 2,692 & 7,634 & 0,006 & 21,152 & 0,087 & 0,5111 \\
\hline \multirow[t]{12}{*}{2003} & & $<1,095$ & 1,290 & 2,990 & 0,008 & 13,750 & 0,034 & 0,4729 \\
\hline & & $>1,095$ & 1,760 & 2,420 & 0,004 & 12,510 & 0,021 & 0,4544 \\
\hline & Granola & ungradiert & 2,038 & 12,669 & 0,011 & 16,636 & 0,020 & 0,6823 \\
\hline & & $<1,075$ & 1,722 & 13,552 & 0,010 & 16,607 & 0,019 & 0,7970 \\
\hline & & $<1,085$ & 1,685 & 12,425 & \multirow{8}{*}{$\begin{array}{c}\text { unter } \\
\text { Bestimmungsgrenze }\end{array}$} & 14,782 & 0,031 & 0,5197 \\
\hline & Nicola & ungradiert & 1,080 & 7,857 & & 20,780 & 0,048 & 0,7707 \\
\hline & & $<1,075$ & 2,980 & 9,890 & & 19,710 & 0,026 & 0,7927 \\
\hline & & $<1,085$ & 1,868 & 8,122 & & 18,110 & 0,031 & 0,8613 \\
\hline & & $>1,085$ & 1,625 & 6,099 & & 17,125 & 0,021 & 0,8220 \\
\hline & Quarta & ungradiert & 2,331 & 10,520 & & 18,190 & 0,029 & 0,5026 \\
\hline & & $<1,075$ & 1,940 & 13,540 & & 19,160 & 0,023 & 0,5185 \\
\hline & & $<1,085$ & 1,830 & 12,940 & & 17,750 & 0,021 & 0,5090 \\
\hline
\end{tabular}


- 141 -

\begin{tabular}{|c|c|c|c|c|c|c|c|c|}
\hline Termin & Sorte & $S D$ & Weinsäure & Äpfelsäure & Maleinsäure & Zitronensäure & Fumarsäure & Chlorogensäure \\
\hline & & & \multicolumn{6}{|c|}{$\mathrm{g} / \mathrm{kg}$ TM } \\
\hline & Quarta & $>1,085$ & 1,540 & 10,520 & \multirow{22}{*}{$\begin{array}{c}\text { unter der } \\
\text { Bestimmungsgrenze }\end{array}$} & 15,110 & 0,013 & 0,5193 \\
\hline \multirow[t]{2}{*}{ FEBRUAR } & Aula & ungradiert & 1,769 & 10,143 & & 15,172 & 0,027 & 0,8170 \\
\hline & & $<1,085$ & 2,460 & 12,173 & & 18,770 & 0,049 & 0,8468 \\
\hline \multirow[t]{13}{*}{2004} & & $<1,095$ & 2,150 & 9,094 & & 17,468 & 0,030 & 0,7461 \\
\hline & & $>1,095$ & 1,876 & 8,218 & & 15,931 & 0,023 & 0,7516 \\
\hline & Granola & ungradiert & 2,351 & 12,822 & & 13,626 & 0,023 & 0,9800 \\
\hline & & $<1,075$ & 2,242 & 14,084 & & 15,578 & 0,017 & 1,0946 \\
\hline & & $<1,085$ & 2,162 & 12,910 & & 14,439 & 0,023 & 1,1143 \\
\hline & Nicola & ungradiert & 1,873 & 9,673 & & 18,613 & 0,021 & 1,2224 \\
\hline & & $<1,075$ & 2,334 & 9,554 & & 19,755 & 0,019 & 1,3465 \\
\hline & & $<1,085$ & 1,950 & 7,812 & & 19,979 & 0,014 & 1,2197 \\
\hline & & $>1,085$ & 1,733 & 7,325 & & 17,521 & 0,014 & 1,2197 \\
\hline & Quarta & ungradiert & 2,401 & 11,770 & & 15,267 & 0,021 & 0,8251 \\
\hline & & $<1,075$ & 2,785 & 12,431 & & 19,614 & 0,035 & 0,9284 \\
\hline & & $<1,085$ & 2,217 & 11,810 & & 17,886 & 0,027 & 0,7538 \\
\hline & & $>1,085$ & 1,822 & 10,086 & & 16,384 & 0,020 & 0,8262 \\
\hline \multirow[t]{6}{*}{ JUNI 2004} & Aula & $<1,085$ & 2,344 & 11,494 & & 17,527 & 0,042 & 0,8873 \\
\hline & & $<1,095$ & 1,868 & 10,148 & & 15,659 & 0,027 & 0,8273 \\
\hline & & $>1,095$ & 1,800 & 8,820 & & 14,569 & 0,023 & 0,7899 \\
\hline & Granola & ungradiert & 2,350 & 12,800 & & 12,650 & 0,024 & 1,0910 \\
\hline & & $<1,075$ & 2,275 & 13,908 & & 12,723 & 0,026 & 1,2238 \\
\hline & & $<1,085$ & 2,548 & 12,343 & & 12,563 & 0,022 & 1,0705 \\
\hline
\end{tabular}


- 142 -

\begin{tabular}{|c|c|c|c|c|c|c|c|c|}
\hline Termin & Sorte & $S D$ & Weinsäure & Äpfelsäure & Maleinsäure & Zitronensäure & Fumarsäure & Chlorogensäure \\
\hline & & & \multicolumn{6}{|c|}{$\mathrm{g} / \mathrm{kg}$ TM } \\
\hline & Nicola & ungradiert & 2,243 & 9,157 & \multirow{8}{*}{$\begin{array}{c}\text { unter der } \\
\text { Bestimmungsgrenze }\end{array}$} & 17,214 & 0,022 & 1,4132 \\
\hline & & $<1,075$ & 2,332 & 10,342 & & 20,506 & 0,018 & 1,4273 \\
\hline & & $<1,085$ & 2,282 & 7,636 & & 17,083 & 0,017 & 1,3356 \\
\hline & & $>1,085$ & 1,583 & 7,148 & & 16,351 & 0,017 & 1,2255 \\
\hline & Quarta & ungradiert & 2,864 & 10,999 & & 16,256 & 0,022 & 0,8344 \\
\hline & & $<1,075$ & 3,087 & 12,770 & & 17,637 & 0,028 & 1,0336 \\
\hline & & $<1,085$ & 2,110 & 10,506 & & 16,491 & 0,027 & 0,9623 \\
\hline & & $>1,085$ & 1,760 & 8,900 & & 14,260 & 0,021 & 0,9050 \\
\hline
\end{tabular}




\subsection{WETTERDATEN}

Nachfolgend sind die Niederschlagsmengen $(\mathrm{mm})$ sowie die Höchsttemperaturen $\left({ }^{\circ} \mathrm{C}\right)$ für den Zeitraum von Ende März bis Ende September in der Region Soltau dargestellt.

\section{Anbaujahr 2000}

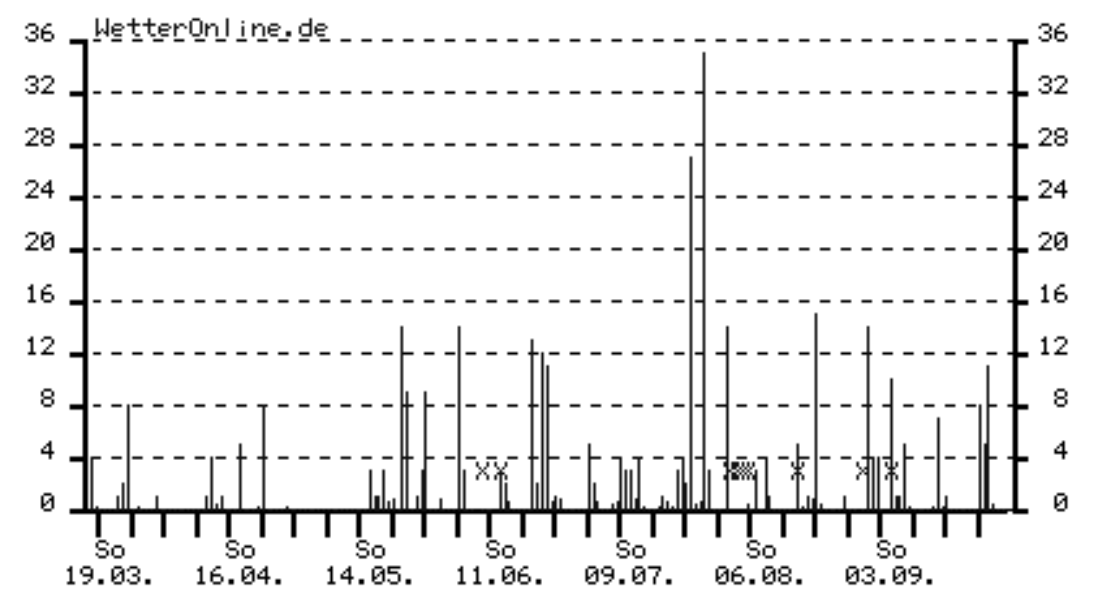

Niederschlag (mm) 18.03.2000 bis 30.09.2000

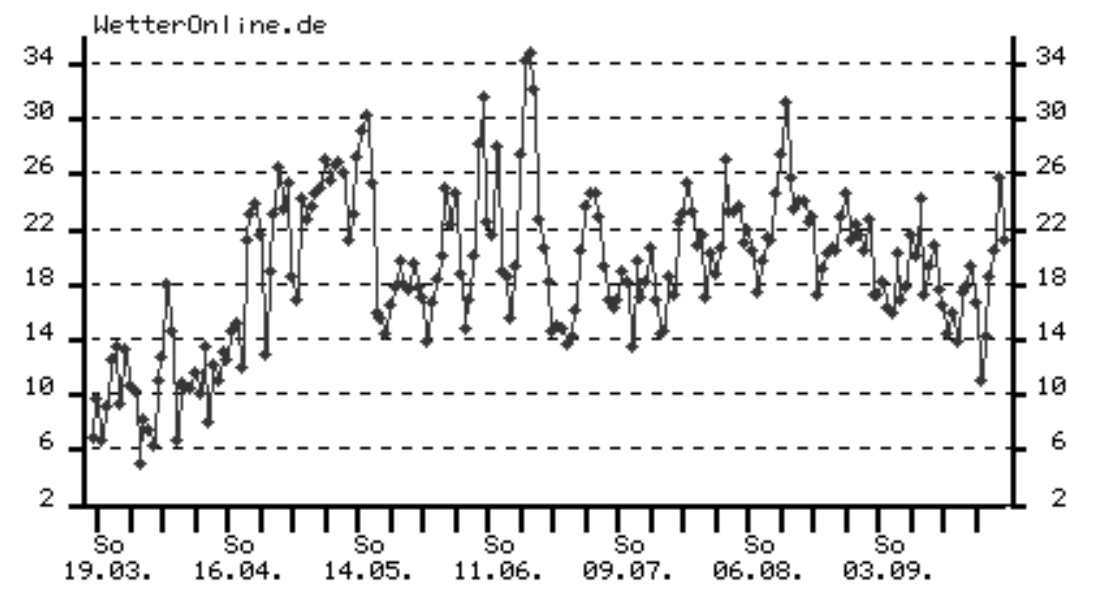

Höchsttemperaturen $\left({ }^{\circ} \mathrm{C}\right)$ 18.03.2000 bis 30.09.2000 
Anbaujahr 2001

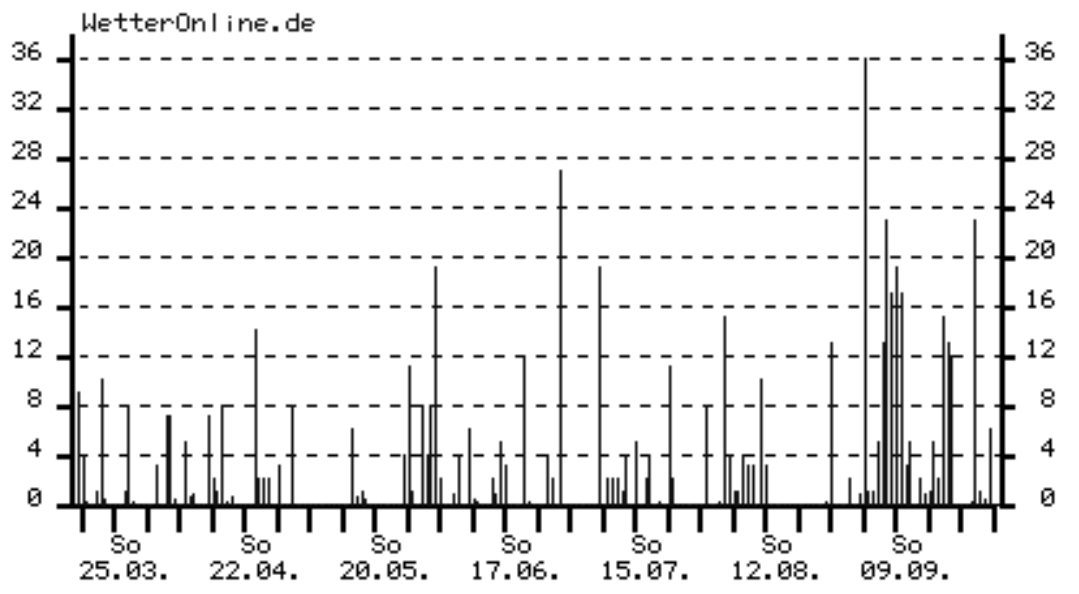

Niederschlag (mm) 18.03.2001 bis 30.09.2001

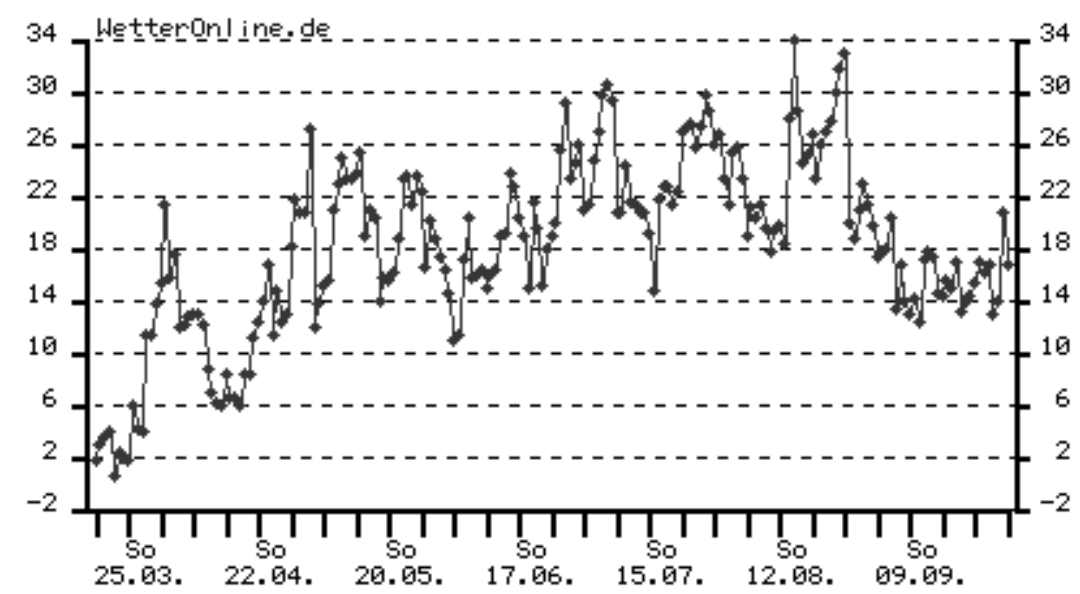

Höchsttemperaturen $\left({ }^{\circ} \mathrm{C}\right) 18.03 .2001$ bis 30.09 .2001

Anbaujahr 2002

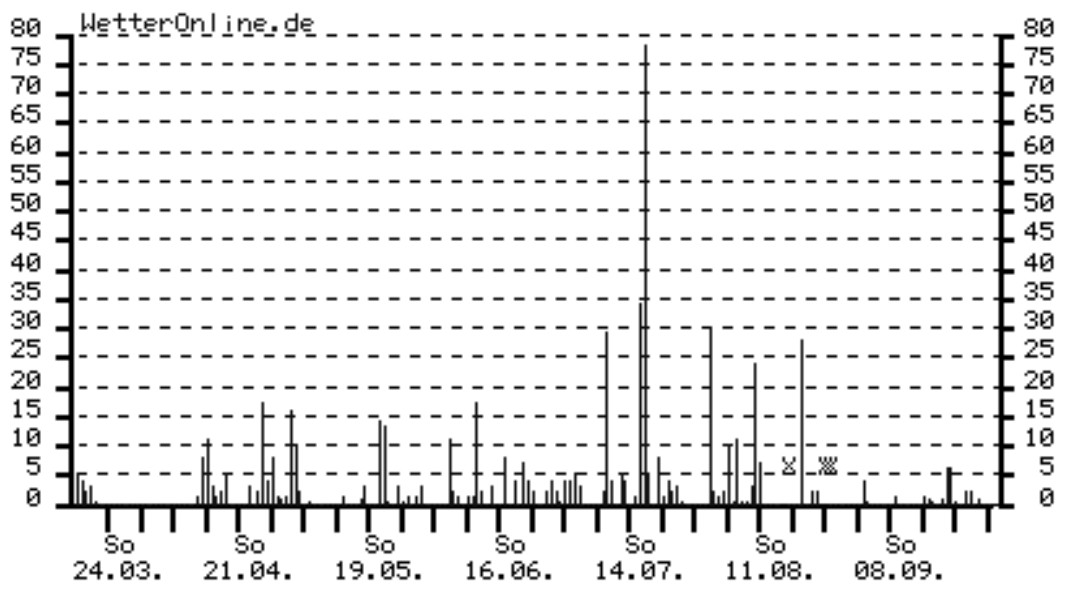

Niederschlag (mm) 18.03.2002 bis 30.09.2002 


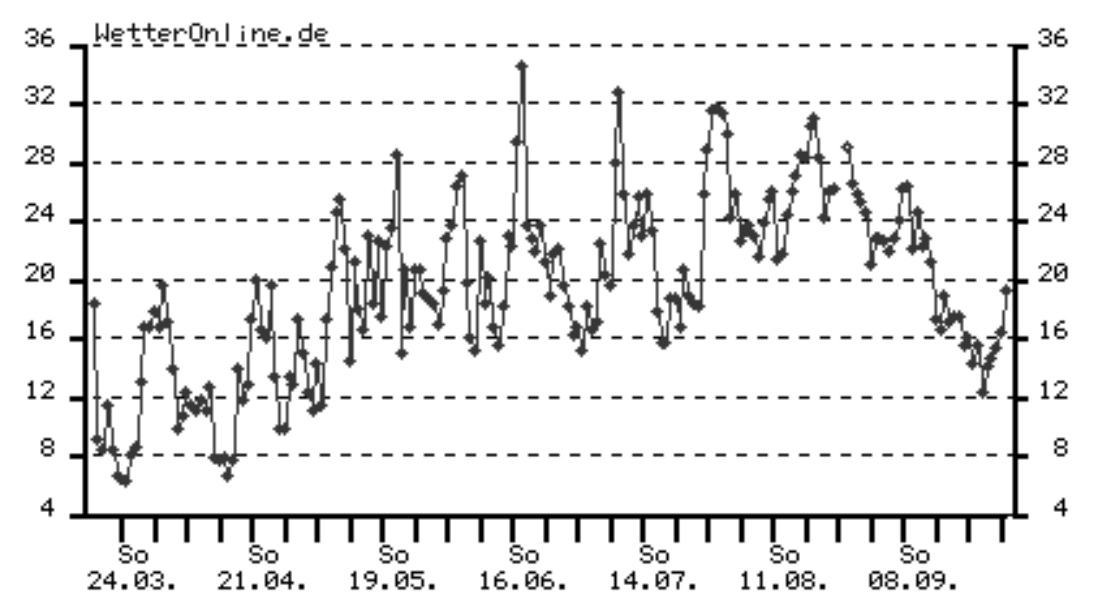

Höchsttemperaturen $\left({ }^{\circ} \mathrm{C}\right)$ 18.03.2002 bis 30.09.2002

\section{Anbaujahr 2003}

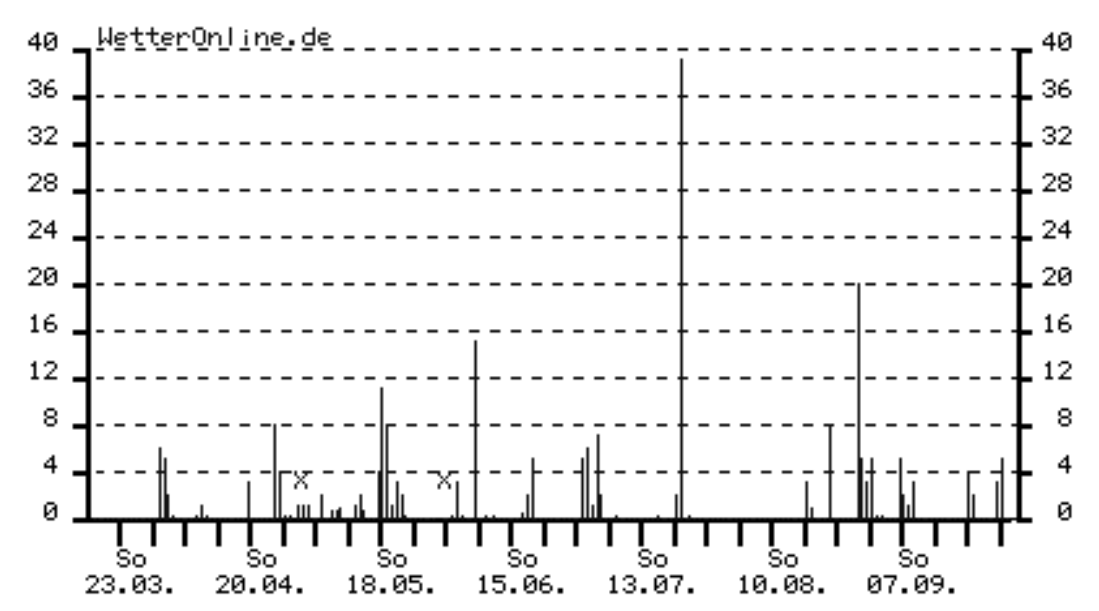

Niederschlag $(\mathrm{mm}) 18.03 .2003$ bis 30.09 .2003

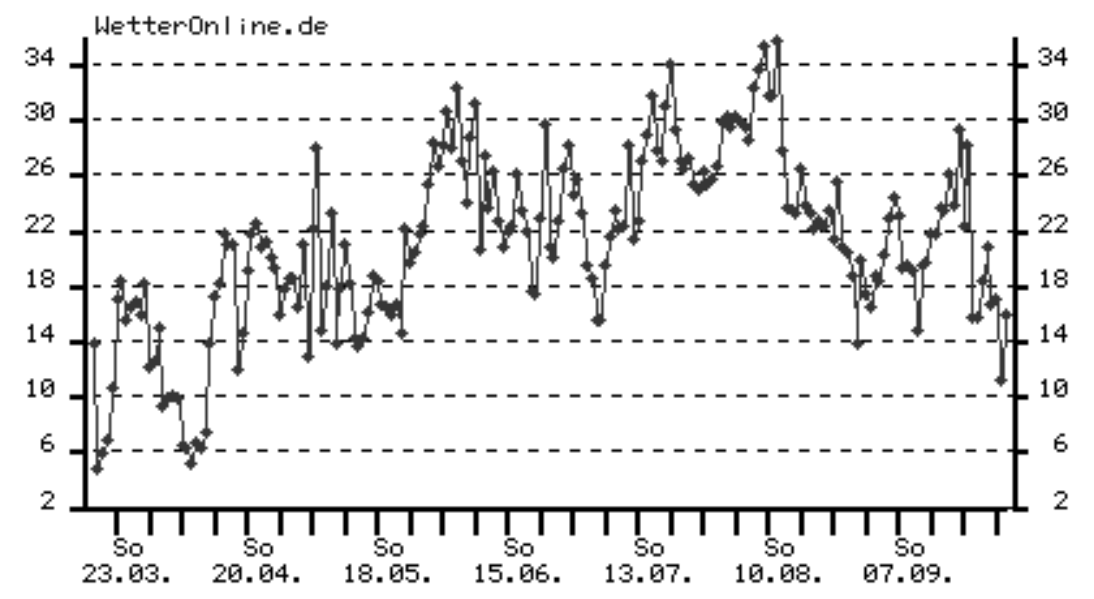

Höchsttemperaturen $\left({ }^{\circ} \mathrm{C}\right)$ 18.03.2003 bis 30.09.2003 


\section{LEBENSLAUF}

ANNEMARIE HEINECKE

PERSÖNLICHE INFORMATIONEN

-Annemarie Heinecke, geb. Schulze

-Familienstand: verheiratet, ein Sohn

-Staatsangehörigkeit: deutsch

-Alter: 29

-Geburtstag: 31.05.1978

-Geburtsort: Lich

-wohnhaft: Masch 11, 29348 Endeholz, Landkreis Celle

\section{SCHULBILDUNG}

1984 - 1988 Grundschule Wienhausen

1988 - 1990 Orientierungsstufe Burgstraße Celle

1990 - 1997 Gymnasium Ernestinum Celle

Abitur 1997 Notendurchschnitt 1,8

AUSBILDUNG

1997 - 1998 1. praktisches Ausbildungsjahr zur Landwirtin bei Herrn

Hartmut Janssen in Balje/ Kreis Stade, Besuch der Fachstufe 1, BBS III Stade

1998 - 1999 2. praktisches Ausbildungsjahr bei Herrn Hans- Heinrich Johannes, Hof Abelbeck/ Kreis Soltau-Fallingbostel, Besuch der Fachstufe 2, BBS Soltau

Juli 1999 Abschlussprüfung zur Landwirtin mit der Note 1,11

STUDIUM UND BERUFLICHE TÄTIGKEIT

1999 - 2003 Studium der Agrarwissenschaften an der Universität Göttingen, Fachrichtung Pflanzenproduktion

September 2003 Master of science, Notendurchschnitt 1,3

seit November 2003 Promotion als externe Promotionsstudentin am Department für Nutzpflanzenwissenschaften Göttingen, Doktormutter: Prof. Dr. Elke Pawelzik

seit März 2004 Promotionsstipendiatin der Konrad- Adenauer- Stiftung

seit Oktober 2006 Referendarin für den höheren landwirtschaftlichen Dienst bei der Landwirtschaftskammer Niedersachsen 